
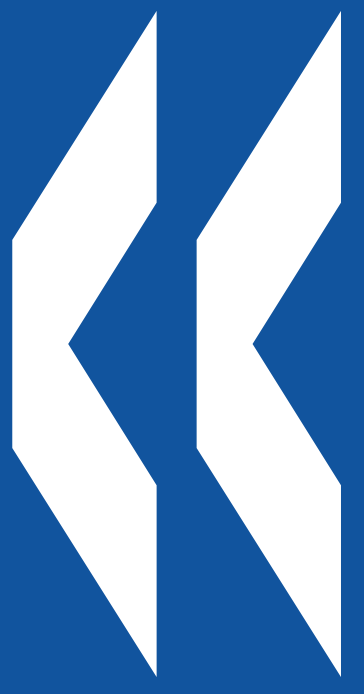

\title{
Directory of OECD Intergovernmental Bodies
}

MANDATES

CHAIRS

MEMBERSHIP

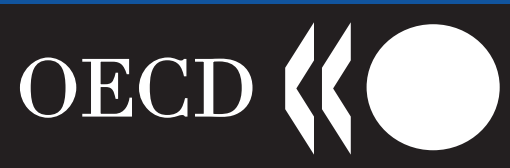





\section{ORGANISATION FOR ECONOMIC CO-OPERATION AND DEVELOPMENT}

\section{DIRECTORY \\ OF \\ BODIES}

Mandates

Membership

Officers

MARCH 2006 



\section{INTRODUCTION}

Article 9 of the Convention of 14th December 1960 on the OECD states that "The Council may establish an Executive Committee and such subsidiary bodies as may be required for the achievement of the aims of the Organisation".

This directory presents the bodies established by the Council which are currently operative. It includes the sub-committees, working parties, groups of experts, ad hoc groups, etc. which those bodies have in their turn set up to assist them in their work. For ease of reference, the titles of the principal bodies are framed; those of their working parties are underlined; and those of third-level sub-groups are in italics.

For each body listed, information is given concerning the chairmanship and vice-chairmanship(s), membership (in cases where the body does not include all OECD Member countries or where non-Members of the Organisation are full participants in its work), observers, date of creation, duration and mandate.

It should be noted that some bodies have been in continuous existence for a lengthy period and that their functions have evolved. Moreover, certain bodies have a precisely defined field of action and/or a sizeable sub-structure, while the definition of the competence of others has remained very broad. The present functions of some bodies, or the relative importance of their activities, may not, therefore, always be clearly and completely reflected by the texts of the mandates alone.

This compilation is updated and published annually. The information in this edition applies to the situation as of the end of March 2006. An electronic version is also available on the OECD Internet Site (http://www.oecd.org). 



\section{MEMBER COUNTRIES OF THE OECD}

$\begin{array}{lll}\text { Australia } & \text { Hungary } & \text { Norway } \\ \text { Austria } & \text { Iceland } & \text { Poland } \\ \text { Belgium } & \text { Ireland } & \text { Portugal } \\ \text { Canada } & \text { Italy } & \text { Slovak Republic } \\ \text { Czech Republic } & \text { Japan } & \text { Spain } \\ \text { Denmark } & \text { Korea } & \text { Sweden } \\ \text { Finland } & \text { Luxembourg } & \text { Switzerland } \\ \text { France } & \text { Mexico } & \text { Turkey } \\ \text { Germany } & \text { Netherlands } & \text { United Kingdom } \\ \text { Greece } & \text { New Zealand } & \text { United States }\end{array}$

\section{PARTICIPATION IN THE WORK OF THE ORGANISATION}

\section{European Community}

Supplementary Protocol No. 1 to the Convention on the Organisation for Economic Co-operation and Development provides that the Commission of the European Communities shall take part in the work of the Organisation.

The European Commission thus takes part in the meetings of the Council of the OECD and in the work of all the other bodies of the Organisation.

\section{European Free Trade Association}

By virtue of the Ministerial Resolution of 23rd July 1960, the Secretary-General of the European Free Trade Association may take part in the work of the Organisation.

In practice, EFTA takes part in only a small number of meetings of OECD bodies.

\section{$\underline{\text { Russian Federation }}$}

A meeting took place on 8 June 1994 between Ministers of the OECD Member countries and the Minister for Foreign Affairs of the Russian Federation, at which were signed the Declaration on Co-operation with the Russian Federation and the Agreement on Privileges and Immunities of the Organisation in Russia [C(94)141]. This action implemented the decision taken by the Council at its 827 th session [C(94)92 and Corrigendum 1; C/M(94)9/FINAL].

A protocol establishing a Liaison Committee between the OECD and the Russian Federation was subsequently signed on 27 May 1997 by the Secretary-General and the Russian Minister of Foreign Affairs [C(97)116/FINAL].

\section{Other Non-Members}

Other non-Members of the Organisation have long participated in the various Codes and Schemes in the agricultural domain, and/or are invited, on a selective basis, to take part, either as full participants or as observers, in the work of certain bodies. These are included in the lists of members or observers of the bodies concerned. Furthermore, non-Members participate in the OECD Global Forums and the Global Dialogue. 


\section{$\underline{\text { International Organisations }}$}

Since 1961, a number of international organisations have been invited to be represented by an observer at meetings or parts of meetings of certain bodies of the Organisation. These include:

African Development Bank

Asian Development Bank (ADB)

Bank for International Settlements (BIS)

Council of Europe

European Bank for Reconstruction and Development (EBRD)

Inter-American Development Bank (IADB)

International Atomic Energy Agency (IAEA)

International Labour Organization (ILO)

International Monetary Fund (IMF)

International Organisation for Migration (IOM)

International Telecommunications Union (ITU)

Organization of American States (OAS/CICAD)

U.N. Commission for Sustainable Development

U.N. Conference on Trade and Development (UNCTAD)

U.N. Development Program (UNDP)

U.N. Economic Commission for Europe (UN/ECE)

U.N. Educational Scientific and Cultural Organization (UNESCO)

U.N. Environment Programme (UNEP)

U.N. Food and Agricultural Organization (FAO)

U.N. High Commissioner for Refugees (UNHCR)

U.N. Industrial Development Organization (UNIDO)

United Nations

World Bank

World Food Council

World Health Organization (WHO)

World Trade Organization (WTO) 
TABLE OF CONTENTS

COUNCIL AND RELATED BODIES 9

ECONOMIC POLICY 61

ENVIRONMENT

DEVELOPMENT

PUBLIC GOVERNANCE AND TERRITORIAL DEVELOPMENT

TRADE 163

FINANCIAL AND ENTERPRISE AFFAIRS

TAX POLICY AND ADMINISTRATION

SCIENCE, TECHNOLOGY AND INDUSTRY 239

EMPLOYMENT, LABOUR AND SOCIAL AFFAIRS 293

ENTREPRENEURSHIP, SMES AND LOCAL DEVELOPMENT. 307

EDUCATION. 317

FOOD, AGRICULTURE AND FISHERIES 343

STATISTICS 379

TRANSPORT. 389

INTERNATIONAL ENERGY AGENCY (IEA)..... 395

OECD NUCLEAR ENERGY AGENCY (NEA) 425

JOINT SUBSIDIARY BODIES TO THE CO-ORDINATED ORGANISATIONS 485

DETAILED INDEX 493 

COUNCILAND RELATED BODIES 



\section{COUNCIL}

Chair:

Mr. Costas Karamanlis

(Greece)

Prime Minister

(2006 Ministerial Session)

Mr. Donald Johnston

Secretary-General

(Sessions of Permanent Representatives)

Vice-Chairs:

Canada

(2006 Ministerial session )

Korea

(2006 Ministerial session )

Members:

Open to all Member countries

Date of creation:

30th September 1961

Duration:

Unspecified

Mandate: Articles 7, 8, 9 and 10.2 of the Convention on the Organisation for Economic

Co-operation and Development

\section{"Article 7}

A Council composed of all the Members shall be the body from which all acts of the Organisation derive. The Council may meet in sessions of Ministers or of Permanent Representatives.

\section{Article 8}

The Council shall designate each year a Chairman, who shall preside at its ministerial sessions, and two Vice-Chairmen. The Chairman may be designated to serve one additional consecutive term.

\section{Article 9}

The Council may establish an Executive Committee and such subsidiary bodies as may be required for the achievement of the aims of the Organisation.

\section{Article 10}

2. The Secretary-General shall serve as Chairman of the Council meeting at sessions of Permanent Representatives. He shall assist the Council in all appropriate ways and may submit proposals to the Council or to any other body of the Organisation." 

GOVERNANCE
Chair:
Mr. Patrick Van Haute
(Belgium)
Vice-Chairs:
Ms. Constance Morella
(United States)
Mr. Adrian Macey
(New Zealand)
Members:
Open to all Member countries
Date of creation:
21st July 2005
Duration:
30th June 2006

Mandate: $\quad$ Resolution of the Council concerning the establishment of a Council Working Party on the Implications of Future Enlargement on OECD Governance [C(2005)100] approved at its 1118th session on 21 July 2005 [C/M(2005)17, Item 214]

\section{Resolution of the Council [C(2005)100]}

\section{RESOLUTION ESTABLISHING \\ A COUNCIL WORKING PARTY ON THE IMPLICATIONS OF FUTURE ENLARGEMENT ON OECD GOVERNANCE}

\section{THE COUNCIL}

Having regard to the Convention on the Organisation for Economic Co-operation and Development of 14 December 1960, and in particular its Articles 5, 6, 7, 9 and 16;

Having regard to the reforms undertaken and the proposals submitted since 2001, and in particular the "Julin Report" on Future Direction of the OECD: Report on OECD's Role in Global Architecture [HOD(2003)2], the "Noboru Report" on A Strategy for Enlargement and Outreach [C(2004)60], and the latest Report by the Secretary-General on Reform [C/MIN(2005)9];

Having regard to the Council conclusions of 22 April and 6 May 2004 on the OECD Reform [C/M(2004)10, Item 143 and C/M(2004)11, Item 153];

Having regard to the Council decision of 28 April 2005 to establish, by the end of July 2005 , a mechanism (including scope, terms of reference and process) to address the governance implications of future enlargement [C(2005)57/REV1 and C/M(2005)10];

Having regard to the Report by the Technical Task Force on Cost Implications of Enlargement [C(2005)87] presented to Council on 21 July 2005;

\section{DECIDES:}

1. A Council Working Party on the implications of future enlargement on OECD governance is hereby established.

2. Within the framework of and respect for the Convention, the Working Party shall examine the governance and management structures of the Organisation and their working methods, including:

- the respective roles of and interrelations between Council, the SecretaryGeneral, and all bodies subsidiary to Council, whether formal or informal; 
- the interactions between the Organisation and Member countries, in particular the co-ordination of the whole-of-government view on priorities and resource allocations;

- the question of decision-making for special cases.

3. This will be done in the light of the Working Party's parallel work on the future role and direction of the Organisation, to be completed by the end of 2005.

4. Each Member Country shall designate a member and up to two alternates as representatives on the Working Party. The European Commission shall take part in the work pursuant to Supplementary Protocol $\mathrm{N}^{\circ} 1$ to the Convention on the OECD and Rule 7 a) of the Rules of Procedures of the Organisation. The Chair of the Working Party and two Vice-Chairs shall be designated by Council. The Working Party may draw on outside expertise as appropriate to assist it in its tasks.

5. The Working Party shall report regularly to Council, including a progress report by November 2005 and a draft final report by April 2006. The Working party report with recommendations shall be submitted via the Council to Ministers in Spring 2006.

6. The mandate of the Working Party shall expire on 30 June 2006, unless the Council decides otherwise.

\section{Extract of the Summary Record [C/M(2005)17]}

\section{"214. DRAFT RESOLUTION ESTABLISHING A COUNCIL WORKING PARTY ON IMPLICATIONS OF FUTURE ENLARGEMENT ON OECD GOVERNANCE \\ THE COUNCIL}

c) adopted the Draft Resolution Establishing a Council Working Party on the Implications of Future Enlargement on OECD Governance, set out in the Annex to document C(2005)100;

d) agreed to designate Ambassador Van Haute as Chair of the Working Party, and Ambassador Morella and Ambassador Macey as Vice-Chairs;

e) agreed that the new Secretary-General designate will be invited to provide advice to the Working Party in its work as soon as she/he is appointed by Council." 


\section{SUB-GROUP ON QUESTIONS OF MANAGEMENT OF THE COUNCIL, ITS SUBSIDIARY BODIES AND THE COMMITTEES OF THE OECD}

Chairs:

Members:

Date of creation:

Duration:
Ms. Veronique Ingram Mr. Hubert Wurth

Open to all Member countries

17th January 2006

28th February 2006
(Australia)

(Luxembourg)

Mandate : Summary record of the $10^{\text {th }}$ session of the WPEG held on 17-18 January 2006 [C/NPEG/M(2006)1]

\section{Extract of document [C/WPEG/M(2006)1]}

THE WORKING PARTY

b) noted the designation by the Chair of Ambassadors Ingram (Australia) and Wurth (Luxembourg) as the co-chairs of the Sub-Group on questions of meeting management for the Council, its subsidiary bodies and the Committees of the OECD and that the conclusions of their sessions would be reported at the WPEG meeting of 27-28 February and included in the final report to the Council." 


\section{EVALUATION SUB-GROUP}

Members:

Mrs. Tanja H. Storm

Mr. Carlos Elizondo Mayer-Serra

Mr. Joan Boer

Mr. Fernando Ballestero

Mr. Shinichi Kitajima

10th February 2005

Date of creation:

Duration:
(Norway)

(Mexico)

(Netherlands)

(Spain)

(Japan)

Mandate : Decision of the Council, 1105th session held on 10 February $2005[C / M(2005) 4$, item 38] and $1106^{\text {th }}$ session held on 24 February 2005 [C/M(2005)5, item 46]

\section{Extract of Summary Record [C/M(2005)4]}

“38. PROPOSAL FOR IN-DEPTH EVALUATION AT THE OECD

THE COUNCIL

b) noted document C(2004)190 and its CORR1;

d) recalled the ten principles agreed in April 2004 to guide the development of in-depth evaluations [C(2004)91];

e) agreed:

i) that the overarching goal of in-depth evaluation at the OECD is to provide a mechanism through which Council can assess whether Committees are conducting processes, delivering outputs and achieving impacts that are in line with Members policy expectations and priorities and with the comparative advantage of the OECD.

viii) that a sub-group of the Council, comprising five of its members proposed by the Chair of the Executive Committee and designated by Council for one year, would be established before the end of February to agree the terms of reference and methodology for evaluation; review the evaluations themselves and present the Evaluation Report to Council; and monitor the follow-up of eventual recommendations arising from the evaluations;

ix) that in-depth evaluations conducted by the Evaluation Sub-group would follow the steps described in "Section VI, How In-depth Evaluations would be conducted" of document C(2004)190 as amended by this decision;

x) that two in-depth evaluations would be conducted in 2005, and at least four in 2006; the mechanism of evaluations would be reviewed after three evaluations and no later than March 2006;" 


\section{COMMITTEE ON CO-OPERATION WITH NON-MEMBERS}

Chair:

Ms. Jocelyne Bourgon

(Canada)

Members:

Open to all Member countries

Date of creation:

16th September 1997

Duration:

31st December 2008

Mandate: - Resolution of the Council concerning the renewal and revision of the mandate of the Committee on Co-operation with Non-Members [C(2002)224/REV1] approved during its $1042^{\text {nd }}$ session on 14 and 15 November 2002 [C/M(2002)22, Item 327]

- Mandate renewed until 31 December 2008 by Council during its $1126^{\text {th }}$ session on 15 December 2005 [C/M(2005)25 Item 327]

Resolution of the Council [C(2002)224/REV1] as amended by Council [C/M(2005)25 Item 327]

\section{RESOLUTION OF THE COUNCIL \\ CONCERNING THE RENEWAL AND REVISION OF THE MANDATE OF THE COMMITTEE ON CO-OPERATION WITH NON-MEMBERS}

\section{THE COUNCIL,}

Having regard to the Convention on the Organisation for Economic Co-operation and Development of 14 December 1960, and in particular Articles 1, 2, 5 and 12;

Having regard to the Rules of Procedure of the Organisation;

Having regard to Council Resolution C(96)64/REV2/FINAL ${ }^{1}$ concerning the participation of non-Member economies in the work of subsidiary bodies of the Organisation;

Having regard to the Communique approved by the Council at Ministerial level on 22 May 1997, and in particular the section concerning co-operation with non-Members;

Having regard to the Council Resolution of 16 September 1997 establishing a Committee on Co-operation with Non-Members [C(97)171/FINAL];

Having regard to the Council Resolution of 12 September 2002 concerning the reform of the development structure of the OECD [C/M(2002)18, Item 258];

\section{DECIDES:}

1. The Committee on Co-operation with Non-Members, established on 16 September 1997, shall continue to serve as an advisory body to the Council on the Organisation's co-operative relations with non-Members, with a view to enhancing the coherence and efficiency of the Organisation in this area. In particular, the Committee shall advise the Council on:

a) the Organisation's relations with non-Members;

1 Replaced subsequently by Council Resolution C(2004)132/Final 
b) the Organisation's structures for co-operation with non-Members and on the coordination of activities concerning non-Members within the Organisation, including those financed under Part II of the budget;

c) the Secretary-General's proposals for the Programme of Work and Budget concerning non-Members;

d) the evaluation of the activities of the Organisation with non-Members;

e) the participation of non-Members in subsidiary bodies of the Organisation; in this regard, it shall submit recommendations to the Council for the implementation of Resolution C(96)64/REV2/FINAL ${ }^{1}$.

2. The Committee shall be composed of representatives of all Member countries and the European Commission, and its Chair shall be designated by the Council. It shall meet and report to the Council as often as necessary. Its proceedings are classified as confidential.

3.

The mandate of the Committee shall expire on 31 December 2008, unless the Council decides otherwise.

1 Replaced subsequently by Council Resolution C(2004)132/Final 


\section{GOVERNING BOARD OF THE DEVELOPMENT CENTRE}

Chair:

Vice-Chairs:

Members: ${ }^{1}$

Date of creation:

Duration:

Mandate: - Resolution of the Council on the Establishment of the Development Centre Governing Board [C(2002)228] as modified in the Council conclusions [C/M(2002)23, Item 337 i)]

- Decision of the Council reforming the Development structure of the OECD [C/M(2002)18, item 258, b) c) d) e)] and document [C(2002)181/REV2]

$\underline{\text { Annex }}$
Ms. Gun-Britt Andersson

Ms. Jana Kotová

Austria
Belgium
Czech Republic
Finland
France
Germany
Greece
Iceland
Ireland
Italy
Korea
Luxembourg
Mexico

1st January 2003

Unspecified
Mr. Bruno Cabras
(Sweden)

(Italy)

(Slovak Republic)

Netherlands

Norway

Portugal

Slovak Republic

Spain

Sweden

Switzerland

Turkey

Brazil

Chile

India

Romania

Thailand
- Decision of the Council establishing a Development Centre of the Organisation [C(62)144(Final)] as amended by the Decision of the Council [C(63)54]. Also amended by the Council Decisions on: the Participation of the Republic of Korea [C/M(91)18, item 181 and $C(91) 137]$, the Participation of Argentina and Brazil [C/M(94)2, item 28 and C(94)13(FINAL)] the Participation of Chile [C/M(98)16, item 187], the Participation of India [C/M(2001)3, item 30] and the participation of Romania [C/M(2004)7, item 100]; by the Decision of the Council of the 22 September 2002 deleting Article 6 [C/M(2002)18, item 258 c)]; by Council's endorsement of the proposals for the future mode of co-operation of the Development Centre's Governing Board, as set out in the Annex to document $\mathrm{C}(2003) 139[\mathrm{C} / \mathrm{M}(2003) 14$, item 231] and by the Decision of the Council of 22 April 2004 amending Article 11 [(2004)71/REV1; C/M(2004)10, item $138 \mathrm{~d}]$.

\footnotetext{
1 Brazil re-joined the Centre on 17 February 2005.

Thailand joined the Centre on 21 March 2005.
}

Turkey joined the Centre on 1 January 2006. 
Resolution of the Council on the Establishment of

the Development Centre Governing Board [C(2002)228]

as modified by the Council conclusions[C/M(2002)23, Item 337 i)]

THE COUNCIL

Having regard to Article 5 of the Convention establishing the OECD and Rule 18 a) iii) of the Rules of Procedure of the Organisation,

Having regard to the Decision of the Council of 23 October 1962 establishing a Development Centre of the Organisation [C(62)144/Final as amended];

Having regard to the Resolution of the Council [C(71)191] establishing an Advisory Board on the Development Centre;

Having regard to the conclusions of the Council of 12 September 2002 [C/M(2002)18] on Reforming the Development Structure of the OECD [C(2002)181/REV2];

On the proposal of the Secretary-General;

DECIDES:

1. There is hereby established the Development Centre Governing Board, composed of representatives of the countries Members of the Centre ${ }^{1}$.

2. The Governing Board shall work on all issues within the framework of the Development Centre's mandate, [C(62)144/Final as amended] and under the general guidance of the Council;

3. The provisions of the Rules of Procedure of the Organisation shall apply to the Governing Board;

4. The Governing Board shall ensure that the Development Centre engage in close co-ordination and co-operation with other parts of the OECD in forming and implementing a common strategy and co-ordinated work programme of the "development cluster," of which the Development Centre is a part.

5. The Resolution of the Council [C(71)191] referred to above is hereby repealed.

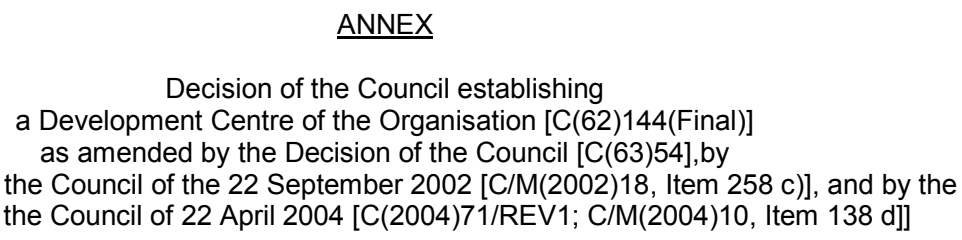

THE COUNCIL,

\footnotetext{
1 In accordance with the provisions of Article 13 of the Convention and Supplementary Protocol No.1 to the Convention, the European Commission takes part in the work of the Governing Board.
} 
Having regard to the Convention on the Organisation for Economic Co-operation and Development of 14th December 1960, (hereinafter called the "Convention"), and, in particular, Articles $1 \mathrm{~b}$ ), $2 \mathrm{e}$ ), $3,5 \mathrm{a}$ ), 12 and 20 of the Convention;

Having regard to the Resolution of the Council adopted at the Meeting of Ministers on 17th November 1961, on Terms of Reference for a Development Centre of the Organisation [Documents OECD/C(61)54, paragraph 11; OECD/C/M(61)7, Item 52];

Having regard to the Financial Regulations of the Organisation and, in particular, to Articles 5 and 15 b) thereof;

Having regard to the Staff Rules and Regulations and to the Rules and Regulations on Experts and Consultants of the Organisation and, in particular, to Regulation 2 b) thereof;

Recognising that there exists in participating countries a great amount of knowledge and experience on the problems of economic development and on the formulation of general economic policies which could be adapted to countries or regions in the process of economic development, and that this would contribute to achieving the objectives of the Organisation set out in the Convention by the placing of such knowledge and experience at the disposal of the countries concerned;

\section{DECIDES:}

\section{Article 1}

There is hereby established, within the framework of the Organisation, a Development Centre (hereinafter referred to as the "Centre").

\section{Article 2}

The purpose of the Centre shall be to bring together the knowledge and experience available in participating countries of both economic development and of the formulation and execution of general economic policies; to adapt such knowledge and experience to the actual needs of countries or regions in the process of economic development and to place the results by appropriate means at the disposal of the countries concerned. In accomplishing this purpose, the Centre shall in particular take into account the interdependence of the political, economic, and cultural conditions existing in the countries in the process of economic development.

\section{Article 3}

The Centre shall undertake the activities appropriate to achieve its purpose as defined in Article 2 in the context of any directives issued by the Council. It may, in particular, engage in training and research, and organise conferences, symposia and other meetings. It may also help meet the needs for advisory services for institutions engaged in teaching, training, or research, or for less-developed countries at their request, subject to Council approval when such services are rendered to Governments of non-participating countries.

\section{Article 4}

The Centre should establish with other international organisations and with national institutions concerned with economic development such working relations as may be appropriate to facilitate the accomplishment of its tasks. Such working relations should in particular allow the Centre to take full advantage of the work of these organisations and institutions. In order to accomplish its purposes the Centre may also encourage, promote and assist the activities of other institutions or organisations. 
The Centre shall report each year to the Council on its activities. It shall submit, either on request by the Council or on its own initiative, other communications to the Council.

Article 6

Article 6 deleted by Decision of the Council of 22 September 2002 [C/M(2002)18, Item 258 c)].

Article 7

The Secretary-General, on the proposal of the President ${ }^{1}$ and with the approval of the Council, may name advisers who shall be consulted by the President as appropriate in the exercise of his duties. The Advisers shall be selected on the basis of their expert knowledge of problems of economic development or on the basis of the functions they may hold with other institutions or in countries in the process of economic development.

Article 8

a) The staff of the Centre shall form part of the Secretariat of the Organisation.

b) Notwithstanding the provisions of Regulation 2(b) of the Rules and Regulations on the Experts and Consultants of the Organisation, the appointment of individuals as consultants to the Centre may be made for periods of up to three years.

Article 9

The expenditure of the Centre shall be defrayed from assets earmarked for it in Part II of the Budget of the Organisation.

\section{Article 10}

Notwithstanding the provisions of the Financial Regulations, the Council may authorise the Secretary-General to seek and accept voluntary contributions, other resources, and payment for services rendered by the Centre. The Council may also authorise the Secretary-General to commit and expend such funds for periods of more than one year.

\section{Article 11}

Participating countries shall be the Member countries which have accepted this Decision and any other country which has been invited by the Organisation to participate and which has addressed a written acceptance to the Secretary-General, including acceptance to contribute to the expenditure of the Centre. Any participating country may withdraw by giving twelve months' written notice to the Secretary-General. The Organisation may suspend or terminate participation of a non-Member country by giving one month's written notice of suspension or twelve months' written notice of termination.

\footnotetext{
1 As of the Decision of the Council of 22 September 2002, the Development Centre is headed by an A7-level official [C/M(2002)18, item 258].
} 


\section{COMMITTEE ON PUBLIC AFFAIRS AND COMMUNICATIONS}

Chair:

Ms. Constance Morella

(United States)

Members:

Open to all Member countries

Date of creation:

26th October 2000

Duration:

31st December 2009

Mandate: - Resolution concerning the modification and renewal of the mandate of the Committee on Public Affairs and Communication approved by the Council at its $1101^{\text {st }}$ session on 16 December 2004 [C/M(2004)27, Item 357]

Resolution of the Council [C(2004)199 and C/M(2004)27, Item 357]

\section{RESOLUTION OF THE COUNCIL CONCERNING THE MODIFICATION AND RENEWAL OF THE MANDATE OF THE COMMITTEE ON PUBLIC AFFAIRS AND COMMUNICATIONS}

\section{THE COUNCIL,}

Having regard to the Convention on the Organisation for Economic Co-operation and Development of 14 December 1960;

Having regard to the Rules of Procedure of the Organisation;

Having regard to the Resolution of the Council establishing a Committee on Public Affairs and Communications [C/M(2000)24, item 304 c) and document $C(2000) 199]$;

Recognising the necessity of ensuring widespread knowledge and understanding of the purpose, activities and work of the Organisation in order to best promote its aims;

Recognising the fact that communications technologies are rapidly modifying and expanding the traditional channels of information dissemination;

Recognising that evolving political, economic and social challenges require informed and actively participating citizens and that governments have a heightened responsibility to ensure transparency and clarity in policy-making;

Recognising that the Organisation can play an important role in assisting governments to improve communication and consultation with civil society on matters dealt with in its work programme;

\section{DECIDES:}

1. The Committee on Public Affairs and Communications shall serve as an advisory body to the Council on the Organisation's public affairs and communications policy and programmes, with a view to enhancing the coherence and efficiency of the Organisation in this area. In particular, the Committee shall exercise its responsibilities of monitoring and evaluation of the implementation of the OECD Publishing Policy as set out in the Appendix to document C(2002)80 and OECD 
Communications Strategy as set out in the Appendices to the documents $C(2004) 74$ and C(2004)198 and to report to the Council on its findings.

2. The Committee shall be composed of representatives of all Member countries and its Chair shall be designated by the Council. It shall meet and report to the Council as often as necessary.

3. The mandate of the Committee shall expire on 31 December 2009 unless the Council decides otherwise. 


\section{LIAISON COMMITTEE WITH INTERNATIONAL NON-GOVERNMENTAL ORGANISATIONS}

Chair:

Mr. Donald Johnston

Secretary-General

Members:

Open to all Member countries

Date of creation:

13th March 1962

Duration:

Unspecified

Mandate: Decision of the Council [C(62)45] on Relations with International non-Governmental Organisations, as amended by [C(64)181, C(66)144(Final) and C(89)15(Final)]

\section{Decision of the Council [C(62)45], as amended}

THE COUNCIL,

Having regard to Article 12 of the Convention on the Organisation for Economic Co-operation and Development of 14th December 1960;

Having regard to the Rules of Procedure of the Organisation and in particular Rule 10 thereof $[\mathrm{OECD} / \mathrm{C}(61) 21]$;

Considering it desirable to specify the fundamental rules governing the procedure for liaison and consultation between the Organisation and international non-Governmental organisations interested in its activities;

Recognising in particular the importance emphasized in paragraph 132 of the Preparatory Committee's Report of maintaining and developing consultations between the Organisation and representatives of labour and management of Member countries;

\section{DECIDES:}

1. The Secretary-General shall be generally responsible for maintaining liaison with international non-Governmental organisations and for preparing and arranging consultations with those most representative of the different sectors of economic life.

2. Any international non-Governmental organisation may be consulted by the Organisation provided that it satisfies the following three conditions:

a) It has wide responsibilities in general economic matters or in a specific economic sector.

b) It has affiliated bodies belonging to all or most of the Member countries in the organisation.

c) It substantially represents the non-Governmental interests in the field or sector in question.

3. The Secretary-General shall prepare a list of the organisations specified in paragraph 2 above and shall submit it for the approval of the Council. 
a) Hold exchanges of views with the Organisation at meetings convened either at its own request or on the initiative of the Secretary-General dealing with subjects of common interest or subjects determined beforehand which have a bearing on the work of the Organisation;

b) Receive general information on the work of the Organisation and certain of the Organisation's documents or summaries thereof, whenever the Secretary-General considers such documents or summaries useful for the study of a particular subject.

5. At the meetings specified in paragraph 4 a) above, the organisation in question may be invited either to express its views orally on questions on the Agenda or to submit a memorandum stating its position.

6. Such meetings shall be convened and organised by a Liaison Committee of which the Chairman shall be the Secretary-General and which shall be open to all members of the Council.

7. All Member countries may designate to attend these meetings representatives of their Governments and/or if they so desire, representatives of national organisations in the field concerned.

8. Where appropriate and in order to make allowance in arranging such consultations, for any difference which may exist between the interests of such organisations, the Secretary-General may make with any of the organisations specified in paragraph 2 above or, if necessary, with any other international non-Governmental organisation, such arrangements as may be appropriate and as shall be previously approved by the Council.

9.

a) International non-Governmental organisations, whether or not specified in the list in paragraph 3 above and which are active in a sector covered by the aims or falling within the province of the Organisation, may be kept informed of such part of the Organisation's work as is likely to be of interest to them and may, in certain cases, be consulted for the study of a given question.

b) Such consultations shall be held either in application of Rule $10 \mathrm{~b}$ ) of the Rules of Procedure of the Organisation or at special meetings arranged between the representatives of such organisations and the officers of such subsidiary bodies of the Organisation as are interested, the Secretary-General, in each case, first ascertaining the opinion of the Chairman of the subsidiary body in question.

c) The provisions of paragraph 7 shall also apply to the cases provided for in sub-paragraph b) above.

d) The Secretary-General shall periodically inform the Council of the names of the Organisations not specified in the list referred to in paragraph 3 above, to which this paragraph applies. 


\section{BUDGET COMMITTEE}

Chair:

Mr. David Lyscom

(United Kingdom)

Members:

Open to all Member countries

Date of creation:

30th September 1961

Duration:

Unspecified

Mandate: Resolution of the Council concerning the Terms of Reference of the Budget Committee [OECD/C(61)8]

\section{$\underline{\text { Resolution of the Council [OECD/C(61)8] }}$}

THE COUNCIL,

Having regard to Article 20 of the Convention on the Organisation for Economic Co-operation and Development of 14th December 1960;

Having regard to Article $37^{1}$ of the Financial Regulations;

On the proposal of the Secretary-General;

DECIDES:

The terms of reference of the Budget Committee, set out in the Annex to this Resolution, are approved.

\section{ANNEX}

\section{Terms of Reference of the Budget Committee of the Organisation}

1. a) The Budget Committee shall consist of one representative from each Member of the Organisation.

b) The Council shall appoint the Chairman of the Budget Committee, for a period of one year.

c) The Committee may elect two Vice-Chairmen from amongst its members.

2. a) The functions and duties of the Budget Committee shall be, in general, to advise the Council as necessary on questions relating to the financial administration of the Organisation, and to carry out the tasks allotted to it in the Financial Regulations.

b) In particular, the Budget Committee shall:

i) Give its opinion on Annual and Supplementary Budgets of the Organisation submitted to the Council for adoption;

ii) Advise on the amount of such Working Capital Fund as the Council may decide to establish;

\footnotetext{
1 Article 37 has been replaced by several references to the Budget Committee in the Financial regulations [C(2001)249/REV1] entered into force on 1 January 2003.
} 
iii) Carry out any additional tasks which might be conferred upon it by the Council.

3. behalf.

The Budget Committee may be authorised by the Council to take decisions on its

4. The Secretary-General shall give the Budget Committee all the information which is necessary for the proper discharge of its functions.

5. The Budget Committee shall meet as often as is required. It shall be convened by the Chairman of the Committee in agreement with the Secretary-General.

6 .

a) The Agenda for each meeting and any relevant papers shall be circulated to all Members of the Organisation normally not less than 14 days before the meeting.

b) Any Member of the Organisation, as well as the Secretary-General, shall have the right to propose the inclusion of any item in the Agenda.

7. A summary record of each meeting shall be circulated to all Members together with the text of any decisions taken by the Budget Committee in accordance with the provisions of the Financial Regulations and of paragraph 3 above. 


\title{
REVIEW COMMITTEE
}

Chair:

Mr. Adrian Macey

(New Zealand)

Members:

Mr. Ulrich Stacher

(Austria)

Ex officio as Chair of the Executive Committee

Mr. David Lyscom

(United Kingdom)

Ex officio as Chair of the Budget Committee

Ms. Veronique Ingram

Mr. Wilhelm Jaggi

Mr. Shuichiro Megata

(Australia)

Mr. Paul Reid

(Switzerland)

(Japan)

(United States)

Date of creation:

1st January 2003

Duration:

31st December 2007

\begin{abstract}
Mandate : - Article 25 of the Financial Regulations [C(2001)249/REV1] as amended by the Council during its $1014^{\text {th }}$ Session held on 25 October 2001 [C/M(2001)20, item 347]

- Mandate extended by Council at its $1099^{\text {th }}$ session held on 24 November 2004 [C/M(2004)25, Item 321].
\end{abstract}

\section{Article 25 of the Financial Regulations [C(2001)249/REV1]}

\section{Article 25 - Review Committee}

§1. There shall be a Review Committee of Council which shall monitor the independence and effectiveness of the internal audit function and review the financial situation of the Organisation. It shall report to Council on a regular basis. It shall be composed of up to seven members designated by Council, including the Chair of the Budget Committee and the Chair of the Executive Committee. The members shall elect the Chair of the Committee. The Committee shall meet with the Auditor-General and, as appropriate, other officials of the Organisation and the Board of Auditors. The Auditor-General shall serve as Secretary to the Committee.

§2. The Review Committee's main objectives shall be as follows:

- review and comment on the annual work programme of the internal audit function;

- review the management responses to, and implementation of, the Auditor-General's recommendations; and

- review the financial situation of the Organisation.

\section{Extract of Council Summary record [C/M(2004)25]}

“321. RENEWAL OF THE MANDATE OF THE REVIEW COMMITTEE

THE COUNCIL

a) noted the report and proposal by the Chair of the Review Committee (Room Document No. 2);

b) noted the comments by Members of the Council, including the request of the United Kingdom that the Committee report to Council as soon as it approves its programme of work for 2005-2006; 
c) agreed to extend the mandate of the Review Committee as set out in Article 25 of the revised Financial Regulations [C(2001)249/REV1], and to re-examine it within the framework of Council's review of the Financial Regulations to be carried out within the next three years in conformity with the provisions of Article 35 of the same document." 


\section{INFORMAL GROUP ON THE SITE}

Chair:

Mr. John Rowan

(Ireland)

Members:

Up to six Council Members

Date of creation:

4th February 2002

Duration:

Unspecified

Mandate : - Informal proposal of 13 December 2001

- Council Summary Record of the $1048^{\text {th }}$ session held on 13 February 2003 [C/M(2003)3, item 40]

- Council Summary Record of the $1082^{\text {nd }}$ session held on 8 April 2004 [C/M(2004)8, item 123]

\section{Extract of the informal proposal of 13 December 2001}

"3. In order to ensure a better and permanent information of the Council, a Site Project Advisory Board consisting of up to six Ambassadors should monitor the Site Project and report regularly to Council (i.e., monthly, under "other business") on time and cost targets and project status. The Project Board would meet at least once a month with representatives of the Secretariat, consultants and architects to be informed about the status of the Site Project regarding time and cost aspects. It should be an informal group along the lines of the Development Group, with Ambassadors acting in a personal capacity to ask questions and pass information to Council. To be manageable in size, it should have up to six members from among interested Ambassadors; transparency would be assured through information of Council, which would, in any case, take all necessary decisions and issue statements. This informal group would have no mandate and would not issue recommendations. The Executive Committee would retain its responsibilities."

\section{Extract of the Summary Record [C/M(2003)3]}

(40)

"THE COUNCIL,

g) underlined the importance of the phasing of the redevelopment for the control of the overall cost of the project, in particular the rent on temporary accommodation in Tour Europe, and asked the ambassadors' informal group on the Site Project to monitor this issue carefully;"

\section{Extract of the Summary Record [C/M(2004)8]}

(123)

"THE COUNCIL, 
c) requested the Secretariat, in accordance with $\mathrm{C} / \mathrm{M}(2003) 22$, Item $337 \mathrm{~h})$ to continue to report regularly to the Executive Committee and the Informal Group on the Site in order to keep Council fully informed of progress on the project." 


\section{PENSION BUDGET AND RESERVE FUND MANAGEMENT BOARD}

Chair:

Members:

Date of creation:

Duration:
Mr. David Lyscom

Mr. Paul Kocher

Mr. Tatsuo Arai

Mr. Dominique Paravicini

Mr. Juan Yermo

Mr. Ivan Divoy

12th May 2005
(United Kingdom)

(Austria)

(Japan)

(Switzerland)

Mandate: $\quad$ Approved by Council at its 1113rd session on 12 May 2005 [C/M(2005)12, Item 143 and document C(2005)49]

\section{Extract of document [C(2005)49]}

STATUTE OF THE PENSION BUDGET AND RESERVE FUND

Part II - Fund Management and Governance

Article 3

\section{General Principles}

1. The Fund shall be managed by a Management Board composed of members named by Council on the proposal of the Member countries, the Secretary-General and the Staff Association.

2. The basic mission of the Management Board, which operates subject to control of the Council, is to propose to the Council for approval the general policies, goals and guidelines for investment of the assets of the Fund, to give external service providers the mandates necessary for the management of the Fund, and to assure that the Council approved policies are respected.

3. The operating budget of the Fund will be approved by Council.

4. The Fund will be administered and audited in accordance with the Financial Rules and Regulations of the Organisation.

5. The Management Board has no responsibility for the operation of the Pension Scheme and the payment of benefits to individuals other than the release of funds as required under Article 2, paragraph 4.

6. The Management Board is assisted by a Fund Secretariat designated by the SecretaryGeneral on recommendation of the Management Board.

7. The Management Board will report at least twice annually to Council on the status of the Fund.

Article 4

Composition of the Management Board 
The Management Board is composed of the following members:

a) four persons named by the Council including necessarily the Chair of the Budget Committee; at least two persons among the four named by Council will be Ambassadors ;

b) one person named by the Council on the proposal of the Secretary-General; and

c) one person named by the Council on the proposal of the Staff Association.

2. The members of the Management Board are appointed for a term of three years and may be renewed. They may be removed by Council at any time.

3. The Management Board selects its Chair and Vice-Chair from among its Ambassador members. The chair will be approved by Council.

\section{Article 5}

\section{Functions of the Management Board}

1. Subject to any decisions of the Council, the Management Board shall:

a) submit to Council, for approval, a code of conduct;

b) submit to Council, for approval, proposals for the general policies, goals and guidelines for investment of the assets of the Fund;

c) select, in accordance with the Financial Regulations, Rules and Instructions of the Organisation, the external service providers necessary for the management of the Fund (e.g., investment advisers, investment managers, actuaries and custodian banks.);

d) review the operations of the Fund and verify their conformity with the policies, goals, and guidelines approved by the Council;

e) as necessary, bring to Council's attention any issue concerning the operation of the Fund;

f) approve, on the proposal of the Fund Secretariat, the Fund's operating budget and annual financial statements and submit them to Council for final approval; and

g) carry out other tasks as assigned by Council.

2. The Management Board shall report at least twice annually to Council on the status of the Fund. Every five years, the Management Board will carry out a thorough review of the Fund's investment policies, goals, guidelines and performance, its actuarial assumptions, rate of contribution and its capitalisation target and report its findings, decisions and recommendations to Council.

\section{Article 6}

\section{Meetings and Decisions of the Management Board}

1. The Management Board will establish its governing rules of procedure.

2. The Management Board shall meet as needed to carry out its functions but no less than quarterly, or at the request of its Chair or the majority of its members.

3. Decisions are taken by a majority of the Management Board members, with the Chair or, in his or her absence, the Vice-Chair having the casting vote." 


\title{
BOARD OF AUDITORS
}

Chair:

Mr. Patrick Mordacq

(France)

Members:

Mr. Gabor Földvari

Mr. John Rossetti

Ms. Leslie Aronovitz

(Hungary)

(Canada)

(United States)

Date of creation:

22nd May 1962

Duration:

Unspecified

\begin{abstract}
Mandate : - Resolution of the Council [C(62)61/Final] of 22 May 1962 concerning the appointment and terms of reference of the Auditors of the Organisation

- Financial Regulations [C(2001)249/REV1, articles 31 to 33] approved by Council on 31 October 2001 and entered into force on 1 January 2003 [C/M(2001)21, Item 368 (i]
\end{abstract}

\section{$\underline{\text { Resolution of the Council [C(62)61/Final] }}$}

\section{THE COUNCIL,}

Having regard to Article 20 of the Convention on the Organisation for Economic Coopération and Development of $14^{\text {th }}$ December 1960;

Having regard to the Financial Regulations of the Organisation and, in particular, to Article $34^{1}$ thereof [OECD/C(61)34];

On the proposal of the Budget Committee;

DECIDES:

Article 1

The external audit of the accounts and financial transactions of the Organisation shall be carried out by the Board of Auditors (hereinafter called the "Auditors»), composed of suitably qualified Government audit officials of four Members, appointed by the Council, one of whom shall always be nominated by France as the host state.

Article 2

The term of office of an Auditor shall be four years and shall run from 1st January of the year in which he is appointed, except in the case of the French Auditor, whose appointment shall be for an indefinite period. At the expiration of his first term of office, a retiring Auditor may be reappointed for one further period of four years.

Article 3

The Auditors appointed by the Council shall not have been employed by the Organisation during the three years preceding the date of their nomination.

\section{Article $4^{2}$}

\footnotetext{
${ }^{1}$ In the Financial Regulations as amended, Article 34 has been renumbered Article 31.

${ }^{2}$ This article was amended by Council on $5^{\text {th }}$ March 1963 [C(63)20(Final)].
} 
The Auditors shall not be entitled to payment of salary or fees by the Organisation; they shall, however, rank as experts of the Organisation of the highest category within the meaning of the Regulations and Rules for Council Experts and Consultants and shall receive from the Organisation reimbursement of travel costs incurred in the execution of their functions, in accordance with the rules applicable for the official travel of Council Experts.

Article 5

The Auditors shall appoint a Chairman from amongst themselves and shall determine their methods of work. The Auditor nominated by the host state shall be entrusted with the current detailed checking work.

\section{Article 6}

The Auditors shall carry out a verification of the annual financial transactions of the Organisation as regards both expenditure and receipts and shall perform such audits as they deem necessary to certify that:

a) the detailed statement of assets and liabilities and accounts, submitted to them by the Secretary-General in accordance with Article $28 \mathrm{~d})^{1}$ of the Financial Regulations, are correct and in accordance with the books and records of the Organisation as specified in Article 27 and 28 of those Regulations;

b) the financial transactions recorded in these statements have been effected in accordance with the relevant rules, the budgetary provisions and other directives which may be applicable, and that budget allocations have not been exceeded;

c) the securities and monies on deposit and on hand have been verified by certificates received diredtly from the depositories or by actual count;

d) the financial administration of the Organisation has been carried out on a sound and economical basis.

The Auditors shall also examine the accounts for stores and supplies and shall undertake such audits, surveys and investigations as may be specifically requested by the Budget Committee, including the audit of the books and accounts of the Staff Provident Fund.

\section{Article 7}

The Secretary-General shall give the Auditors such assistance and furnish them with such facilities as they may need for the proper discharge of their duties. They shall, in particular, have free access to the books of account, records and documents of the Organisation which are in their opinion necessary for the execution of the audit.

\section{Article 8}

a) Each year the Auditors shall draw up a joint report certifying the accounts and setting out the comments warranted by their audit. They shall also report on the soundness of the financial administration of the Organisation and may in this report make such observations as they deem necessary on the efficiency of financial procedures, the accounting system and the internal financial control.

b) Such observations that, in the judgement of the Auditors, need not be brought to the attention of the Council, shall be attached to the report as an addendum for consideration in the first instance by the Budget Committee.

\section{Article 9}

The Auditors' report shall be submitted to the Budget Committee not later than nine months after the end of financial year to which the accounts refer. The report shall be transmitted to the Secretary-General beforehand, so that he will have at least 15 days in which to furnish such explanations and justifications as he may consider necessary.

\footnotetext{
${ }^{1}$ In the Financial Regulations as amended, provisions of articles 27 and 28 appear in articles 30 and 32.
} 
The Budget Committee shall transmit the Auditors' report to the Council, together with the explanations of the Secretary-General and, if necessary, with its own observations.

\section{Extract of the Financial Regulations [C(2001)249/REV1]}

“...

\section{Part VIII}

\section{EXTERNAL AUDITING}

\section{Article 31- Mandate of the Board of Auditors}

§1. The accounts and the soundness of the financial administration of the Organisation shall be audited by a Board of Auditors, appointed by Council, under the conditions and subject to the terms of reference established by Council.

§2. The primary function of the Board of Auditors, by means of its audits, is to enable the Members, through Council, to ensure that the systems instituted to report on the use of the financial resources granted to the Organisation and to ensure the fulfilment of its mission are efficient and cost-effective.

To that end, the Board of Auditors shall conduct such audits and investigations as it thinks necessary, in accordance with its terms of reference, the present Regulations and the missions conferred upon it by Council.

§3. The Secretary-General shall furnish the Board of Auditors with such facilities as it may require to carry out its duties.

\section{Article 32 - Submission of the Accounts to the Board}

The Secretary-General shall submit the accounts to the Board of Auditors no later than the 31 March after the close of the financial period.

\section{Article 33 - Report of the Board on the Accounts}

§1. The Board of Auditors shall report to Council on the financial statements no later than the 31 May of the year following the close of the financial period in question. No later than the 31 July, the Board of Auditors shall prepare a second report on the out-turn of the Budget and Programme of Work, and on the sound financial management of the Organisation. These two reports shall constitute the joint report certifying the accounts and setting out the comments warranted by their audit.

§2. On the basis of this report, Council shall discharge the Secretary-General from all liability in respect of his or her administration. Upon this discharge, the net results will be allocated." 


\section{ANNUAL MEETING OF SUSTAINABLE DEVELOPMENT EXPERTS}

Chair:

Mr. Richard Manning

Members:

Open to all Member countries

Date of creation:

13th May 2004

Duration:

December 2006

Mandate : $\quad-1086^{\text {th }}$ Session of the Council held at Ministerial Level on 13 and 14 May 2004 [C/M(2004)12/PART1, item 164 d)]

\section{Extract of Summary Record [C/M(2004)12/PART1, Item 164]}

\section{"THE COUNCIL}

d) noted the report C/MIN(2004)2, welcomed the results of the three-year project on sustainable development and endorsed the recommendations for further work on sustainable development in the OECD;"

\section{Extract of document [C/MIN(2004)2, Annex 2]}

"Regarding institutional arrangements, the Ad Hoc Group recommends establishing an Annual Meeting of Sustainable Development Experts, initially for a two year period. This meeting will:

- Provide a substantive policy dialogue on sustainable development, to promote mainstreaming of sustainable development across the Organisation, and promote enhanced inter-ministry co-ordination among OECD Member governments;

- Review an annual survey on the ongoing, OECD-wide work on sustainable development, with a particular focus on priority, "cross-cutting" areas, identified by the Sustainable Development Experts.

- Report to the Council, making recommendations on future areas for prioritisation, mainstreaming and improved co-ordination among OECD subsidiary bodies.

This Meeting would be composed of representatives of all Member Countries and be chaired by the Chair of the Committee most closely related to the topics discussed at the meeting.

This Annual Meeting of Sustainable Development Experts shall include joint sessions consisting of relevant OECD Committee Chairs/Bureaus and expert group sessions on specific, identified areas. In one meeting, for example, specific sessions could focus on common obstacles of reforming environmentally harmful subsidies. Depending on the Agenda, the duration of these meetings could be 2-3 days." 


\section{LIAISON COMMITTEE BETWEEN THE RUSSIAN FEDERATION AND THE OECD}

Co-Chairs:

Members:

Date of creation:

Duration:
Mr. Donald Johnston

Secretary General
(Russian Federation)

Open to all Member countries

Russian Federation

22nd May 1997

Unspecified

\section{Mandate :}

The OECD has been co-operating with the Russian Federation since 1992, establishing a unique relationship with the country in several ways. The Russia Programme is the largest for any non-member and, consequently, covers an extensive range of market-reform activities. Russia applied for OECD membership in 1996. The Organisation responded that accession was a shared ultimate goal, thus making Russia the only current non-Member country to have received a positive signal in response to a membership request. As a result, mechanisms were developed through which co-operation was strengthened in the interim, including the establishment of a Liaison Committee in 1997. Currently, Russia is the only country that has a Liaison Committee with OECD Members. The Committee monitors and reviews the implementation of the annual work programmes, and serves as the platform for discussion of progress in economic reform process in the Russian Federation, the OECD-Russia co-operation and other issues of mutual interest. The Committee meets about once a year on average.

PROTOCOL BETWEEN THE RUSSIAN FEDERATION AND THE ORGANISATION FOR ECONOMIC CO-OPERATION AND DEVELOPMENT (OECD) ON THE ESTABLISHMENT OF THE LIAISON COMMITTEE BETWEEN THE RUSSIAN FEDERATION AND THE OECD [C(97)116/FINAL]

THE RUSSIAN FEDERATION AND THE ORGANISATION FOR ECONOMIC COOPERATION AND DEVELOPMENT, HEREAFTER "THE PARTIES",

Having regard to the Declaration on Co-operation between the Russian Federation and the OECD (hereafter "the Declaration"), signed in Paris on June 8, 1994, and in particular paragraph 5 thereof,

Having regard to the letter from the Prime Minister of the Russian Federation to the Secretary-General of the OECD, dated 20 May 1996, and to the reply by the Secretary-General, dated 6th February 1997,

Determined to intensify the co-operation between them in accordance with the Declaration in order to assist the Russian Federation in its progress towards establishing a fullyfledged market economy within a framework of democratic institutions,

Mindful that this co-operation should help the Russian Federation to meet and sustain all the conditions for its membership in the OECD, an ultimate goal shared by both Parties, and that it should therefore focus on the areas that are relevant to this end,

Have agreed on the following: 
The Parties establish a Liaison Committee (hereafter "the Liaison Committee") in order to monitor and review the implementation of the annual work programmes provided for in paragraph 3 of the Declaration and assess their results as well as to discuss progress in the economic reform process in the Russian Federation, the co-operation between the Parties and other issues of mutual interest.

\section{Article 2}

The Liaison Committee consists, on the one hand, of Delegations from all OECD Member countries and of members of the OECD Secretariat and, on the other hand, of representatives of the Governmental bodies of the Russian Federation, supported by appropriate experts.

\section{Article 3}

The Liaison Committee will meet periodically, as necessary and agreed, both at the level of Permanent Representatives to the OECD and senior officials representing the Russian Governmental bodies, and at the level of Ministers from both Parties, including on the occasion of OECD Council Ministerial sessions.

The Liaison Committee will adopt its agenda and any rules of procedure that might be necessary for the efficient conduct of its work. 


\section{GLOBAL FORUM ON AGRICULTURE}

Chair:

Members:

Non-Member Participants:

Date of creation:

Duration:
No formally-appointed Chair

Open to all Member countries

Open to invited non-Members

2001

Unspecified

\section{Mandate:}

The OECD Global Forums were created at the beginning of the Organisation's 2001-02 Programme of Work [C/PWB(2000)01/02/FINAL]. They constitute one of the two main pillars of the OECD's outreach programme, the other being that of the country and regional programmes. The Forums cover a set of thematic areas and provide a basis for building networks with global (though not universal) participation. The Forums address trans-boundary issues of concern to OECD Members and non-Members from multiple world regions for which OECD analytical work based on the use and development of comparable data can enhance the policy dialogue with relevant nonMembers world-wide. Global Forum meetings often involve high-level policy makers, policy analysts and various other stakeholders and help build consensus on how to make policies more effective at achieving stated government objectives.

The Global Forum on Agriculture promotes dialogue among Members and nonMembers on agricultural policies and agricultural trade reform. Whereas the OECD has made considerable efforts to reduce trade distortions caused by OECD Members' domestic agricultural policies, and this Global Forum responds to the need to address comprehensively the effect of multilateral trade liberalisation on domestic agricultural policies in Member and non-Member economies alike. Agricultural development is essential if developing non-Members are to meet the agreed international development goals and the scope for agricultural development is conditioned fundamentally by the nature of the trading environment.

The OECD's basic collection of policy data and quantitative methodology provide a springboard for understanding the impacts of reform on national and global markets, and for analysing how those changes feed through to different groups in society. In the discussions of the Global Forum, OECD's analytical approaches are applied to participants beyond the Members of the Organisation, and the flexible interaction among experts and policy-makers on these topics is supported by a programme of work undertaken by the OECD Secretariat focussing on monitoring agricultural policies in non-Members and the agricultural trade agenda (Doha Development Agenda).

Thereby, the Global Forum on Agriculture anticipates and prepares the ground to contribute substantive information and policy insights into upcoming issues and priorities essential to meaningful policy dialogue. 


\section{GLOBAL FORUM ON COMPETITION}

Chair:

Members:

Non-Member Participants:

Date of creation:

Duration:
No formally-appointed Chair

Open to all Member countries

Open to invited non-Members

2001

Unspecified

\section{Mandate:}

The OECD Global Forums were created at the beginning of the Organisation's 2001-02 Programme of Work [C/PWB(2000)01/02/FINAL]. They constitute one of the two main pillars of the OECD's outreach programme, the other being that of the country and regional programmes. The Forums cover a set of thematic areas and provide a basis for building networks with global (though not universal) participation. The Forums address trans-boundary issues of concern to OECD Members and non-Members from multiple world regions for which OECD analytical work based on the use and development of comparable data can enhance the policy dialogue with relevant nonMembers world-wide. Global Forum meetings often involve high-level policy makers, policy analysts and various other stakeholders and help build consensus on how to make policies more effective at achieving stated government objectives.

The Global Forum on Competition (GFC) has been established as an efficient mechanism to (i) disseminate OECD Members' experience and best practices, (ii) to obtain information about non-Members' conditions, experiences and views, (iii) to promote a greater understanding of why legitimate differences in approaches between developing and developed economies may continue to be warranted; (iv) to create larger networks of government officials that have the level of mutual understanding that comes from OECD-style dialogue; and (v) to promote policy dialogue, with an opportunity for contribution by the private sector and NGOs.

Other stated purposes have been described as "supporting effective law enforcement against world-wide cartels", and "increasing the efficiency of procedures to review transborder mergers". World-wide cartels operate beyond the OECD area; hence, the anti-cartel programme which OECD Members endorsed in 2000 and actively pursued since then, cannot succeed without involvement of non-Members and their acquiring the tools and skills necessary to take effective remedial action. Similarly, ongoing work within the OECD aimed at reducing the burden on global business of merger clearance rules by offering competition authorities the possibility to meet and develop options for reform will fall short of its full potential unless non-Members can be included in the dialogue.

The Forum also focuses on bringing competition principles to bear in regulatory reform. This underscores the fact that the scope of the GFC extends beyond competition law enforcement matters to include competition policy issues broadly defined. The GFC is also increasingly being viewed as a forum in which non-Members can benefit from the type of peer review process that Members have available to them in the Committee.

The GFC promotes widespread association with OECD standards in the field of competition, including the 2001 Recommendation on Structural Separation in Regulated Industries, the 1998 Recommendation against Hard-Core cartels and the 1995 Recommendation on Cooperation. In addition, the GFC provides a venue to add a development dimension to the OECD's work on competition policy. 


\section{GLOBAL FORUM ON GOVERNANCE}

Chair:

Members:

Non-Member Participants:

Date of creation:

Duration:
No formally-appointed Chair

Open to all Member countries

Open to invited non-Members

2001

Unspecified

\section{Mandate:}

The OECD Global Forums were created at the beginning of the Organisation's 2001-02 Programme of Work [C/PWB(2000)01/02/FINAL]. They constitute one of the two main pillars of the OECD's outreach programme, the other being that of the country and regional programmes. The Forums cover a set of thematic areas and provide a basis for building networks with global (though not universal) participation. The Forums address trans-boundary issues of concern to OECD Members and non-Members from multiple world regions for which OECD analytical work based on the use and development of comparable data can enhance the policy dialogue with relevant nonMembers world-wide. Global Forum meetings often involve high-level policy makers, policy analysts and various other stakeholders and help build consensus on how to make policies more effective at achieving stated government objectives.

Governments of OECD Members and of non-Members are redefining their roles in the face of new challenges. The Global Forum on Governance has been created to analyse these challenges, develop solutions, and to promote measures and practices that enhance the effectiveness of democratic institutions. The Forum is based on the understanding that inefficient and non-transparent governance structures are a major threat to the rule of law, democracy, human rights, fairness, social justice and, in the international context, to peace. They also hinder economic development, undermine the business climate and discourage both foreign and domestic investment.

The improvement of the quality of public governance covers modernizing government (including improving the management of public finances), open government and e-government, regulatory reform and public sector integrity (transparency of public procurement, anti-corruption policies in particular). In the area of corporate governance, the dialogue seeks to enhance the awareness of, and commitment to, improved corporate governance, market integrity and sound business practices, following OECD corporate governance principles as a benchmark. One particular area of concern is financial governance. Finally, the forum seeks to encourage the improvement of statistics as the basis for sound governance.

The Forum operates through a variety of workshops, technical activities, work programmes and conferences. Several of its activities are undertaken in co-operation with other international organisations 


\section{GLOBAL FORUM ON INTERNATIONAL INVESTMENT}

Chair:

Members:

Non-Member Participants:

Date of creation:

Duration:
No formally-appointed Chair

Open to all Member countries

Open to invited non-Members

2001

Unspecified

\section{Mandate:}

The OECD Global Forums were created at the beginning of the Organisation's 2001-02 Programme of Work [C/PWB(2000)01/02/FINAL]. They constitute one of the two main pillars of the OECD's outreach programme, the other being that of the country and regional programmes. The Forums cover a set of thematic areas and provide a basis for building networks with global (though not universal) participation. The Forums address trans-boundary issues of concern to OECD Members and non-Members from multiple world regions for which OECD analytical work based on the use and development of comparable data can enhance the policy dialogue with relevant nonMembers world-wide. Global Forum meetings often involve high-level policy makers, policy analysts and various other stakeholders and help build consensus on how to make policies more effective at achieving stated government objectives.

The Global Forum on International Investment (GFII) has been created to provide Members, non-Members and other investment stakeholders with a platform to help foster consensus on major investment policy issues. These issues encompass in particular those addressed by the OECD Declaration on International Investment and Multinational Enterprises, i.e. National Treatment for foreign-owned enterprises, corporate conduct, investment (dis)incentives and the avoidance of conflicting requirements on multinational enterprises, as well as cross-cutting issues such as the linkages of investment, inter alia, with governance, environment, development co-operation, SME development, labour affairs, education, and taxation. The development dimension of the investment is increasingly shaping the GFII agenda and the future GFII activities will be designed in a way also to feed into the "OECD Strategy on Investment for Development".

One important aim of this consensus-building and experience sharing is to widen the circle of non-Members adhering to this Declaration and thus to OECD standards. Several nonMembers have indeed done so, or are expected to do so in the near future, while several others have expressed serious interest. A related aim is to help achieve consensus on investment-related issues in the follow-up processes to Monterrey, Johannesburg and the Doha Development Agenda.

These issues are particularly intricate, as the views on the policy requirements for maximising the benefits of foreign direct investment in developing countries continue to be widely divergent. The OECD expects to help narrow these differences by offering the GFII as a venue for in-depth discussion of some of the issues concerned, and for sharing best practices in a nonnegotiating setting. The Global Forum on International Investment aims to do so by building networks of policy makers from Members and four categories of non-Members: (i) those who adhered or interested in adhering to the OECD Declaration, (ii) those with sizeable two-way direct investment flows, (iii) other countries that are opinion leaders in the field of international investment policy and (iv) those developing countries committed to pursuing investment-related reforms and with which OECD has developed investment dialogue and co-operation. 


\section{GLOBAL FORUM ON THE KNOWLEDGE ECONOMY}

Chair:

Members:

Non-Member Participants:

Date of creation:

Duration:
No formally-appointed Chair

Open to all Member countries

Open to invited non-Members

2001

Unspecified

\section{Mandate:}

The OECD Global Forums were created at the beginning of the Organisation's 2001-02 Programme of Work [C/PWB(2000)01/02/FINAL]. They constitute one of the two main pillars of the OECD's outreach programme, the other being that of the country and regional programmes. The Forums cover a set of thematic areas and provide a basis for building networks with global (though not universal) participation. The Forums address trans-boundary issues of concern to OECD Members and non-Members from multiple world regions for which OECD analytical work based on the use and development of comparable data can enhance the policy dialogue with relevant nonMembers world-wide. Global Forum meetings often involve high-level policy makers, policy analysts and various other stakeholders and help build consensus on how to make policies more effective at achieving stated government objectives.

The Global Forum on Knowledge Economy has two main branches: i) the digital economy, and ii) biotechnology, bridged by a set of common elements of a policy nature.

The Digital Economy and Electronic Commerce branch promotes an internationally coherent approach to the formulation of government policies and regulatory frameworks for the digital economy and e-commerce. This contributes to growth of commerce and trade and the economic growth of OECD and non-OECD economies more broadly. The dialogue aims at removing obstacles to fulfilling the potential offered by new technologies. To achieve this objective, the Global Forum deals with such issues emerging from the use of these technologies that require international co-ordination, engaging stakeholders in a wide-ranging policy debate and ultimately promoting a rules-based environment.

The OECD, through the Global Forum mechanism, contributes to the definition of a truly global policy framework for the development of ICTs and the digital economy. One of its main elements will be the Security of Information Systems and Networks, including coherent policy strategies. In the fiscal area, non-Member economies are associated with the implementation of the Ottawa Ministerial Taxation Framework Conditions for Electronic Commerce, which requires a global strategy to ensure effective taxation of electronic commerce and to avoid double taxation.

Contributions to the World Summit on the Information Society (WSIS) and the G8 DOT force respond to the high pressure on the OECD to provide needed substantive input. Leveraging ODA for the best use of ICT links development co-operation with ICT and involves considerable involvement from the development co-operation community and reaches both emerging economies and poorer countries.

The Biotechnology branch of the Global Forum on the Knowledge Economy deals with two areas pertinent for economic and social progress worldwide: i) human health and environmental safety assessment methods, and ii) biological resource centres. 
Based on consensus in the biotechnology field on the importance of biotechnology activity on human health and environmental safety assessment methods, the Forum unites OECD Members and non-Members in discussing and setting international standards in the globally important area of biosafety.

Access to well-developed biological resource centres (BRCs) will increasingly be at the core of successful life science research and ex situ biodiversity conservation. The activity of the Global Forum in this area brings together OECD Members and non-Members in making a reality of the OECD blueprint for a global network of BRCs. The aim is to increase the coherence of international efforts, to improve capacity in Members and non-Members, and to encourage the transfer of technology and know-how. Additional focus will be put on ensuring appropriate and safe access to health-related biotechnology research, processes and materials for use in combating infectious diseases.

Common elements of the activities covered by the Global Forum on the Knowledge Economy include: Science and Technology Indicators -- international standards and benchmarking in strategic science and technology areas; International Mobility - measurement and analysis of highly-skilled labour force's mobility ("brain drain/circulation") and its impact on economic development; World Education Indicators; and the Programme for International Student Assessment (PISA). 


\section{GLOBAL FORUM ON SUSTAINABLE DEVELOPMENT}

Chair:

Members:

Non-Member Participants:

Date of creation:

Duration:
No formally-appointed Chair

Open to all Member countries

Open to invited non-Members

2001

Unspecified

\section{Mandate:}

The OECD Global Forums were created at the beginning of the Organisation's 2001-02 Programme of Work [C/PWB(2000)01/02/FINAL]. They constitute one of the two main pillars of the OECD's outreach programme, the other being that of the country and regional programmes. The Forums cover a set of thematic areas and provide a basis for building networks with global (though not universal) participation. The Forums address trans-boundary issues of concern to OECD Members and non-Members from multiple world regions for which OECD analytical work based on the use and development of comparable data can enhance the policy dialogue with relevant nonMembers world-wide. Global Forum meetings often involve high-level policy makers, policy analysts and various other stakeholders and help build consensus on how to make policies more effective at achieving stated government objectives.

The OECD Council at Ministerial level (MCM), recognised sustainable development as an overarching goal of OECD governments and the OECD and expressed its commitment to work energetically with countries outside the OECD's membership to achieve the joint sustainable development goals. Issues to be addressed in the Global Forum have also been shaped by the outcomes of the World Summit on Sustainable Development (WSSD), held in Johannesburg, in August-September 2002.

The Global Forum on Sustainable Development focuses principally on the environmental dimension of sustainable development and its linkages with economic and social policies. It builds on twelve years of co-operation with non-Members in this field, and on the 2002 inaugural meeting of this Global Forum on the financing the environmental dimension of sustainable development at which participants emphasised the importance of continuing work on this topic within the Forum. While financing issues are important within the framework of international efforts to promote sustainable development, implementation is crucial as well. There are also important linkages to the Millennium Development Goals and to the post-Doha and Monterrey agendas, which commit to advancing economies, trade and human welfare in the $21^{\text {st }}$ century.

Environmental finance, especially for water - a priority at the WSSD - receives particular attention. The creation of markets to address issues previously dealt with in the public domain (e.g. biodiversity, greenhouse gas emissions) and environmental compliance and enforcement are also addressed. Further focus are the environmental dimensions of the Guidelines on Multinational Enterprises and of the Doha Development Agenda in collaboration with other Global Forums, such as that on International Investment.

This Global Forum engages OECD Members and Non-Members in debate on evolving policies and approaches for tackling climate change issues. The result aims at a better understanding of mitigation commitments post-Kyoto to come into effect after 2012 and provides a solid analytical basis for a new round of negotiations (as of 2005) under the UN Framework Convention on Climate Change. 


\section{GLOBAL FORUM ON TAXATION}

Chair:

Members:

Non-Member Participants:

Date of creation:

Duration:
No formally-appointed Chair

Open to all Member countries

Open to invited non-Members

2001

Unspecified

\section{Mandate:}

The OECD Global Forums were created at the beginning of the Organisation's 2001-02 Programme of Work [C/PWB(2000)01/02/FINAL]. They constitute one of the two main pillars of the OECD's outreach programme, the other being that of the country and regional programmes. The Forums cover a set of thematic areas and provide a basis for building networks with global (though not universal) participation. The Forums address trans-boundary issues of concern to OECD Members and non-Members from multiple world regions for which OECD analytical work based on the use and development of comparable data can enhance the policy dialogue with relevant nonMembers world-wide. Global Forum meetings often involve high-level policy makers, policy analysts and various other stakeholders and help build consensus on how to make policies more effective at achieving stated government objectives.

The objective of Global Forum on Taxation is to encourage and develop the on-going dialogue among tax officials in OECD countries and non-OECD economies, allowing for the discussion of best practices in policy and administration and the development of models, standards and guidelines on international tax issues in the mutual interest of all parties.

The main topics for the Global Forum on Taxation coincide with the core work of the OECD's Committee on Fiscal Affairs, namely tax treaties and transfer pricing. Additionally, there have been growing demands for dialogue in other key areas, such as electronic commerce, harmful tax practices and exchange of information. In order to carry out the work, the Forum organises approximately twenty five policy dialogue events per year, held in Paris, and at the OECD multilateral tax centres.

A major new element of the Global Forum is the development of partnerships with other Organisations working in the tax area. In 2003, the recently launched International Tax Dialogue, which is a joint initiative between the OECD, the World Bank and the International Monetary Fund (and possibly the United Nations), became operational. The Committee of International Organisations on Tax Administration (CIOTA) became fully operational in 2003 and it is also a key partner in this Partnership. This new initiative will permit the development of tax programmes which explicitly take into account activities being carried out by the OECD's international partners. Such co-operation will improve programme co-ordination and result in more effective delivery of policy dialogue and advice.

Taxation poses challenges not only for non-Members but also for Members. By producing, issuing and discussing with non-Members the results of its analysis on relevant issues, OECD plays a useful bridge-building role. As such, it contributes to advancing the process of cooperation on taxation and promotes adherence to the OECD led international standards and guidelines. 


\section{GLOBAL FORUM ON TRADE}

Chair:

Members:

Non-Member Participants:

Date of creation:

Duration:
No formally-appointed Chair

Open to all Member countries

Open to invited non-Members

2001

Unspecified

\section{Mandate:}

The OECD Global Forums were created at the beginning of the Organisation's 2001-02 Programme of Work [C/PWB(2000)01/02/FINAL]. They constitute one of the two main pillars of the OECD's outreach programme, the other being that of the country and regional programmes. The Forums cover a set of thematic areas and provide a basis for building networks with global (though not universal) participation. The Forums address trans-boundary issues of concern to OECD Members and non-Members from multiple world regions for which OECD analytical work based on the use and development of comparable data can enhance the policy dialogue with relevant nonMembers world-wide. Global Forum meetings often involve high-level policy makers, policy analysts and various other stakeholders and help build consensus on how to make policies more effective at achieving stated government objectives.

The objective of the Global Forum on Trade (GFTr) is to promote dialogue among Members and non-Members in support of trade liberalisation and closely related issues. To date, this dialogue has concentrated on the Doha Development Agenda (DDA). Among the principal subjects discussed have been the so-called "Singapore issues" (investment, competition, government procurement and trade facilitation), the effects on market access of environmental requirements, the implications of closer multilateral co-operation in the competition field and the opportunities and challenges of improving market access through the removal of border and behindthe-border barriers. The agenda for the GFTr will continue to pursue dialogue based on OECD analysis of key trade and development issues in the context of the DDA.

Experience from these and earlier Global Forum on Trade meetings indicates that they can be helpful in promoting mutual understanding of the concerns expressed by various parties and in expanding the areas of agreement. Through these events, the OECD plays a useful bridgebuilding role, drawing on its unique analytical perspectives and fostering dialogue on key issues with non-Members. Moreover, the Global Forum on Trade has successfully addressed horizontal issues resulting in joint initiatives and co-operation with other bodies of the OECD as well as partnerships with international organisations (including WTO, World Bank, UNCTAD and APEC). 


\section{GLOBAL FORUM ON EDUCATION}

Chair:

Members:

Non-Member Participants:

Date of creation:

Duration:
No formally-appointed Chair

Open to all Member countries

Open to invited non-Members

24th February 2005

Unspecified

Mandate: Council Decision establishing a Global Forum on Education approved at its $1106^{\text {th }}$ session held on 24 February 2005 [C/M(2005)5, Item 47 and document C(2005)19]

\section{Extract of document [C(2005)19 Annex]}

\section{"Rationale for creating a Global Forum on Education}

Global Forums address issues which defy solution in individual countries or regions and for which the relevance of OECD work is dependent on interaction and peer learning with relevant non-Members world-wide.

1. There is increasing recognition that education plays a key role in achieving goals of sustainable economic development. Most non-Members have embarked on reforms to meet the Education for All (EFA) challenge and equity of access to lifelong learning. Several have turned to the OECD for policy reviews and recommendations, but resources are often insufficient to respond to demand on an individual country basis. A Global forum on Education would help to satisfy this demand in areas of current EDU activities (inter alia tertiary education, special needs and lifelong learning) and would be a useful vehicle for attracting additional voluntary contributions for Secretariat work. Synergies would also be found through interaction between regional reform work implemented through OECD reviews (e.g. Baltics, SEE, Latin America and Africa). Although education has been listed as a topic for the Knowledge Economy Forum, the Forum has never addressed any education issue directly.

Policy issues discussed at the Forum meetings are the subject of specific peer learning, including the analytical use and the development of comparable data.

2. The Directorate for Education's Programme for Non-Member Economies (NME) has had a long experience in organising regional projects for peer learning (EC-Phare co-operation in higher education; EC-Phare co-operation in secondary education; SEE education networks; Baltic programme, etc.) on numerous themes: education reform in relation to the needs of the labour market; a leadership role for ministries of education in decentralised systems; role of parliamentary committees in formulating education policy, etc. It is not unlikely that non-Member participation in PISA will outnumber OECD Members in the foreseeable future. This is already the case of special education needs statistics and indicators. Even countries which do not currently have the capacity or finance for joining these networks can benefit from establishing similar systems for future adhesion.

The Forums constitute stable networks of policy makers from Member and non-Member economies that contribute to mutually beneficial dialogue and thus enhance non-Members' capacity to benefit from OECD work and bear on it. 
3. Substantial networks of education officials and experts in both Member and non-Member countries have been established through the Education and the Economy activity begun in 1991: peer reviews of non-Member economies; World Education Indicators (WEI); the Programme for International Student Assessment (PISA); and, improving outcomes for students with special needs programme. The Forum would allow these networks to interact and be strengthened as well as to be expanded to include a wider range of non-Member economies.

\section{Forum activities are characterised by a clear focus and continuity over the medium term, and there are appropriate monitoring and evaluation mechanisms.}

4. Being closely linked to current work of the Directorate tailored for the needs of the nonMember audience would ensure a clear focus and appropriate monitoring.

\section{The Forums gain name recognition outside the OECD as vehicles for international co- operation on specific subjects.}

5. OECD outreach education activities began with the Education and the Economy Conference in 1992 which drew 130 high level representatives from 27 countries, the European Commission, the World Bank, European Bank for Reconstruction and Development (EBRD), social partners and observers from the Council of Europe and UNESCO. Over the ensuing years the OECD has built us a solid reputation through analytical work, targeted seminars (e.g. education reform in relation to the needs of the labour market, the role of parliamentary committees in formulating education policy, etc.), and more than 35 country reviews. The recommendations of these country reviews were valuable for the former Partner in Transition countries and have had an important impact on non-Members to:

- identify major developments, problems and issues in the moves to adapt education systems to the needs of market-based economies;

- relate these moves to wider trends, viz. democratisation, technological change, demographic factors and the progress of science; and

- consider and further develop an agenda of problems and tasks on which further collaborative work might be undertaken.

6. This work laid the foundation for open review of options in partnership with the countries concerned and established the reputation of the Organisation for activities focusing on the "consumer" of education, on the responsiveness of policy and practitioners to the social, economic and political changes occurring and on the role education must play in preparing young people for society. OECD review recommendations have played an important role in promoting bilateral projects with Member countries and multilateral programmes through EU agencies and Banks. This reputation has led to other agencies using the format for regional projects (e.g. the European Training Foundation in South Eastern Europe and the Association for the Development of Education in Africa in sub-Saharan Africa) to the Organisation being asked to play a key role as Co-ordinator for education policy in the Stability Pact." 


\section{GLOBAL FORUM ON DEVELOPMENT}

Chair:

Members:

Non-Member Participants:

Date of creation:

Duration:
No formally-appointed Chair

Open to all Member countries

Open to invited non-Members

23rd February 2006

Unspecified

Mandate : - Council Decision regarding a Global Forum on Development adopted at its $1130^{\text {th }}$ session held on 23 February 2006 [C/M(2006)4, item 53 and C(2005)191/REV1]

\section{Annex 2 to [C(2005)191/REV1]}

\section{MANDATE OF THE OECD GLOBAL FORUM ON DEVELOPMENT}

The OECD Global Forums were created in the framework of the Organisation's 200102 Programme of Work [C/PWB(2000)01/02/FINAL]. Established in fields where the OECD has leading expertise and experience, Global Forums, together with the country and regional approaches, are the main pillars of the OECD's global relations programme. The Forums cover a set of thematic areas and provide a basis for building networks with global (though not universal) participation. They address trans boundary issues that are of concern to OECD members and non members from multiple regions, allowing OECD analytical work based on the use and development of comparable data to enhance the global policy dialogue with relevant non members. Global Forum meetings often involve high level policy makers, policy analysts and various other stakeholders. They help build consensus on more effective policy towards achieving stated government objectives.

The Global Forum on Development will be built on the Organisation's role as a knowledge based organisation bridging research and policy to underpin substantive, evidence based policy dialogue, and to monitor trends and policies - at the conception, implementation and evaluation/monitoring stages - as well as to forge consensus amongst policy makers on policy evolution.

The Global Forum on Development will address priority issues in the field of development policy through multi year thematic cycles, structured around an annual plenary meeting and a limited number of informal preparatory or follow up events. The themes will be identified based on priority setting in the context of the OECD's development-related work, thus ensuring co ordination and complementarity with development related outreach in other parts of the Organisation. Periodic assessments will be carried out to ascertain whether the respective themes are effectively addressed by the Global Forum, and to prepare the timely introduction of new thematic cycles.

The Global Forum on Development will help:

- Build consensus among diverse development stakeholders for more synergetic and coherent outputs through policy dialogue and peer learning, and an interdisciplinary approach to its activities.

- Enhance the visibility and impact of the OECD in the field of development, and allow the Organisation to take a stronger leadership role on key global development issues. 
- Enable a core network of participants to follow key policy issues on a multi-annual basis.

- Further enhance OECD wide coherence on development related work, and promote horizontal and multidisciplinary approaches, including beyond the organisation through partnerships with other international organisations.

- Mainstream outreach work on development, and contribute to policy progress and consensus with non members through OECD methods of work. 


\section{GLOBAL DIALOGUE ${ }^{1}$}

Chair:

Members:

Non-Member Participants: ${ }^{2}$

Date of creation:

Duration:
Chair of the ECSS

Open to all Member countries

\section{Brazil}

China

India

Jordan

Russian Federation

South Africa

14th October 2004 : First session held on 8 December 2004

Unspecified

Mandate : - Summary record of the $1095^{\text {th }}$ session of the Council held on 14 October 2004 [C/M(2004)21, Item 277 and document C(2004)166]

\section{Extract of Document [C(2004)166]}

\section{Purpose and Themes}

3. The purpose of the Global Dialogue should be to give ECSS delegates the opportunity to exchange views with their counterparts from invited non-member(s) of strategic importance on important issues of global interest with a view to helping shape the agenda of well informed OECD discussions on these issues. The purpose would not be to ask non-members to report on their own domestic situations, in contrast with similar dialogue events held previously in the framework of the ECSS. The Global Dialogue should contribute to the global positioning of the OECD and strengthen its partnership with non-Members of strategic importance. It should not duplicate with other forums, within or outside of the Organisation.

4. The theme of the discussion for the Global Dialogue should therefore be closely linked to a substantive issue on the agenda of the ECSS meeting itself, preferably focusing on one of the issues likely to be discussed at the forthcoming MCM. In this manner, the Global Dialogue could clearly serve a useful purpose by contributing to shaping the agenda of OECD discussions on an important issue of global interest."

\footnotetext{
1 On 22 September 2005, Council agreed to a "pause de reflexion" [C/M(2005)19, Item 242].

2 For the 2nd session held in 2005.
} 



\section{EXECUTIVE COMMITTEE}

Chair:

Members:

Date of creation:

Duration:
Mr. Ulrich Stacher

(Austria)

Open to all Member countries

30th September 1961

Unspecified

Mandate: - Article 9 of the Convention on the Organisation for Economic Co-operation and Development

- Rules 21 b), 22 and 25 of the Rules of Procedure of the Organisation

- Resolution of the Council concerning the Executive Committee [C(77)75(Final)], as amended [C/M(97)2, Item $19 \mathrm{c})]$

- Resolution of the Council on the role of the Executive Committee C/M(99)21, Item 306 II

- Resolution of the Council on the merger of the Council Working Party on Staff Policy with the Executive Committee [C/M(2000)21, Item 257]

\section{Article 9 of the Convention}

"The Council may establish an Executive Committee and such subsidiary bodies as may be required for the achievement of the aims of the Organisation."

\section{Rules $21 \mathrm{~b}), 22$ and 25 of the Rules of Procedure}

"Rule 21

b) The Executive Committee and the Committees may set up temporary working parties to assist them in their work. Joint working parties may be set up by the Executive Committee or Committees on a temporary basis to study questions concerning several Committees.

If, however, a working party had been in existence for more than a year, it cannot be maintained subsequently without the approval of the Executive Committee.

\section{Rule 22}

a) Within their competence, the Committees shall proceed to study such questions as they are instructed to do by the Council or the Executive Committee. To this end, they may refer certain points for preliminary investigation to one of their Sub-Committees or another Committee.

b) The Committees may decide to study any other questions within their competence. The Council may decide that the study undertaken by a Committee should not be carried further.

c) Where a Committee requests another Committee to undertake a study, in the absence of any express terms of reference to that effect, it must report its request to the Executive Committee which may decide that the study should not be made. 
a) Reports, proposals and documents submitted by a Committee to the Council shall be subject to prior consideration by the Executive Committee.

b) Upon its examination, the Executive Committee shall transmit the reports, proposals or documents with its comments and suggested amendments, if any, to the Council. If necessary the Executive Committee may refer a report, proposal or document back to the Committee for further consideration.

c) Between sessions of the Council, the Executive Committee may issue directives to the Committees, provided that the Council is kept regularly informed."

\section{Resolution of the Council [C(77)75(Final)]}

THE COUNCIL,

Having regard to Article 9 of the Convention on the Organisation for Economic Co-operation and Development of 14th December 1960 ;

Having regard to the Resolution of the Council of 14th March 1977, concerning the Executive Committee [C(77)42] ;

\section{DECIDES :}

1. The Council shall be assisted by an Executive Committee consisting of fourteen Members to be designated annually by the Council. The Executive Committee shall carry on its work in accordance with the general and specific instructions of the Council and shall report on it to the Council.

2. The Council shall designate annually from among the Members of the Executive Committee a Chairman and one or more Vice-Chairmen.

3. The Members of the Organisation shall be kept informed of the proceedings of the Executive Committee by the circulation in good time of agendas and summary records.

4. The present Resolution cancels the Resolution of the Council concerning the Executive Committee of 14th March 1977, referred to above.

\section{Extract from document [C/M(97)2]}

"THE COUNCIL

c) agreed to ... amend the first sentence of Article 1 of Council Resolution C(77)75/Final as follows: "The Council shall be assisted by an Executive Committee open to all Members ; ..."

\section{Extract from CE(99)6/REV2, §19 [approved by Council on} 28 October 1999 in C/M(99)21, Item 306 II] 
i) The Executive Committee shall take up matters submitted to it by Groups of the Council chaired by Ambassadors prior to their submission to Council, whenever these consider it necessary.

ii) The Executive Committee shall try to take more initiatives to identify areas it could examine with a view to relieving the Council of some of its tasks; it shall proceed to examine such matters with the endorsement of the Council.

iii) The Executive Committee shall transmit to Council only matters on which it has reached a consensus, or in respect of which there are clearly identified outstanding problems that the Council alone can resolve.

iv) The Council shall in principle refrain from discussing issues on which consensus has been reached in the Executive Committee; a list annexed to the Council agenda will indicate all of the items prepared by bodies directly subsidiary to the Council and that are likely to be approved without discussion. This will not, however, exclude the possibility for each Member of the Council to ask for a debate.

v) Any Member country having a particular position on a document shall try to inform the Secretariat of this sufficiently in advance of Executive Committee meetings so that a possible compromise may be formulated in full transparency with regard to all.

vi) The Secretariat shall circulate the documents in both official languages at least one week before Executive Committee meetings, and each document shall indicate the name of an official who may be contacted regarding the document.

\section{Extract from document [C/M(2000)21, Item 257]}

\section{"THE COUNCIL,}

d) agreed on the merger of the Working Party on Staff Policy and the Executive Committee, and on the consequent amendment (underlined) to the last sentence of Regulation 23 of the Staff Regulations, Rules and Instructions: "The Staff Association may be invited to present to the Executive Committee its views on any matter within its terms of reference, and to discuss them with it in accordance with arrangements to be agreed with the Chairman of the Executive Committee, the Secretary-General and the Staff Association. 



\section{EXECUTIVE COMMITTEE IN SPECIAL SESSION}

Chair:

Mr. Bernd Pfaffenbach

Designated Chair

(Germany)

Members:

Open to all Member countries

Date of creation:

10th October 1972

Duration:

Unspecified

Mandate: $\quad$ Minutes of the 293rd and 305th sessions of the Council [C/M(72)15 (Final) Annex and $\mathrm{C} / \mathrm{M}(72) 27$ (Final) Part I]

\section{Extract from document [C/M(72)15(Final) Annex]}

\section{"THE COUNCIL}

noting the intentions of Member Governments to work for reform of the international monetary system and, at the same time, to achieve further progress towards trade liberalisation;

considering that negotiations in these fields will take place in world-wide organisations;

considering that the present situation required more information, active co-operation and consultation among Member Governments;

1. agreed that the OECD has an important role to play in analysing and consulting on international monetary, trade, investment and related economic issues, including particularly their interrelationships;

2. instructed the competent bodies of the OECD to continue their work on international monetary and trade questions, recognising that negotiations are due to take place in other organisations;

3. agreed that, to this end, meetings of the Council at Ministerial level may be desirable, and that the competent bodies of the Organisation, particularly the Executive Committee, the Economic Policy Committee and its appropriate Working Parties, and the Trade Committee, should discuss these questions;

4. agreed that Member countries will be represented at an appropriately high level in the meetings referred to above;

5. instructed the Secretary-General to propose to the Council such adaptation and improvement of existing structures and procedures of the Organisation as may appear appropriate to discharge adequately and in the most effective manner the role agreed above.

The Council, in adopting the foregoing text, noted that, in making proposals pursuant to paragraph 5 of the text, the Secretary-General would take into account the statements made during the discussion of this agenda item."

\section{Extract from document [C/M(72)27(Final) Part I, Item 242]}




\section{"THE COUNCIL}

(242) a) recalled the guidance given at Ministerial level at its 293rd Meeting, following the examination of international monetary and trade issues, on the way in which the Organisation should contribute to discussion in these fields;

b) recalled that Ministers agreed, to this end, that meetings of the Council at Ministerial level may be desirable, and that the competent bodies of the Organisation, particularly the Executive Committee, the Economic Policy Committee and its appropriate Working Parties, and the Trade Committee, should discuss these questions;

c) regarded the report by the High-level Group on Trade and Related Problems [C(72)175], which contains a series of considerations corresponding to the preoccupations of Ministers on the interrelationships between the various issues discussed, as a useful contribution to the discussions on international monetary, trade, investment and related economic issues in the above-mentioned Committees;

d) invited the Executive Committee to carry forward, on the basis of the Ministerial guidance referred to above, and in the light of the considerations contained in the Report by the High-level Group, the discussions on international monetary and trade issues initiated by Ministers;

e) agreed that for the discussions foreseen in d) above, the Executive Committee will meet at the high level appropriate and that the provisions for taking part in such discussions by Member countries not members of that Committee are satisfied;

f) invited the Executive Committee to meet as soon as possible, at the high level appropriate, to organise its work under the present instruction;

g) requested the Secretary-General to keep the Council informed on the progress of the work under the present instruction and agreed to discuss on the basis of such reports questions concerned with holding a meeting at Ministerial level." 
ECONOMICPOLICY 

Chair:

Vice-Chairs:

Members:

Observers:

Date of creation:

Duration:
Mr. Harvey Rosen

Mr. Henri Bogaert

Mr. Takashi Omori

Open to all Member countries

Bank for International Settlements (BIS)

European Free Trade Association (EFTA)

International Monetary Fund (IMF)

World Bank

30th September 1961

31st December 2008
(United States)

(Belgium)

(Japan)

Mandate: - Paragraph 12 of the Report by the Preparatory Committee

- Council Decision regarding a Sunset Clause for all Committees [C/M(2004)5, item 75] entered into force on 22 April 2004 [C/M(2004)10, item 143, IV, c)]

\section{Paragraph 12 of the Report by the Preparatory Committee}

12. "It is further recommended that the mandate of the Economic Policy Committee should be as follows:

a) The Economic Policy Committee will keep under review the economic and financial situation and policies of Member countries with a view to attaining the objectives of the Convention.

b) In reviewing the economic policy of Member countries, the Committee will pay special attention to the international effects of national policies in the light of the increasing interdependence of their economies and of the recognition that efforts of individual countries will be influenced by the actions of others, with a view to establishing a climate of mutual understanding conducive to the harmonious adjustment of policies." 


\section{WORKING PARTY ON SHORT-TERM ECONOMIC PROSPECTS}

Chair:

Members:

Observers:

Date of creation:

Duration:
Secretariat

Open to all Member countries

Bank for International Settlements (BIS)

European Free Trade Association (EFTA)

International Monetary Fund (IMF)

World Bank

17th July 1963

31st December 2008

Mandate: - Meeting of the Economic Policy Committee on 27th-28th February 1963

- Report by the Chairman to the Council [C(63)39]

- Meeting of the Economic Policy Committee on 10th-11th July 1963

- Report by the Chairman to the Council [C(63)101]

\section{Extract from document [C(63)39, paragraph 6]}

"e) The Committee considered a suggestion for more systematic exchange of short-term forecasts of economic developments and invited the Secretary-General to make arrangements for this."

\section{Extract from document $[\mathrm{C}(63) 101]$}

"11. The Committee agreed upon arrangements to enable the Secretariat to prepare, for its next meeting, forecasts of the broad movements of the supply and use of resources in 1964 . The Secretariat will be communicating with Delegations to this end.

The Economic Policy Committee has subsequently confirmed that its Working Group on Short-term Economic Prospects should meet shortly before meetings of the Committee." 
Chair:

Vice-Chair:

Members:

Observers:

Date of creation:

Duration:
Mr. Joe Grice

(United Kingdom)

Mr. Jean-Luc Schneider

(France)

Open to all Member countries

Bank for International Settlements (BIS)

European Free Trade Association (EFTA)

International Monetary Fund (IMF)

World Bank

20th May 1980

31st December 2008

Mandate: New Working Party on Macro-Economic and Structural Policy Analysis [CPE(80)7]

\section{Annex to document [CPE(80)7]}

1.

This Working Party is charged with the policy analytic aspects of macro-economic and structural problems. With a view to highlighting the analytic aspects of policy issues and proposals and with special emphasis on the medium term, it will report regularly to the Economic Policy Committee its findings with respect to the means of achieving the main objectives of economic policy, notably growth, high employment, welfare and price stability, using, where appropriate, quantitative assessment. The Working Party will in particular consider:

i) Control of demand and inflation, including the role of fiscal policy, monetary policy and prices and incomes policy;

ii) Supply side policies, including policies affecting labour supply, investment, factor mobility and energy;

iii) Allocation and distribution of resources, including public expenditure and revenue decisions, financing and analysis of major expenditure programmes.

2. The Working Party will call as necessary on subgroups to prepare the technical aspects of its work. Subgroups will, in general, be ad hoc, temporary, and tailored to a specific technical question.

3. In executing its mandate, the Working Party will bear in mind the special problems of the less-industrialised Member countries as well as relations with non-Member countries. In its activities it will take into account related work being done in other Working Parties and Committees of the OECD and in other international fora. 

PAYMENTS EQUILIBRIUM $^{1}$

Chair:

Members:

Observer:

Date of creation:

Duration:
Mr. Lorenzo Bini Smaghi

Canada

France

Germany

Italy

Japan

Netherlands
(Company Name)

Sweden

Switzerland

United Kingdom

United States

European Commission

Chairman of the $\mathrm{G} 10$ deputies

Bank for International Settlements (BIS)

International Monetary Fund (IMF)

30th September 1961

31st December 2008

Mandate: - Sixth Meeting of the Economic Policy Committee Report to the Council by the Chairman [C(61)66]

- Agreed Minute by the Economic Policy Committee 19th April 1961 [CPE(61)4]

\section{Extract from the Report to the Council by the Chairman [C(61)66]}

"1. The Economic Policy Committee held its Sixth Meeting on 18th and 19th April. This was the first meeting since the ratification of the OECD Convention by the United States and Canada and, in anticipation of their full membership of the OECD, both countries were strongly represented.

$2 \quad$ At the beginning of the meeting, the Head of the United States Delegation, Mr. Heller, said that he could give every assurance that the United States would be an active, interested and flexible member of the new Organisation. His Government attached particular importance to this meeting of the Committee and they looked forward to close and continuous working partnership within the Committee to deal with economic problems as they unfolded.

3. In pursuit of this aim, the United States Delegation made proposals for extending and intensifying the Committee's work. These were warmly welcomed by the other members of the Committee. Following discussion of these proposals, it was decided to establish two working groups to study and consult upon problems of policy in two areas where such action seemed likely to produce the most valuable results. The first group would deal with the problem of economic growth. The second group would deal with the balance of payments and with monetary, fiscal and other related policies. The Committee hoped to consider reports from these two groups with a view to making further proposals for action to the Ministerial Council of OECD."

\section{Extract from Document [CPE(61)4]}

\footnotetext{
1 To help prepare the technical background for its meetings and assist the Secretariat in its assessment of monetary policy issues, the Working Party asked the Secretariat to convene a small informal group of monetary experts, drawn from Member countries of the Working Party on a personal basis. The Secretariat has taken the initiative to seek consultation from such a group about once a year, starting in the late 1960s.
} 
"The Economic Policy Committee has considered the proposals made by the United States Delegation at its meeting on 18th-19th April 1961, for a programme of closer co-ordination of economic policy [CPE(61)2]. The Committee agrees to set up two Working Parties to deal with the problems outlined below, and to submit their findings and recommendations to the full Committee as soon as possible:

i) Policies for the promotion of economic growth .....

ii) Policies for the promotion of better international payments equilibrium

The Working Party will analyse the effect on international payments of monetary, fiscal and other policy measures and will consult together on policy measures, both national and international, as they relate to international payments equilibrium." 

Chair:

Vice-Chairs:

Members:

Observer:

Date of creation:

Duration:

\author{
Mr. Niels Thygesen \\ (Denmark) \\ Mr. Dominique Bocquet \\ Mr. Blair Comley \\ (France) \\ (Australia)
}

Open to all Member countries

Russian Federation

(on ad hoc basis)

Bank for International Settlements (BIS)

European Free Trade Association (EFTA)

International Monetary Fund (IMF)

World Bank

World Trade Organization (WTO)

30th September 1961

31st December 2008

Mandate : - Council Decision regarding the Revision of the mandate of the Economic and Development Review Committee [C/M(2006)2, item 15] approved at its $1128^{\text {th }}$ session held on 26 January 2006

\section{Extract of the Council Summary Record [C/M(2006)2]}

“15. PROPOSED REVISION OF THE MANDATE OF THE ECONOMIC AND DEVELOPMENT REVIEW COMMITTEE

\section{THE COUNCIL}

a) noted document $\mathrm{C}(2006) 5$;

b) decided, mindful of the vision of the founders of the Organisation as laid out in Article 1 of the Convention on the OECD, notably "to achieve the highest sustainable economic growth and employment and a rising standard of living in Member countries" and "to contribute to sound economic expansion in Member as well as non-member countries", that the Economic and Development Review Committee (EDRC) will examine on a regular basis and make comments and country-specific recommendations on the macroeconomic and structural policies of the Member countries and selected non-Member economies and on the interaction of these policies in raising economic performance;

c) noted that the modus operandi of the EDRC is laid out in its Agreed Principles and Practices [Annex to C(2006)5], which will be updated by the Committee from time to time as appropriate;

d) agreed that the mandate to the EDRC set out in sub-paragraph b) above shall expire on 31 December 2008, unless Council decides otherwise." 

E N V IRON M EN T 



\section{ENVIRONMENT POLICY COMMITTEE}

Chair:

Vice-Chairs:

Members:

Observers:

Date of creation:

Duration:
Mr. Kevin Keeffe

Ms. Nicole Ladouceur

Mr. István Pomázi

Mr. Kazuhiko Takemoto

Mr. Yvo de Boer

Mr. Robert Lowson
(Australia)

(Canada)

(Hungary)

(Japan)

(Netherlands)

(United Kingdom)

Open to all Member countries

Council of Europe

U.N. Commission for Sustainable Development

U.N. Economic Commission for Europe (ECE)

U.N. Environment Programme (UNEP)

World Bank

World Health Organization (WHO)

World Trade Organization (WTO)

22nd July 1970

30th June 2009

Mandate: - Resolution of the Council concerning the Renewal of the Mandate of the Environment Policy Committee [C(2004)99/REV1] approved by the Council on 9 June 2004 at its $1088^{\text {th }}$ session [C/M(2004)14, Item 191]

\section{Resolution of the Council [C(2004)99/REV1]}

\section{THE COUNCIL,}

Having regard to Articles 1, 2, 5(a) and 12 of the Convention on the Organisation for Economic Co-operation and Development of 14 December 1960;

Having regard to the Terms of Reference of the Environment Committee [C(85)47/FINAL], as extended by the Resolution of the Council of 23 February 1990 [C/M(90)4/FINAL, Item 48], and as amended and extended by the Resolution of the Council of 12 March 1992 [C(92)25/FINAL], and extended by the Resolution of the Council [C(97)9/FINAL], and extended by the Resolution of the Council [C(99)76/FINAL];

Having regard to the Rules of Procedure of the Organisation;

Recognising that the quest of societies for economic well being and improved living standards often places undesirable and sometimes unanticipated pressures on the natural environment and on finite natural resources;

Mindful also of the potential risk to human health and well-being from certain socio-economic activities;

Aware that sustainable development requires that economic, environmental and social policies be pursued by governments in an integrated and reinforcing manner; 
Believing that the effective and efficient implementation of environmental policies is dependent on sound economic analysis, technological innovation and diffusion, and strong legal, institutional and administrative arrangements;

Aware also that close co-operation among governments, industry, labour and non-governmental environmental organisations, as well as public participation and access to environmental information, are critical to building and maintaining public support for environmental investments and policies;

Conscious that OECD Member countries have a responsibility to safeguard their own environments, and have expressed a commitment to assist other nations in addressing their environmental challenges at the national level as well as to engage them in co-operative efforts to confront regional and global-scale environmental threats;

Recalling that OECD Environment Ministers, adopted in May 2001, the "OECD Environmental Strategy for the First Decade of the $21^{\text {st }}$ Century", to provide clear directions for environmentally sustainable policies in OECD Member countries, and to guide the future work of the OECD in the field of environment. The Strategy identifies five inter-linked objectives for enhancing cost-effective and operational environmental policies in the context of sustainable development:

- Maintaining the integrity of ecosystems through the efficient management of natural resources.

- De-coupling environmental pressures from economic growth.

- Improving information for decision making: Measuring progress through indicators.

- The social and environmental interface: Enhancing the quality of life.

- Global environmental interdependence: Improving governance and co-operation.

- $\quad$ Recalling that OECD Environment Ministers reviewed the implementation of the OECD Environmental Strategy in April 2004 and agreed that OECD countries are currently "not on track" for implementing the Strategy by 2010 , and more ambitious policies are needed;

\section{DECIDES:}

1. The Environment Policy Committee will have the following responsibilities:

a) Provide a senior-level forum for Member countries to share views on, and consider policy responses to, major environmental issues and threats.

b) Encourage co-operation among Member countries in the pursuit of shared environmental objectives, including, inter alia, co-ordinated consultation on policies, approaches and major actions taken or proposed; work to identify the costs of inaction; data sharing; and joint research and analysis.

c) Promote, in support of sustainable development, the integration of environmental, economic and social policies, technological innovation and diffusion, and protection of unique environmental values and natural ecosystems.

d) Assess on a systematic basis the environmental performances of Member countries in relation to their national and international policies and commitments.

e) Assess and report on the implementation of the "OECD Environmental Strategy for the First Decade of the $21^{\text {st }}$ Century".

f) Develop and promulgate environmental and decoupling indicators, and standardised, comparable sets of data and statistics, as a basis for identifying environmental trends, progress and deficiencies in individual Member countries and the OECD as a whole.

g) Promote the sharing with non-member countries of the environmental management expertise, information and experience which reside in Member countries and the OECD. 
h) Ensure that the views and expertise of non-government institutions are drawn upon in the conduct of OECD's environmental work, utilising, inter alia, the Business and Industry Advisory Committee to the OECD (BIAC), the Trade Union Advisory Committee to the OECD (TUAC) and relevant non-governmental organisations.

2. In the pursuit of these objectives, the Environment Policy Committee shall maintain close working relationships with other relevant bodies of the Organisation, seeking to ensure that environmental considerations are fully addressed in the overall work of the OECD, in particular the project on sustainable development, in a well co-ordinated and horizontal manner.

3. The Environment Policy Committee shall also maintain, as appropriate, and in conformity with the OECD Convention and Rules of Procedures, relations with other international organisations, seeking to achieve co-ordinated and complementary work programmes in areas of shared interest and mutual benefit, and ensuring that the experience and expertise of other bodies is appropriately incorporated into OECD environmental work.

4. These terms of reference are valid until 30 June 2009, unless the Council decides otherwise.

5. The Resolution of the Council of 24 June 1999 concerning the renewal of the mandate of the Environment Policy Committee [C(99)76/FINAL], is hereby repealed.

6. Paragraph 15 of the Annex of the Rules of Procedure shall be amended to read as follows:

"Environment Policy Committee: its terms of reference are defined in the Resolution of the Council [C(2004)99/REV1]." 


\section{JOINT WORKING PARTY ON AGRICULTURE AND THE ENVIRONMENT}

Chair:

Vice-Chairs:

Members:

Observer:

Date of creation:

Duration:
Ms. Katherine Smith

Mr. Chang-Gil Kim

Mr. Grant King

Mr. Frode Lyssandtrae

Ms. Annalisa Zezza

Open to all Member countries

U.N. Food and Agricultural Organization (FAO)

January 1993

31st January 2009
(United States)

(Korea)

(New Zealand)

(Norway)

(Italy)

Mandate: - Mandate agreed by the Committee for Agriculture at its session on 28-29 November $2000[\mathrm{AGR} / \mathrm{CA}(2000) 8]$ and by EPOC (under the written procedure) until the end of January 2004, under the name of "Joint Working Party on Agriculture and the Environment."

- New mandate agreed by Committee for Agriculture in December 2003, and by the EPOC by written procedure in January 2004 [AGR/CA(2003)14]

\section{Extract from document $[\mathrm{AGR} / \mathrm{CA}(2003) 14]$}

\section{“Objectives}

The Joint Working Party on Agriculture and the Environment will provide a forum to exchange information, identify and analyse the implications for achieving environmentally sustainable agriculture of policies and market approaches in the context of technological change, agricultural policy reform and multilateral trade and environmental agreements, and communicate the results to the wider public."

\section{Terms of reference}

The Joint Working Party will:

- Identify and analyse policy relevant domestic and trans-boundary issues at the interface between agriculture and the environment in both OECD and, where relevant, nonOECD countries; quantify the relationships between agriculture and the environment, including in a forward-looking perspective; monitor and evaluate policy measures and actions addressing environmental issues in agriculture; and provide guidance on an integrated and coherent approach for agricultural and environmental policies to help achieve sustainable agriculture.

- Undertake the analysis of agricultural and environmental issues of relevance to policy makers; in particular to: co-ordinate, undertake and review relevant work mandated by the two parent Committees; co-ordinate, receive reports and review relevant on-going and proposed work carried out elsewhere in the OECD; advise and report to the parent Committees on new and emerging problems and major issues with respect to agrienvironment relationships; identify successful policies and courses of action at national and international levels; and identify new initiatives for consideration by the appropriate bodies of the Organisation. 
- Co-operate and liaise with other competent bodies in the OECD, and ensure appropriate co-ordination with other relevant international organisations, in particular the Food and Agricultural Organisation of the United Nations, the United Nations Environment Programme and the Commission on Sustainable Development and the Convention on Biological Diversity, and with relevant non-governmental organisations, representing the farming, agro-food industry, and environmental interests; strengthen efforts to present and communicate the work to relevant organisations, the media and wider public.

\section{Mode of operation}

The Joint Working Party, comprised of agriculture and environment representatives from OECD governments and supported by expert groups and workshops as considered necessary, will meet twice yearly until the end of the mandate of 5 years, with a review of the work at the end of 3 years to provide guidance for the remaining 2 years.

The Bureau of the Joint Working Party will be elected each year, composed of a chair and at least two vice chairs to ensure a balanced representation of both agricultural and environmental interests.

Other Committees of the Organisation could be represented through their respective OECD Directorates at meetings of the Joint Working Party to gather information, and to raise issues and make suggestions, as appropriate.

The Committee for Agriculture and the Environment Policy Committee delegate the declassification of documents to the Joint Working Party, but retain the possibility to take a final decision on the declassification of documents.

The Joint Working Party will regularly report to both the Committee for Agriculture and the Environment Policy Committee, through written reports or oral presentations." 


\section{JOINT WORKING PARTY ON TRADE AND ENVIRONMENT}

Co-Chairs: ${ }^{1}$

Vice-Chairs:

Members:

Observers:

Date of creation:

Duration:
Ms. Harriet Lapidaire-Van Ree

$\cdots$

Mr. Jérôme Catimel

Mrs. Nicole Dispa

Mrs. Jennifer Prescott

$\cdots$

Open to all Member countries

Brazil

Hong Kong, China

European Free Trade Association (EFTA)

International Monetary Fund (IMF)

North American Commission for Environment Co-operation

(NACEC)

U.N. Conference on Trade and Development (UNCTAD)

U.N. Environment Programme (UNEP)

World Trade Organization (WTO)

1st April 1991

31st December 2008
(Netherlands)

(...)

(Canada)

(France)

(United States)

(...)

Mandate: Terms of Reference for Future Work of Joint Session of Trade and Environment Experts [COM/ENV/TD/A(95)75], Report on work undertaken since 1995

[COM/ENV/TD(97)47], Report on Trade and Environment to the Council meeting at Ministerial Level on 26-27 May 1999 [C/MIN(99)14]

\section{Extract of document [COM/ENV/TD/A(95)75, Annex]}

“...

The Joint Session should:

- focus on analytical work, including empirical studies of selected policy areas and economic sectors, aimed at promoting the mutual compatibility of trade and environment policies in practice, in order to contribute to sustainable development, while building on its work to date;

- focus on those areas where it has the greatest value-added while supporting the activities of other OECD bodies and international organisations, and avoiding duplication;

- co-operate and liaise with other relevant OECD bodies, and with relevant international organisations including the WTO, UNEP, UNCTAD, ISO, and the Commission on Sustainable Development;

\footnotetext{
1 The election of the 2006 Bureau will take place in June 2006.
} 
- consult with Partners in transition, Dynamic non Member economies and developing countries, and provide them with expertise as appropriate;

- consult regularly as appropriate with both industry and environmental NGOs on environment and trade related matters;

- advise and report to the parent Committees on new and emerging problems and major issues with respect to trade-environment relationships;

- assist the parent Committees in ensuring the coherence and consistency of the trade and environment related work being carried out in the various bodies of the OECD; and

- achieve the above while meeting twice a year at expert level and once more at higher level, as appropriate." 


\section{JOINT MEETINGS OF TAX AND ENVIRONMENT EXPERTS}

Co-Chairs:

Members:

Date of creation:

Duration:
Mr. Christian Valenduc

Mr. Aldo Ravazzi

Open to all Member countries

1st January 2001

31st December 2008
(Belgium)

(Italy)

Mandate: Text of the mandate in document [COM/ENV/EPOC/DAFFE/CFA(2000)105] approved by EPOC under written procedure and renewed during the 61st session of the CFA [DAFFE/CFA/(2001)72] (Identical text in both documents)

\section{Extract from document [DAFFE/CFA(2001)72, Annex II]}

\section{ANNUAL JOINT MEETINGS ON TAXATION AND ENVIRONMENT TERMS OF REFERENCE}

"1. The Committee on Fiscal Affairs (CFA) and the Environment Policy Committee (EPOC) agree to continue the joint meetings of tax and environment experts, from the Working Party No2 on Tax Policy Analysis and Tax Statistics of the CFA, and the Working Party on National Environmental Policy of EPOC.

2. These experts will take part in annual back-to-back meetings with the following terms of reference, taking into account ongoing work following the OECD programme on sustainable development, and the specific economic, fiscal and environmental conditions of OECD countries":

a) To monitor and analyse existing environmentally related taxes, including collecting and analysing data within a common statistical framework.

b) To assess the environmental effectiveness of relevant taxes (and where appropriate related economic support measures, fees and charges) and to review practical implementation issues, drawing on experiences in Member countries.

c) To examine further issues arising from the integration of environmental concerns into the design of tax systems.

3. The Group of experts will provide input into the OECD Sustainable Development work and to follow-up work to this project involving consideration of tax and environment issues.

4. The Group of experts will also monitor developments and contribute, where appropriate, to tax aspects of the follow-up to the Kyoto Protocol to the United Nations Framework Convention on Climate Change.

5. The Group of experts will report, on an annual basis, the findings of the Joint Meetings, including discussions of policy options and transmit these to the CFA and the EPOC.

6. The terms of reference are established for an indefinite period from 1 January 2001, but subject to review and endorsement every second year by both the CFA and the EPOC."

\footnotetext{
1 Should the need arise for two meetings per year, this need will be brought to the attention of the Committee on Fiscal Affairs and the Environment Policy Committee in a formal request for an adjustment.
} 


\section{WORKING PARTY ON GLOBAL AND STRUCTURAL POLICIES}

Chair:

Vice-Chairs:

Members:

Date of creation:

Duration:
Ms. Veronique Deli

Mr. Harald Neitzel

Mr. Csaba Nemes

Mr. Chan-woo Kim

Mr. Michele Pittini

Open to all Member countries

June 2001

31st December 2009

\author{
(Mexico) \\ (Germany) \\ (Hungary) \\ (Korea) \\ (United Kingdom)
}

$\begin{array}{ll}\text { Mandate : - } & \text { Approved, renewed and revised by the Environment Policy Committee at its session } \\ & \text { on 13-15 April 2005 [ENV/EPOC/M(2005)1], [ENV/EPOC(2004)32/ADD1] and } \\ & \text { [ENV/EPOC/RD(2005)9] }\end{array}$

\section{Extract from document [ENV/EPOC(2004)32/ADD1]}

"1. To define, oversee and co-ordinate the Environment Policy Committee (EPOC) work programme on global and international environmental policy issues, including the environmental implications of structural economic policies and institutional change, recognising that effective policies in these areas are essential for the promotion of sustainable development.

$2 . \quad$ To identify, analyse and propose strategies, policies and instruments to promote the effective integration of environmental concerns into international structural and sectoral economic policies, including those addressed towards the sustainable management of natural resources and ecosystems. Special emphasis should be given to improved understanding of issues related to the effective and efficient management of the global commons (e.g. biodiversity and climate), focusing mainly on experience with, and opportunities to foster, partnerships and institutional capacitybuilding.

3. To analyse the environmental and economic implications of climate change, focusing on strategies and policies, and to provide information and analysis to policy-makers and main stakeholders to enable them to better understand mitigation and adaptation options, including approaches which would benefit from international co-operation.

4. To complement the work of the Annex 1 Expert Group on the UNFCCC, by undertaking policy analysis in support of EPOC interests related to climate change, and by supporting AIXG work related to ongoing international climate change negotiations and, more generally, to communicate and co-ordinate with other OECD entities to facilitate the effectiveness and transparency of OECD work on climate change.

5. To support the efforts of other Bodies of the Organisation (e.g. Committee on Investment $(\mathrm{Cl})$; Working Party on Export Credits and Credit Guarantees (ECG); and (DAC) ENVIRONET) in identifying, analysing and proposing strategies, policies and instruments to manage the environmental implications of economic globalisation,, notably increased trade, investment, international competition, export credits, the influence of national environmental requirements on location and investment decisions, and the changing structure and role of multinational enterprises. 
6. To analyse ways in which environmental and economic globalisation policies can be made more mutually supportive, thereby encouraging stronger economic growth, reduced poverty, and improved environmental quality (e.g. through improved management of environmental infrastructure and/or improved regulatory capacity in both OECD and non-Member countries).

7. To develop and apply quantitative analytical tools to facilitate analysis of the environmental and economic implications of structural policy changes over time. Special emphasis in these analyses should be placed on improving understanding of these implications for both OECD and non-Member countries.

8. To ensure the appropriate application of economic analysis in its work and that of any supporting task forces, panels, or expert groups.

9. To establish* and oversee the work of any ad hoc task forces, panels, or expert groups required to help carry out the work programme (in particular, the Working Group on the Economic Aspects of Biodiversity).

10. To ensure that policy conclusions and recommendations arising out of the work of the Working Party are transmitted to the Environment Policy Committee, and communicated effectively to interested outside parties, including appropriate mass media.

11. The Terms of Reference are established until 31st December 2009."

The establishment of new level 3 bodies (other than project-oriented, short-term task groups) will require prior endorsement of the Environment Policy Committee. 


\section{WORKING GROUP ON ECONOMIC ASPECTS OF BIODIVERSITY}

Chair:

Mr. Arthur Eijs

(Netherlands)

Vice-Chairs:

Ms. Eszter Kovacs

Mr. Shaun Mowat

(Hungary)

Mr. Carlos Muñoz

(United Kingdom)

(Mexico)

Members:

Date of creation:

Duration:
Open to all Member countries

23rd June 1993

30th June 2009

Mandate: - Approved by the Working Party on Global and Structural Policies at its meeting on 15-16 November 2004 [ENV/EPOC/GSP/BIO(2004)2/REV2]

\section{Annex I to document [ENV/EPOC/GSP/BIO(2004)2/REV2]}

1.

To help define and to implement the Programme of Work (PWB) of the Working Party on Global and Structural Policies (WPGSP) concerning the economic aspects of biodiversity, as part of the latter's work on natural resource management and climate change, inter alia by:

- developing a PWB related to the economic aspects of biodiversity every two years, as part of the regular programme planning cycle of the OECD;

- $\quad$ analysing the economic efficiency, environmental effectiveness, and social consequences of biodiversity policies associated with incentive measures, market creation, and the valuation of biodiversity resources;

- $\quad$ analysing linkages between biodiversity and the economic value of ecosystem services, as well as linkages between biodiversity and other "cross-cutting" natural resource management problems (e.g. agriculture, wetlands, habitat equivalency policies, invasive alien species, and water);

- analysing recent experiences with the management of "protected areas", including their links to non-protected areas;

- analysing domestic (sectoral, national, regional) and international distributive issues related to biodiversity conservation, with the aim of promoting a distribution of benefits and costs that supports sustainable use and conservation policies;

- monitoring, and periodically reporting on implementation of, OECD Council Recommendation C(2004)81;

- investigating the potential role of the private sector in supporting government objectives toward more sustainable biodiversity use and conservation (e.g. private sector participation; corporate social responsibility; public-private partnerships);

- $\quad$ contributing additional biodiversity-related outputs as may be requested by the WPGSP from time to time (e.g. Environmental Outlook; implementation of the OECD Environmental Strategy; sustainable development; costs of inaction); and 
- developing empirically-based, proactive, and pragmatic guidance to OECD Member countries on the economic aspects of biodiversity policies examined by the Working Group.

2.

To provide support for others working on issues relevant to the WGEAB, inter alia by:

- $\quad$ supporting implementation of the Convention on Biological Diversity (CBD), insofar as CBD interests interact with those of the WGEAB, the WPGSP, and EPOC.

- $\quad$ maintaining active participation in the UNCBD process, and co-ordinating with relevant international organisations, such as the Secretariat of the CBD, IUCN, UNCTAD, UNEP, the World Bank, FAO, UNCSD, UNESCO, and the Club du Sahel;

- $\quad$ engaging in appropriate forms of dialogue about the economic aspects of biodiversity management with non-OECD countries;

- $\quad$ keeping abreast of the economic aspects of biodiversity issues (e.g. internationallyagreed development goals, including those contained in the Millennium Declaration) under discussion in related international fora (e.g. WSSD; CSD); and

- proactively disseminating information concerning WGEAB outputs through publications, workshops, training seminars, conferences and other events. 


\section{WORKING PARTY ON NATIONAL ENVIRONMENTAL POLICIES}

Chair:

Vice-Chairs:

Members:

Date of creation:

Duration:
Mr. Aldo Ravazzi

Mr. Kwang Hee Nam

Mr. Antonio Díaz de León

Mr. Bob Davies

Open to all Member countries

April 2001

31st December 2009
(Italy)

(Korea)

(Mexico)

(United Kingdom)

Mandate: - Mandate approved by the Environment Policy Committee at its session on 27-29 November 2000.

- Mandate renewed and modified by the Environment Policy Committee at its meeting on 9-10 November 2004 [ENV/EPOC(2004)32 and ENV/EPOC/M(2004)2].

\section{Document [ENV/EPOC(2004)32]}

"The Environment Policy Committee agrees that the Working Party on National Environmental Policies shall have the following terms of reference:

1. To define, oversee and co-ordinate the Environment Policy Committee's (EPOC) work programme on the development and implementation of environmental policies at national and subnational levels, with particular emphasis on the decoupling of environmental pressures from economic growth, the efficient use of environmental resources and the integration and co-ordination of economic, environmental and social policies, which are essential components of sustainable development.

2. To identify, analyse, and propose strategies, policies and instruments that promote the aforementioned policy objectives and encourage the effective integration of environmental concerns into national economic and sectoral policies, to encourage the efficient use of environmental resources, and the decoupling of environmental pressures from economic growth, including the analysis of the economic aspects and implications of such strategies, policies and instruments, with particular reference to:

a) existing and new policy instruments which can promote sound economic and environmental policy integration, and enhance the effectiveness and economic efficiency of environmental policies, with a particular focus on policy mixes;

b) failures of markets, government intervention, information and institutions which constitute impediments to effective policy integration and co-ordination.

c) the implementation of environmental policies, including effective and efficient compliance, monitoring and enforcement;

d) the social and distributive implications of environmental policies, including environmental justice and the links between health and the environment, and, 
e) the integration and co-ordination of environmental policies with other public policies with which there are likely to be significant interactions (e.g. public finance, labour markets industrial policy, and innovation policies).

3. To identify, analyse and propose strategies, policies and instruments to encourage more sustainable patterns of production and consumption.

4. To develop tools and methodologies for the economic valuation of environmental benefits and costs, including the cost of inaction, as well as the ex ante and ex post evaluation of specific environmental policies and instruments.

5. To ensure the appropriate application of economic analysis in its work and that of any other supporting task forces, panels or expert groups, in particular Working Group on Waste Prevention and Recycling (WGWPR) and Working Group on Transport (WGT).

$6 . \quad$ To establish ${ }^{\uparrow}$ and oversee the work of any task forces, panels or expert groups required to help carry out the work programme.

7. To maintain effective working relationships, as appropriate, with other relevant OECD Committees, Working Parties, Groups and programmes within the OECD -- including the Committee on Fiscal Affairs, Working Parties of the Economic Policy Committee (EPC), the Working Party on Innovation and Technology Policies, the Employment, Labour and Social Affairs Committee, and EPOC's Working Party on Global and Structural Policy and Working Party on Environmental Performance, Working Group on Environmental information and Outlooks and OECD's horizontal activity on sustainable development -- and with other relevant international organisations and bodies, and to carry out joint work as appropriate.

8. To ensure that policy conclusions and recommendations arising out of the work of the Working Party are transmitted to the Environment Policy Committee, and communicated effectively to interested outside parties, including relevant mass media."

\footnotetext{
1 The establishment of new level 3 bodies (other than project-oriented, short-term task groups) will require prior endorsement of the Environment Policy Committee.
} 


\section{WORKING GROUP ON WASTE PREVENTION AND RECYCLING}

Chair:

Vice-Chairs:

Members:

Observers:

Date of creation:

Duration:
Mr. Francisco Aleza Enciso

Mr. Marco Buletti

Ms. France Jacovella

Mr. Jozsef Kelemen

Mr. Soichiro Seki

Open to all Member countries

U.N. Economic Commission for Europe (ECE)

U.N. Environment Programme (UNEP)

November 2000

31st December 2006
(Spain)

(Switzerland)

(Canada)

(Hungary)

(Japan)

Mandate: - Adopted by the Working Party on National Environmental Policy at its $8^{\text {th }}$ meeting on 17-18 November 2004 [ENV/EPOC/WPNEP/M(2004)2]

\section{Extract from [ENV/EPOC/WPNEP/M(2004)2]}

1.

To carry out and oversee the implementation of projects and tasks assigned by the Council, the Environment Policy Committee or the Working Party on National Environmental Policy;

2.

To identify, develop, analyse and evaluate policies and instruments for reducing the environmental impacts of waste generation and management, and thereby contributing to the overall reduction of environmental burden associated with the use of resources. This includes waste prevention and minimisation, and the management of remaining waste amounts, focusing inter alia on

- $\quad$ Decoupling of waste generation from economic growth;

- $\quad$ Material use efficiency; and

- Extended producer responsibility, including incentives for producers to design for environment.

3. To advise Member countries on the most environmentally effective and economically efficient policy options to prevent and reduce waste generation, as well as to manage remaining wastes, based on an analysis of the full benefits and costs of these policies;

4. To strengthen environmentally sound management (ESM) of wastes, through the implementation of the Council Recommendation on ESM, including the possible development of waste-stream specific ESM guidance;

5. To ensure environmentally sound and economically efficient recovery and trade of recoverable waste by facilitating the efficient implementation of the Council Decision $\mathrm{C}(2001) 107 / \mathrm{FINAL}$ and consolidating and updating the other Council Acts on transboundary movements of waste, as appropriate; 
To explore the potential of and the barriers to "sustainable materials management", and consider measures to promote this approach;

7.

To advise the Working Party on National Environmental Policy and the Environment Policy Committee on major emerging waste related problems and issues, as well as on appropriate and cost-efficient policies and tools to address these emerging challenges;

8. To ensure that the projects of the Working Group on Waste Prevention and Recycling are developed in a manner which responds to relevant priority objectives of the Environment Programme, and are carried out in close co-operation with other relevant OECD bodies and international organizations, such as the Secretariat of the Basel Convention . 
Chair:

Vice-Chairs:

Members:

Observers:

Date of creation:

Duration:
Mr. Axel Friedrich

Ms. Veronique Deli

Mr. Kotaro Kawamata

Mr. Aldo Ravazzi

Mr. Robert Thaler
(Germany)

(Mexico)

(Japan)

(Italy)

(Austria)

Open to all Member countries

U.N. Economic Commission for Europe (ECE)

U.N. Environment Programme (UNEP)

World Health Organization (WHO)

4th November 1994

31st December 2006

Mandate : - Approved by the Working Party on National Environmental Policy at its $9^{\text {th }}$ session on 16-17 June 2005 [ENV/EPOC/WPNEP/M(2005)1]

\section{Extract from document [ENV/EPOC/WPNEP/M(2005)1]}

"1. To help define and oversee the Programme of Work on Transport and the Environment, in the light of the OECD work and guidelines on Environmentally Sustainable Transport (EST) and of the implementation of OECD's Environmental Strategy for the first Decade of the $21^{\text {st }}$ Century, adopted by OECD Environment Ministers at their meeting in May 2001. In particular, to undertake work in the following areas:

a) In the context of the implementation of an EST strategy, analyse the relationship between economic growth and the environmental impacts of transport and explore the range of policies for decoupling transport impacts and economic growth, with a particular focus on economic instruments for internalising externalities in the transport sector.

b) Analyse the impacts of globalisation and trade flows on transport volume and structure, with a particular emphasis on modes of international freight transport. Develop strategies to minimise the associated environmental impacts in an economically efficient manner while optimising transport efficiency.

c) To report on the implementation of the OECD Council Recommendation on Assessment and Decision-making for Integrated Transport and Environment Policy, including the Environmentally Sustainable Transport (EST) guidelines in OECD countries.

2. To provide a forum for information exchange on emerging issues, trends and challenges in the transport sector, and for review of transport/environment action plans.

3. To disseminate the outcome of its work in non-members as appropriate and support outreach activities, in co-operation with other relevant international organisations.

4. To report to the WPNEP on major new and emerging environmental problems and issues related to transport and on appropriate policy options to address them. 
5. To promote and enhance co-ordination and co-operation, as appropriate with other relevant OECD related bodies, in particular the European Conference of Ministers of Transport (ECMT), the Joint OECD/ECMT Transport Research Centre, the International Energy Agency, and other organisations such as the European Commission, the UN Economic Commission for Europe and the World Health Organisation.

6. The Terms of Reference are established until 31 December 2006." 


\section{WORKING PARTY ON ENVIRONMENTAL PERFORMANCE}

Chairs:

Vice-Chairs:

Members:

Date of creation:

Duration:
Mr. Øyvind Lone

Mr. Marc Aviam

Mr. István Pomázi

Mr. Aldo Ravazzi

Mr. Akinori Ogawa

Ms. Veronique Deli

Open to all Member countries

December 1991

31st December 2009
(Norway)

(France)

(Hungary)

(Italy)

(Japan)

(Mexico)

Mandate: - Mandate approved by the Environment Policy Committee at its $14^{\text {th }}$ Session in November 1998, this group was formerly known as "Group on the Environmental Performance" [ENV/EPOC(98)22/FINAL and ENV/EPOC/M(98)4].

- Mandate renewed and modified by the Environment Policy Committee at its meeting on 9-10 November 2004 [ENV/EPOC(2004)32 and ENV/EPOC/M(2004)2].

\section{Document [ENV/EPOC(2004)32]}

"The Environment Policy Committee agrees that the Working Party on Environmental Performance shall have the following terms of reference:

1. To oversee and co-ordinate the OECD programme of Member country environmental performance reviews as carried out by the Environment Directorate, as well as any extension to non-Member countries as may be agreed by the Environment Policy Committee and the Council.

2. To examine with a peer review mechanism the reports and recommendations emerging from the individual country studies.

3. To report annually to the Environment Policy Committee on the results of the country studies conducted each year, identifying in particular major policy issues which the Environment Policy Committee may wish to examine.

4. To advise the Environment Policy Committee on measures that member countries might take to improve their individual or collective environmental performances, and to monitor progress with implementing the OECD Environmental Strategy.

5. To identify opportunities and requirements for improving the conduct of the performance reviews (including data needs, indicators and methodologies) and recommending necessary modifications of the review content and process, drawing on task groups and other relevant Environment Policy Committee subsidiary groups as required.

6. To keep under review, and direct, the Environment Directorate's work on the analysis of trends, and the development of indicators, statistics and reporting concerning the environment and sustainable development, drawing on task forces and other subsidiary groups as required. 
7. To ensure that the work programme on environmental reviews, data and indicators is developed in a manner which responds to relevant priorities and policy objectives of the Environment Policy Committee.

8. To maintain close working relationships with other relevant international organisations to avoid duplication of effort and to achieve efficient divisions of responsibilities in areas of mutual interests (e.g. data collection).

9. To carry out or supervise other projects and tasks assigned by the Environment Policy Committee or the Council." 
Chair:

Vice-Chairs:

Members:

Date of creation:

Duration:
Mr. Yuichi Moriguchi

Ms. Jenny Boshier

Ms. Veronique Deli

Ms. Manuela Notter

Mr. Phil Ross

Open to all Member countries

October 1979

30th June 2009
(Japan)

(Australia)

(Mexico)

(Sweden)

(United States)

Mandate: - Approved by the Working Party on Environmental Performance at its meeting on 2 July 2004 [ENV/EPOC/GEP(2004)7/FINAL]

\section{Extract from [ENV/EPOC/GEP(2004)7/FINAL]}

1. To carry out or supervise the implementation of projects and tasks assigned by the Working Party on Environmental Performance, the Environment Policy Committee or the Council.

2. To advise the Environment Policy Committee and its Working Parties on major new and emerging problems and issues, and on appropriate policy options concerning information and reporting relating to environment and to sustainable development, and to recommend ways and means for national and international action.

3. To give special attention:

a) to further development of internationally comparable data on environmental conditions and trends;

b) to report on the state of the environment in OECD member countries at appropriate intervals decided by the Environment Policy Committee;

c) to further development of indicators relating to environment and to sustainable development, including indicators of environmental performance, key indicators, sectoral indicators and indicators derived from environmental accounting;

d) to contribute to the improvement of environmental outlooks and projections, environmental accounts, environmental information systems and environmental reporting.

4. To maintain close working relationships with other relevant groups within OECD.

5. To maintain close working relationships with other relevant international organisations to avoid duplication of effort and to achieve efficient division of responsibilities in areas of mutual interests (e.g. data collection). 
6. To ensure that its projects are developed in a manner which responds to relevant priority objectives of the OECD Environment Programme. 


\section{WORKING PARTY ON CHEMICALS, PESTICIDES AND BIOTECHNOLOGY}

Chair:

Vice-Chairs:

Members:

Participating Countries: ${ }^{1}$

Observers:

Date of creation:

Duration:
Mrs. Susan Hazen

Mr. Ulrich Schlottmann

Mr. Chung-Seop Lee

Ms. Ana Fresno Ruiz

Open to all Member countries

Israel

Slovenia

South Africa

Israel

Slovenia

March 1971

31st December 2009
(United States)

(Germany)

(Korea)

(Spain)

Mandate: - Terms of reference for the Working party on Chemicals, Pesticides and Biotechnology [ENV/EPOC(2004)32]

- The Working Party meets together with the Chemicals Committee in a Joint Meeting

\section{Extract from document [ENV/EPOC(2004)32}

1. In conjunction with the Chemicals Committee ${ }^{2}[1]$ to carry out, or to supervise, the implementation of projects and tasks assigned by the Environment Policy Committee or the Council;

2.

To identify and examine existing, emerging and new problems and policy issues of common interest and priority concern relating to the control of chemicals, pesticides and products of modern biotechnology;

3. To advise the Environment Policy Committee on major existing, emerging and new problems and issues and on appropriate policy options to secure improved control of chemicals, pesticides and products of modern biotechnology and to recommend ways and means for national and international approaches;

4. In conjunction with the Chemicals Committee, to identify and elaborate the principles for and elements of overall chemicals, pesticides and biotechnology management policies which meet both the needs of environmental and human health protection and take economic objectives into account;

5. In conjunction with the Chemicals Committee, to work on issues related to the practical implementation of the Council Acts related to the Mutual Acceptance of Data, including Test Guidelines and Good Laboratory Practice, and furthermore to give special attention to:

\footnotetext{
1 Full participant for issues related to Mutual Acceptance of Data.

2 The Chemicals Committee is the body mentioned as the "Management Committee" in Council Decision[C(78)127(Final) establishing the Special Programme on the Control of Chemicals
} 
a) improving the means of developing, acquiring and disseminating the data necessary for assessing chemicals, pesticides and applications of biotechnology;

b) improving the efficiency of existing procedures for the assessment of the potential hazards of chemicals;

c) assisting member countries in developing policies and practices for the management of risks posed by them;

d) assisting member countries in their co-operative efforts to share the burdens of the systematic investigation of existing chemicals; and

e) facilitate co-operation between OECD countries and specific non-members in order to promote effective and efficient chemical safety policies throughout the world.

6. To hold from time to time special meetings at high level, as required, in order to give general orientation to the work on chemicals, pesticides and biotechnology;

7. To maintain close working relationships with other relevant groups within OECD;

8. To maintain close working relationships with other relevant international organisations;

9. To ensure that its projects are developed in a manner which responds to relevant priority objectives of the Environment Programme.

10. The above terms of reference are established until 31 December 2009. 
Chair:

Vice-Chair:

Members:

Observer:

Date of creation:

Duration:
Mr. Eisaku Toda

Ms. Betty Hakkert

Australia

Austria

Belgium

Canada

Czech Republic

Denmark

Finland

France

Germany

Greece

Hungary

Ireland

Italy

Japan

Korea

Mexico
(Japan)

(Netherlands)

Netherlands

New Zealand

Norway

Poland

Portugal

Slovak Republic

Spain

Sweden

Switzerland

Turkey

United Kingdom

United States

European Commission

Israel

Slovenia

South Africa

India

June 1999

31st December 2008

Mandate: Renewed by the $39^{\text {th }}$ Joint Meeting of the Chemicals Committee and the Working Party on Chemicals, Pesticides and Biotechnology [ENV/JM/M(2006)1, Annex II]

\section{[Extract of document [ENV/JM/M(2006)1, Annex II]}

\section{"I.}

\section{Objective}

1. The objective of the Working Group of National Co-ordinators of the Test Guidelines Programme is to direct and oversee the work on: (i) OECD Guidelines for the Testing of Chemicals, including, as appropriate, Test Guideline development and the facilitation and harmonisation of test method validation; (ii) Guidance Documents on testing issues; and (iii) Detailed Review Papers on the state-of science of defined hazard areas. This work is undertaken to meet the regulatory needs, animal welfare and cost considerations regarding test methods in member countries and interested non-member economies.

II.

Tasks

2. The Working Group of National Co-ordinators of the Test Guidelines Programme shall:

i. Oversee the work of the Test Guidelines Programme which consists of:

- the development of new and the updating of existing Test Guidelines to cover regulatory data requirements for the human health and environmental 
assessment of chemical substances, including but not limited to pesticides and industrial chemicals, in member countries;

- involvement in the validation of new and updated test methods, as appropriate;

- the development of Guidance Documents providing: (i) further guidance on the use of Test Guidelines, (ii) testing strategies, or (iii) information on specific issues associated with the Test Guidelines Programme;

- $\quad$ the development of Detailed Review Papers, providing the current state-ofscience in a particular test or hazard area; and

- facilitating the active involvement of member countries and non-member economies and other stakeholders in projects in the development of Test Guidelines, Guidance Documents and Detailed Review Papers;

- engagement in international co-operation, as appropriate, for the harmonisation of hazard and risk assessment of chemical substances to benefit both member countries and non-members.

ii. Direct and oversee the work of its subsidiary expert bodies, including:

- those for Endocrine Disrupters Testing and Assessment (EDTA) and Validation Management (VMGs);

- $\quad$ all ad hoc Expert Groups, established to assist in the development of specific Test Guidelines, Guidance Documents and/or Detailed Review Papers.

iii. Review the progress made in the conduct of this work, identify new projects and update annually the three-year workplan of the Test Guidelines Programme, taking into account other work under the Joint Meeting and work undertaken elsewhere, as appropriate;

iv. Maintain close working relations with other international organisations active in the area of method development for chemical hazard and risk assessment; and

v. Report on its activities to the Joint Meeting of the Chemicals Committee and the Working Party on Chemicals.

3. Further details of tasks and responsibilities are provided in Guidance Document No.1 in the Series on Testing and Assessment, as amended from time to time [OCDE/GD(95)71, 1995].

III.

Participation

4. The Working Group of National Co-ordinators of the Test Guidelines Programme is comprised of National Co-ordinators (from member countries and non-member economies that adhere to the Council Decision on the Mutual Acceptance of Data) appointed by member countries or non-member governments, representatives of the European Commission, invited experts and, as appropriate, observers from non-member economies. National Co-ordinators should be able to provide a co-ordinated national view with respect to all areas of the Test Guidelines Programme.

5. The Chair and Vice-Chair(s) should be National Co-ordinators and are elected by the Working Group of National Co-ordinators of the Test Guidelines Programme for a term of three years. Elections are held at the last meeting of each three-year period. The Chair and ViceChair(s) together should provide expertise on both human health and the environment, and will function as the main consultative body (the Bureau) for the Secretariat between meetings of the Working Group.

6. The Working Group of National Co-ordinators of the Test Guidelines Programme should meet when required by the needs of the Programme, but normally once per year in the month of May." 


\section{WORKING GROUP ON GOOD LABORATORY PRACTICE}

Chair:

Vice-Chair:

Members:

Observer:

Date of creation:

Duration:
Ms. Helen Liddy

Francisca Liem

Australia

Austria

Belgium

Canada

Czech Republic

Denmark

Finland

France

Germany

Greece

Hungary

Ireland

Italy

Japan

Korea
(Australia)

(United States)

Netherlands

New Zealand

Norway

Poland

Portugal

Slovak Republic

Spain

Sweden

Switzerland

United Kingdom

United States

European Commission

Israel

Slovenia

South Africa

India

November 1990

31st December 2008

Mandate: $\quad$ Renewed by the $39^{\text {th }}$ Joint Meeting of the Chemicals Committee and the Working

Party on Chemicals, Pesticides and Biotechnology [ENV/JM/M(2006)1, Annex I]

\section{Extract of document [ENV/JM/M(2006)1, Annex I]}

“I.

\section{Objectives}

1. The objectives of the Working Group on Good Laboratory Practice (GLP) are to facilitate and support the implementation by Member countries and interested non-members of the Council Acts (i) concerning Mutual Acceptance of Data in the Assessment of Chemicals [C(81)30(Final)], (ii) on Compliance with Principles of Good Laboratory Practice [C(89)87(Final)], and (iii) concerning the Adherence by Non-Member Countries to the OECD Council Acts related to the Mutual Acceptance of Date [C(97)114/Final]. This should be done by promoting a common understanding of, and harmonised approaches to, technical and administrative matters related to Good Laboratory Practice and monitoring of compliance with the GLP Principles.

\section{Tasks}

2. The Working Group on GLP, under the supervision of the Joint Meeting of the Chemicals Committee and the Working Party on Chemicals, Pesticides and Biotechnology shall: a) foster direct exchange of information and sharing of experiences, in particular among GLP compliance inspectors; b) discuss and, to the extent possible, resolve issues of common concern, particularly those issues relevant to international recognition of GLP compliance monitoring using on-site evaluation visits as appropriate; c) foster the harmonisation and development of specific guidance on technical and administrative matters pertaining to GLP Principles and monitoring of compliance therewith, including training of GLP inspectors; d) assist non-members in establishing and implementing procedures 
consistent with those of OECD; and e) advise the Joint Meeting regarding major policy issues related to GLP and compliance monitoring.

3. The Working Group on GLP shall take into account relevant activities related to international standard setting and assessment of compliance as well as other international activities in the areas of interest to its work. It shall meet regularly, at least once a year, and report thereafter to the Joint Meeting.

III.

\section{Participation}

4. The Working Group on GLP should include persons nominated by governments who are responsible for GLP compliance monitoring in member countries and in those non-members which are members of that part of the Chemicals Programme related to the mutual acceptance of data, as well as from the European Commission. Participation should be limited to one person per authority. Observers from other non-members may take part in the framework of the 1997 Council Decision. A Chairman and a Vice-Chairman shall be elected by the Members of the Working Group for two-year periods.

IV.

Term

5. The Joint Meeting will assess the need for the continuation of the Working Group on GLP at the end of the next three-year phase of the Special Programme on the Control of Chemicals (31st December 2008)." 


\section{WORKING GROUP ON PESTICIDES}

$\begin{array}{lll}\text { Chair: } & \text { Mr. Richard Paul Davis } & \text { (United Kingdom) } \\ \text { Vice-Chair: } & \text { Mr. John Reeve } & \text { (New Zealand) } \\ \text { Members: } & \text { Open to all Member countries } & \\ \text { Observers: } & \begin{array}{l}\text { Israel } \\ \text { Slovenia }\end{array} \\ \text { Date of creation: } & \text { January 1994 } \\ \text { Duration: } & \text { 31st December } 2008\end{array}$

Mandate: Renewed at the $39^{\text {th }}$ Joint Meeting of the Chemicals Committee and the Working Party on Chemicals Pesticides and Biotechnology [ENV/JM/M(2006)1, Annex IV]

\section{Extract of document [ENV/JM/M(2006)1, Annex IV]}

\section{"I. Objective}

4. The objective of the Working Group on Pesticides (WGP) is to direct and oversee the work of the Pesticide Programme. The Working Group on Pesticides is a subsidiary body to the Joint Meeting of the Chemicals Committee and Working Party on Chemicals, Pesticides and Biotechnology. The term "pesticides" includes both chemical and biological pesticides.

II.

Tasks

2. The Working Group on Pesticides shall:

(i) oversee the work on pesticides which aims to (a) help member countries harmonise and improve the efficiency of pesticide assessment and control procedures, (b) minimise non-tariff trade barriers, and (c) reduce risks to human health and the environment from the use of pesticides. These goals will be pursued through activities including, but not limited to:

- Work sharing ${ }^{1}$ and harmonisation: to facilitate and promote work sharing among OECD countries for pesticide evaluation (to support registration, reregistration and risk management) such that work sharing ultimately will become the routine way of working;

- Risk Reduction: to exchange ideas and to facilitate and promote the development and implementation of risk reduction policies and practices in OECD countries;

- Communication and Co-operation: to promote communication, collaboration and co-operation on work sharing and risk management among member countries and also with other stakeholders including industry, other interest groups and international organisations;

\footnotetext{
1. Work sharing is meant to include all types of sharing of work in pesticide review, from the ad-hoc exchange of information, to well structured divisions of work such as parallel reviews and joint reviews.
} 
(ii) review the progress made in the conduct of this work, identify new projects and update the work plan, taking into account other work under the Environment Policy Committee, the Joint Meeting of the Chemicals Committee and Working Party on Chemicals, Pesticides and Biotechnology, the Agriculture Committee and other relevant OECD Committees and Groups, and work undertaken elsewhere, as appropriate;

(iii) maintain close working relations and co-ordinate activities related to agricultural pesticides and biocides with other international organisations and selected nonmembers;

(iv) report on its activities to the Joint Meeting of the Chemicals Committee and Working Party on Chemicals, Pesticides and Biotechnology, and shall liaise with the Joint Working Party of the Committee for Agriculture and the Environment Policy Committee.

III.

\section{Participation}

3. The Working Group on Pesticides shall be comprised of the OECD member countries, the European Commission and observers (e.g. from IPCS, UNEP Chemicals, FAO). As appropriate, experts from non-member economies, environmental citizen organisations, PAN, EPPO, industry and grower associations can be invited. The Chair of the Working Group on Pesticides and a ViceChair shall be elected by the members for a term of three years. The Chair, Vice-Chair and chairs of the WGP steering groups, will function as the main consultative body for the Secretariat between meetings of the Working Group.

4. once per year."

The Working Group shall meet when required by programme need, but no less than 


\title{
WORKING GROUP ON THE HARMONISATION OF REGULATORY OVERSIGHT IN BIOTECHNOLOGY
}

\author{
Chair: \\ Mr. Helmut Gaugitsch \\ (Austria) \\ Vice-Chairs: \\ Mr. Stephen Yarrow \\ Mr. Kenichi Hayashi \\ Mr. Hans Bergmans \\ Ms. Sally McCammon \\ (Canada) \\ (Japan) \\ (Netherlands) \\ (United States) \\ Members: \\ Open to all Member countries \\ Observers: \\ Argentina \\ Russian Federation \\ Slovenia \\ Date of creation: \\ 1st February 1995 \\ Duration: \\ 31st December 2008
}

Mandate: $\quad$ Renewed at the $39^{\text {th }}$ Joint Meeting of the Chemicals Committee and the Working

Party on Chemicals, Pesticides and Biotechnology [ENV/JM/M(2006)1, Annex V]

\section{Extract of document [ENV/JM/M(2006)1, Annex V]}

"As a subsidiary body to the Joint Meeting of the Chemicals Committee and Working Party on Chemicals, Pesticides and Biotechnology, the Working Group on Harmonisation of Regulatory Oversight in Biotechnology has the following terms of reference:

1. To oversee the implementation of the projects which are included in the Programme of Work on Harmonisation of Regulatory Oversight in Biotechnology for 2006 - 2008 as approved by the Joint Meeting, which have been established with the aims of promoting international harmonisation of regulatory oversight of biotechnology and biosafety among member countries; these projects include:

- identifying and addressing emerging issues that facilitate biotechnology and biosafety regulatory harmonisation.

- publishing science based consensus documents; and,

- participating in information dissemination and co-operating with non-member economies.

2. To advise the Joint Meeting on matters related to environmental aspects of products of modern biotechnology and to recommend appropriate policies and actions aimed at the harmonisation of biotechnology regulatory oversight, and thereby promoting the safety of products derived through modern biotechnology.

3. To ensure co-ordination with the work of the Task Force for the Safety of Novel Foods and Feeds, in particular, with respect to the development of Consensus Documents.

4. $\quad$ To recommend the most appropriate means of undertaking the various activities, for example, through the lead country approach, small steering groups or workshops. 

the Joint Meeting.

6. To maintain close working relationships with other relevant groups within the OECD through OECD's Internal Co-ordination Group on Biotechnology (ICGB), and with subsidiary bodies to the Joint Meeting of the Chemicals Committee and Working Party on Chemicals, Pesticides and Biotechnology on issues of mutual interest.

7. To maintain close working relationships with other relevant international organisations, especially, UNEP, CBD Secretariat, UNIDO, WHO, FAO and WTO.

8. To report to the Environment Policy Committee through the Joint Meeting. At the same time, the Working Group will co-ordinate its efforts, through the ICGB, with the relevant work of other Committees such as the Committee for Scientific and Technological Policy and the Committee for Agriculture, and will inform them on the progress of work relevant to their interests, and will refer issues to them as appropriate; and

9 .

The Group will elect a Chair and vice-Chairs for a period of one year."

Duration: The Terms of Reference are established until 31st December 2008. 


\section{TASK FORCE FOR THE SAFETY OF NOVEL FOODS AND FEEDS}

Chair:

Vice-Chairs:

Members:

Observers:

Date of creation:

Duration:
Ms. Lisa Kelly

Mr. William Yan

Mr. Hans-Joerg Buhk

Ms. Diána Bánáti

Mr. Hideyuki Kobayashi

Ms. James Maryanski

Open to all Member countries

Argentina

Russian Federation

Slovenia

5th November 1998

31st December 2008
(Australia)

(Canada)

(Germany)

(Hungary)

(Japan)

(United States)

Mandate: Renewed at the $39^{\text {th }}$ Joint Meeting of the Chemicals Committee and Working Party on Chemicals, Pesticides and Biotechnology [ENV/JM/M(2006)1, Annex VI]

\section{Extract of document [ENV/JM/M(2006)1, Annex VI]}

"The Task Force for the Safety of Novel Foods and Feeds is a subsidiary body of the Joint Meeting of the Chemicals Committee and the Working Party on Chemicals, Pesticides and Biotechnology. Taking the above work programme into account, the overall terms of reference are given as follows:

- To oversee the implementation of the projects which are included in the Programme of Work for the Safety of Novel Foods and Feeds as approved by the Joint Meeting. The Programme is intended to promote international harmonisation in the safety assessment and regulation of novel foods and feeds (especially products of modern biotechnology). The programme of work on the safety of novel foods and feeds as proposed by the Task Force to the Joint Meeting is organised into three areas:

- publishing science based consensus documents;

- addressing emerging issues that will promote facilitating the next steps in harmonisation; and

- information dissemination activities and co-operation with non-member economies.

- To co-ordinate with the activities of the Working Group for Harmonisation in Biosafety, especially in the development of Consensus Documents and BioTrack Online.

- To advise the Joint Meeting on matters related to the safety and regulation of novel foods and feeds. To recommend appropriate policies and actions aimed at harmonisation, as well as promoting the safe use of novel foods and feeds.

- To recommend the most appropriate means of undertaking the various projects, for example, through the lead country approach, small steering groups or workshops. 
- To develop proposals for future work taking into account the priorities established by the Joint Meeting.

- To maintain close working relationships with other subsidiary bodies of the Joint Meeting of the Chemicals Committee and Working Party on Chemicals, Pesticides and Biotechnology on issues of mutual interest.

- To report to the Environment Policy Committee (EPOC) through the Joint Meeting. At the same time, through OECD's Internal Co-ordination Group for Biotechnology (ICGB), the Task Force will co-ordinate its efforts with the relevant work of other Committees such as the Committee for Scientific and Technological Policy and the Committee for Agriculture, and will inform them on the progress of work relevant to their interests, and will refer issues to them as appropriate.

- To maintain close working relationships with other relevant organisations, especially, FAO, WHO, UNIDO, UNEP, CBD Secretariat, and WTO, so avoiding duplication and ensuring complementarity with other intergovernmental activities such as those of the Codex Alimentarius Commission.

The Task Force will carry out its work in as transparent a manner as possible. It will include observers from BIAC, TUAC and consumer groups. Where appropriate, it will seek input from nonmember economies (especially developing countries) for example in the development of consensus documents by collaborating with FAO and WHO. The Task Force will elect a Chair and vice-Chairs for a period of one year. The duration of the terms of reference will be determined by the parent body, the Joint Meeting." 


\section{WORKING GROUP ON CHEMICAL ACCIDENTS}

Chairs:

Vice-Chairs:

Members:

Observer:

Date of creation:

Duration:
Ms. Debbie Dietrich

Ms. Kim Jennings

Mr. Tom Foote

Mr. Roland Fendler

Mr. Mark Hailwood

Mr. Giancarlo Ludovisi

Mr. Cees Braams

Mr. Åke Persson

Mr. Tobias Biermann

Open to all Member countries

Slovenia

1st February 1995

31st December 2008
(United States)

(United States)

(Canada)

(Germany)

(Germany)

(Italy)

(Netherlands)

(Sweden)

(European Commission)

Mandate: Renewed at the $39^{\text {th }}$ Joint Meeting of the Chemicals Committee and the Working Party on Chemicals, Pesticides and Biotechnology [ENV/JM/M(2006)1, Annex III]

\section{Extract of document [ENV/JM/M(2006)1, Annex III]}

“1.

As a subsidiary body to the Joint Meeting of the Chemicals Committee and the Working Party on Chemicals, Pesticides and Biotechnology, the Working Group on Chemical Accidents (WGCA) shall have the following terms of reference:

- to oversee the work and foster the implementation of the projects and activities which are included in the Programme of Work on Chemical Accidents for 2006-2008 as approved by the $38^{\text {th }}$ Joint Meeting in June 2005 using, in particular, the lead country approach;

- $\quad$ to recommend appropriate policy options, including ways and means for national and international action, for enhancing the prevention of, preparedness for, and response to, chemical accidents;

- to improve, primarily through the efforts of member country experts, the awareness, knowledge, and capabilities in member and non-member economies, with respect to relevant technology, practices and policies for chemical accident prevention, emergency preparedness and response, and in particular by:

a) furthering the implementation of the OECD Guiding Principles on Chemical Accident Prevention, Preparedness and Response in and beyond OECD and ensuring that the Guiding Principles remain up-to-date and incorporates experience in member countries and international organisations;

b) furthering the implementation of the Guidance on Safety Performance Indicators in and beyond OECD and ensuring that Guidance on SPI remains up-to-date and incorporates experience in member countries and international organisations; 
c) analysing issues in selected areas of mutual interest, including those aimed at facilitating the use of the Guiding Principles and the Guidance on SPI;

d) promoting efforts to ensure that appropriate safety measures are in place at potentially hazardous installations, including measures to prevent accidents and mitigate effects of accidents which might occur, and

e) continuing to promote the exchange of information and experience among stakeholders (e.g., public authorities, industry, workers and their representatives and the public); and

f) facilitating the collection and analysis of data on chemical accidents, including economic data in order to enhance the integration of economic considerations into selected policies and procedures for chemical accident prevention, preparedness and response;

- to promote OECD work in this area in order to benefit both members and nonmembers and, to this end, engage in international co-operation as appropriate;

- to maintain close working relationships with other relevant OECD groups and with UNEP, UNECE, EEB, IMO, WHO, IPCS, ILO, OCHA and other appropriate international organisations in order to co-ordinate the planned and ongoing work and to ensure close liaison with other stakeholders including industry and trade unions.

2. The WGCA shall be comprised of representatives nominated by member countries and representatives of the European Commission, observer countries and international organisations that carry out work in the field of chemical accidents. Experts from BIAC, TUAC and relevant environmental organisations can be invited to participate. Members of the WGCA should be able to represent various issues related to chemical accidents, including prevention, preparedness, response and clean-up.

3. The Chair and Vice-Chairs (i.e. the Bureau) of the Working Group shall be elected by the members at the annual meeting. The Bureau will function as the main consultative body for the Secretariat between meetings of the Working Group. The WGCA shall meet normally once a year." 
Chair:

Vice-Chairs:

Members: ${ }^{1}$

Participating Countries: ${ }^{2}$

Observers:

Date of creation:

Duration:
Mrs. Susan Hazen

Mr. Yuho Shishiyama

Mr. Georg Karlaganis

Ms. Yvon Slingenberg

Australia
Austria
Belgium
Canada
Czech Republic
Denmark
Finland
France
Germany
Greece
Hungary
Ireland
Italy
Japan
Korea

Israel

Slovenia

South Africa

Israel

Slovenia

1st October 1978

31st December 2008
(United States)

(Japan)

(Switzerland)

(European Commission)

Mexico

Netherlands

New Zealand

Norway

Poland

Portugal

Slovak Republic

Spain

Sweden

Switzerland

Turkey

United Kingdom

United States

European Commission

Mandate: - Decision of the Council concerning a Special Programme on the Control of Chemicals [C(78)127(Final)]

- This mandate was extended by the Council at its $535^{\text {th }}, 598^{\text {th }}, 606^{\text {th }}, 665^{\text {th }}, 736^{\text {th }}$, $799^{\text {th }}, 872^{\text {nd }}, 948^{\text {th }}, 1027^{\text {th }}$ and $1107^{\text {th }}$ meetings $[\mathrm{C} / \mathrm{M}(2005) 6$, item 70$]$

- The Chemicals Committee meets together with the Working Party on Chemicals, Pesticides and Biotechnology

Extract from the Decision of the Council [C(78)127(Final)]

"THE COUNCIL,

\footnotetext{
1 The following countries became Participants to the Programme subsequent to the adoption by the Council of decision [C(78)127(Final)]: Czech Republic, Finland, Greece, Hungary, Ireland, Italy, Japan, Korea, Mexico, New Zealand, Poland, Portugal, Slovak Republic, Spain, Turkey.

2

2 Full participant for issues related to Mutual Acceptance of Data.
} 
Having regard to the Convention on the Organisation for Economic Co-operation and Development of 14th December 1960, and, in particular, Articles 2 a) and b), 3, 5 a) and 20 thereof;

Having regard to the Rules of Procedure of the Organisation;

Having regard to the Financial Regulations of the Organisation and, in particular,

Articles 5 and 10 thereof;

Having regard to the Resolution of the Council of 25th March 1975, amending the Mandate of the Environment Committee [C(75)17(Final)];

Having regard to the Recommendation of the Council of 7th July 1977, establishing guidelines in respect of procedure and requirements for anticipating the effects of chemicals on man and in the environment [C(77)97(Final)];

Considering that at its meeting on 24th-26th April 1978 the Environment Committee agreed to certain working arrangements for its Programme on Chemicals in the Environment and endorsed the suggestion that within the framework of the Chemicals Group's programme, Member countries wishing jointly to carry out supplementary work which is urgently needed by them should agree to form a Special Programme on the Control of Chemicals financed within the framework of Part II of the Budget;

Considering that Australia, Austria, Belgium, Canada, Denmark, France, Germany, the Netherlands, Norway, Sweden, Switzerland, the United Kingdom, the United States and the Commission of the European Communities (hereinafter referred to as "the Participants") have stated their intention to participate in a Special Programme on the Control of Chemicals (hereinafter called the "Programme").

DECIDES:

Part I

RESPONSIBILITIES OF THE ENVIRONMENT COMMITTEE CONCERNING THE CONTROL OF CHEMICAL SUBSTANCES

a) The Chemicals Group of the Environment Committee shall be responsible for the work in the field of control of chemical substance to protect the environment and man's health while avoiding negative effects for the economy and trade.

b) The Chemicals Group should from time to time hold special meetings, as required, in order to give general orientation to the work on chemicals. On such occasions, it should be composed of high-level representatives responsible for the administration of national chemical regulation. Conclusions then reached as well as specific directives indicated in respect of priority tasks will be reported to the Environment Committee.

Part II

\section{PROGRAMME}

Article 1

\section{PURPOSE}

Within the framework of the chemicals' activities of the Organisation, a Programme with a view to providing a forum for co-operation between those Member countries wishing jointly to carry out supplementary work which is urgently needed by them to develop and harmonize practices in order to improve the control of chemicals, is hereby established. The results of the work are intended to contribute to the protection of man and his environment from chemicals' hazards, and to prevent the creation of non-tariff barriers to trade. The Definition of the Programme is set out in the Appendix to this Decision of which it is an integral part. It may be adapted as necessary on subsequent proposals of the Management Committee referred to in Article 2 below.

Article 2

MANAGEMENT COMMITTEE OF THE PROGRAMME 
a) A Management Committee of the Programme (hereinafter referred to as the "Management Committee") shall be established and shall be composed of one representative appointed by each Participant.

b) Each Participant may appoint an alternate to its representative on the Management Committee.

c) The Management Committee shall designate each year among its Members, a bureau composed of a Chairman and an appropriate number of Vice-Chairmen.

d) Taking due account of the overall activities of the Organisation in the field of chemicals, the Management Committee shall submit each year to the Council proposals with respect to the annual programme of work and budget.

Article 3

\section{FUNCTIONS OF THE MANAGEMENT COMMITTEE}

a) The Management Committee shall be responsible for ensuring the carrying out of the Programme and may consider all questions related thereto. It shall exercise the functions defined in this Decision in accordance with the Decisions and Resolutions of the Council.

b) The Management Committee may set up working groups as required to carry out specific tasks.

c) The Management Committee shall submit each year to the Council a report on the work under the Programme which might include proposals for appropriate action resulting from this work. Such reports and proposals shall be reported to the Environment Committee in order to ensure coordination between activities financed under Part I and those financed under Part II of the Budget.

d) The Management Committee shall receive regular reports on the implementation of the Programme.

Article 4

\section{EXPENDITURE}

a) The expenditure arising from the implementation of the Programme shall be defrayed from the appropriations authorised for it under Part II of the Budget of the Organisation.

b) The Programme may include activities to be financed in whole or in part from grants by public or private institutions.

c) Notwithstanding the provisions of Article $14 \mathrm{~b}$ ) of the Financial Regulations, the Secretary-General may accept grants not exceeding FF 200000 each in respect of activities which have been included in the annual programme as adopted by the Council.

d) Notwithstanding the provisions of Article $16 \mathrm{~b}$ ) of the Financial Regulations, appropriations in respect of the Programme for which no commitment has been entered into before 31st December 1978, shall be automatically carried forward to the Financial year 1979.

Article 5

\section{PARTICIPANTS}

a) The Participants shall be the Member countries as listed in the Preamble and the Commission of the European Communities.

b) Any other Member country of the Organisation may participate at a later stage in the Programme.

Article 6

DURATION

a) The Programme is established for the period 1st October 1978, to 31st December 1981. 
b) The Council shall review the provisions of this Decision before the end of this period, taking into account the experience acquired in carrying out the Programme.

\section{Extract of Summary record [C/M(2005)6, item 70]}

(70)

"THE COUNCIL,

b) Agreed to extend the duration of the Special Programme on the Control of Chemicals to 31st December 2008;

c) Agreed to review the provisions of the Decision concerning a Special Programme on the Control of Chemicals [C(78)127(Final)], including the need for the continuation of a Special Programme, prior to 31st December 2008." 
DE VEL OPM E N T 

Chair:

Vice-Chairs:

Members: ${ }^{2}$

Observers:

Date of creation:

Duration:
Mr. Richard Manning

Mr. Jeroen Verheul

Ms. Stephanie Lee

Mr. George Carner

(Netherlands)

(New Zealand)

(United States)

Australia
Austria
Belgium
Canada
Denmark
Finland
France
Germany
Greece
Ireland
Italy
Japan

Luxembourg

Netherlands

New Zealand

Norway

Portugal

Spain

Sweden

Switzerland

United Kingdom

United States

European Commission

International Monetary Fund (IMF)

U.N. Development Programme (UNDP)

World Bank

14th January 1960

31st December 2008

Mandate: - Paragraph 14 of the Report by the Preparatory Committee

- Council Decision regarding a Sunset Clause for all Committees [C/M(2004)5, item

75] entered into force on 22 April 2004 [C/M(2004)10, item 143, IV, c)]

\section{Paragraph 14 of the Report by the Preparatory Committee}

14. As decided by the Ministerial Resolution of 23rd July 1960 [OECD(60)13], the Development Assistance Group shall, upon the inception of the OECD, be constituted as the Development Assistance Committee, and given the following mandate:

a) The Committee will continue to consult on the methods for making national resources available for assisting countries and areas in the process of economic development and for expanding and improving the flow of long-term funds and other development assistance to them.

\footnotetext{
1 The predecessor to the Development Assistance Committee, the Development Assistance Group (DAG) was set up on 13 January 1960 by the Special Economic Committee and approved by Council on 14 January 1960 [CM(60)2(Final) Item 14C].

2 OECD countries that are not members of the DAC are entitled to participate in all meetings of the DAC and its Subsidiary Bodies in areas of mutual interest.
} 
b) The Development Assistance Committee will acquire the functions, characteristics and membership possessed by the Development Assistance Group at the inception of the Organisation.

c) The Committee will select its Chairman, make periodic reports to the Council and its own Members, receive assistance from the Secretariat as agreed with the Secretary-General, have power to make recommendations on matters within its competence to countries on the Committee and to the Council, and invite representatives of other countries and international organisations to take part in particular discussions as necessary.

d) The Development Assistance Committee may act on behalf of the Organisation only with the approval of the Council.

e) In case the responsibilities of the Development Assistance Committee were to be extended beyond those set forth under a), any Member country not represented in the Development Assistance Committee could bring the matter before the Council. 


\section{DAC WORKING PARTY ON STATISTICS (WP-STAT)}

Chair:

Vice-Chairs:

Members:

Observers:

Date of creation:

Duration:
Mr. Fritz Meijndert

Mr. Geert Deserranno

Ms. Hedwig Riegler
Australia
Austria
Belgium
Canada
Denmark
Finland
France
Germany
Greece
Ireland
Italy
Japan

(Netherlands)

(Belgium)

(Austria)

Luxembourg

Netherlands

New Zealand

Norway

Portugal

Spain

Sweden

Switzerland

United Kingdom

United States

European Commission

International Monetary Fund (IMF)

U.N. Development Programme (UNDP)

World Bank

19th July 1968

31st December 2006

Mandate: - Terms of reference for the DAC Working Parties approved on 13th-14th March 1975 [DAC(75)18]

- $\quad$ Change of name, 5 February 1998 [DCD/DAC/M(98)3]

- $\quad$ New mandate approved by the DAC on 17 September 2003

[DCD/DAC/M(2003)6/FINAL]

\section{Extract from document [DCD/DAC/M(2003)6/FINAL, ANNEX 1]}

\section{THE WORKING PARTY ON STATISTICS}

"The Working Party on Statistics will keep under review and propose improvements in the statistical reporting of resource flows to developing and transition countries and multilateral agencies. It will make recommendations to the DAC about: ODA eligibility; guidelines and definitions for reporting; data comparability; and the use of DAC statistics. It will propose, for decision by the DAC, amendments to the statistical reporting directives; deal with related subjects referred to it by the DAC; and report to the DAC as appropriate." 
Chair:

Vice-Chairs:

Members: ${ }^{1}$

Participating Countries:

Invited Organisations:

Date of creation:

Duration:
Mr. Michel Reveyrand

Ms. Helen Allotey

Mr. Christopher Hall

Australia

Austria

Belgium

Canada

Denmark

Finland

France

Germany

Greece

Ireland

Italy

Japan

Bangladesh

Bolivia

Cambodia

Ethiopia

Fiji

Ghana

Indonesia

Kyrgyzstan

Madagascar

Mali

Morocco
(France)

(Ghana)

(World Bank)

Luxembourg

Netherlands

New Zealand

Norway

Portugal

Spain

Sweden

Switzerland

United Kingdom

United States

European Commission

Mozambique

Nicaragua

Niger

Philippines

Senegal

South Africa

Tanzania

Uganda

Viet Nam

Zambia

African Development Bank

Asian Development Bank (ADB)

Education for All - Fast Track Initiative (EFA-FTI)

European Bank for Reconstruction and Development (EBRD)

Global Fund to Fight AIDS, Tuberculosis and Malaria

Inter-American Development Bank (IADB)

International Monetary Fund (IMF)

Stategic Partnership with Africa (SPA)

U.N. Development Programme (UNDP)

United Nations Development Group (UNDG)

World Bank

24th April 2003

31st December 2006

Mandate : - Approved by the DAC on 17 September 2003 [DCD/DAC/M(2003)6/FINAL]

\footnotetext{
${ }^{1}$ OECD countries that are not members of the DAC are entitled to participate in all meetings of the DAC and its Subsidiary Bodies in areas of mutual interest.
} 


\section{Adapted extract from document DCD/DAC/EFF/(2005)15/REV1}

1. The DAC Working Party on Aid Effectiveness (WP-EFF) is the major international forum where the bilateral and multilateral community of donors, joined by an increased number of developing countries, work on improving the effectiveness of aid for greater impact on development and poverty reduction. Its current work is guided by the Paris Declaration on Aid Effectiveness endorsed by 90 countries and 26 multilateral institutions gathered at a High Level Forum in March 2005. This document sets out a practical blueprint for donors and partner countries who have subscribed to some 50 specific commitments aimed to increase country ownership, donor harmonisation and alignment, results orientation and mutual accountability. Participants have also agreed to be regularly measured against a set of 12 indicators and related targets for 2010 . The international community will take stock of progress made at a 3rd High Level Forum to be hosted by Ghana in 2008.

2. In this context, the Working Party on Aid Effectiveness, referred to as the "Partnership of donors and partner countries hosted by the DAC" was given the specific mandate to co-ordinate the international monitoring of the PD Indicators of progress (PD- §11). With the locus of action now shifting from policy formulation to implementation at country level, the WP-EFF also acts as a catalyst for dissemination and supports the implementation of the PD commitments on harmonisation and alignment with a focus on the results agenda, public financial management and procurement. To do so, the WP-EFF relies on the expertise of its four specialised Joint Ventures:

- Joint Venture on Monitoring the Paris Declaration (JV-MPD)

- Joint Venture on Managing for Development Results (JV-MfDR)

- Joint Venture on Public Financial Management (JV-PFM).

- Joint Venture on Procurement (JV- Procurement).

3. In line with the Paris Declaration (PD-\$11), partner country participation in the Working Party has expanded from the original group of 14 to some 23 partner countries (final list to be determined). The WP-EFF has also established for itself the principle of a "tripartite" chairing arrangement with representation from a bilateral donor, a multilateral organisation, and a partner country, reflecting the partnership commitment of mutual responsibility and accountability in implementing the Paris agenda. 


\section{DAC NETWORK ON DEVELOPMENT EVALUATION ${ }^{1}$}

Chair:

Vice-Chairs:

Members:

Observers:

Invited Organisations:

Date of creation:

Duration:
Ms. Eva Lithman

Ms. Satoko Miwa

Mr. Finbar O'Brien

Australia

Austria

Belgium

Canada

Denmark

Finland

France

Germany

Greece

Ireland

Italy

Japan
(Sweden)

(Japan)

(Ireland)

Luxembourg

Netherlands

New Zealand

Norway

Portugal

Spain

Sweden

Switzerland

United Kingdom

United States

European Commission

International Monetary Fund (IMF)

U.N. Development Programme (UNDP)

World Bank

African Development Bank

Asian Development Bank (ADB)

European Bank for Reconstruction and Development (EBRD)

Inter-American Development Bank (IADB)

28th March 2003

31st December 2006

Mandate: Approved by the DAC on 17 September 2003 [DCD/DAC/M(2003)6/FINAL]

\section{Extract from document [DCD/DAC/M(2003)6/FINAL, ANNEX 1]}

"The DAC Network on Development Evaluation will:

i) Strengthen the exchange of information, experience and co-operation on evaluation among Network members and, as appropriate, with development evaluation partners, with a view to:

- Improving the evaluation activities of individual members.

- Encouraging harmonisation and standardisation of methodological and conceptual frameworks.

- Facilitating co-ordination of major evaluation studies.

- Encouraging development of new methods in evaluation and best practice.

\footnotetext{
${ }^{1}$ The "DAC Network on Development Evaluation" is taking over the functions of the former "Working Party on Aid Evaluation" [DCD/DAC(2003)12/REV1 and DCD/DAC/M2003)4].
} 
ii) Contribute to improved development effectiveness by:

- Synthesising and extracting policy, strategic and operational lessons from evaluations for consideration by the DAC and the wider development community.

- Promoting joint or co-ordinated evaluations and studies undertaken by individual members.

iii) Provide advice and support to the DAC and its subsidiary bodies, notably on peer reviews, development results and aid effectiveness.

iv) Promote and support evaluation capacity development in partner countries." 


\section{DAC NETWORK ON GENDER EQUALITY (GENDERNET) ${ }^{1}$}

$\begin{array}{lll}\text { Chair: } & \text { Ms. To Tjoelker } & \text { (Netherlands) } \\ \text { Members: } & \text { Australia } & \text { Luxembourg } \\ & \text { Austria } & \text { Netherlands } \\ & \text { Belgium } & \text { New Zealand } \\ \text { Canada } & \text { Norway } \\ & \text { Denmark } & \text { Portugal } \\ & \text { Finland } & \text { Spain } \\ & \text { France } & \text { Sweden } \\ & \text { Germany } & \text { Switzerland } \\ & \text { Greece } & \text { United Kingdom } \\ & \text { Ireland } & \text { United States } \\ & \text { Italy } & \text { European Commission } \\ & \text { Japan } & \\ & \text { International Monetary Fund (IMF) } \\ & \text { U.N. Development Programme (UNDP) } \\ \text { World Bank } & \\ \text { Observers: } & \text { African Development Bank } & \\ & \text { Asian Development Bank (ADB) } & \\ \text { Invited Organisations: } & \text { Commonwealth Secretariat } \\ & \text { Inter-American Development Bank (IADB) } \\ & \text { U.N. Development Fund for Women (UNIFEM) } \\ \text { United Nations } \\ \text { 28th March 2003 } \\ \text { Date of creation: } & \text { 31st December 2006 } \\ & \end{array}$

Mandate: Approved by the DAC on 17 September 2003 [DCD/DAC/M(2003)6/FINAL]

\section{Extract from document [DCD/DAC/M(2003)6/FINAL, ANNEX 1]}

"The DAC Network on Gender Equality will:

- Contribute to improving the quality and effectiveness of development co-operation. Progress towards gender equality and women's empowerment is vital for improving economic, social and political conditions in developing countries. The knowledge, insights and experience of both women and men are required if development is to be effective, sustainable and truly people-centred.

- Provide strategic support to the policies of the DAC. Act as a catalyst and provide professional expertise for mainstreaming gender equality perspectives in the DAC,

\footnotetext{
1 The "DAC Network on Gender Equality" is taking over the functions of the former "Working party on Gender Equality" [DCD/DAC(2003)12/REV1 and DCD/DAC/M(2003)4].
} 
reinforcing this priority in members' programmes and support for partner countries' development efforts.

- Meet the needs of members of the DAC and members of the network. The GENDERNET provides a unique opportunity to exchange innovative and catalytic thinking on strategies and practices for integrating gender perspectives and women's empowerment to support partner's own efforts in all spheres of development co-operation.

Based on the mandate above, the GENDERNET will continue to play a catalytic role to ensure mainstreaming of a gender equality perspective into DAC work. In doing so, it will continue to collaborate closely with the other DAC subsidiary bodies." 


\section{DAC NETWORK ON ENVIRONMENT AND DEVELOPMENT CO-OPERATION (ENVIRONET) ${ }^{1}$}

Chairs:

Vice-Chair:

Members:

Observers:

Invited Organisations:

Date of creation:

Duration:
Mr. Pierre Giroux

Mr. Stephan Paulus

Australia

Austria

Belgium

Canada

Denmark

Finland

France

Germany

Greece

Ireland

Italy

Japan
(Canada)

(Germany)

Luxembourg

Netherlands

New Zealand

Norway

Portugal

Spain

Sweden

Switzerland

United Kingdom

United States

European Commission

International Monetary Fund (IMF)

U.N. Development Programme (UNDP)

World Bank

International Institute for Environment and Development (IIED)

International Institute for Sustainable Development (IISD)

U.N. Environment Programme (UNEP)

World Conservation Union (IUCN)

World Resources Institute

28th March 2003

31st December 2006

Mandate: Approved by the DAC on 17 September 2003 [DCD/DAC/M(2003)6/FINAL]

\section{Extract from document [DCD/DAC/M(2003)6/FINAL, ANNEX 1]}

"The DAC Network on Environment and Development Co-operation will:

- Contribute to the formulation of coherent approaches to sustainable development in the context of the OECD cross-sectoral approach to sustainable development.

- Formulate specific guidance for development co-operation efforts in support of environment and sustainable development.

\footnotetext{
1 The "DAC Network on Environment and Development Co-operation" is taking over the functions of the former "Working Party on Development Co-operation and Environment" [DCD/DAC(2003)12/REV1 and DCD/DAC/M(2003)4].
} 
- Provide its members with a policy forum for sharing experience and disseminating good practice with regard to the integration of environmental concerns in development cooperation." 


\section{DAC NETWORK ON POVERTY REDUCTION (POVNET)}

Chair:

Vice-Chair:

Members:

Observers:

Date of creation:

Duration:
Mr. James Smith

Mr. Hitoshi Shoji

Australia

Austria

Belgium

Canada

Denmark

Finland

France

Germany

Greece

Ireland

Italy

Japan
(United States)

(Japan)

Luxembourg

Netherlands

New Zealand

Norway

Portugal

Spain

Sweden

Switzerland

United Kingdom

United States

European Commission

International Monetary Fund (IMF)

U.N. Development Programme (UNDP)

World Bank

8th June 1998

31st December 2006

Mandate: $\quad$ New mandate approved by the DAC on 17 September 2003

[DCD/DAC/M(2003)6/FINAL]

\section{Extract from document [DCD/DAC/M(2003)6/FINAL, ANNEX 1]}

"The DAC Network on Poverty Reduction will:

- Focus on the multidimensionality of poverty and on the relationship between inequality, economic growth and poverty reduction in developing countries.

- Provide a forum for the exchange of experience and best practice on pro-poor growth, i.e. involving the poor in generating growth and benefiting from growth and globalisation.

- Address, from this perspective, strategies and policies in areas such as infrastructure, agriculture, trade and investment capacity building, information and communication technology, the role of the private sector and public-private partnerships.

- Promote the pursuit of the Millennium Development Goals and a central role for broadbased growth and its determinants within the strategic framework of national Poverty Reduction Strategies.

The POVNET will involve other stakeholders in its work, including partner countries and development organisations beyond the DAC Permanent Observers (World Bank, IMF, UNDP). It will interact with other DAC bodies, including the Networks on Gender Equality and on Environment and Development Co-operation, whose Chairs will be invited ex officio to take part, whenever justified by 
the agenda, in POVNET meetings. The POVNET will also interact with other OECD policy communities, as appropriate, to strengthen the development dimension of their work and promote policy coherence for development taking account of ongoing research. The POVNET will determine the appropriate modalities for implementing its work programme." 


\section{DAC NETWORK ON GOVERNANCE (GOVNET) ${ }^{1}$}

Chair:

Vice-Chairs:

Members:

Observers:

Invited Organisations: ${ }^{2}$

Date of creation:

Duration:
Mr. Eduard Westreicher

Mr. John Lobsinger

Ms. Sheelagh Stewart

Mr. Sanjay Pradhan

Australia
Austria
Belgium
Canada
Denmark
Finland
France
Germany
Greece
Ireland
Italy
Japan

Australia

Austria

Canada

Denmark

Finland

German

Greece

Italy

Japan
(Germany)

(Canada)

(United Kingdom)

(World Bank)

Luxembourg

Netherlands

New Zealand

Norway

Portugal

Spain

Sweden

Switzerland

United Kingdom

United States

European Commission

International Monetary Fund (IMF)

U.N. Development Programme (UNDP)

World Bank

African Development Bank

Asian Development Bank (ADB)

European Centre for Development Policy Management (ECDPM) International Institute for Democracy and Electoral Assistance (IDEA)

U.N. Economic Commission for Africa (UNECA)

U.N. Office of the High Commissioner for Human Rights (OHCHR) United Nations

4th December 2000 [DCD/DAC/GOVNET(2001)1]

31st December 2006

Mandate: - The Network was created by merging the DAC informal Network on Participatory Development and Good Governance (PD/GG) and the DAC informal Network on Institutional and Capacity Development (I/CD) during the 754th meeting of the DAC [DCD/DAC/M(2000)5]

- New mandate approved by the DAC on 17 September 2003 [DCD/DAC/M(2003)6/FINAL]

- Mandate extended until 31 December 2006 by the DAC at its 816 th Meeting on 17 June 2004 [DCD/DAC/M(2004)8/FINAL].

\section{Extract from document [ DCD/DAC/M(2003)6/FINAL, ANNEX 1]}

“...

${ }^{1}$ Formerly "DAC Network on Good Governance and Capacity Development (GOVNET)".

${ }^{2}$ A number of developing country experts are invited at each meeting in relation to items for discussion. 
1. "The DAC Network on Governance (GOVNET) aims at improving the effectiveness of donor assistance in governance and in support of capacity development. It provides members with a policy forum for exchanging experiences, and lessons, as well as identifying and disseminating good practice, and developing pro-poor policy and analytical tools. The GOVNET work focuses on how to improve the effectiveness of support in a broad range of areas including: the fight against corruption, public service reform, capacity development, human rights, democracy, the rule of law, assessing governance development, and difficult partnerships. This list is not intended to be exclusive. The work of the Network covers relationships between the State, citizens, civil society and the private sector.

2. The membership of the GOVNET is composed of representatives from responsible Ministries of DAC members and observers. Representatives from other OECD Directorates, the OECD Development Centre and the Sahel and West Africa Club may also attend meetings of the GOVNET. Experts from developing countries, international NGOs and policy research institutes may be invited by the GOVNET to enhance the implementation of its work programme.

3. In keeping with general OECD practice, plenary meetings are usually held every nine months in Paris. Ad-hoc steering groups of interested members can ensure the implementation of individual work programme components, in accordance with the lines agreed upon by the GOVNET. They may meet, as necessary, either in Paris or other locations, or elect to meet via other communication means.

4. GOVNET also seeks to interact and establish effective links with other DAC groups and OECD regarding both governance and capacity development issues, through the Secretariat and by participating in meetings, in order to enhance overall aid effectiveness. Members are encouraged to liaise with other parts of their governments where this will enhance collaboration and coherence."

\footnotetext{
${ }^{1}$ The Fragile States Group (FSG), www.oecd.org/dac/fragilestates, is a forum that brings together experts on governance, conflict prevention and reconstruction from bilateral and multilateral development co-operation agencies to facilitate co-ordination and share good practice to enhance development effectiveness in 'fragile states'. It forms a bridge between the DAC Network on Governance (GOVNET) and the Conflict, Peace and Development Co-operation (CPDC), and also benefits from inputs from other DAC Networks and Working Parties. This group was formerly called the "Learning and Advisory Process on Difficult Partnerships (LAP)" [DCD/DAC/RD(2005)10/RD1 and DCD/DAC/M(2005)8/FINAL].
} 
Chair:

Vice-Chairs:

Members:

Observers:

Invited Organisations:

Date of creation:

Duration:
Mr. Tom Owen-Edmunds

Mr. Björn Holmberg

Ms. Cristina Hoyos

Ms. Inger Buxton

Australia
Austria
Belgium
Canada
Denmark
Finland
France
Germany
Greece
Ireland
Italy
Japan

(United Kingdom)

(Sweden)

(Switzerland)

(European Commission)

Luxembourg

Netherlands

New Zealand

Norway

Portugal

Spain

Sweden

Switzerland

United Kingdom

United States

European Commission

International Monetary Fund (IMF)

U.N. Development Programme (UNDP)

World Bank

International Committee of the Red Cross (ICRC)

U.N. High Commissioner for Refugees (UNHCR)

U.N. Office for the Coordination of Humanitarian Affairs (UNOCHA)

1995

31st December 2006

Mandate: - Transformed into a Network in June 2000 [DCD/DAC/M(2000)5]

- New mandate approved by the DAC on 17 September 2003 [DCD/DAC/M(2003)6/FINAL]

- Mandate extended until 31 December 2006 by the DAC at its 816th Meeting on 17 June 2004 [DCD/DAC/M(2004)8/FINAL]

\section{Extract from document [DCD/DAC/M(2003)6/FINAL, ANNEX 1]}

"1.

The DAC, through its Network on Conflict, Peace and Development Co-operation, strives to improve the effectiveness of development co-operation and the coherence of members' policies by promoting the principles and agreements in the DAC conflict guidelines and statement Helping Prevent Violent Conflict. The Network enhances donors' work with developing country actors - especially in fragile, difficult, conflict-prone countries - to promote structural stability and peace; prevent and manage violent conflict; and provide relief and reconstruction assistance in crises.

2.

The Network's objectives are thus to enhance donors' efforts, as they work with developing country actors - especially in fragile, difficult or crisis countries - to: integrate a conflict prevention lens and create a culture of prevention in all government branches; help prevent and manage violent conflict by promoting structural stability and peace; and provide humanitarian and 
reconstruction assistance. By sharing best practices and lessons learned, and providing policy guidance, the Network aims to mainstream conflict prevention; encourage information sharing; build capacity in donor agencies; and promote partnerships within and between OECD and partner countries and other external actors. ${ }^{1}$

3.

The Network aims to:

- Better integrate conflict prevention/peace-building into development co-operation policies.

- Help developing countries build legitimate and accountable security systems, as an integral part of governance and public sector management: Improve donor approaches to helping partners manage their security systems and related expenditures effectively.

- $\quad$ Take account of the political economy of war, such as corruption, criminality and powerful groups and individuals with vested interests in sparking and perpetuating violent conflict: Enhance how donor countries work with business to contribute to a positive, constructive environment in conflict-prone situations and address related policy coherence issues.

- $\quad$ Continue to provide policy guidance by responding to emerging issues and evolving needs (e.g. crisis and reconstruction countries; terrorism).

- Improve knowledge management and communications by sharing information and publishing and disseminating conflict-related outputs and the guidelines."

1 The OECD DAC's Learning and Advisory Process on Difficult Partnerships (LAP, www.oecd.org/dac/lap) is a forum that brings together experts on governance, conflict prevention and reconstruction from bilateral and multilateral development co-operation agencies to facilitate co-ordination and share good practice to enhance development effectiveness in difficult partnership countries or 'fragile states'. It forms a bridge between the DAC Network on Governance (GOVNET) and the Conflict, Peace and Development Co-operation (CPDC), and also benefits from inputs from other DAC Networks and Working Parties. 

PUBLIC GOVERNANCE AND TERRITORIAL DEVELOPMENT 



\section{PUBLIC GOVERNANCE COMMITTEE (PGC) ${ }^{1}$}

Chair:

Vice-Chairs:

\section{Members:}

Observers:

Date of creation:

Duration:
Ms. Pia Marconi

Ms. Lynne Tacy

Ms. Elisabeth Dearing

Ms. Roberta Santi

Ms. Katju Holkeri

Mr. Friedrich-Wilhelm Moog

Mr. Koos Roest

Mr. Lubomir Plai

Open to all Member countries

Brazil

Chile

Slovenia

30th September 1961

31st December 2009
(Italy)

(Australia)

(Austria)

(Canada)

(Finland)

(Germany)

(Netherlands)

(Slovak Republic)

Mandat : - Resolution of the Council concerning the Mandate of the Public Management Committee [C(99)175/FINAL] approved at its $964^{\text {th }}$ session held on 9 December 1999

- Change of name from "Public Management Committee" to "Public Governance Committee" approved by Council at its $1075^{\text {th }}$ session held on $15^{\text {th }}$ January 2004 [C/M(2004)1, item 13 and C(2003)206]

- Resolution of the Council renewing the terms of reference of the Public Governance Committee approved at its $1092^{\text {nd }}$ session held on 26 July 2004 [C/M(2004)18, item 235 and C(2004)116 and CORR1]

\section{Resolution of the Council [C(2004)116 and CORR1]}

\section{"THE COUNCIL,}

Having regard to Articles 1 and 2 of the Convention on the Organisation for Economic Co-operation and Development of 14th December 1960;

Having regard to the Resolution of the Council amending the name and the Mandate of the Technical Co-operation Committee of 23rd June 1989 [C(89)92(Final)], the mandate renewal resolutions of 23rd June 1994 [C(94)125/Final] and 9th December 1999 [C(99)175/Final], and the Resolution of the Council amending the name of the Public Management Committee of 15 January 2004 [C/M(2004)1];

Having regard to the Rules of Procedure of the Organisation and in particular to paragraph 4 of the Annex thereto;

Recognizing that globalisation and societal change are strengthening the need for improved governance at supranational, national and sub-national level;

\footnotetext{
1 Formerly "Public Management Committee".
} 
Recognizing the importance of good public governance as an essential element in strengthening pluralistic democracy, promoting sustainable development and in maintaining confidence in public administration;

Recognizing the importance of good public management in ensuring policy effectiveness, economic efficiency and sound fiscal balances, and in maximizing the quality of and programme results achieved with regard to government expenditure;

Recognizing that public governance reforms are and must be specific to the public sector as well as context-dependent and country-specific, dealing with different situations but aiming at the same long-term goals;

Recognizing the interest of non-member countries in sharing OECD values and experience in enhancing public governance;

Considering the central role of public governance as both an agent for achieving structural adjustment and international competitiveness, as well as a subject for reform itself;

Considering the statement of the Public Governance Committee on the PGC Mandate which sets out how PGC will contribute to the economic and social policy objectives of Member countries;

\section{DECIDES:}

1. The Public Governance Committee is responsible for designing and implementing a concentrated programme:

i) to identify and help address the strategic challenges that governments face in modernising public governance in a changing world, particularly by strengthening trust in public institutions and the capacity to adapt to the new challenges;

ii) to assist members and non-members in achieving more coherent and effective policies, and in raising the integrity, quality and performance of their public institutions and services;

iii) to promote key elements of a good governance framework, and thus contribute to the improvement of the effectiveness, efficiency, transparency, responsiveness and accountability of public institutions.

2. In carrying out its responsibilities, the Committee shall:

i) provide a forum for exchanges of experience among civil servants engaged in designing and implementing policies for modernising public governance and management;

ii) follow, assess and report on key developments and results in modernising public governance and public management in member and, as appropriate, non-member countries;

iii) develop a range of tools and frameworks to enable comparative evidence-based analysis of public management issues from a governance perspective.

iv) share results of its work with interested non-member countries and other relevant international organizations and institutions;

v) contribute to the Organisation's activities for technical assistance and other forms of support to the improvement of public governance and management in nonmember countries.

vi) contribute a public governance and public management perspective on major policy concerns addressed by the Organisation, including its horizontal activities;

vii) maintain close working relationships with other relevant bodies of the Organisation and other international institutions. 
3. These terms of reference shall remain in force until 31st December 2009, unless the Council decides otherwise. The Committee will review progress in achieving the goals of the mandate at the mid-point of the mandate.

4. The Resolution of 14 January 2000 concerning the renewal of the mandate of the Public Management Committee [C(99)175/FINAL] is hereby repealed.

5. Paragraph 4 of the Annex of the Rules of Procedure shall be amended to read as follows:

4. "Public Governance Committee: its terms of reference are defined in the Resolution of the Council C(2004)116 and C(2004)116/CORR1." 


\section{WORKING PARTY ON REGULATORY MANAGEMENT AND REFORM}

Chair:

Bureau Members:

Members:

Observers:

Date of creation:

Duration:
Mr. George Redling

Mr. Mark Courtney

Ms. Kirsi Kuuttiniemi

Mr. John F. Morrall III

Mr. Daniel Trnka

Open to all Member countries

Brazil

Chile

Slovenia

March 1991

31st December 2009
(Canada)

(United Kingdom)

(Finland)

(United States)

(Czech Republic)

Mandate: The Working Party, unique in the OECD in bringing together policy officials responsible for cross-cutting and horizontal regulatory reform policies, works to build policy support and skills for good regulations in Member countries, emphasizing regulatory quality - combining both good regulation where needed to protect health, safety, and the environment and to enhance the functioning of markets, and deregulation where free markets work better. 


\section{WORKING PARTY OF SENIOR BUDGET OFFICIALS (SBO)}

Chair:

Members:

Observers:

Ad hoc Observers:

Date of creation:

Duration:
Mr. Ian Watt

(Australia)
Open to all Member countries

Brazil

Chile

Israel

Slovenia

International Monetary Fund (IMF)

World Bank

1980

31st December 2009

Mandate:

\section{WORKING PARTY OF SENIOR BUDGET OFFICIALS}

1. The Working Party of Senior Budget Officials (SBO) aims to improve the effectiveness and efficiency of resource allocation and management in the public sector.

2. The Working Party addresses the entire budget cycle, including budget formulation, budget approval (role of the legislature), budget implementation (management, organizational structure), and audit.

3. The SBO provides a collaborative forum for policy-makers and senior officials to address major budgeting concerns, including information exchange on emerging issues, trends and challenges; as well as identifying and disseminating good practice and developing policy and analytical tools. The SBO establishes separate networks for specific components of the budget cycle. ${ }^{1}$

4. In support of its mission, the SBO carries out analysis and research on the full range of budgeting issues. It conducts "peer review" examinations of the budgeting systems of individual Member countries and analyzes individual aspects of the budgeting system across Member countries. The SBO also maintains a comprehensive database of national budgeting practices in Member countries.

5. The Working Party recognizes that the institutions for allocating, managing and accounting for public resources are fundamental to good governance, and it therefore co-operates with non-Members in order to share the results of its work, including through the maintenance of regional networks.

6. The duration of the Working Party's mandate is concurrent with that of the Public Governance Committee.

\footnotetext{
${ }^{1}$ At present, there are 4 satellite networks: the Network of Chairpersons of Parliamentary Budget Committees, the Network on Financial Management, the Network on Performance and Results, and the Network on Organizational Structures.
} 


\section{NETWORK ON FINANCIAL MANAGEMENT ${ }^{1}$}

Chair:2

Members:

Observers:

Ad hoc Observers:

Date of creation:

Duration:
Mr. Ian Mackintosh

Open to all Member countries

Brazil

Chile

Israel

Slovenia

International Monetary Fund (IMF)

World Bank

2001

31st December 2009
(United Kingdom)

\section{Mandate:}

\section{NETWORK ON FINANCIAL MANAGEMENT \\ TERMS OF REFERENCE}

1. The Network supports the mandate of the Working Party of Senior Budget Officials "to improve the effectiveness and efficiency of resource allocation and management in the public sector" by assisting Member countries to design and implement financial management and accountability reforms.

2.

More specifically, the Network will assist Member countries and Outreach partners in:

The implementation of accrual based financial reporting and budgeting systems;

Fostering convergence in the accrual treatment of specific transactions, and to liaise with the appropriate standard-setting bodies in this regard;

Enhancing the structure and format of government financial statements;

Establishing incentive-based cash and asset management practices;

Adopting effective internal and external control and audit practices; and

Other related activities.

3. The Network provides a forum for senior officials and conducts research and analysis addressing the above issues in line with the operating methods specified in the Mandate of the Working Party of Senior Budget Officials. The Network shall provide an annual report on its activities to the Working Party.

4. The duration of the Network's mandate is concurrent with that of the Working Party of Senior Budget Officials.

\footnotetext{
1 Previously "Network of Financial Management and Accountability Officials".

2

2 Chair selected on ad hoc basis.
} 


\section{NETWORK OF PARLIAMENTARY BUDGET COMMITTEE CHAIRPERSONS}

Chair:

Members:

Observers:

Ad hoc Observers:

Date of creation:

Duration:
The host country acts as the chair of the meeting (revolving annually)

Open to all Member countries
Brazil
Chile
Israel
Slovenia

International Monetary Fund (IMF)

World Bank

2001

31st December 2009

Mandate:

\section{NETWORK OF PARLIAMENTARY BUDGET COMMITTEE CHAIRPERSONS TERMS OF REFERENCE}

1. The Network supports the mandate of the Working Party of Senior Budget Officials "to improve the effectiveness and efficiency of resource allocation and management in the public sector" by assisting the legislatures of Member countries to effectively play their role in the budget process.

2. More specifically, the Network will assist the legislatures of Members and Outreach partners in:

Improving the working methods for scrutinizing the government's budget proposals;

Designing the appropriate rules and restrictions, if any, for amending the government's budget proposal;

Building capacity in the design of budgeting and management reforms in Member countries;

Improving the working methods for holding the government to account for budget implementation; and

Other related activities.

3. The Network provides a forum for parliamentarians and their staff, and conducts research and analysis addressing the above issues in line with the operating methods specified in the Mandate of the Working Party of Senior Budget Officials. The Network shall provide an annual report on its activities to the Working Party.

4. The duration of the Network's mandate is concurrent with that of the Working Party of Senior Budget Officials. 


\section{NETWORK ON ORGANISATIONAL STRUCTURES}

Chair:

Members:

Open to all Member countries

Observers:

Brazil

Chile

Israel

Slovenia

Date of creation:

1st January 2004

Duration:

31st December 2009

\section{Mandate:}

\section{NETWORK ON ORGANISATIONAL STRUCTURES TERMS OF REFERENCE}

1. The Network supports the mandate of the Working Party of Senior Budget Officials "to improve the effectiveness and efficiency of resource allocation and management in the public sector" by assisting Member countries to reform the organizational structure of ministries and other government bodies.

2. More specifically, the Network assists member countries, and Outreach partners in their development of policies for:

the organizational design of ministries and other government bodies on a whole-ofgovernment basis;

the allocation of functions across ministries and other government bodies;

the governance arrangements for non-ministerial bodies;

the internal structure of ministries and other government bodies;

developing processes to systematically support the renewal of organizational structures.

3. The Network provides a forum for senior officials and conducts research and analysis addressing the above issues in line with the operating methods specified in the Mandate of the Working Party of Senior Budget Officials. The Network provides an annual report on its activities to the Working Party.

4. The duration of the Network's mandate is concurrent with that of the Working Party of Senior Budget Officials. 


\section{NETWORK ON PERFORMANCE AND RESULTS}

Chair:

Members:

Observers:

Date of creation:

Duration: $\cdots$

Open to all Member countries

Brazil

Chile

Israel

Slovenia

1st January 2004

31st December 2009

Mandate:

\section{NETWORK ON PERFORMANCE AND RESULTS}

TERMS OF REFERENCE

1.

The Network supports the mandate of the Working Party of Senior Budget Officials "to improve the effectiveness and efficiency of resource allocation and management in the public sector" by assisting Member countries to design and implement performance- and results-based budgeting and management reforms.

2. More specifically, the Network will assist Member countries and Outreach partners in :

Establishing mechanisms to ensure the reliability and consistency of performance and results information;

Developing evaluation policies and processes

Designing systems for linking performance and results information and the resource allocation process;

Establishing accountability regimes based on performance and results information; and

The definition of appropriate performance and results outcomes and/or outputs for the range of government activities;

The measurement of defined outcomes and/or outputs;

Other related activities.

3. The Network provides a forum for senior officials and conducts research and analysis addressing the above issues in line with the operating methods specified in the Mandate of the Working Party of Senior Budget Officials. The Network shall provide an annual report on its activities to the Working Party.

4. The duration of the Network's mandate is concurrent with that of the Working Party of Senior Budget Officials. 


\section{NETWORK OF SENIOR OFFICIALS FROM CENTRES OF GOVERNMENT ${ }^{1}$}

Chair:

Head of the Centre of Government of the host country (revolving annually)

Members:

Open to all Member countries

Observers: Brazil

Chile

Slovenia

Date of creation:

1980

Duration:

31st December 2009

\section{Mandate:}

NETWORK OF SENIOR OFFICIALS FROM CENTRES OF GOVERNMENT

The Network of Senior Officials from Centres of Government aims:

- $\quad$ to review issues of making the centre of national government work effectively;

- $\quad$ to understand decision- and policy-making systems;

- $\quad$ to strengthen the relations among peers in order to encourage them to exchange experiences and priorities;

- $\quad$ to work on broad governance issues; and

- $\quad$ to provide the Public Governance Committee with insight and guidance on ongoing activities and future work.

\footnotetext{
1 Meetings of the network began in the early 1980s and were consolidated into an annual event in the 1990s.
} 


\section{HUMAN RESOURCES MANAGEMENT WORKING PARTY}

Chair:

Members:

Observers:

Date of creation:

Duration:
Mr. Mike Watts

Open to all Member countries

Brazil

Chile

Slovenia

1985

31st December 2009

(United Kingdom)

Mandate:

\section{HUMAN RESOURCES MANAGEMENT WORKING PARTY}

1. The Human Resources Management Working Party aims to improve public sector governance in Member countries by addressing human resources-related public management.

2. The Working Party addresses the entire field of human resources in Government focusing specifically on issues such as leadership and the management of senior civil servants, civil service ethics, employment policies retention, performance management and knowledge management.

3. The HRMWP provides a collaborative forum for senior officials of central government bodies in charge of general government management or more human resources-focused bodies to address major HRM-related concerns, such as future shortage skills, the competitiveness of the public employer, the improvement of performance, the need for more citizen-focused public services, or finding a well balanced system of pay and employment.

4. It includes information exchange on emerging issues, trends and challenges, identifies and disseminates best practices, as well as develops policy and analytical tools. The HRMWP establishes separate networks for specific components of human resources. Active networks include networks on performance-related pay, the management of senior civil servants, and knowledge management.

5. In support of its mission, the HRMWP carries out analysis and research on the full range of HRM issues and maintains a comprehensive database on public sector pay and employment and on human resources management. 


\section{STEERING GROUP ON THE COMPLEMENTARY AREAS OF E-GOVERNMENT WORK ${ }^{1}$}

Chair:

Members:

Date of creation:

Duration:
Revolving chair

$\begin{array}{ll}\text { Australia } & \text { Korea } \\ \text { Denmark } & \text { Mexico } \\ \text { France } & \text { Netherlands } \\ \text { Germany } & \text { Norway } \\ \text { Greece } & \text { Portugal } \\ \text { Hungary } & \text { United Kingdom } \\ \text { Italy } & \text { United States } \\ \text { Japan } & \end{array}$

\section{Mandate:}

2001

31st December 2006

\section{THE STEERING GROUP}

ON THE COMPLEMENTARY AREAS OF E-GOVERNMENT WORK

\section{TERMS OF REFERENCE}

1. The Steering Group on the Complementary Areas of E-Government Work aims to provide guidance on the areas of work that are complementary to the core work on e-government at the OECD, and that could not be covered by the OECD budget.

2. In particular, the Steering Group identifies a specific set of work that should be carried out by the Secretariat in a specific timeframe, and provides guidance on how this work could be carried out.

3. Steering Group countries provide voluntary contributions to the OECD E-Government Project in support of this work.

\footnotetext{
1 Formerly Working Group on E-Government.
} 
Chair:

Members:

Observers:

Ad hoc Observers:

Date of creation:

Duration:
Ms. Catherine MacQuarrie

(Canada)

Open to all Member countries

Brazil
Chile
Slovenia

Asian Development Bank (ADB) World Bank

2002

31st December 2009

Mandate:

EXPERT GROUP ON CONFLICT OF INTEREST:

ENSURING ACCOUNTABILITY AND TRANSPARENCY

IN THE PUBLIC SERVICE

TERMS OF REFERENCE

1. This ad hoc Expert Group provides input and guidance to the Secretariat in implementing selected topics in relation to the Public Governance Committee's programme of work on Governance and Management of Public Institutions and Resources. In addition, the Expert Group provides a unique forum for:

- exchanging first-hand experiences on emerging issues and best practices;

- reviewing trends and best practice guidelines developed by the Secretariat;

- disseminate lessons and support the dialogue with non-member countries.

2. The Expert Group reviews issues related to conflicts of interest in the public service and other vulnerable areas in the public-private sector interface.

3. The Expert Group will prepare a report on the implementation of the 2003 OECD Recommendation on Managing Conflict of Interest in the Public Service that will be presented for the Council in 2006. 


\section{NETWORK OF SENIOR E-GOVERNMENT OFFICIALS}

Chair:

Members:

Observers:

Date of creation:

Duration:
Host country

(revolving for each meeting)

Open to all Member countries

Brazil

Chile

Slovenia

United Nations

1st June 2003

31st December 2006

\section{Mandate:}

\section{SENIOR E-GOVERNMENT OFFICIALS NETWORK}

\section{TERMS OF REFERENCE}

1. The Senior E-Government Officials Network aims to improve the effectiveness and efficiency of e-government initiatives in the public sector.

2. The Network also seeks to ensure that e-government is better integrated into the broader public management agenda.

3. The OECD provides a collaborative forum for policy-makers and senior officials to address major e-government concerns, including identification of and information exchange on emerging issues, trends and challenges, as well as identifying and disseminating good practices and developing policy and analytical tools.

4. In support of its mission, the Senior E-Government Officials Network carries out analysis and research on the full range of e-government issues. It conducts "peer review" examinations of national e-government initiatives and analyses individual aspects of e-government across member countries. The network also maintains a database of national e-government practices in member countries.

5. The network recognizes ICT use as a contributing element to good governance and cooperates with non-member countries in order to share the results of its work. 


\section{GROUP ON REGULATORY POLICY}

Chairs:

Members:

Observers:

Date of creation:

Duration:
Chairs from participating committees

Open to all Member countries

Business and Industry Advisory Committee (BIAC) Trade Union Advisory Committee (TUAC)

1996

31st December 2010

Mandate : - Resolution of the Council adopted at its 1121st session held on 14 October 2005 [C(2005)122 and C/M(2005)20]

\section{Resolution of the Council [C(2005)122 and C/M(2005)20]}

\section{THE COUNCIL,}

Having regard to the Convention on the Organisation for Economic Co-operation and Development of 14th December 1960, and in particular articles 1 and 2;

Having regard to the Rules of Procedure of the Organisation;

Having regard to the Resolution of Council establishing an OECD Special Group on Regulatory Policy of 8th November 2002 [C(2002)189/REV2];

Recognising the need for regulatory reform in a global environment with increased international competition, market openness and greater attention to the rule of law;

Acknowledging the importance of regulatory reform as a dynamic, long-term multidisciplinary process for sustainable economic growth;

Recognising the importance of a whole-of-government approach to create a regulatory environment favourable to the creation and growth of firms, productivity gains, competition, investment and international trade, and promoting good governance principles;

Recognising that the 2005 OECD Guiding Principles for Regulatory Quality and Performance provide a sound basis for further assessment of Member countries' regulatory frameworks from a multi-disciplinary perspective, including capacities for high quality regulation, competition policy, market openness and specific sectoral approaches;

Taking account of the high value that non-Member countries attach to OECD work on regulatory reform, enhancing the mutual sharing of values, experiences and best practice, including the collaborative work undertaken under the APEC-OECD Co-operative Initiative on Regulatory Reform;

\section{DECIDES:}

1. The Group on Regulatory Policy is to function as a platform for high level, multidisciplinary policy dialogue on regulatory reform at the OECD, drawing on the expertise of the Public Governance, Trade and Competition Committees and of their subsidiary bodies. Its role will be:

\footnotetext{
1 Formerly "Special Group on Regulatory Policy".
} 
i) to identify and help address the strategic challenges that governments face in designing and implementing regulatory reform;

ii) to provide a framework for concluding country peer reviews on regulatory reform and of the monitoring exercises conducted in expert committees;

iii) to facilitate a thematic exchange of experience regarding regulatory policies among Member countries;

iv) to facilitate a policy dialogue with non-Member countries on regulatory policy and reform.

2. In carrying out its responsibilities, the Group on Regulatory Policy shall:

i) be open to all Member countries. Its Chair will be assured on a rotating basis by representatives of the bureaux of the Trade, Competition and Public Governance Committees or their respective subsidiary bodies.

ii) ensure close working relationships with the participating Committees and with other relevant bodies of the Organisation;

iii) share results, when appropriate, with interested non-Members and other relevant international organizations and institutions, including APEC.

3. These terms of reference shall remain in force until 31 December 2010, unless the Council decides otherwise. 


\section{TERRITORIAL DEVELOPMENT POLICY COMMITTEE}

Chair:

Vice-Chairs:

Members:

Ad hoc Observer:

Date of creation:

Duration:
Mr. Fabrizio Barca

Mr. Wolf-Dietrich Huber

Ms. Marilyn Kapitany

Mr. Bernard Morel

Mr. Takayuki Hara

Mr. Roberto Villareal Gonda

Mr. Sandy Baruah
(Italy)

(Austria)

(Canada)

(France)

(Japan)

(Mexico)

(United States)

Open to all Member countries

Morocco

20th January 1999

31st December 2009

Mandate: - Resolution of the Council concerning the Renewal of the Mandate of the Territorial Development Policy Committee set out in annex I to document [C(2004)114] adopted by the Council on $8^{\text {th }}$ July 2004 at its 1091th session [C/M(2004)17, item 216 and C(2004)114/CORR1]

- The TDPC was created by the Resolution [C(98)198/FINAL] adopted by the Council on $20^{\text {th }}$ January 1999 under the written procedure [C/M(99)1/PROV]

\section{Resolution of the Council [C(2004)114 and C(2004)114/CORR1]}

\section{"THE COUNCIL,}

Having regard to Articles 5 a) and 9 of the Convention on the Organisation for Economic Co-operation and Development;

Having regard to the Resolution of the Council concerning the Creation of a Territorial Development Policy Committee [C(98)198/FINAL];

Having regard to the report "The OECD Committee Structure - A review" [CE(98)3];

Having regard to the Resolution of the Council concerning the Renewal of the Mandate of the Territorial Development Policy Committee [C/M(2001)26, item 426 and C(2001)257/REV1];

Having regard to the emerging synergies with the work in the newly created directorate on Public Governance and Territorial Development;

Having regard to the Rules of Procedure;

Having regard to the mission statement agreed on by the Territorial Development Policy Committee for its future work:

The mission of the TDPC is to improve policy performance in enhancing well-being and living standards across all OECD regions by influencing the main factors that generate and sustain regional competitive advantage and by promoting effective and innovative governance. TDPC should serve as a premier international forum for senior-level 
government policy makers to identify, discuss, and disseminate a vision of development policy that is place-based, multi-level, innovative and geared to different types of regions. This policy approach focuses on economic growth while integrating environmental and social concerns, which are necessary to enhancing regional competitive advantage.

To accomplish its mission, and to permit an evaluation of the overall policy impact of this approach, the Committee will develop high-quality and relevant statistical indicators, will compare economic development issues and policies across countries, and will assess multi-level governance mechanisms.

Having regard to the conclusions of the High Level Meeting on Territorial Policy held in Switzerland in June 2003;

Considering that the conclusions of the High-Level Meeting underlined the role of regional policies in OECD countries in promoting long-term, sustained economic growth, regional competitiveness through private and public investment, entrepreneurship and greater reliance on local assets.

Considering that, as a consequence of the above trends, central governments are increasingly called upon to stimulate and foster regional strategies that are more likely to be effective, and to enhance the capacities of local communities to participate in their own development;

Considering that in responding to these challenges, OECD countries can obtain great benefits from international co-operation both to develop new policy frameworks and share the results of experiments and innovations; and

Recognising the consensus of the TDPC to transform the Committee into the premier international forum for discussion of these issues;

Recognising and linking the important contribution of the Working Parties on Policies in Rural and Urban Areas, and on Statistics and Indicators; and

Recognising the importance the Committee attaches to contributing to the evaluation process in the OECD.

On the proposal of the Secretary-General after consultation with the Committee on Territorial Development Policy, the Council:

\section{DECIDES:}

1. The terms of reference of the Territorial Development Policy Committee are to:

a) implement the general principles contained in the agreed mission statement, specifically to enhance regional competitive advantage, based on a progressive policy shift from subsidy-based sectoral policies that thwart business innovation to integrated place-based policies which address the specific causes that prevent each region from realising its full potential;

b) provide a forum for member countries to share views on regional development policy implementation in the OECD area and to improve the understanding of economic, social, environmental and institutional trends;

c) contribute a regional perspective on major policy concerns and priorities of the Organisation, including its horizontal activities; 
d) undertake policy analysis of competitiveness strategies, with a view to promoting regional advantages and unused potentials for growth, as well as enhancing cohesion and integrating economic, social and environmental concerns, as captured by the concept of sustainable development ;

e) analyse and promote innovative policies at the territorial level that will enable member countries, through shared efforts and an exchange of experience, to further improve their governance, with particular reference to horizontal and vertical institutional partnerships;

f) develop a range of comparable data, indicators and other statistical tools to support policy analysis;

g) strengthen the contribution of the three Working Parties to the Territorial Development Policy Committee by further developing their work on specific priority aspects of regional development;

h) make available the outcome of its work to interested non-member countries.

2. In pursuit of these objectives, the Territorial Development Policy Committee, and its Working Parties, shall maintain close working relationships with other relevant bodies of the Organisation, in particular the Public Governance Committee and its subsidiary bodies, seeking to ensure complementarity and co-operation between levels of government.

3. The Territorial Development Policy Committee shall maintain, as appropriate, and in conformity with the OECD Convention and Rules of Procedure, relations with other international organisations.

4. The terms of reference of the Territorial Development Policy Committee shall enter into force on 1 January 2005 and shall expire on 31 December 2009, unless the Council decides otherwise.

5. Paragraph 29 of the Annex to the Rules of Procedure of the Organisation shall be amended as follows: Territorial Development Policy Committee: its terms of reference are defined in the Resolution of the Council C(2004)114 and C(2004)114/CORR1." 


\section{WORKING PARTY ON TERRITORIAL POLICY IN URBAN AREAS}

Chair:

Vice-Chairs:

Members:

Observer:

Date of creation:

Duration:
Mr. Takayuki Hara

Mr. Adam Ostry

Mr. Vincent Fouchier

Ms. Brigitte Helff

Mr. José Manuel Rodriguez

Alvarez

Open to all Member countries

Mr. Mohamed Souafi

20th January 1999

31st December 2009
(Japan)

(Canada)

(France)

(Germany)

(Spain)

(Morocco)

Mandate: Decision of the Territorial Development Policy Committee [DT/TDPC(99)23]

Renewal of the Working Party's Mandate by the Territorial Development Policy

Committee during its 6th Session on 22, 23 January 2002 [DT/TDPC/M(2002)1]

Working Party on Territorial Policy in Urban Areas [DT/TDPC(99)23]

The Territorial Development Policy Committee,

Having regard to Articles 1, 2, 5a) and 12 of the Convention on the Organisation for Economic Co-operation and Development of 14th December 1960;

Having regard to the resolution of the Council creating the Territorial Development Policy Committee and granting it the responsibility to "make ... special arrangements, including the establishment of Working Parties, as may be necessary to capitalise on and further develop work on specific, priority aspects of territorial development, such as urban affairs, ..." [C(98)198/FIN];

Having regard to the Rules of Procedure of the Organisation;

Taking account of the importance of urban issues in territorial development policies;

Noting that since 1979, the OECD programme of work on urban affairs has provided analysis and policy guidance on issues of pressing concern to Member countries such as distressed urban areas, urban governance, urban environmental policy and urban economic development;

Recognising that policies to improve the quality of life, social cohesion, and economic opportunities in cities are an important element in national strategies for territorial development, that the benefits and costs associated with urban growth often have regional and even national consequences, and that urban policy is an effective means of achieving the integration of economic, social and environmental issues;

Taking account that better urban policies are a response to the medium-term objective of the Secretary-General, to advise "Member governments on ways to maximise the benefits of economic development, whether local, national or global, and at the same time, to ensure that economic growth is consistent with sustainability as a global objective"; 
Noting that new challenges for cities are emerging in relation to economic activity and investment, social change, public finance and services, environmental conditions and technological innovation for which existing policies may be inadequate, and that institutional changes are often needed to enhance the capacity of urban governments, in partnership with civil society and the private sector, to respond more effectively to urban problems;

Observing that there is a growing trend for countries to consult with each other on urban trends and on policies at the national, regional and local level to guide urban development; that Member countries are working toward similar objectives for urban policy; and that successful urban policies in Member countries may be an example elsewhere in the world, where urbanisation remains a potent force for change and development;

And in light of the priorities of the TDPC for national and regional reviews, which may focus on urban policy and urban regions, and for horizontal studies of territorial policy and prospects, which can benefit from analyses with an urban dimension;

\section{DECIDES:}

1 concerning:

The Working Party on Territorial Policy in Urban Areas shall report to the TDPC

a) The nature, scale and complexity of economic, social and environmental challenges which urban regions in OECD countries are facing, and potential sources of longterm development;

b) Ways to improve the monitoring of changes and trends in urban areas, and to achieve the sustainable development of urban regions in OECD countries through a cross-sectoral, integrating approach;

c) The interaction between urban municipalities and other levels of government, and between cities and other sub-national, territorial units, stressing in particular urban/rural links.

d) The results of national and regional territorial reviews with a focus on urban regions, in particular by using internationally comparable indicators, identifying best practices among Member countries and suggesting the means to co-ordinate sectoral and territorial approaches in these regions.

2. The Working Party shall initially concentrate on a study of better management of urban growth, including follow-up on earlier work on regeneration of urban brownfields and on urban housing, and new work on urban sprawl and infrastructure, with a focus on coherent policies and effective policy instruments for landuse and spatial planning. The Working Party shall also contribute to prospective studies with a focus on the policy implications of trends that could affect the competitiveness and sustainability of cities in the medium term. Issues of governance are to be integrated to these topics.

3.

In the pursuit of these objectives, the Working Party on Territorial Policy in Urban Areas shall work with the Territorial Development Policy Committee (TDPC), the other TDPC working parties and other competent bodies in the Organisation. This will permit OECD to harness all its capabilities for the comprehensive study of priority urban development issues and to ensure that the Organisation's overall work programme on territorial development proceeds in a coordinated manner.

4. The Working Party shall maintain, as appropriate, and in conformity with the OECD Convention and Rules of Procedure, relations with other international organisations and shall carry out its tasks taking fully into account the work of these organisations. 
5. The duration of the Working Party's mandate is concurrent with that of the Territorial Development Policy Committee. 


\section{WORKING PARTY ON TERRITORIAL POLICY IN RURAL AREAS}

Chair:

Vice-Chairs:

Members:

Date of creation:

Duration:
Ms. Margaret Clark

Mr. Yukiya Saika

Mr. Sergio Soto Priante

Mr. Lutfi Elvan

Mr. Mark Drabenstott
(United Kingdom)

(Japan)

(Mexico)

(Turkey)

(United States)

Open to all Member countries

20th January 1999

31st December 2009

Mandate: Decision of the Territorial Development Policy Committee [DT/TDPC(99)22]

Renewal of the Working Party's Mandate by the Territorial Development Policy

Committee during its 6th Session on 22, 23 January 2002

[DT/TDPC/M(2002)1]

\section{The Working Party on Territorial Policy in Rural Areas [DT/TDPC(99)22]}

The Territorial Development Policy Committee,

Having regard to Articles 1, 2, 5a) and 12 of the Convention on the Organisation for Economic Co-operation and Development of 14 December 1960;

Having regard to the resolution of the Council creating the Territorial Development Policy Committee and granting it the responsibility to "Make such special arrangements, including the establishment of Working Parties, as may be necessary to capitalise on and further develop work on specific, priority aspects of territorial development, such as ... rural development, ..." [C(98)198/FINAL];

Having regard to the Rules of Procedure of the Organisation;

Taking account of the importance of rural issues in territorial development policies;

Noting that since 1991, the OECD Rural Development Programme has provided analysis and policy guidance on important issues such as rural amenities, partnerships for rural development, employment creation and services in rural areas, rural governance and the generation of appropriate data and internationally comparable statistics;

Recognising that dynamic rural development policies improve national and rural well-being by facilitating structural reform in the various sectors and by diversifying the economic base of rural areas and that rural policies are an effective means of achieving integrated solutions to economic, social and environmental problems, e.g., through appropriate valorisation of resources in rural areas and promotion of their recreational, ecological and cultural heritage;

Noting that new challenges for rural areas are emerging in relation to agriculture restructuring, development of services and new activities, social change, environmental conditions and technological innovations for which existing policies may be inadequate and that institutional changes are often needed to facilitate co-ordination between several ministries at the national level, as well as the participation of both local and regional authorities and the private sector; 
Observing that there is a growing trend for countries to consult with each other on rural trends and on policies at national, regional and local level to guide rural development and that the OECD Member countries will greatly benefit from analysis of rural conditions and changes in the economic and social structure of rural areas, carried out in a multinational framework and based on comparable information, both quantitative and qualitative;

Recognising that the activities carried out within this framework are horizontal in nature and involve close co-operation with different committees within the Organisation;

And in light of the priorities of the TDPC for national and regional reviews, which may focus on rural policy and rural regions, and for horizontal studies of territorial policies and prospects, which can benefit from analyses with a rural dimension;

\section{DECIDES:}

1. The Working Party on Territorial Policy in Rural Areas shall report to the TDPC concerning:

a) The nature, scale and complexity of economic, social and environmental challenges which rural regions in OECD countries are facing, and potential sources of long term development;

b) Ways to improve the monitoring of changes and trends in rural regions and to achieve the sustainable development of rural regions through a cross-sectoral, integrated approach;

c) Selected aspects of rural developments such as rural amenities, multisectoral initiatives, new forms of partnerships and governance and the interrelation of urban and rural development;

d) The results of national and regional territorial reviews with a focus on rural regions, in particular by using internationally comparable indicators, identifying best practices among Member countries and suggesting the means to co-ordinate sectoral and territorial approaches in these areas;

2 . The Working Party on Territorial Policy in Rural Areas shall concentrate on growth factors in rural regions, how rural areas contribute to the growth of the economy as a whole and on policy recommendations on the basis of reviews of several rural regions. The impact of information technologies on rural development will also be reviewed. Follow-up of the work on rural amenities will include the preparation of a conference on valuation/evaluation of methods for pricing such amenities. The Working Party shall also contribute to prospective studies with a focus on the policy implications of trends that could affect the competitiveness and sustainability of rural regions in the medium term.

3.

In the pursuit of these objectives, the Working Party on Territorial Policy in Rural Areas shall work with the Territorial Development Policy Committee (TDPC), the other TDPC working parties and other competent bodies in the Organisation. This will permit OECD to harness all its capabilities for the comprehensive study of priority rural development issues and to ensure that the Organisation's overall work programme on territorial development proceeds in a co-ordinated manner.

4. The Working Party on Territorial Policy in Rural Areas shall maintain, as appropriate and in conformity with the OECD Conventions and Rules of Procedure, relations with other international organisations and shall carry out its task with all due regard to the work of these organisations. 
5.

The duration of the Working Party's mandate is concurrent with that of the Territorial Development Policy Committee. 


\section{WORKING PARTY ON TERRITORIAL INDICATORS}

Chair:

Vice-Chairs:

Members:

Date of creation:

Duration:
Mr. Ray Bollman

Mr. Giovanni Barbieri

Mr. Ray Bollman

Ms. Eleonore Irmen

Mr. Bernard Morel

Mr. Prodromos-loannis (John)

Prodromidis

Mr. Martin Schuler

Open to all Member countries

20th January 1999

31st December 2009
(Canada)

(Italy)

(Canada)

(Germany)

(France)

(Greece)

(Switzerland)

Mandate: Decision of the Territorial Development Policy Committee [DT/TDPC(99)24]

Renewal of the Working Party's Mandate by the Territorial Development

Policy Committee during its 6th Session on 22, 23 January 2002

[DT/TDPC/M(2002)1]

\section{The Working Party on Territorial Indicators [DT/TDPC(99)24]}

The Territorial Development Policy Committee,

Having regard to Articles 1, 2, 5a) and 12 of the Convention on the Organisation for Economic Co-operation and Development of 14 December 1960;

Having regard to the resolution of the Council creating the Territorial Development Policy Committee and granting it the responsibility to "make ... special arrangements, including the establishment of Working Parties, as may be necessary to capitalise on and further develop work on specific, priority aspects of territorial development, such as ...territorial indicators and data bases; ..." [C(98)198/FINAL];

Having regard to the Rules of Procedure of the Organisation;

Considering that quantitative information on territorial differences across OECD Member countries is indispensable for facilitating international communication, comparison and co-operation with respect to sustainable development conditions and trends;

Emphasising that territorial statistics and indicators can help to better understand national and sub-national patterns and dynamics of structural change and adjustment in economic competitiveness and innovation, in social cohesion and convergence, in environmental quality and amenity;

Emphasising the contribution of territorial statistics and indicators to integrative, cross-sectoral policies that balance economic, social and environmental concerns and have the potential to reduce disparities; 
Recognising that sub-national territorial statistics and indicators can improve OECD's analytical capacities in general, facilitate analyses on territorial development problems, perspectives and policies in particular and aid in the development and application of indicators to target and evaluate policies;

\section{DECIDES:}

1. tasks:

The Working Party on Territorial Indicators shall report to the TDPC on the following

a) Establishing a statistical information base using existing information where possible and providing quantitative information on sub-national development conditions and trends that can be interpreted in a multi-national context, supporting, in particular, the analytical work of the Territorial Development Policy Committee (TDPC) and its working parties;

b) Developing a suitable territorial data base covering relevant demographic, economic, social, institutional and environmental topics, as well as developing and refining methods of territorial data collection, processing and presentation;

c) Selecting and interpreting sets of territorial indicators, both basic, multi-purpose, revealing the diversity and disparities of territorial development in general as well as specific policy related indicators, for different types of territory, such as rural and urban areas, leading or lagging regions, etc.;

d) Contributing to the indicator work of other OECD directorates, task forces and international organisations as well as national, regional and local initiatives in OECD Member countries and abroad by offering conceptual frameworks, or by providing territorial data and indicators for spatially dis-aggregated quantitative analyses.

2. In the pursuit of these objectives, the Working Party on Territorial Indicators shall work with the Territorial Development Policy Committee (TDPC), the other TDPC working parties and other competent bodies in the Organisation. This will permit OECD to harness all its capabilities for the comprehensive study of key territorial development issues and to ensure that the Organisation's overall work programme on territorial development proceeds in a co-ordinated manner.

3. The Working Party on Territorial Indicators shall maintain, as needed and in accordance with the OECD Conventions and Rules of Procedure, relations with other international organisations and perform its task with all due regard to the work of these organisations.

4. The duration of the Working Party's mandate is concurrent with that of the Territorial Development Policy Committee. 

TR A D E 



\section{TRADE COMMITTEE}

\section{Co-Chairs:}

Vice-Chairs:

Members:

Observers:

\author{
Mr. Crawford Falconer \\ Mr. Yoichi Suzuki
}

Mrs. Laurence Dubois-Destrizais

Mr. Richard Van Rijssen

Mr. Henk Jan Bakker

Ex officio as Chairman of the Working Party of the Trade Committee

(New Zealand)

(Japan)

(France)

(Netherlands)

(Netherlands)
Open to all Member countries

Argentina
Brazil
Chile
Hong Kong, China
Singapore

European Free Trade Association (EFTA)
International Monetary Fund (IMF)
World Bank
World Trade Organization (WTO)

30th September 1961

31st December 2008

Duration:

Mandate: - Resolution of the Council concerning the revision of the mandate of the Trade Committee [C(2006)6] approved at its $1128^{\text {th }}$ session on 26 January 2006

[C/M(2006)2, item 16]

\section{Resolution of the Council [C(2006)6]}

THE COUNCIL,

Having regard to Articles 1 and 2 of the Convention on the Organisation for Economic Co operation and Development;

Having regard to the Ministerial Resolution of 23rd July 1960 [OECD(60)9(Final)] and to Paragraph 16 of the Report by the Preparatory Committee concerning the creation of a Trade Committee;

Having regard to the Rules of Procedure of the Organisation; development

Considering that international trade is essential for growth and sustainable economic

Considering that the mission of the Trade Committee is to provide a forum for international co operation, dialogue and policy analysis in order to help countries benefit fully from trading opportunities and adjust to changing trade patterns, as encompassed in Article 1 of the OECD Convention;

\section{DECIDES:}

1. The Trade Committee shall have the following responsibilities: 
a) Encourage frank and open dialogue among OECD Members and undertake and disseminate rigorous, objective trade policy analysis, in order to:

- increase understanding of evolving trade policy issues, including on controversial subjects;

- build support for liberalised trade within a strengthened multilateral, rules-based trading system;

- help facilitate ongoing and future trade negotiations in the World Trade Organisation (WTO);

- facilitate the promotion of coherence between trade policy and other related domestic and international policies.

b) Support the work on establishing common guiding principles and exchange of information in respect of Members' official export credit systems.

c) Collaborate closely with other relevant bodies of the OECD on cross-cutting issues related to trade.

d) Engage invited non-Members in the analytical work and policy dialogue of the Committee as appropriate.

e) As appropriate, consult and share information with the advisory bodies to the OECD, BIAC and TUAC, as well as civil society organisations and academia.

f) Co-operate with other international organisations on issues of mutual interest.

2. These terms of reference shall remain in force until 31 December 2008, unless the Council decides otherwise.

3. Paragraph 5 of the Annex to the Rules of Procedure of the Organisation shall be amended as follows: "Trade Committee: its terms of reference are defined in the Resolution of the Council C(2006)6". 


\section{WORKING PARTY OF THE TRADE COMMITTEE}

Chair:

Vice-Chairs:

Members:

Observers:
Mr. Henk Jan Bakker

Mr. Stuart Carre

Ms. Maria Francesca Spatolisano

Mrs. Helen Recinos

Mr. Tim Crowe

Open to all Member countries

\author{
Argentina \\ Brazil \\ Chile \\ Hong Kong, China \\ Singapore \\ World Bank \\ International Monetary Fund (IMF)
}

February 1962

31st December 2008
(Netherlands)

(Canada)

(European Commission)

(United States)

(Australia)

Date of creation:

Duration:

Mandate: Paragraph 5 of TD/TC/M(2005)2/PROV concerning the revision of the mandate of the Working Party of the Trade Committee approved at its $142^{\text {nd }}$ Session on 25 October 2005

\section{Extract of document TD/TC(2005)6}

\section{“THE TRADE COMMITTEE,}

AGREED that its Working Party, which is composed of the Permanent Delegates to the $\mathrm{OECD}$, assisted by such other persons as they may require, shall have the following terms of reference:

a) The Working Party should carry forward the work of the Trade Committee, between the latter's sessions, taking as guidance the discussions and conclusions of the Trade Committee;

b) The Working Party should engage invited non-Members in the analytical work and policy dialogue of the Committee as appropriate;

c) The Working Party may, as appropriate, appoint special groups to deal with particular questions;

d) Should the Working Party consider that there is urgent need to submit a report to the Council and should it not be possible to convene the Trade Committee at short notice, the report shall be issued as a report of the Trade Committee, once the individual members of the Working Party have obtained its approval by the representative of their respective countries in the Trade Committee; 
e) The terms of reference of the Working Party shall remain in force until 31 December 2008, unless the Trade Committee decides otherwise." 


\section{WORKING PARTY ON EXPORT CREDITS AND CREDIT GUARANTEES}

$\begin{array}{lll}\text { Chair: }^{1} & \text { Mrs. Nicole Bollen } & \text { (Netherlands) } \\ \text { Vice-Chairs: } & \text { Mr. Pekka Karkovirta } & \text { (Finland) } \\ & \text { Mr. Hye Min Lee } & \text { (Korea) } \\ \text { Bureau Members: } & \text { Mr. Dirk Terweduwe } & \text { (Belgium) } \\ & \text { Mr. Detlev Malzkuhn } & \text { (Germany) } \\ \text { Members: } & \text { Australia } & \text { Luxembourg } \\ & \text { Austria } & \text { Mexico } \\ & \text { Belgium } & \text { Netherlands } \\ & \text { Canada } & \text { New Zealand } \\ & \text { Czech Republic } & \text { Norway } \\ & \text { Denmark } & \text { Poland } \\ & \text { Finland } & \text { Portugal } \\ & \text { France } & \text { Slovak Republic } \\ & \text { Germany } & \text { Spain } \\ & \text { Greece } & \text { Sweden } \\ & \text { Hungary } & \text { Switzerland } \\ & \text { Ireland } & \text { Turkey } \\ & \text { Italy } & \text { United Kingdom } \\ & \text { Japan } & \text { United States } \\ & \text { Korea } & \\ & \text { World Trade Organization (WTO) } & \\ \text { Observer: } & \text { 5th November 1963 } & \\ \text { Date of creation: } & \text { December 2008 } & \\ \text { Duration: } & & \end{array}$
Mandate: - Report by the Special Meeting of the Trade Committee on Export Credits and Credit Guarantees [C(63)141, Annex]
- Minutes of the 56th Meeting of the Council on 10th December 1963 [C/M(63)22(Final), Annex, Item 225]

Annex to document $[\mathrm{C}(63) 141]$

\section{ESTABLISHMENT OF A GROUP ON EXPORT CREDITS AND CREDIT GUARANTEES}

\section{Draft terms of reference}

"1. At its meeting on 5th and 6th November 1963, the Trade Committee considered the report of the special meeting on export credits and credit guarantees held on 23rd and 24th October 1963 [TC(63)42] and decided to set up a Group on Export Credits and Credit Guarantees, made up of senior government officials with a major responsibility in the formulation of policies in this field,

\footnotetext{
1 The 2006 Bureau elections will take place in April 2006.
} 
accompanied by senior officials of the export credit and credit insurance institutions. The composition of the Group shall be as defined in paragraph 10 of the report. ${ }^{1}$

2. The group on Export Credits and Credit Guarantees is charged with carrying forward the work of the OECD in this field. In particular, it is responsible for holding regular confrontations on the policies pursued by the Governments of Member countries, in the field of export credits and credit guarantees, with the general objectives of:

- Evaluating these policies;

- Determining the problems which arise;

- $\quad$ Resolving or mitigating these problems by multilateral discussion.

Further objectives of the Group should be to aim, on the basis of experience acquired from the confrontations, at:

- Working out common guiding principles;

- Considering all possibilities of improving co-operation between Member countries in this field by such means as prior consultation, prior notification and/or a question-and-answer procedure or by other suitable means.

Account should be taken of the competence of the Development Assistance Committee in the field of development aid, including the undertakings reached in that Committee, and appropriate liaison should be established between the work arising from the confrontations envisaged and the work of the DAC.

3. As recommended in paragraph 4 of the report of the special meeting [TC(63)42], these confrontations should be concentrated, at least at the outset, on transactions exceeding five years' duration. The Group is requested to make all necessary arrangements for the provision of the information required, as outlined in paragraphs 5-7 of the report. It shall review this information system and make whatever improvements may be necessary, as recommended by the special meeting.

4. The Group shall have full latitude and discretion to pursue its work, to elect its officers, to establish the form of liaison it considers necessary with the DAC or other bodies of the Organisation, and to determine the frequency and manner of its reporting. In particular, it shall take whatever measures it considers desirable, in consultation with the Chairman of the Development Assistance Committee and the Secretariat, to ensure adequate co-ordination of its work with that of the Development Assistance Committee. When the reports of the Group call for action by the Organisation as such, they shall be forwarded in toto to the Council, with any comments the Trade Committee may wish to make.

\section{Extract from document $[\mathrm{C} / \mathrm{M}(63) 22$ (Final), Annex, Item 225]}

\section{"THE COUNCIL}

\footnotetext{
1 Para. 10 of TC(63)42 states: "10. The Group on Export Credits and Credit Guarantees should be composed of representatives of countries which have in existence facilities for financing or guaranteeing export credits which are controlled or assisted, directly or indirectly, by governmental or para-governmental bodies. These countries are as follows: Austria, Belgium, Canada, Denmark, France, Germany, Ireland, Italy, Netherlands, Norway, Portugal, Spain, Sweden, Switzerland, United Kingdom, United States. Furthermore, representatives of the Commission of the European Economic Community may attend the meetings of the Group. In addition, Japan should be invited to join the Group on Export Credits and Credit Guarantees at the moment her accession to the OECD becomes effective..."
} 
(225)

a) noted that the Trade Committee had set up a Group on Export Credits and Credit Guarantees, whose draft terms of reference were set out in the Annex to [C(63)141];

b) agreed that Japan should be invited to participate in the Group's work;

c) noted the statement by the Delegate for Greece to the effect that his country would wish to be represented in the Group when it introduced the facilities referred to it in paragraph 10 of [C(63)141]." 


\section{JOINT WORKING PARTY ON AGRICULTURE AND TRADE}

$\begin{array}{lll}\text { Chair: } & \text { Mr. Craig Burns } & \text { (Australia) } \\ \text { Vice-Chair: } & \text { Ms. Cornelia Berns } & \text { (Germany) } \\ \text { Members: } & \text { Open to all Member countries } \\ \text { Observers: } & \begin{array}{l}\text { Argentina } \\ \text { Brazil } \\ \text { Chile }\end{array} \\ & \text { World Trade Organization (WTO) } \\ \text { Date of creation: } & \text { 6th June 1962 } \\ \text { Duration: } & \text { 31st December } 2008\end{array}$

Mandate: Joint Working Party on Agriculture and Trade Terms of Reference [AGR/CA/M(2000)1] and [TD/TC/M(2000)1]

\section{Extract from document [COM/AGR/CA/TD/TC(2000)7/REV1]}

“6. $\quad$...The 1998 Ministerial Mandate defines the overall context of the policy dimensions related to trade and agriculture. The programmes of work to be derived from the new mandate for the JWP will be fully consistent with the 1998 Ministerial Mandate.

7. Against this background, it is proposed to define the mandate in a short and relatively open and general manner, while reflecting ongoing and planned work, in particular the work programme defined by the Agriculture and Trade Committees for 1999/2000 and that under discussion for $2001 / 2002$. It is also proposed to simplify and shorten its name to The Joint Working Party on Agriculture and Trade. The mandate would read as follows:

"The Joint Working Party on Agriculture and Trade is to provide analytical support to the process of agricultural trade liberalisation by

1. analysing actual and projected effects of agricultural trade liberalisation;

2. examining ongoing and new agricultural trade and trans-boundary policy issues and their impacts;

3. examining the trade effects of agricultural support policies and regulatory frameworks;

4. analysing the characteristics of effective policies that are minimally trade distorting.

It is proposed that the life of the JWP is open-ended, but with review of the mandate at five-year intervals." "

\footnotetext{
1 The election of the 2006 Bureau will take place in May 2006.
} 


\section{JOINT GROUP ON TRADE AND COMPETITION}

Co-Chairs: ${ }^{1}$

Vice-Chairs:

Members:

Observers:
Mr. Stefan Amarasinha

Mr. David Smith

Mr. Domenico Da Empoli

Ms. Monica Widegren

...

$\cdots$

Mr. Frédéric Jenny
(European Commission)

(Australia)

(Italy)

(Sweden)

(...)

(...)

(France)

Open to all Member countries

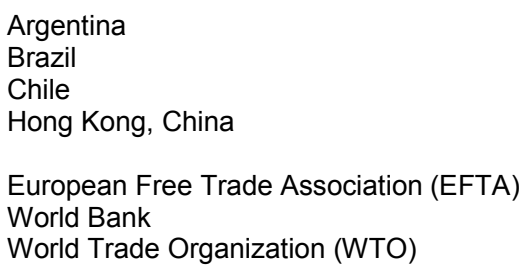

Date of creation:

May 1996

Duration:

May 2006

Mandate: Terms of Reference for the Joint Group on Trade and Competition based on documents [COM/DAFFE/CLP/TD(96)50/REV2, COM/DAFFE/CLP/TD(96)102, COM/DAFFE/CLP/TD(2000)6, COM/DAFFE/COMP/TD/M(2002)43 and COM/DAFFE/TD(2004)6]

\section{Extract from document [COM/DAFFE/CLP/TD(2000)6]}

will:

"In order to strengthen the coherence of trade and competition policies the Joint Group

a) Take stock of analysis undertaken so far;

b) Deepen that work in accordance with the terms of the programme of work adopted for the Joint Group.

This programme of work will include: (i) competition policies related to market access such as scope and coverage, and actual enforcement of competition laws; (ii) international options to improve coherence of trade and competition policies; (iii) the effects on competition of trade measures and policies; and (iv) the effects of regulation on market access and the competitive process.

In order to make best use of resources, this Joint Group will assume responsibility for the pursuit of trade and competition work for the duration of its mandate, and will report progress as

\footnotetext{
1 Bureau elections for 2006 will take place once the mandate is renewed.
} 
appropriate to OECD Ministerial meetings. The Joint Group shall operate until the 2002 OECD Ministerial. Renewal of its terms of reference beyond that point will require agreement between the Committee on Competition Law and Policy and the Trade Committee." 


\section{JOINT WORKING PARTY ON TRADE AND ENVIRONMENT}

Co-Chairs: ${ }^{1}$

Vice-Chairs:

Members:

Observers:

Date of creation:

Duration:
Ms. Harriet Lapidaire-Van Ree

$\cdots$

Mr. Jérôme Catimel

Mrs. Nicole Dispa

Mrs. Jennifer Prescott

$\cdots$

Open to all Member countries

Brazil

Hong Kong, China

European Free Trade Association (EFTA)

International Monetary Fund (IMF)

North American Commission for Environment Co-operation

(NACEC)

U.N. Conference on Trade and Development (UNCTAD)

U.N. Environment Programme (UNEP)

World Trade Organization (WTO)

1st April 1991

31st December 2008
(Netherlands)

(...)

(Canada)

(France)

(United States)

(...)

Mandate: Terms of Reference for Future Work of Joint Session of Trade and Environment Experts [COM/ENV/TD/A(95)75], Report on work undertaken since 1995

[COM/ENV/TD(97)47], Report on Trade and Environment to the Council meeting at Ministerial Level on 26-27 May 1999 [C/MIN(99)14]

\section{Extract of document [COM/ENV/TD/A(95)75, Annex]}

“...

The Joint Session should:

- focus on analytical work, including empirical studies of selected policy areas and economic sectors, aimed at promoting the mutual compatibility of trade and environment policies in practice, in order to contribute to sustainable development, while building on its work to date;

- focus on those areas where it has the greatest value-added while supporting the activities of other OECD bodies and international organisations, and avoiding duplication;

- co-operate and liaise with other relevant OECD bodies, and with relevant international organisations including the WTO, UNEP, UNCTAD, ISO, and the Commission on Sustainable Development;

\footnotetext{
1 The election of the 2006 Bureau will take place in June 2006.
} 
- consult with Partners in transition, Dynamic non Member economies and developing countries, and provide them with expertise as appropriate;

- consult regularly as appropriate with both industry and environmental NGOs on environment and trade related matters;

- advise and report to the parent Committees on new and emerging problems and major issues with respect to trade-environment relationships;

- assist the parent Committees in ensuring the coherence and consistency of the trade and environment related work being carried out in the various bodies of the OECD; and

- achieve the above while meeting twice a year at expert level and once more at higher level, as appropriate." 
FINANCIALAND ENTERPRISE AFFAIRS 



\section{IN VESTMENT COMMITTEE}

\begin{tabular}{|c|c|c|}
\hline Chairs: & Mr. Manfred Schekulin & (Austria) \\
\hline Vice-Chairs: & $\begin{array}{l}\text { Mr. Vernon MacKay } \\
\text { Mr. Wesley Scholz }\end{array}$ & $\begin{array}{l}\text { (Canada) } \\
\text { (United States) }\end{array}$ \\
\hline Members: & \multicolumn{2}{|c|}{ Open to all Member countries } \\
\hline Observers: & \multicolumn{2}{|l|}{$\begin{array}{l}\text { Argentina } \\
\text { Brazil } \\
\text { Chile }\end{array}$} \\
\hline & \multicolumn{2}{|c|}{$\begin{array}{l}\text { International Monetary Fund (IMF) } \\
\text { U.N. Conference on Trade and Development (UNCTAD) } \\
\text { World Bank } \\
\text { World Trade Organization (WTO) }\end{array}$} \\
\hline Date of creation: & \multicolumn{2}{|l|}{ 1st March 2004} \\
\hline Duration: & \multicolumn{2}{|l|}{ 31st December 2008} \\
\hline
\end{tabular}

Mandate: - Resolution of the Council on the Terms of Reference of the Investment Committee [C(2004)3 and CORR1 and C/M(2004)3, item 40, ii)] entered into force on 22 April 2004 [C/M(2004)10, Item 143, IV, c)].

\section{$\underline{\text { Resolution of the Council [C(2004)3 and CORR1] }}$}

THE COUNCIL

Having regard to the Convention on the Organisation for Economic Co-operation and Development of 14th December 1960 and, in particular, articles 1, 3, 5a) and 9 thereof;

iii);

Having regard to the Rules of Procedure of the Organisation and in particular Rule $18 \mathrm{a}$ )

Having regard to the Financial Rules of the Organisation;

Having regard to the Council's conclusions of 25 July 2002 on the Structures of Committees and Multidisciplinarity: Recommendations [C/M(2002)17].

Having regard to the recommendation contained in document C(2003)176/REV1, Implementation of the Nicholson Report Recommendations to create a committee from the merger of the Committee on Capital Movements and Invisible Transactions and the Committee on International Investment and Multinational Enterprises;

Having regard to document $\mathrm{C}(2004) 3$ on the merger of the Committee on Capital Movements and Invisible Transactions and the Committee on International Investment and Multinational Enterprises;

On the proposal of the Secretary-General;

DECIDES:

\section{Article 1}


The Committee on Capital Movements and Invisible Transactions and the Committee on International Investment and Multinational Enterprises are abolished.

\section{Article 2}

An Investment Committee (hereafter the Committee) is hereby established.

\section{Article 3}

In carrying out its responsibilities, the Committee shall:

1. Have the task of further developing and strengthening co-operation among Member countries and with non-members in the fields of international investment and multinational enterprises, capital movements and international financial and other services.

2. Serve as a policy forum to examine issues in these fields and their role in globalisation and sustainable development, and to encourage best practices.

3. Carry out the tasks assigned to it by virtue of the OECD Declaration on International Investment and Multinational Enterprises and related Council Decisions and of the OECD Codes of Liberalisation of Capital Movements and of Current Invisible Operations, as amended by this Council Decision C(2004)3, and shall carry out such other tasks as the Council may assign to it.

4. Promote dialogue with the business community, labour representatives and nongovernmental organisations.

5. Engage in and support activities with non-member economies to strengthen cooperation and best practices, in co-operation with other international organisations.

6. Be responsible for monitoring and promoting co-ordination of all work carried out within the Organisation in the field of international investment and multinational enterprises, and for presenting proposals for this purpose to the Council or to other committees.

\section{Article 4}

1. The reference in any existing OECD instrument to the "Committee on Capital Movements and Invisible Transactions" or "Committee on International Investment and Multinational Enterprises" shall be read as a reference to the "Investment Committee".

2. Article 18 of Decision C(61)95, as amended, relating to the Code of Liberalisation of Current Invisible Operations is repealed and all subsequent articles are renumbered accordingly.

\section{Article 5}

The Annex to the Rules of Procedure of the Organisation shall be amended as follows:

- Entries 8 and 24 are deleted.

- A new entry shall be added which shall read "Investment Committee, its terms of reference are defined in the Decision of the Council C(2004)3 and CORR1."

\section{Article 6}

The Decision shall come into force on 1 March 2004. The terms of reference of the Investment Committee as defined in Article 3 of the present Decision shall be reviewed at the latest before 31 December 2008, unless the Council decides otherwise. 


\section{WORKING GROUP ON BRIBERY IN INTERNATIONAL BUSINESS TRANSACTIONS}

Chair:

Mr. Mark Pieth

(Switzerland)

Vice-Chair:

Mrs. Maria Gavouneli

(Greece)

Members:

Non-Member Participants: ${ }^{1}$
Open to all Member countries

\section{Argentina \\ Brazil \\ Bulgaria \\ Chile \\ Estonia \\ Slovenia}

Observers:

Council of Europe International Monetary Fund (IMF)

Organization of American States (OAS)

U.N. Office on Drugs and Crime (UNODC)

World Bank

World Trade Organization (WTO)

Date of creation:

5th October 1994

Duration:

31st December 2008

Mandate: - Minutes of the meeting held 5 October 1994 of the IME Committee [IME/M(94)2/ANN]

- Revised Recommendation on Combating Bribery in International Business Transaction [C(97)123/FINAL]

- Decision of the Council concerning further work on Combating Bribery in International Business Transactions [C(97)240/FINAL]

The Committee on International Investment and Multinational Enterprises, as a follow-up to the Recommendation on Bribery in International Business Transactions adopted by the Council in May 1994, established the Working Group on Bribery in International Business Transactions. Recommendation.

The mandate of the Working Group was amended by the 1997 Revised

\section{Extract from the Revised Recommendation [C(97)123/FINAL]}

\section{"Follow-up and institutional arrangements}

VIII. INSTRUCTS the Committee on International Investment and Multinational Enterprises, through its Working Group on Bribery in International Business Transactions, to carry out a programme of systematic follow-up to monitor and promote the full implementation of this Recommendation, in co-operation with the Committee for Fiscal Affairs, the Development

\footnotetext{
1 Full participants, on a basis of equality with Member countries.
} 
Assistance Committee and other OECD bodies, as appropriate. This follow-up will include, in particular:

i) receipt of notifications and other information submitted to it by the Member countries;

ii) regular reviews of steps taken by Member countries to implement the Recommendation and to make proposals, as appropriate, to assist Member countries in its implementation; these reviews will be based on the following complementary systems:

- a system of self-evaluation, where Member countries' responses on the basis of a questionnaire will provide a basis for assessing the implementation of the Recommendation;

- a system of mutual evaluation, where each Member country will be examined in turn by the Working Group on Bribery, on the basis of a report which will provide an objective assessment of the progress of the Member country in implementing the Recommendation.

iii) examination of specific issues relating to bribery in international business transactions;

iv) examination of the feasibility of broadening the scope of the work of the OECD to combat international bribery to include private sector bribery and bribery of foreign officials for reasons other than to obtain or retain business;

v) provision of regular information to the public on its work and activities and on implementation of the Recommendation.

$\mathrm{X}$.

INSTRUCTS the Committee on International Investment and Multinational Enterprises to review the implementation of Sections III and, in co-operation with the Committee on Fiscal Affairs, Section IV of this Recommendation and report to Ministers in Spring 1998, to report to the Council after the first regular review and as appropriate there after, and to review this Revised Recommendation within three years after its adoption.

\section{Co-operation with non members}

XII. INSTRUCTS the Committee on International Investment and Multinational Enterprises through its Working Group on Bribery, to provide a forum for consultations with countries which have not yet adhered, in order to promote wider participation in the Recommendation and its followup.

\section{Relations with international governmental and non-governmental organisations}

XIII. INVITES the Committee on International Investment and Multinational Enterprises through its Working Group on Bribery, to consult and co-operate with the international organisations and international financial institutions active in the combat against bribery in international business transactions and consult regularly with the non-governmental organisations and representatives of the business community active in this field."

Decision of the Council Concerning Further Work on Combatting Bribery in International Business Transactions [C(97)240/FINAL]

THE COUNCIL, 
Having regard to Article 5 a) of the Convention on the Organisation for Economic Cooperation and Development of 14 December 1960;

Considering the Revised Recommendation of the Council on Combating Bribery in International Business Transactions adopted on 23 May 1997 [C(97)123/FINAL];

Noting the existing mandate of the Committee on International Investment and Multinational Enterprises, through its Working Group on Bribery in International Business Transactions, pursuant to Section VIII of the Revised Recommendation, "to carry out a programme of systematic follow-up to monitor and promote the full implementation of the Revised Recommendation, in co-operation with the Committee for Fiscal Affairs, the Development Assistance Committee and other OECD bodies, as appropriate", including "examination of specific issues relating to bribery in international business transactions";

Noting in particular that there will be an examination of the feasibility of broadening the scope of the work of the OECD to include private sector corruption in international business transactions;

Noting the view of the Negotiating Conference on a Convention on Combating Bribery of Foreign Public Officials in International Business Transactions, that further work was needed on a number of related corruption issues;

DECIDES that the Committee on International Investment and Multinational Enterprises, through its Working Group on Bribery in International Business Transactions, in the context of its work pursuant to the 1997 Revised Recommendation as well as, where appropriate, the monitoring and follow-up which will be carried out under article 12 of the Convention, and in co-operation with other OECD bodies and international organisations, shall examine on a priority basis the following issues with a view to reporting conclusions to the 1999 OECD Council meeting at Ministerial level:

- bribery acts in relation with foreign political parties;

- advantages promised or given to any person in anticipation of that person becoming a foreign public official;

- bribery of foreign public officials as a predicate offence for money laundering legislation;

- $\quad$ the role of foreign subsidiaries and of offshore centres in bribery transactions." 


\section{WORKING PARTY OF THE INVESTMENT COMMITTEE}

Chair:

Ms. Anna-Maj Hultgard

(Sweden)

Members:

Open to all Member countries

Non-Member Participants:

Argentina

Latvia

Brazil

Lithuania

Chile

Romania

Estonia

Slovenia

Israel

Date of creation:

20th September 2004

Duration:

31st December 2008

Mandate: The Investment Committee: Strategy and Organisation [DAF/INV(2004)1 and DAF/INV/M(2004)1]

\section{Extract from document [DAF/INV(2004)1]}

“.

1. The Working Party shall carry out the following tasks:

(i) To assist the Investment Committee in implementing the Declaration on International Investment and Multinational Enterprises and related Decisions, including with respect to its responsibilities in relation to the 2000 Guidelines on Multinational Enterprises; in considering all questions concerning the interpretation or implementation of the provisions of the OECD Codes of Liberalisation of Capital Movements and of Current Invisible Operations pursuant to their Articles 18 and 19; [] and in encouraging non-Members to adhere to the Declaration.

(ii) To undertake other tasks as requested by the Investment Committee.

2. In fulfilling its tasks, the Working Party will consult, as appropriate, other OECD bodies, international organisations or experts as well as BIAC, TUAC, other non-governmental organisations and non-Member economies.

3. Non-Members adhering to the Declaration participate in the work of the Working Party relating to the Declaration.

4. The Working Party will make regular reports on its activities to the Investment Committee.

5. The mandate of the Working Party will remain in force until 31 December 2008 unless the Investment Committee decides otherwise." 


\section{ADVISORY GROUP ON CO-OPERATION WITH NON-MEMBERS ON INVESTMENT MATTERS}

Chair:

Members:

Observers:

Date of creation:

Duration: $\ldots$

Open to all Member countries

Argentina

Brazil

Chile

January 2001

31st December 2008

Mandate: The Investment Committee: Strategy and Organisation [DAF/INV(2004)1 and DAF/INV/M(2004)1]

\section{Extract from document [DAF/INV(2004)1]}

“...

1. The Advisory Group on Cooperation with non-Members will assist the Investment Committee in carrying out its work with non-Member economies and in providing input as appropriate to other OECD activities with non-Members; it will advise the Committee on work priorities, ensuring the integration of non-Member and other Committee's work, costs and funding, and evaluation of work performance.

2. The Advisory Group will be guided in its activities and recommendations to the Committee by the following principles: i) projects should be designed so as to enhance opportunities for government-to-government dialogue and be selected if the Organisation has a demonstrated comparative advantage relative to other organisations; ii) policy areas for dialogue should be based on on-going core work of the Committee and be consistent with the Committee's work strategy under the Investment for Development Initiative; iii) their selection should meet country and region needs; iv) projects reflecting sustained commitments for outreach should be preferred over one-off events; v) projects should be designed to lead to measurable improvements by the target countries/regions in the policy areas they seek to address;

3. The Advisory Group will be open to all interested delegations and nonMember observers in the Committee.

4. The Chair of the Advisory Group will make regular reports on its activities to the Committee.

5. The mandate of the Advisory Group will remain in force until 31 December 2008 unless the Investment Committee decides otherwise." 

Chair:

Vice-Chairs:

Members:

Observers:

Date of creation:

Duration:

$$
\text { Mr. Kurt Schneiter }
$$

Mr. David Bowie

Mr. Ambrogio Rinaldi

Mr. Claude Wirion

Mr. Alastair Evans

Mr. Shingo Hashimoto
(Switzerland)

(United States)

(Italy)

(Luxembourg)

(United Kingdom)

(Japan)

Open to all Member countries

Israel

Russian Federation

International Actuarial Association (IAA)

International Association of Insurance Supervisors (IAIS)

International Monetary Fund (IMF)

30th September 1961

31st December 2006

Mandate : - Decision to rename the "Insurance Committee", the "Insurance and Private Pensions Committee" and Resolution concerning the mandate of the Insurance and Private Pensions Committee adopted by the Council at its 1110th session on 13 April 2005 [C(2005)27/REV1 and C/M(2005)9/PROV, item 100].

Resolution of the Council [C(2005)27/REV1 and C/M(2005)9, Item 100]

\section{RESOLUTION OF THE COUNCIL CONCERNING THE MANDATE OF THE INSURANCE AND PRIVATE PENSIONS COMMITTEE ${ }^{1}$}

THE COUNCIL

Having regard to Articles $2 \mathrm{~d}$ ) and 3 of the Convention on the Organisation for Economic Co-operation and Development of 14 December 1960;

Having regard to the Rules of the Procedure of the Organisation;

Having regard to the Resolution of the Council on the Terms of Reference of the Insurance Committee of 25 September 1985 [C(85)98(Final)] as amended;

\section{DECIDES}

1. THE TERMS OF REFERENCE OF THE INSURANCE AND PRIVATE PENSIONS COMMITTEE

- The Insurance and Private Pensions Committee (hereinafter called "The Committee") will promote international co-operation to improve awareness and understanding, especially among policymakers, of major insurance and pensions issues through market and policy analysis, data collection and benchmarking good

\footnotetext{
${ }^{1}$. Formerly the Insurance Committee.
} 
practices. This awareness and understanding will help Members and non-Members in developing efficient, open and sound market-oriented insurance and pensions systems, based on high levels of transparency, confidence and integrity.

- The work on private pensions will continue to be developed by the Working Party on Private Pensions. It will in particular include the development of principles and guidelines for the regulation of private pensions.

- The Committee shall pursue efforts at further liberalisation and regulatory reform in the field of insurance and private pensions and shall co-operate with relevant OECD bodies, and especially with the Investment Committee on work related to insurance and pensions provisions of the OECD Codes of liberalisation and with the Committee on Financial Markets on regulatory issues.

- The Committee shall keep itself informed of the activities carried out in other international bodies in respect of insurance and private pension, coordinate work with these bodies and shall provide a forum for consultations among Member countries to enable them to exchange views on issues raised in such bodies.

- The Committee shall promote policy dialogue with non-Member economies, encourage the implementation of best principles and practices and provide related assistance. The work related to non Member economies will be fully integrated in the programme of work of the Committee.

- The Committee shall monitor and co-ordinate work undertaken by the Organisation in the insurance and private pensions field and, as appropriate, submit opinions, recommendations and proposals to the Council or to other Committees.

2. The Terms of Reference of the Insurance and Private Pensions Committee shall remain in force until 31 December 2006 unless the Council decides otherwise.

3. The Resolution of 25 September 1985 [C(85)98(Final)] is hereby repealed.

4. Paragraph 9 of the Annex to the Rules of Procedure shall be amended to read as follows:

"Insurance and Private Pensions Committee: its terms of reference are defined in the Resolution of the Council C(2005)27/REV1". 


\section{TASK FORCE ON PRIVATE HEALTH INSURANCE}

Chair:

Mr. Kurt Schneiter

(Switzerland)

Members:

Open to all Member countries

Date of creation:

22nd June 2001

Duration:

31st December 2006

Mandate: Summary record of the 67th session of the Insurance Committee

[DAFFE/AS/M(2001)2, Item 10] and document [DAFFE/AS/PHI/WD(2001)1, § 3]

Extract from document [DAFFE/AS/M(2001)2, Item 10]

"10. Private Health Insurance

The Committee:

[...]

-- supported the creation of a task force on private health insurance which would be open to public and private health sector representatives; the think tank's first two tasks would be to finalise the comparative report on private health insurance in the OECD countries and to monitor the collection and analysis of statistical data on private health insurance;"

\section{Extract from document [DAFFE/AS/PHI/WD(2001)1, §3]}

"3. [...] The Insurance Committee (IC) established in June a Task Force on private health insurance, (...) whose short term main objective will be to assist in [the private health insurance] part of the [horizontal] project [on health] [...]. The Task Force may also discuss issues not directly covered by the project but of relevance for some of the topics discussed therein (for instance genetic testing, disability insurance and ageing)." 


\section{WORKING PARTY OF GOVERNMENTAL EXPERTS ON INSURANCE}

Chair:

Members:

Observers:

Date of creation:

Duration:
Mr. Claude Wirion

(Luxembourg)

Open to all Member countries

International Association of Insurance Supervisors (IAIS)

International Monetary Fund (IMF)

November 1992

31st December 2006

Mandate: -- Document [DAFFE/AS(92)23] approved by the Insurance Committee at its 50th session

-- Summary Record of the $69^{\text {th }}$ Session of the Insurance Committee [DAFFE/AS/M(2002)2] and Document [DAFFE/AS(2002)3]

- Change of name of the "Working Party of governmental experts on insurance solvency" to "Working Party of insurance governmental experts"

[DAFFE/AS/M(2002)2]

\section{Extract from document [DAFFE/AS(92)23]}

follows ${ }^{1}$ :

"The mandate of the "Group of governmental experts on insurance solvency" is as

- this technical and ad hoc Group of governmental experts will survey and analyse regulatory and supervisory systems and techniques existing in Member countries concerning the solvency of insurance companies, the main issues currently raised in this field and measures and practices used or that could be used to address them;

- the Group will regularly report to the Insurance committee on the developments of its work;

- the Group will submit to the Insurance Committee a final report for comments and approval."

\section{Extract from the Summary Record of the $69^{\text {th }}$ Session of the Insurance Committee}

\section{[DAFFE/AS/M(2002)2]}

"9. "The Committee:

$[\ldots]$

-- endorsed the change of name of the "Working Party of governmental experts on insurance solvency" to "Working Party of insurance governmental experts."

\footnotetext{
1 The concept of "solvency" used in this mandate must be understood in the broad sense of the financial health of insurance companies (and groups of such companies), including reinsurance aspects.
} 


\section{Extract from document [DAFFE/AS(2002)3]}

"84. The Working Party will be expected to develop several further activities in 2003-2004. These activities will first include all the issues to be discussed by the Insurance Committee between governmental experts only. The Group is indeed the only forum where the Committee could hold such restricted discussion and creation of new OECD groups are currently strictly discouraged. In 2003-2004, it may be expected that such issues will be numerous; they will include the contribution to the CMIT discussion and examination of the Member countries reservations to the new obligations of the Invisible Code, the implementation of the Reinsurance Decision, the monitoring of solvency and selected other regulatory developments as well as all the issues covered by this programme of work where prior governmental discussion would be required (being on terrorism risk management, financial integrity or private heath insurance). This may especially concern issues to be developed in co-operation with the Committee on Financial Markets where delegates are governmental and central banks representatives only. All in all, the Group will thus basically deal with most of the activities of the Committee. Taking this increasing and larger role of the Group into consideration, it is also suggested to delete the word solvency in the name of the group, which would now read: the Working Party of insurance governmental experts." 


\section{WORKING PARTY ON PRIVATE PENSIONS}

Chair:

Vice-Chairs:

Members:

Observers:

Date of creation:

Duration:
Mr. Ambrogio Rinaldi

Mr. Greg Brunner

Ms. Mary Hutch

Open to all Member countries

Brazil

Israel

Russian Federation

European Federation for Retirement Provision (EFRP)

International Actuarial Association (IAA)

International Association of Pension Funds' Supervisory

Organisations (AIOS)

International Monetary Fund (IMF)

International Organisation of Pension Supervisors (IOPS)

International Social Security Association (ISSA)

World Bank

November 1998

31st December 2006

Mandate: Document [DAFFE/AS(99)3/REV1] approved by the Insurance Committee in March 1999 by written procedure.

\section{Extract from document [DAFFE/AS(99)3/REV1]}

\section{$\underline{\text { Terms of Reference }}$}

"The Working Party on private pensions has the following tasks and objectives:

- $\quad$ survey and monitoring of private pensions systems in OECD Member countries and analysis of related policy and technical issues;

- formulation of appropriate policy conclusions and/or recommendations on the different approaches related to regulation and supervision of private pension systems;

- $\quad$ keeping abreast of OECD activities related to private pensions; co-operation and co-ordination on these issues with other relevant OECD bodies as well as with other international bodies;

- $\quad$ promotion of policy dialogue with Non Member countries on private pensions issues.

The programme of work of the Working Party will specify the orientations and details of implementation of the current terms of reference. The Working Party will regularly report to the Insurance Committee [---]. The Delegations may include representatives of the industry (insurance and pension funds in particular) except for closed governmental sessions, to be held upon decision by the Chair of the Working Party." 
TASK FORCE ON PERSONAL PENSION PLANS

Chair:

Mr. John Bowman

(United Kingdom)

Members:

Open to all Member countries

Date of creation:

June 2001

Duration:

31st December 2006

Mandate: - Summary Record of the 66th session of the Insurance Committee [DAFFE/AS/M(2001)1, Item 8] and document [DAFFE/AS(2000)7/REV1, § 31]

- Summary Record of the 67th session of the Insurance Committee

[DAFFE/AS/M(2001)2, Item 12.1] and document [DAFFE/AS(2001)3, § 14]

The Insurance Committee will deal, in co-operation with its Working Party on Private Pensions, with issues involving the role of insurance companies in pension systems, and the development and regulation of retirement-related insurance products. Work on the latter will be initiated by a Task Force on Personal Pension Plans, which will be managed jointly by the Working Party and the Committee. This activity will be enlarged to comparison between insurance, pensions and savings instruments. 


\section{TASK FORCE ON PENSION STATISTICS}

Chair:

Members:

Non-Member Participant:

Date of creation:

Duration:
Mr. José Pavão Nunes

(Portugal)
Open to invited non-Member countries

June 2001

31st December 2006

Mandate: - Programme of Work of the Working Party on Private Pensions approved during the 5th session of the Working Party on Private Pensions [DAFFE/AS(2000)7/REV1, para. 8] and document [DAFFE/AS/PEN/WD(2002)8 para. 8 and 23]

\section{Extracts from document [DAFFE/AS/PEN/WD(2002)8]}

"8. In order to address the overall project objective, three main priorities are identified as follows:

- to review country data coverage of pension statistics and make recommendations for improving the methodology of pension statistics gathering;

- to improve the international comparability of pension statistics;

- to provide users with up-to-date statistics and indicators on salient aspects of retirement systems across OECD and INPRS countries.

\section{[...]}

23. The mandate of the Task Force on Pension Statistics is; i) to develop a thorough knowledge of the methodology used in the compilation of private pension data throughout OECD countries, ii) to review strengths and weaknesses of existing data, initially through a data collection pilot project for selected OECD countries, iii) to examine ways and means to improve the comparability of international pension statistics and provide recommendation, iv) to carry out the data collection monitoring and finally, $v$ ) to explore related issues and make recommendations as the task force finds appropriate" 


\section{TASK FORCE ON TERRORISM INSURANCE}

Chair:

Secretariat

Members:

Open to all Member countries

Date of creation:

December 2001

Duration:

31st December 2006

Mandate: - Summary Record of the 68th session of the Insurance Committee [DAFFE/AS/M(2002)1/REV1, Item 3]

- Summary Record of the 69th session of the Insurance Committee [DAFFE/AS/M(2002)2, Item 5]

Extract from document [DAFFE/AS/M(2002)1/REV1, Item 3]

"The Committee:

$[\ldots]$

-- decided to create a Task force on the terrorism risk."

Extracts from document [DAFFE/AS/M(2002)2, Item 5]

\section{“5. $\quad$ TERRORISM RISKS}

$[\ldots]$

\section{b) Definition of terrorism risks}

The Committee:

-- discussed the document DAFFE/AS/WD(2002)7 which suggests a framework for future work on the definition of terrorism risk (definition criteria, introduction to the concept of insurable terrorism risks and mega terrorism) to be mainly undertaken through the Task Force created at the occasion of the December 2001 meeting, and underlined the need of a flexible approach in order to encompass as much as possible country specificity.

\section{$[\ldots]$}

\section{c) Policy options}

The Committee:

-- noted the content of documents DAFFE/AS/WD(2002)9 - Communiqué of the Ministerial meeting requesting that the Secretariat should develop policy analysis and 
recommendations on how to define and cover terrorism risks and to assess the respective roles of the insurance industry, financial markets and governments, including for the coverage of "mega-terrorism" risks - discussed and endorsed the modalities for implementation of that mandate presented in document DAFFE/AS/WD(2002)8, taking into consideration that at this stage the Committee should adopt an open approach on options whose usefulness or feasibility will have to be carefully assessed (by the Task Force and the Committee)." 


\section{COMMITTEE ON FINANCIAL MARKETS}

Chair:

Vice-Chairs:

Members:

Observers:

Date of creation:

Duration:
Mr. Thomas Wieser

Mr. Erich Harbrecht

Mr. Shingo Hashimoto

Mr. Wilbur Monroe

Open to all Member countries

Hong Kong, China

Singapore

Bank for International Settlements (BIS)

European Investment Bank (EIB)

International Monetary Fund (IMF)

World Bank

17th November 1969

31st December 2008
(Austria)

(Germany)

(Japan)

(United States)

Mandate: - Resolution of the Council concerning the Establishment and Terms of Reference of a Group of Governmental Experts on Financial Markets [C(69)131(Final)]

- Resolution of the Council amending the Resolution of the Council concerning the Establishment and Terms of a Group of Governmental Experts on Financial Markets [C(71)28(Final)]

- Decision of the Council concerning the future of the Exchange Guarantee Agreement Between Certain Central Banks and of the Committee for Monetary and Foreign Exchange Matters [C(75)134(Final)]

- Council Decision regarding a Sunset Clause for all Committees [C/M(2004)5, item

75] entered into force on 22 April 2004 [C/M(2004)10, item 143, IV, c)]

\section{Resolution of the Council [C(69)131(Final)]}

THE COUNCIL,

Having regard to the Decision of the Council meeting at Ministerial level of 3rd December 1964, concerning the Work of the Organisation and, in particular, Section II c) thereof [C(64)172];

Having regard to the Resolution of the Council of 26th January 1965, concerning the Improvement of Capital Markets of Member States [C/M(65)2(Final), Item 19 a) and b)];

Having regard to the Rules of Procedure of the Organisation;

Considering that at its meeting of 8th July 1969, it approved the suggestions contained in paragraphs 14 and $16 \mathrm{~b}$ ) of the Report by Working Party No. 7 of the Council dated 2nd June 1969, on the Work of the Organisation on Financial Affairs [C(69)74; C/M(69)13(Final), Item 118];

\section{DECIDES:}

1. There is hereby established a Group of Governmental Experts on Financial Markets composed of persons chosen by the interested Member countries by reason of their knowledge of problems concerning financial markets and the reputation which they have acquired in this subject 
in their countries. Observers of the International Monetary Fund and the International Bank for Reconstruction and Development may attend meetings of the Group of Experts.

2. The Chairmanship of the Group of Experts shall, for an initial period of two years, be assigned to the Chairman of the Committee for Invisible Transactions of the Organisation. Thereafter the Group of Experts shall designate a Chairman in accordance with the provisions of the Rules of Procedure of the Organisation.

3. In application of the Decision of the Council of 3rd December 1964, and of the Resolution of the Council of 26th January 1965, referred to above, the Group of Experts shall have as general terms of reference the study of measures intended to improve the operation of national financial markets and the international financial market.

4. The Group of Experts shall report to the Council on its work and propose to it as necessary recommendations on questions concerning financial markets.

5. a) A new paragraph 10 is inserted in the Annex to the Rules of Procedure as follows:

"10. Group of Experts on Financial Markets: Its terms of reference are defined in the Council Resolution [C(69)131(Final)]."

b) Paragraphs 10 to 24 of the Annex to the Rules of Procedure shall be renumbered 11 to 25 and the references to some of these paragraphs in Rules 21 and 28 of the Rules of Procedure shall be amended accordingly.

\section{$\underline{\text { Resolution of the Council [C(71)28(Final)] }}$}

THE COUNCIL,

Having regard to the Resolution of the Council of 17th November 1969 concerning the Establishment and Terms of Reference of a Group of Governmental Experts on Financial Markets [C(69)131(Final)];

Having regard to the Rules of Procedure of the Organisation;

\section{DECIDES:}

1. The terms "Group of Governmental Experts on Financial Markets" and "Group of Experts" appearing in the Resolution of the Council of 17th November 1969, referred to above, are replaced respectively by the terms "Committee on Financial Markets" and "Committee".

2. Paragraph 10 of the Annex to the Rules of Procedure is amended as follows:

"10. Committee on Financial Markets: Its terms of reference are defined in the Resolution of the Council [C(69)131(Final)], amended by the Resolution of the Council [C(71)28(Final)]."

\section{Extract from the Decision of the Council [C(75)134(Final)]}

\section{"THE COUNCIL}

IV. AGREES that the Committee on Financial Markets shall, in addition to the tasks which it is undertaking under its existing mandate, review technical developments in foreign exchange markets." 


\section{WORKING PARTY ON FINANCIAL STATISTICS}

Chair:

Vice-Chairs:

Members:

Observers:

Date of creation:

Duration:
Mr. Patrick O'Hagan

(Canada)

Ms. Beatriz Sanz Medrano

Ms. Susan Hume McIntosh

(Spain)

(United States)

Open to all Member countries

Hong Kong, China

Israel

Singapore

Bank for International Settlements (BIS)

European Investment Bank (EIB)

International Monetary Fund (IMF)

World Bank

World Trade Organization (WTO)

7th March 1967

31st December 2008

Mandate: $\quad$ Minutes of the 135th session of the Council [C/M(67)4(Final)]

\section{Extract from document $[\mathrm{C} / \mathrm{M}(67) 4($ Final), Item 36$]$}

\section{"THE COUNCIL}

(36) a) noted the Report on the Improvement of Capital Markets by the Committee for Invisible Transactions $[\mathrm{C}(66) 122]$ and the Comments thereon by the Payments Committee [C(67)13];

b) approved the publication of the document [C(66)122] and of a Statistical Annex thereto after the Committee for Invisible Transactions had made any additions and corrections needed to perfect presentation and accuracy, and on the understanding that the document would indicate the constitution, composition and independent character of that Committee, and that it would be made clear that the report was the work of experts, which did not necessarily carry the endorsement of the Organisation in all respects and which did not bind the latter or individual Member States either generally or in any particular detail;

c) agreed that a group of official statisticians be convened to examine how financial statistics in this field could be improved;" 


\section{WORKING PARTY ON DEBT MANAGEMENT}

Chair:

Mr. Ove Sten Jensen

(Denmark)

Vice-Chairs:

Mr. Herwig Smissaert

(Belgium)

Mr. Rob Stewart

(Canada)

Mr. Benoît Coeuré

(France)

Mr. Gerhard Schleif

(Germany)

Mr. Zsolt Bango

Ms. Maria Cannata

(Hungary)

Mr. Greg Horman

(Italy)

Mr. Robert Stheeman

(New Zealand)

(United Kingdom)

Members:

Observers:

Date of creation:

Duration:
Open to all Member countries

Hong Kong, China

Israel

Singapore

Bank for International Settlements (BIS)

European Investment Bank (EIB)

International Monetary Fund (IMF)

World Bank

4th December 1981

31st December 2008

Mandate: Summary Record of the 36th Meeting of the Committee on Financial Markets [CMF/M(81)3]

\section{Extract from document [CMF/M(81)3, Item 7 (iv)]}

"(iv) Future informal meetings of government debt management experts

\section{THE COMMITTEE}

a) endorsed the proposal made at the Expert Group's final meeting held in March 1981 that government debt management experts should meet from time to time, perhaps at 12 to 18 month intervals, to discuss debt management problems of common interest; this was all the more desirable as government debt managers had so far no other opportunities to meet at international level;

b) instructed the Secretariat to organise such meetings, it being understood, however, that any papers for discussion by the experts would have to be prepared by the experts themselves and that the Secretariat would only be responsible for the technical organisation of such meetings;

c) welcomed the suggestion that the Committee should receive reports on the outcome of such meetings." 


\section{COMPETITION COMMITTEE}

Chair:

Vice-Chairs:

Members:

Observers:

Date of creation:

Duration:
Mr. Frédéric Jenny

Ms. Sheridan Scott

Mr. Finn Lauritzen

Mr. Ulf Böge

Mr. Daehyung Kang

Mr. Jonathan May

Mr. Philip Lowe

Mr. François Souty

Ex Officio as UNCTAD co-ordinator

Mr. Alberto Heimler

Ex Officio as Chair of the Working Party N.2 on Competition and Regulation

Mr. Thomas Barnett

Ex Officio as Chair of the Working Party N.3 on Enforcement and Co-operation

Open to all Member countries
Brazil
Indonesia
Israel
Lithuania
Romania
Russian Federation
Slovenia
South Africa
Chinese Taipei
European Free Trade Association (EFTA)
U.N. Conference on Trade and Development (UNCTAD)
World Trade Organization (WTO)

(Canada)

(Korea)

(United Kingdom)

(European Commission)

(France)

(Italy)

(United States)

5th December 1961

31st December 2008

Mandate: - Resolution of the Council concerning the Committee of Experts on Restrictive Business Practices and amending its name and terms of reference [C(87)138(Final)]

- Extract from the Communiqué [C(91)91] adopted by the Council at Ministerial level on 4-5 June 1991

- Change of name from 'Committee on Competition Law and Policy' to 'Competition Committee' agreed by Council at its 1017th session [C/M(2001)23, item 402] and document [C(2001)261]

- Council Decision regarding a Sunset Clause for all Committees [C/M(2004)5, item 75] entered into force on 22 April 2004 [C/M(2004)10, item 143, IV, c)]

\section{Resolution of the Council [C(87)138(Final)]}

"THE COUNCIL,

Having regard to Article 1 of the Convention on the Organisation for Economic Cooperation and Development; 
Having regard to paragraph 37 of the Report of the Preparatory Committee of 17 th December 1960 [OECD(60)21(Final)];

Recognising that the stimulation of freer competition which entails effective policies and procedures to prevent harmful practices, is of great importance for the achievement of maximum economic growth and employment, combined with price stability, and a rising standard of living in the countries concerned and for the expansion of world trade;

Noting that most OECD Member countries and the European Communities have competition laws and policies; and that the Convention establishing the European Free Trade Association (EFTA) as well as the free trade agreements between EFTA Member countries and the European Communities contain provisions on this matter.

Considering that, in view of the growing internationalisation of trade and industry, international co-operation is increasingly necessary to deal with competition problems;

Having regard to the Resolution of the Council concerning action in the field of restrictive business practices and the establishment of a Committee of Experts [OECD/C(61)47(Final)];

Having regard to the Rules of Procedure of the Organisation;

\section{DECIDES:}

I. The Committee of Experts on Restrictive Business Practices established by Council Resolution C(61)47(Final) shall be known as the "Committee on Competition Law and Policy".

II. The Members of the Committee shall be appointed by the Governments of Member countries and chosen so far as possible by virtue of the official responsibilities assigned to them in their own countries in matters relating to competition law and policy, taking fully into account the desirability of ensuring continuity in the work of the Committee.

III. The terms of reference of the Committee on Competition Law and Policy shall be:

1. To review developments in competition laws and policies both in individual countries and in international organisations;

2. To examine and comment upon particular competition law and policy issues taking into account the interaction between competition and other government policies;

3. To promote co-operation between Member countries in the elaboration and enforcement of competition laws and policies;

4. To co-operate with other Committees of the Organisation on issues related to competition;

5. To exchange views on the competition law and policy issues arising in other international fora;

6. To report and make recommendations as appropriate to the Council on matters within the competence of the Committee.

IV. Paragraph 21 of the Annex to the Rules of Procedure of the Organisation shall be amended to read:

'21. Committee on Competition Law and Policy: its terms of reference are defined in the Resolution of the Council C(87)138(Final)'.

V. This Resolution shall replace the Resolution of the Council OECD/C(61)47(Final)." 


\section{JOINT GROUP ON TRADE AND COMPETITION}

Co-Chairs: ${ }^{1}$

Vice-Chairs:

Members:

Observers:
Mr. Stefan Amarasinha

Mr. David Smith

Mr. Domenico Da Empoli

Ms. Monica Widegren

...

$\cdots$

Mr. Frédéric Jenny
(European Commission)

(Australia)

(Italy)

(Sweden)

(...)

(...)

(France)

Open to all Member countries

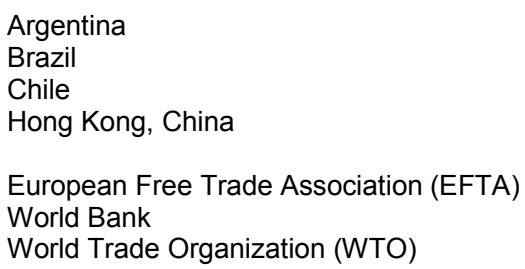

Date of creation:

May 1996

Duration:

May 2006

Mandate: Terms of Reference for the Joint Group on Trade and Competition based on documents [COM/DAFFE/CLP/TD(96)50/REV2, COM/DAFFE/CLP/TD(96)102, COM/DAFFE/CLP/TD(2000)6, COM/DAFFE/COMP/TD/M(2002)43 and COM/DAFFE/TD(2004)6]

\section{Extract from document [COM/DAFFE/CLP/TD(2000)6]}

will:

"In order to strengthen the coherence of trade and competition policies the Joint Group

a) Take stock of analysis undertaken so far;

b) Deepen that work in accordance with the terms of the programme of work adopted for the Joint Group.

This programme of work will include: (i) competition policies related to market access such as scope and coverage, and actual enforcement of competition laws; (ii) international options to improve coherence of trade and competition policies; (iii) the effects on competition of trade measures and policies; and (iv) the effects of regulation on market access and the competitive process.

In order to make best use of resources, this Joint Group will assume responsibility for the pursuit of trade and competition work for the duration of its mandate, and will report progress as

\footnotetext{
1 Bureau elections for 2006 will take place once the mandate is renewed.
} 
appropriate to OECD Ministerial meetings. The Joint Group shall operate until the 2002 OECD Ministerial. Renewal of its terms of reference beyond that point will require agreement between the Committee on Competition Law and Policy and the Trade Committee." 


\section{WORKING PARTY NO. 2 ON COMPETITION AND REGULATION}

Chair:

Members:

Observers:

Date of creation:

Duration:
Mr. Alberto Heimler

(Italy)

Open to all Member countries

Brazil
Indonesia
Israel
Lithuania
Romania

U.N. Conference on Trade and Development (UNCTAD) World Trade Organization (WTO)

1st October 1994

May 2006

Mandate: Summary Record of the 66th meeting of the Committee on Competition Law and Policy [DAFFE/CLP/M(94)2] and document [DAFFE/CLP/M(94)2].

\section{Extract from document [DAFFE/CLP/M(94)2, § 17]}

"17. $\quad[\ldots]$ the Committee agreed to establish a new Working Party No. 2 (Working Party No. 2 on Competition and Regulation) and decided to give this Working Party the following tasks:

To review, analyse and make recommendations on competition issues related to the creation, operation, reforming or dismantling of sectoral or economy-wide regulatory regimes." 


\section{WORKING PARTY NO. 3 ON CO-OPERATION AND ENFORCEMENT}

Chair:

Members:

Observers:

Date of creation:

Duration:
Mr. Thomas O. Barnett

(United States)

Open to all Member countries

Brazil
Indonesia
Israel
Lithuania
Romania

U.N. Conference on Trade and Development (UNCTAD) World Trade Organization (WTO)

October 1964

May 2006

Mandate: - Summary Records of the 7th, 13th, 20th, 40th and 60th meetings of the Committee of Experts on Restrictive Business Practices [RBP/M(64)2, RBP/M(67)2, $\mathrm{RBP} / \mathrm{M}(71) 1, \mathrm{RBP} / \mathrm{M}(81) 2$ and DAFFE/CLP/M(91)2]

- New name and mandate approved during the 89th session of the Competition Committee held on 15-17 October 2003 [DAFFE/COMP/M(2003)3 and Annex 1]. Former name: "Working Party No. 3 on International Co-operation".

\section{Extract of Summary Record [DAFFE/COMP/M(2003)3, Annex 1]}

\section{Working Party No. 3 on Co-operation and Enforcement}

Working Party 3 promotes effective enforcement of competition laws and co-operation among competition law enforcement agencies.

Specifically, the Working Party shall, as directed by the Competition Committee, pursue the following tasks:

- $\quad$ Merger Control Procedures

- increase effective co-operation in reviews of transnational mergers;

- identify areas of differences, convergence, and possible improvement; and

$\circ \quad$ identify and seek to reduce unnecessary regulatory costs to firms and competition authorities.

- $\quad$ Hard Core Cartels

$\circ$ increase co-operation and information exchanges among competition law enforcement agencies;

- develop and promote effective enforcement practices and tools; and

- raise public awareness of the harm of hard core cartels.

- $\quad$ Other Areas of Competition Law Enforcement 
- provide a forum to review and discuss other areas of co-operation and competition law enforcement.

- $\quad$ Council Recommendations

- periodically review existing OECD Council Recommendations in the area of its mandate and identify areas in which the Recommendations can be strengthened; and

- consider new recommendations as needed.

- $\quad$ Co-operation with Other Institutions

- co-operate with other international institutions addressing similar competition issues and contribute to their work. 

Chair:

Bureau Members:

Members:

Observers:

Date of creation:

Duration:
Ms. Veronique Ingram

Mr. Edward Doyle

Mr. Pekka Timonen

Mr. Marcello Bianchi

Mr. Shingo Hashimoto

Mr. Rudolf Müller

Ms. Susan Baker
(Australia)

(Canada)

(Finland)

(Italy)

(Japan)

(Switzerland)

(United States)

Open to all Member countries

Bank for International Settlements (BIS)

International Monetary Fund (IMF)

World Bank

15th June 2000

Unspecified

Mandate: - Summary Record of June 2000 meeting of Steering Group on Corporate Governance [DAFFE/CA/CG/M(2000)1] and document [C/PWB(99)99/2000, page 169]

- Document [C(2001)147]

\section{Extract from document [DAFFE/CA/CG/M(2000)1, Item 1]}

"1. The Steering Group will:

- $\quad$ Provide co-ordinated guidance and active support by Member countries for the global corporate governance outreach activities on the basis of the OECD Principles, in co-operation with the World Bank;

- Support the development of a sustained policy discussion among Member countries on corporate governance trends and developments and thus prepare the process of reassessment of the Principles in due course;

- Provide high-quality inputs on a voluntary basis on specific corporate governance issues, in the context of projects fully funded by individual Member countries;

- $\quad$ Carry out other corporate governance work agreed by Member countries." 


\begin{tabular}{|c|c|c|}
\hline Chair: & Mr. Lars Johan Cederlund & (Sweden) \\
\hline Members: & Open to all Member countries & \\
\hline Observer: & World Bank & \\
\hline Vice-Chairs: & $\begin{array}{l}\text { Mr. Eric Preiss } \\
\text { Mrs. Anita Ryng }\end{array}$ & $\begin{array}{l}\text { (France) } \\
\text { (Poland) }\end{array}$ \\
\hline Bureau Members: & $\begin{array}{l}\text { Finland } \\
\text { France } \\
\text { Korea } \\
\text { Norway } \\
\text { Poland }\end{array}$ & \\
\hline Date of creation: & March 2001 & \\
\hline uration: & Unspecified & \\
\hline
\end{tabular}

Mandate: Constitution of the Working Group [DAFFE/CA/CG(2001)6] and [DAFFE/CA/PRIV(2001)1/REV1]

\section{Extract from document [DAFFE/CA/PRIV(2001)1/REV1, paragraph 1]}

"1. [...] the mandate of the "Working Group" is to:

i. Develop policy dialogue and information exchange among Member countries on issues dealing with privatisation and governance of state-owned assets and their effectiveness;

ii. Develop best practices principles on the basis of this dialogue;

iii. Serve as a pool of expertise from which member and non-member countries can draw, in the process of designing, adjusting or implementing their programmes;

iv. Guide the process of dialogue on these issues with non-member economies. 
TAX POLICY AND ADMINISTRATION 



\section{COMMITTEE ON FISCAL AFFAIRS (CFA)}

Chair:

Deputy-Chair:

Vice-Chairs:

Members:

Observers:

Date of creation:

Duration:

\author{
Mr. Paolo Ciocca \\ (Italy) \\ Mr. Frank Mullen \\ (Ireland) \\ Mr. Wolfgang Nolz \\ Ms. Marie-Christine Lepetit \\ Mr. Robin Oliver \\ (Austria) \\ (France) \\ (New Zealand)
}

Open to all Member countries

Argentina
China
Russian Federation
South Africa

International Monetary Fund (IMF)
World Bank

1st May 1971

31st December 2008

Mandate: - Paragraph 36 of the Report by the Preparatory Committee

- Resolution of the Council concerning the Activities of the Organisation in the Field of Taxation [C(71)41]

- Recommendation of the Council on Tax Avoidance and Evasion [C(77)149(Final)]

- Recommendation of the Council on the Determination of Transfer Prices between Associated Enterprises [C(79)83(Final)]

- Minutes of the 669th session of the Council [C/M(87)16(Final)]

- Recommendation of the Council on Tax Treaty Override [C(89)146(Final)]

- Recommendation of the Council concerning the model tax convention on income and capital [C(94)11/FINAL]

- Recommendation of the Council on the Transfer Pricing Guidelines for Multinational Enterprises and Tax Administrations [C(95)126/FINAL]

- Recommendation of the Council on Counteracting Harmful Tax Competition [C(98)17/FINAL]

- Council Decision regarding a Sunset Clause for all Committees [C/M(2004)5, item 75] entered into force on 22 April 2004 [C/M(2004)10, item 143, IV, c)]

\section{Paragraph 36 of the Report by the Preparatory Committee}

36. The Preparatory Committee recommends the creation of a Fiscal Committee to continue the activities of the type now undertaken by the OEEC and to deal with such other functions in this field as the Council may decide.

\section{Extract from the Resolution of the Council [C(71)41]}

"THE COUNCIL, 


\section{DECIDES:}

1. The Fiscal Committee shall henceforth be known as the Committee on Fiscal Affairs.

2. The Committee on Fiscal Affairs shall be responsible for investigating the methods by which taxation can be used to promote improved allocation and use of economic resources, both domestically and internationally and for proposing ways of increasing the effectiveness of taxation as a policy instrument for achieving Governmental objectives, but excluding work on the use of fiscal policy for demand management purposes.

3. The activities of the Fiscal Committee, as defined in paragraph 36 of the Report of the Preparatory Committee and in the Recommendations and Resolution of the Council of 30th July $1963^{1}$, 28th June 1966, and 27 th June 1968 , referred to above, notably the work relating to double taxation, shall be assumed by the Committee on Fiscal Affairs.

4. Paragraph 21 of the Annex to the Rules of Procedure shall be amended and shall read as follows:

"21. Committee on Fiscal Affairs: Its terms of reference are defined in the Resolution of the Council [C(71)41]."

5. This Resolution shall take effect on 1st May 1971."

Extract from the Recommendation of the Council [C(77)149(Final)]

"THE COUNCIL,

I. RECOMMENDS Governments of Member countries:

a) To strengthen, where necessary, their legal, regulatory or administrative provisions and their powers of investigation for the detection and prevention of tax avoidance and evasion, with regard to both their domestic and international aspects, and to exchange experiences with respect to such action;

b) To facilitate, improve and extend exchange of information between their national tax administrations, with a view to combating tax avoidance and evasion, notably by making more intensive use of international conventions or instruments in force and by seeking new arrangements of a bilateral or multilateral character, with due regard to the provision of adequate safeguards for taxpayers;

c) To exchange experiences on a continuing basis on tax avoidance and evasion practices, on techniques for detecting and preventing them and on ways and means of improving tax compliance in general.

II. INSTRUCTS the Committee on Fiscal Affairs to pursue its work with a view to facilitating the achievement of the above aims and to submit to the Council, as appropriate, specific proposals for increased co-operation between Member countries in this field."

\section{Extract from the Recommendation of the Council [C(79)83(Final)]}

"THE COUNCIL,

\footnotetext{
${ }^{1}$ This Recommendation was repealed on 11th April 1977 [C(77)40(Final)].
} 
1. To pursue its work on issues pertinent to transfer pricing and to the assessment of taxable profits of associated enterprises in general;

2. To report periodically to the Council on the results of its work in these matters together with any relevant proposals for improved international co-operation."

\section{Extract from document [C/M(87)16(Final), Item 207]}

\section{"THE COUNCIL}

(207) a) noted the Note by the Secretary-General on the joint OECD and Council of Europe Draft Multilateral Convention on Mutual Administrative Assistance in Tax Matters [C(87)129] and the Draft Convention on Mutual Administrative Assistance in Tax Matters and the Commentary annexed thereto;

b) noted the decision by the Committee of Ministers of the Council of Europe of 25th June 1987 to open the Convention for signature, subject to a similar decision being taken by the Council of the Organisation for Economic Co-operation and Development;

c) noted the statements made by Members of the Council;

d) agreed that the draft Convention can be opened for signature by Member countries as from 25th January 1988;

e) authorised the Secretary-General to carry out the tasks vested in him by Articles 24 and 32 of the Convention;

f) requested the Secretary-General to transmit to it any future recommendations and opinions of the co-ordinating body provided for in Article 24 of the Convention, together with any observations by the Committee on Fiscal Affairs;

g) authorised the Secretary-General to receive in a separate account of the Organisation the funds required for organising the meetings provided for in Article 24(3) of the Convention and to incur all expenditure necessary to that end. The financing will be assured by equal contributions from the signatories of the Convention.

[Austria, Luxembourg, Portugal and Switzerland abstained.]"

Extract from the Recommendation of the Council [C(89)146(Final)]

"THE COUNCIL,

I. RECOMMENDS Member countries:

1. To undertake promptly bilateral or multilateral consultations to address problems connected with tax treaty provisions, whether arising in their own country or raised by countries with which they have tax treaties; 
2. To avoid enacting legislation which is intended to have effects in clear contradiction to international treaty obligations.

II. INSTRUCTS the Committee on Fiscal Affairs to follow developments in this area and to bring to the attention of the Council any action which would constitute a material breach of Member countries' international treaty obligations."

\section{Extract from the Recommendation of the Council [C(94)11/FINAL]}

"THE COUNCIL,

I. RECOMMENDS the Governments of Member countries:

1. To pursue their efforts to conclude bilateral tax conventions on income and on capital with those Member countries with which they have not yet entered into such conventions, and to revise those of the existing conventions between them that may no longer be in keeping with present-day needs;

2. When concluding new bilateral conventions or revising existing bilateral conventions between them, to conform to the Model Tax Convention, as interpreted by the Commentaries thereto.

II. INVITES the Governments of Member countries:

1. To notify the Organisation of the text of any new or revised tax conventions on income and on capital concluded with each other or with non-member countries;

2. To continue to notify the Committee on Fiscal Affairs of their Reservations on the Articles and Observations on the Commentaries.

III. INSTRUCTS the Committee on Fiscal Affairs to continue its on-going review of situations where the provisions set out in the Model Tax Convention or the Commentaries thereon may require modification in the light of experience gained by Member countries, and to make appropriate proposals for periodic updates.

IV. DECIDES to repeal the Recommendation of the Council C(92)122/FINAL (23 July 1992)."

\section{Extract from the Recommendation of the Council [C(95)126/FINAL]}

$$
\text { "THE COUNCIL, }
$$

I. RECOMMENDS to the Governments of Member countries:

1. that their tax administrations follow, when reviewing, and if necessary, adjusting transfer pricing between associated enterprises for the purposes of determining taxable income, the guidance in the Report referred to above - considering the integrity of the Report and the interaction of the different chapters -- for arriving at arm's length pricing for transactions between associated enterprises;

2. that tax administrations should encourage taxpayers to follow these Guidelines and to that end that they give the 1995 Report publicity in their country and have it translated, where necessary, into their national language(s);

3. that they develop further co-operation between their tax administrations, on a bilateral or multilateral basis, in matters pertaining to transfer pricing; 
1. to notify the Committee on Fiscal Affairs of any modifications to the text of any laws or regulations that are relevant to the determination of transfer pricing or of the introduction of new laws or regulations.

III. INSTRUCTS the Committee on Fiscal Affairs:

1. to pursue its work on issues pertinent to transfer pricing and to issue the additions to the Guidelines referred to in the 1996 Report.

2. to monitor the implementation of these Guidelines in co-operation with the tax authorities of Member countries and with the participation of the business community and to amend and update (with the approval of the Council), if necessary, these Guidelines in the light of this monitoring.

3. to report periodically to the Council on the results of its work in these matters together with any relevant proposals for improved international co-operation.

4. to develop its dialogue with non-member countries, consistently with the policy of the Organisation, with the aim of assisting them to become familiar with the Guidelines and where appropriate encourage them to associate themselves with the Guidelines.

IV. DECIDES to repeal the Recommendation on the determination of Transfer Prices between Associated enterprises issues on the 29th May 1979 ([C(79)83/Final]."

\section{Extract from the Recommendation of the Council [C(98)17/FINAL]}

"THE COUNCIL",

I. RECOMMENDS to the Governments of Member countries:

1. to implement the recommendations, including the Guidelines for dealing with Harmful Preferential Tax Regimes, which are set out in an Appendix to this Recommendation, of which it forms an integral part.

II. INSTRUCTS the Committee on Fiscal Affairs:

1. to establish a Forum on Harmful Tax Practices;

2. to implement the relevant measures identified in the attached Appendix;

3. to report periodically to the Council on the results of its work in these matters together with any relevant proposals for further improvements in the co-operation to counter harmful tax practices;

4. to develop its dialogue with non-member countries, consistently with the policy of the Organisation, with the aim of assisting these countries to become familiar with the analysis and conclusions of the Report and, where appropriate, to encourage them to associate themselves with the recommendations set out in the Report."

\footnotetext{
${ }^{1}$ Luxembourg and Switzerland abstained in Council on the approval of the Report and the adoption of the Recommendation
} 


\section{BOARD FOR CO-OPERATION WITH NON-OECD ECONOMIES}

Co-Chairs:

Members:

Date of creation:

Duration:
Mr. Yoshiki Takeuchi

Mr. Paul Vlaanderen

Australia

Austria

Canada

Hungary

Japan

Korea

Mexico
(Japan)

(Netherlands)

Netherlands

New Zealand

Norway

Spain

Turkey

United Kingdom

United States

Mandate: Summary Record of the 60th Session of the Committee on Fiscal Affairs [DAFFE/CFA/M(2001)1, Item VIII]

\section{Extract from document [DAFFE/CFA/M(2001)1, Item VIII]}

“...

\section{Creation of a Board for Co-operation with NMEs}

35. The Committee accepted the recommendations of the CFA Bureau to create a new Board on Co-operation with Non-Member Economies on Fiscal Affairs. The Board will have responsibility for supervising the alignment of the co-operation programme and CFA core topics. Reporting directly to the CFA, the Board will consist of delegates from countries (1) that are actively involved in Committee activities and (2) contribute significantly to co-operation with non-member economies. Based on the criteria, Mr. Sugie and Mr. McCloskey will serve as Co-Chairs and the remaining delegates will be from United Kingdom, Norway, United States, Netherlands, Korea and Mexico. The Deputy Chair of the CFA, Mr. Simpson, will serve as a liaison between the Board and the CFA Officers. Spain also requested membership on the Board. While there was no objection, the delegate from Japan reminded the Committee that membership is conditioned on meeting the two criteria noted above." 


\section{ADVISORY GROUP FOR CO-OPERATION WITH NON-OECD ECONOMIES}

Chair:

Members:

Date of creation:

Duration:
Mr. John McGinley

Australia
Austria
Canada
Hungary
Japan
Korea
Mexico

1991

31st December 2008
(United Kingdom)

Netherlands

New Zealand

Norway

Spain

Turkey

United Kingdom

United States

Mandate: - The Advisory Group first appeared, albeit only briefly, as the Steering Group for the Multilateral Training Network, before it was converted into its current form. The Steering Group held its first meeting on 16 December 1991 [CCEET/DAFFE/CFA/M(92)18]

- It was converted and given a mandate in its current form on 22 January 1993, Summary Record of the 44th Session of the Committee on Fiscal Affairs [DAFFE/CFA/M(93)1, item X]

- Summary Record of the Second Meeting of the Steering Group for the Multilateral Training Network for Tax Officials from Central and Eastern Europe, the Baltic States and the NIS [CCEET/DAFFE/M(93)17]

\section{Extract from document [DAFFE/CFA/M(93)1, Item X]}

- The Committee noted the Secretariat statement that on the $22^{\text {nd }}$ January, the Steering Group for the Multilateral Training network would be asked to agree to convert itself into a "Consultative Group on Taxation and Tax Training". The creation of this Group was agreed to by the Steering Group and its Mandate was to provide guidance on the training courses, to provide a forum for policy exchanges between the Economies in Transition and to facilitate the exchange of views on bilateral and multilateral assistance programmes."

\section{Extract from document [CCEET/DAFFE/M(93)17]}

"ITEM VII - Conversion of the Steering Group into a Consultative Group on Taxation and Tax Training $[\ldots]$

After an extended discussion, the Steering Group agreed to change its name to Consultative Group on Taxation and Tax Training (CGTTT), with the mandate as set out in Annex III.

It was agreed that the main function of the CGTTT would be to review the operation of the tax training network. Th CGTTT would also encourage the development of a policy dialogue between the economies in Transition, on the one hand, and between these countries and the OECD countries, on the other hand. It was also noted that the new Group could help strengthen the link between the training courses and the bilateral and multilateral assistance programmes and would also provide a useful forum for exchanging views on these programmes." 


\section{JOINT MEETINGS OF TAX AND ENVIRONMENT EXPERTS}

Co-Chairs:

Members:

Date of creation:

Duration:
Mr. Christian Valenduc

Mr. Aldo Ravazzi

Open to all Member countries

1st January 2001

31st December 2008
(Belgium)

(Italy)

Mandate: Text of the mandate in document [COM/ENV/EPOC/DAFFE/CFA(2000)105] approved by EPOC under written procedure and renewed during the 61st session of the CFA [DAFFE/CFA/(2001)72] (Identical text in both documents)

\section{Extract from document [DAFFE/CFA(2001)72, Annex II]}

\section{ANNUAL JOINT MEETINGS ON TAXATION AND ENVIRONMENT TERMS OF REFERENCE}

"1. The Committee on Fiscal Affairs (CFA) and the Environment Policy Committee (EPOC) agree to continue the joint meetings of tax and environment experts, from the Working Party No2 on Tax Policy Analysis and Tax Statistics of the CFA, and the Working Party on National Environmental Policy of EPOC.

2. These experts will take part in annual back-to-back meetings with the following terms of reference, taking into account ongoing work following the OECD programme on sustainable development, and the specific economic, fiscal and environmental conditions of OECD countries":

a) To monitor and analyse existing environmentally related taxes, including collecting and analysing data within a common statistical framework.

b) To assess the environmental effectiveness of relevant taxes (and where appropriate related economic support measures, fees and charges) and to review practical implementation issues, drawing on experiences in Member countries.

c) To examine further issues arising from the integration of environmental concerns into the design of tax systems.

3. The Group of experts will provide input into the OECD Sustainable Development work and to follow-up work to this project involving consideration of tax and environment issues.

4. The Group of experts will also monitor developments and contribute, where appropriate, to tax aspects of the follow-up to the Kyoto Protocol to the United Nations Framework Convention on Climate Change.

5. The Group of experts will report, on an annual basis, the findings of the Joint Meetings, including discussions of policy options and transmit these to the CFA and the EPOC.

6. The terms of reference are established for an indefinite period from 1 January 2001, but subject to review and endorsement every second year by both the CFA and the EPOC."

\footnotetext{
1 Should the need arise for two meetings per year, this need will be brought to the attention of the Committee on Fiscal Affairs and the Environment Policy Committee in a formal request for an adjustment.
} 
Chair:

Mr. Pascal Saint-Amans

(France)

Vice-Chair:

Mr. Helmut Loukota

(Austria)

Members:

Open to all Member countries

Observers:

\author{
Argentina \\ China \\ Russian Federation \\ South Africa \\ International Monetary Fund (IMF) \\ World Bank
}

Date of creation:

May 1971

Duration:

December 2008

Mandate: $\quad$ Minutes of the 1st and 56th sessions of the Committee on Fiscal Affairs [CFA/M(71)1 and DAFFE/CFA/M(99)1, Item VIII] and document [DAFFE/CFA(99)8, § 61]

\title{
Extract from document [DAFFE/CFA(99)8, § 61]
}

“61.

"The general mandate of Working Party No. 1 on Tax Conventions and related Questions is to act as a forum for the discussion of issues related to the negotiation, application and interpretation of tax conventions, to examine proposals for the modification of the OECD Model Tax Convention and to draft appropriate recommendations for dealing with the issues it has examined and for periodic updates to the Model Tax Convention." 
STEERING GROUP ON THE REVISION OF THE MODEL TAX CONVENTION

Chair:

Mr. Pascal Saint-Amans

(France)

Members:

Open to all Member countries

Date of creation:

January 1991

Duration:

31st December 2008

Mandate: Summary Record of the 51st session of the Working Party No. 1 on Double Taxation of the Committee on Fiscal Affairs [DAFFE/CFA/WP1/M(91)1]

Extract from document [DAFFE/CFA/WP1/M(91)1, Item VI, § 6$]$

"6. A Steering Group would be constituted to screen these issues and present them to the Working Party with possible recommendations." 
Chair:

Members:

Date of creation:

Duration:
Mr. Helmut Loukota

Open to all Member countries

February 1993

31st December 2008

(Austria)

Mandate: Summary Record of 54th session of the Working Party No. 1 on Double Taxation of the Committee on Fiscal Affairs [DAFFE/CFA/WP1/M(93)1] and document [DAFFE/CFA/CFA/WP1(93)5, § 2]

\section{Extract from document [DAFFE/CFA/WP1/M(93)1, item VI, § 5]}

"5. Application of the Model to partnerships: the Working Party accepted the Steering Group's recommendation to set up a special working group to examine this issue. It was decided, however, that the study would also cover trusts and other non-corporate entities"

\section{Extract from document [DAFFE/CFA/CFA/WP1 $(93) 5, \S 2]$}

"2. $[\ldots]$ It was stressed, however, that the aim of this study was not so much to find uniform solutions as to provide more guidance on how they could be solved bilaterally." 


\section{WORKING PARTY NO. 2 ON TAX POLICY ANALYSIS AND TAX STATISTICS}

Chair:

Mr. Christian Valenduc

(Belgium)

Vice-Chairs:

Mr. Marc Seguin

Mr. Anders Kristoffersson

(Canada)

(Sweden)

Members:

Open to all Member countries

Observers:

Argentina

China

Russian Federation

South Africa

International Monetary Fund (IMF)

World Bank

Date of creation:

May 1971

Duration:

31st December 2008

Mandate: Summary Records of the 1st, 56th, and 62nd Sessions of the Committee on Fiscal Affairs [CFA/M(71)1, DAFFE/CFA/M(99)1, DAFFE/CFA/M(2002)1/REV1] and documents [DAFFE/CFA(99)9 and DAFFE/CFA/WP2(2002)1]

\section{Extract from Document [DAFFE/CFA/WP2(2002)1]}

"1.[...] a new mandate for Working party No.2:

"To analyse and measure the social and economic implications of tax policy, as referred to it by the Committee on Fiscal Affairs. In particular:

- $\quad$ to be responsible for the annual publication of Revenue Statistics and Taxing Wages;

- $\quad$ to analyse current tax policy issues;

- $\quad$ to provide advice and experience in tax-related issues to other parts of the OECD;

- to be responsible for the maintenance and appropriate dissemination of the OECD Tax Database."..." 


\section{WORKING PARTY NO. 6 ON THE TAXATION OF MULTINATIONAL ENTERPRISES}

Chair:

Vice-Chairs:

Members:

Observers:

Date of creation:

Duration:
Mr. David Grecian

Mr. Alain Castonguay

Ms. Kirsten Aamand

Mr. Kiyoshi Nakayama

Mr. Angelo Digeronimo

Open to all Member countries

Argentina

China

Russian Federation

South Africa

January 1973

31st December 2008

\author{
(Australia) \\ (Canada) \\ (Denmark) \\ (Japan) \\ (Switzerland)
}

Mandate: Summary Reccords of the 4th, 38th and 60th Sessions of the Committee on Fiscal Affairs [CFA/M(73)1, CFA/M(90)1 and DAFFE/CFA/M(2001)1]

At its meeting of 30-31 January 2001, the Committee on Fiscal Affairs adopted a revised work programme, which includes the following topics:

Sub-group on Cross-Border Related Party Financial Dealings

The initial focus of the sub-group's work will be on providing guidance on applying the arm's length principle of Article 9 of the OECD Model Tax Convention to (cross-border) loans and thin capitalisation. Once this work has been completed the sub-group will start working on complex cross-border related party financial dealings.

Dispute Resolution

Emphasis will be on examining ways (including use of arbitration) of improving the working of the Mutual Agreement Procedure of Article 25 of the Model Tax Convention.

\section{Monitoring}

The work on monitoring the implementation and application of the OECD Transfer Pricing Guidelines covers four main areas: (1) peer reviews; (2) updates of legislation and practice; (3) difficult case paradigms and (4) practical examples.

\section{Electronic Commerce}

The sub-group on Electronic Commerce will continue monitoring developments in electronic commerce and the impact of the communications revolution on the application of the arm's length principle of Articles 7 and 9 of the OECD Model Tax Convention. The sub-group would also review any input from the Business Profits TAG, for example on transfer pricing or attribution of profit issues relating to servers and web-sites.

\section{Extending the OECD Transfer Pricing Guidelines}

The Working Party will take forward its work on extending the OECD Transfer Pricing Guidelines by continuing its work on developing guidance on the attribution of profits to permanent establishments in general and more specifically on guidance related to banking, global trading and insurance. 
Tax Competition

The Working Party is to complete generic application notes on specific categories of regimes for taxing intra-group activities and for rulings. It will also continue to assist the Forum on Harmful Tax Practices on matters relating to the taxation of multinationals.

Outreach Activities

Work with non-member countries will continue to provide technical assistance in all aspects of transfer pricing. Future work is likely to focus more on developing bilateral dialogue with interested non-member countries on transfer pricing policy issues in order to encourage them to ensure their tax policy is consistent with the OECD Transfer Pricing Guidelines. 


\section{STEERING GROUP ON TRANSFER PRICING GUIDELINES}

Chair:

Members: ${ }^{1}$

Date of creation:

Duration:
Mr. David Grecian

\author{
Australia \\ Canada \\ France \\ Germany \\ Japan
}

(Australia)

Netherlands

Switzerland

United Kingdom

United States

Mandate: Summary Record of the 41st Session of the Working Party No. 6

[DAFFE/CFA/WP6/M(92)1, Item VII] and document [DAFFE/CFA/WP6(92)3]

\section{Extracts from document [DAFFE/CFA/WP6(92)3]}

"1. At its last meeting the Working Party decided that its 1979 report on Transfer Pricing ("Transfer Pricing and Multinational Enterprises") should now be reviewed and this view was endorsed by the Bureau of the Committee on Fiscal Affairs at its' January 1992 meeting. The purpose of this note is to discuss the organisation of the work related to this revision.

\section{$[\ldots]$}

3. Given the Secretariat's limited resources, a significant input from the delegates will be required to carry out these tasks. As was done when the 1979 report was drafted, a special Working Group could therefore be set up to take charge of the revision, with the understanding that the Working Group would report regularly to the Working Party. The Secretariat will also enquire whether Member countries would be prepared to second staff to work full-time on this project."

\footnotetext{
${ }^{1}$ Rotating members: Belgium, Italy, Korea \& Mexico
} 


\section{WORKING PARTY NO. 8 ON TAX AVOIDANCE AND EVASION}

Chair:

Mr. Per Olav Gjesti

(Norway)

Vice-Chairs:

Mr. Heinz Jirousek

(Austria) $\ldots$

(...)

Members:

Open to all Member countries

Observers:

Argentina

China

Russian Federation

South Africa

International Monetary Fund (IMF)

World Bank

Date of creation:

January 1977

Duration:

31st December 2008

Mandate: Minutes of the 12th Session of the Committee on Fiscal Affairs [CFA/M(77)1] and documents [DAFFE/CFA(93)8/REV1 and DAFFE/CFA(96)36]

\section{Extract from document [DAFFE/CFA(96)36]}

"At its 25 June 1996 meeting, the Committee adopted the following mandate:

"To examine both from a domestic and international point of view the legal, policy and administrative aspects of tax avoidance and evasion."

To achieve this mandate the Working Party will, amongst other things, undertake studies on the practical and political aspects of exchange of information, including the use of new technologies to improve such exchanges. The Working Party will also examine ways to increase tax compliance in the financial area, including an analysis of the implications for tax authorities of provisions which limit their access to banking and other relevant information. The Working Party will monitor the implementation of the Recommendation on the tax deductibility of bribes to foreign public officials." 
Chair:

Members: ${ }^{1}$

Date of creation:

Duration:

\author{
Australia \\ Belgium \\ Canada \\ France \\ Ireland \\ Italy
}

(..)

\author{
Japan \\ Netherlands \\ Sweden \\ Switzerland \\ United Kingdom \\ United States
}

2002

31st December 2008

Mandate: Summary Record of the 49th Meeting of Working Party No. 8

[DAFFE/CFA/WP8/M(99)3, Item IV]

\section{Extract from [DAFFE/CFA/WP8/M(99)3, Item IV]}

"10. The Secretariat presented its note DAFFE/CFA/WP8(99)8 which proposes establishing a study group comprised of delegates from WP8 and the Special Session on Innovative Financial Transactions (SSIFT). The Secretariat explained that this proposal was made in order to advance the work and to get more substantive input from the SSIFT. The Secretariat pointed out that, despite requests for comments from the SSIFT on the withholding tax issues, the Secretariat only received two written comments from SSIFT delegates. Given the limited input to date from the SSIFT on the withholding tax issues, the Working Party agreed to form a small study group consisting of both SSIFT and WP8 delegates. The following countries offered to participate in the group: Australia, Italy, Sweden, the United Kingdom, and the United States. The Delegate for Japan reserved judgement on the group and stated that it would comment on the group once a blueprint of the group's work had been developed."

\footnotetext{
1 Current members. The Group is open to all Member countries.
} 
Co-Chairs:

Members: ${ }^{1}$

Date of creation:

Duration:
Mr. Luc de Blieck Mr. Michael Nugent

Australia

Austria

Belgium

Canada

Czech Republic

Finland

France

Italy

1998

31st December 2008
(Netherlands)

(Australia)

Japan

Netherlands

Norway

Spain

Sweden

United Kingdom

United States

European Commission

Mandate: Document [DAFFE/CFA/WP8(98)16/REV1]

The Work Program for the TIES Sub-group is drawn from unfinished work from the merger of the WP8 Cybertax Sub-group and the ad-hoc group on EDI and work referred by other groups under the Committee on Fiscal Affairs (CFA).

The main items for the TIES group that flow from the above-mentioned areas are, and suggestions by delegates are:

(i) adapting the OECD Standard Magnetic Format (SMF) for use in the current technological environment;

(ii) creating a reference or user manual for automatic exchange of information (Eol) using the OECD SMF [both refer: DAFFE/CFA/WP8(96)6 and DAFFE/CFA/M(98)1];

(iii) developing an electronic format for a certificate of residence [refer: DAFFE/CFA/WP8/M(98)1 and DAFFE/CFA/WP8(98)9];

(iv) conducting a pilot exercise to electronically exchange Tax Identification Numbers (TINs) [refer: DAFFE/CFA/WP8/M(98)1];

(v) updating and expanding the 1995 survey on the implementation of the OECD standard Magnetic Format;

(vi) addressing data security and data quality issues for exchange of information; and

(vii) considering the benefits and appropriate processes for exchanging information on consumption taxes.

\footnotetext{
1 Current members. Sub-Group open to all Member countries.
} 


\section{WORKING PARTY NO. 9 ON CONSUMPTION TAXES}

Chair:

Vice-Chairs:

Members:

Observers:

Date of creation:

Duration:
Mr. Michael Hardy

Mr. Rainer Nowak

Mr. Arthur Kerrigan

Mr. Richard Brown

Mr. Yasushi Onishi

Open to all Member countries

Argentina

Chile

China

Russian Federation

South Africa

International Monetary Fund (IMF)

World Bank

January 1998

31st December 2008
(Australia)

(Canada)

(European Commission)

(United Kingdom)

(Japan)

Mandate: Document [DAFFE/CFA(97)21/CORR1]

\section{Extract of Document [DAFFE/CFA(97)21/CORR1]}

\section{"Proposed mandate and duration}

51.

Proposed draft mandate:-

Having regard to the continuing rise in importance of Value Added Tax and other consumption taxes as major sources of government revenues and having regard to the increasing international dimension of such taxes, the Committee on Fiscal Affairs endorses the work of the Consumption Tax Group as set out in this note and proposes that the work of the Group continues under the status of Special Sessions during 1997-98 and will be reviewed in 1998 in order to accord Working Party status. The CTG will continue to provide a forum where the administrative, control and policy issues associated with consumption taxes can be discussed.

52. In particular the CTG will concentrate its work on those areas of VAT and other consumption taxes where international co-operation will be necessary for ensuring the effective administration of taxation in the future, notably in the field of international services involving telecommunications and related supplies and to be a source of tax data information on consumption taxes to both Member countries and developing economies alike.

53. It is recommended that the mandate remain in force for three years. The CFA will review the mandate at the end of this period based on a further report from the CTG." 


\title{
FORUM ON HARMFUL TAX PRACTICES
}

Co-Chairs:

Members:

Observers:

Date of creation:

Duration:
Mr. Christian Comolet-Tirman

(France)

...

(...)

Open to all Member countries

\author{
Argentina \\ China \\ Russian Federation \\ South Africa \\ International Monetary Fund (IMF) \\ World Bank
}

July 1998

31st December 2008

Mandate: Recommendation of the Council on Counteracting Harmful Tax Competition [C(98)17/FINAL]

\section{Extract from document [C(98)17/FINAL]}

"1. to establish a Forum on Harmful Tax Practices;

2. to implement the relevant measures identified in the attached Appendix

3. to report periodically to the Council on the results of its work in these matters together with any relevant proposals for further improvements in the co-operation to counter harmful tax practices;

4. to develop its dialogue with non-member countries, consistently with the policy of the Organisation, with the aim of assisting these countries to become familiar with the analysis and conclusions of the Report and, where appropriate, to encourage them to associate themselves with the recommendations set out in the Report." 


\section{FORUM ON TAX ADMINISTRATION}

Chair:

Mr. Bjarne Hope

(Norway)

Members:

Open to all Member countries

Observers:

Argentina
Brazil
Chile
China
Estonia
International Monetary Fund (IMF)
United Nations
World Bank

India

Russian Federation

Singapore

South Africa

Date of creation:

June 1997 (revised in 2002)

Duration:

31st December 2008

Mandate: - To provide an open forum for tax administrators to provide strategic analysis of, and propose responses to, important tax administration issues. The work methods will involve virtual and ad hoc meeting procedures [DAFFE/CFA(97)37] as approved by the Committee on Fiscal Affairs during its 53rd Session [DAFFE/CFA/M(97)2].

- Name changed and mandate modified by the CFA in June 2002 [DAFFE/CFA/M(2002)2/CONF, Item VIII] and document [DAFFE/CFA(2002)28/REV1, § 7]

The "Forum on Strategic Management" - now the Forum on Tax Administration - was created by the CFA in June 1997 to act as the focal point for CFA work on tax administration. The CFA recognised the need for a forum in which tax administrators could exchange experiences in addressing existing and future strategic challenges for tax administrations in a rapidly changing and globalising environment.

The aims of the FTA are:

- To share information \& experiences on common tax administration issues, such as service and compliance approaches as well as non-tax specific administrative issues such as performance measurement \& management.

- To share thoughts on emerging administrative challenges. 


\title{
FORUM ON TAX ADMINISTRATION COMPLIANCE SUB-GROUP (FTACOMP) ${ }^{1}$
}

Chair:

Mr. Lennart Wittberg

(Sweden)

Members:

Open to all Member countries

Observers:

\author{
Argentina \\ Chile \\ China \\ Russian Federation \\ South Africa
}

Date of creation:

2002

Duration:

31st December 2008

Mandate: Document [DAFFE/CFA/FSM(2002)1] approved by the CFA at its 62nd session in January 2002 [DAFFE/CFA/M(2002)1].

The FSM* Compliance Sub Group was created in 2002 by the Forum on Strategic Management. The following mandate has been agreed:

The mandate of the Compliance Sub-group of the Forum on Tax Administration is to provide a forum for members to share experiences and knowledge of compliance approaches to progress good practice in compliance activities and administration both domestically and internationally.

Specifically it will:

- Periodically monitor and report on trends in compliance approaches, strategies and activities.

- Consider and compare member compliance objectives, the strategies to achieve those objectives and the underlying behavioural compliance models and assumptions being used.

- Consider and compare member compliance structures, systems (including case selection, actioning, and management) and staff skills and training.

- Create and maintain best practice papers and discussion papers on emerging trends and innovative approaches.

\footnotetext{
1 Formerly "Sub-Group on Compliance", name changed on 27th june 2002.

* Now called "Forum on Tax Administration" or "FTA" [DAFFE/CFA/M(2002)2/CONF].
} 


\section{FORUM ON TAX ADMINISTRATION TAXPAYER SERVICES SUB-GROUP ${ }^{1}$}

Chair:

Mr. Terry Hawes

(United Kingdom)

Members:

Open to all Member countries

Observers:

Argentina

Chile

China

Russian Federation

South Africa

Date of creation:

2001

Duration:

31st December 2008

Mandate: Document [DAFFE/CFA/FTA/ESERV(2002)1/REV1] discussed the 1 st meeting of the FTA in October 2002

\section{Extract from document [DAFFE/CFA/FTA/ESERV(2002)1/REV1]}

\section{"Mandate}

The primary mandate of the Forum on Tax Administration (FTA) eServices Sub-group* is to provide a forum for members to share experiences and knowledge in Taxpayer Service provision and to progress good practice both in Taxpayer Service domestically and internationally.

\section{Specifically it will:}

- Periodically monitor and report on trends in Taxpayer Service delivery, with a particular focus on the development and deployment of e-Services by Tax administration.

- Examine ways to promote the uptake and use of e-Services by Tax administrations.

- Examine options for cross border administrative simplification and consistency, thus making it easier to comply."

\footnotetext{
1 Formerly "Forum on Tax Administration E-Service Sub-Group".
} 

Chair:

Ms. Silvia López Ribas

(Spain)

Date of creation:

18th December 2003

Duration:

31st December 2010

Mandate: - Decision of the Council establishing an OECD Network on Fiscal Affairs Across Levels of Government approved at its 1074th session held on 18 December 2003 [C/M(2003)29, item 414 and C(2003)192]

- The mandate was extended by Council during its $1128^{\text {th }}$ session held on 26 January $2006[\mathrm{C} / \mathrm{M}(2006) 2$, item 17]

\section{Extract of the Summary Record [C/M(2003)29, item 414]}

(414)

"THE COUNCIL

b) agreed to the creation of an OECD Network on Fiscal Relations Across Levels of Government for a period of three years until December 2006, with a review to be made at the end of 2005 to determine whether the Network's mandate should be extended, and agreed to the proposed mode of financing subject to Council decision on the 2005-2006 biennium;

c) agreed with its proposed activities, output, work programme, membership and funding as described in C(2003)192 and its CORR1/REV1 and the Annex hereto."

\section{Extract of Document C(2003)192}

"7. The main objectives of the Network would be to:

- Provide a place where officials and others can exchange experience and views on the policy issues involved in reforming fiscal relations across levels of government;

- Analyse aspects of the design of fiscal relations across levels of government and their impact on local, regional and national development;

- Establish and maintain a consolidated statistical database, covering both quantitative and qualitative aspects of fiscal relations across levels of government for Network members."

\section{Extract of $[C / M(2006) 2$, item 17]}

(17)

"THE COUNCIL

b) Agreed to the extension of the mandate of the Network on Fiscal Relations Across Levels of Government for a period of four additional years, until December 2010, with a review to be made at the end of 2009 to determine whether the Network's mandate should be further extended." 

SCIENCE, TECHNOLOGYAND INDUSTRY 



\section{Chair:}

Vice-Chairs:

Members:

Observers:

$$
\text { Mr. Jacques Serris }
$$

Ms. Jessie Borthwick

Mr. Ward Ziarko

Mr. Klaus Matthes

Mr. Vilhjálmur Lundviksson

Mr. Shinichiro Ohgaki

Mr. Tae-Young Shin

Mr. Theo Roelandt

Mr. Luis Sanz Menendez

Mr. George Dragnich
(France)

(Australia)

(Belgium)

(Germany)

(Iceland)

(Japan)

(Korea)

(Netherlands)

(Spain)

(United States)

Open to all Member countries

China

Israel

Russian Federation

South Africa

Council of Europe

Date of creation:

3rd February 1972

Duration:

31st December 2009

Mandate: - Resolution of the Council Concerning the Renewal of the Committee for Scientific and Technological Policy [C(2004)120] approved by Council at its 1091st session on 8 July 2004 [C/M(2004) 17, item 217]

- Resolution of the Council Concerning the Renewal of the Committee for Scientific and Technological Policy [C(99)185/FINAL]

\section{Resolution of the Council [C(2004)120]}

THE COUNCIL,

Having regard to Articles 1 and 2 of the Convention on the Organisation for Economic Co-operation and Development of 14 December 1960;

Having regard to the Resolution of the Council of 17 November 1999 concerning the terms of reference of the Committee for Scientific and Technological Policy [C(99)185/FINAL], and to the conclusions of the $964^{\text {th }}$ Session of the Council on 9 December 1999 concerning the extension of the mandate of the Committee for Scientific and Technological Policy [C/M(99)25/PROV, Item 338];

Having regard to the conclusions of the meeting of the Committee for Scientific and Technological Policy at Ministerial level on 29-30 January 2004 [PAC/COM/NEWS(2004)4];

Having regard to the continuing need for a consultative mechanism within the OECD whereby science, technology and innovation policy issues, problems, and challenges of a national and international nature can be examined by Member countries and reported to the Council; 
Having regard to the Rules of Procedure of the Organisation;

\section{DECIDES:}

1. The Committee for Scientific and Technological Policy shall be responsible for encouraging co-operation among Member countries and, as appropriate, with non-member economies, in the field of science, technology and innovation policy, with a view to contributing to the achievement of their economic, social and scientific aims, including growth and the creation of skilled jobs, sustainable development, improved well-being of their citizens and advancing the frontiers of knowledge. It shall pay particular attention to the integration of science, technology and innovation policy with other aspects of government policy, which is of increasing importance in the development of increasingly globalised knowledge economies.

2. The Committee for Scientific and Technological Policy shall, more particularly, be responsible for:

a) Improving, through analytical work and the development of relevant internationally comparable indicators, the understanding of the process through which science, technology and innovation contribute to increased knowledge, productivity growth, economic performance, skilled job creation, sustainable development and social well-being.

b) Promoting the exchange of information and discussion among Member countries on the objectives, instruments and financing of science, technology and innovation policy, in order to facilitate international comparison, to develop evaluation models and to identify relevant best policy practices, particularly as relates to the production and dissemination of knowledge and the strengthening of links between research, higher education and industry, including in the fields of human resource development, innovation policy and mobility.

c) Promoting the exchange of information and discussion among Member countries on policies designed to maintain a strong and creative base of scientific research endowed with adequate tangible and intangible infrastructure.

d) Improving the understanding of Member countries both of foreseeable developments of technology and impact of biotechnologies and their likely national as well as international economic, social and environmental consequences, and the impact of globalisation on their national and regional research and innovation systems.

e) Promoting the exchange of information and discussion among Member countries on measures to promote public understanding of science and technology, to make science and technology studies and training more attractive; and to strengthen, within each Member country, dialogue and interaction with science, industry, and civil society in formulating and implementing science, technology and innovation policies.

f) Facilitating international co-operation in science and technology, as well as, as appropriate, policy co-ordination among Member countries, and among Member and non-member economies on the development of research, access to scientific information and the international mobility of researchers.

g) Facilitating the efforts of the governments of Member countries to strengthen the scientific and technological capabilities of developing countries.

3. In the pursuit of these objectives, the Committee for Scientific and Technological Policy shall determine the strategic orientations of its subsidiary bodies, and receive regular reports from them to ensure their co-ordination, policy integration and evaluation. It shall maintain close working relationships with other relevant bodies of the Organisation working on issues that affect the design 
and implementation of science and technology policies. The Committee shall co-operate with other international and regional organisations active in this policy field. It may consult with nongovernmental bodies as and when necessary.

4. These terms of reference shall enter into force on 1 January 2005 and shall expire on 31 December 2009, unless the Council decides otherwise.

6. Paragraph 14 of the Annex to the Rules of Procedure shall be amended to read as follows:

"14. Committee for Scientific and Technological Policy: Its terms of reference are defined in the Resolution of the Council C(2004)120." 
Chair:

Vice-Chairs:

Members:

Observers:

$$
\text { Mr. Fred Gault }
$$

Mr. Ward Ziarko

Mr. Giorgio Sirilli

Mr. Tomohiro ljichi

Ms. Lynda Carlson

Open to all Member countries
(Canada)

(Belgium)

(Italy)

(Japan)

(United States)

Date of creation:

China

Israel

Russian Federation

South Africa

U.N. Educational Scientific and Cultural Organization (UNESCO)

Duration:

September 1962

31st December 2009

\begin{abstract}
Mandate Summary record of the 84th Session of the Committee for Scientific and Technological Policy [DSTI/STP/M(2004)3, para. 34] and [ DSTI/STP(2004)14]

Summary record of the 74th Session of the Committee for Scientific and Technological Policy [DSTI/STP/M(2000)1, para. 11 and Annex 2 B]
\end{abstract}

Extract from documents [DSTI/STP/M(2004)3, para. 34 and DSTI/STP(2004)14]

The Committee:

Agreed to provisionally approve the CSTP Working Parties' new mandates pending the Council's decision on the CIBE/CSTP merger.

\title{
MANDATE OF THE WORKING PARTY OF NATIONAL EXPERTS ON SCIENCE AND TECHNOLOGY INDICATORS
}

1. The Working Party will monitor, supervise, direct and co-ordinate statistical work and contribute to the development of indicators and quantitative analyses needed to meet the requirements and priorities of the Committee for Scientific and Technological Policy (CSTP). In particular, the Working Party will:

i) Ensure the continued improvement of the methodologies for the collection of internationally comparable data for measuring the input, output, diffusion and impact of science, technology and innovation (including linkages to economic growth) as laid down in the series of manuals produced by the Working Party; encourage the use of these methodologies in member countries and non-member economies. This includes developing and maintaining manuals and standards for measurement in the areas of research and development, human resources in S\&T, innovation, patents, globalisation and other S\&T related matters. 
ii) Ensure the timely availability of internationally comparable S\&T data and their analysis, such as the R\&D data collected through biennial OECD surveys and OECD analytical reports, and the further development of data collection and dissemination systems for other S\&T and knowledge indicators.

iii) Assist in developing and interpreting statistical indicators which aid formulation and evaluation of science and technology policies. This work should be undertaken in the light of policy priorities expressed by the CSTP, its subsidiary bodies and by member countries.

iv) As required, pursue any other work, needed to assist the CSTP or its subsidiary bodies in the development of quantitative analyses of S\&T-related issues such as the international mobility of researchers, internationalisation of research efforts and more generally the contribution of science and technology to economic growth.

2. The Working Party will promote efficient use of resources by seeking opportunities to work in collaboration with other groups with similar interests, both within the OECD and other competent international fora. The Working Party will also provide technical expertise to other organisations (within and outside of the OECD) on S\&T indicators.

3. The Working Party will co-operate, in particular, with other OECD statistical subgroups and working parties in dealing with broader statistical issues connecting industrial, science and technology, information technology, and human resources activities, and will co-ordinate the development of a coherent set of S\&T indicators across the various areas.

4. Finally, the Working Party will act as a clearing house via which member countries and nonmember economies can exchange information and experience on methods of collection, compilation, analysis and presentation of data which they use as science and technology indicators.

5. The Terms of Reference of the Working Party of National Experts on Science and Technology Indicators shall remain in force until 31 December 2009, unless the CSTP decides otherwise." 


\section{WORKING PARTY ON BIOTECHNOLOGY}

Chair:

Vice-Chairs:

Members:

Observers:

Date of creation:

Duration:
Mr. David Harper

Mr. John Jaworski

Mr. Hiroshi Yoshikura

Mr. Kurt A. Zuelke

Open to all Member countries

China

Israel

Russian Federation

South Africa

March 1994

31st December 2009
(United Kingdom)

(Canada)

(Japan)

(United States)

Mandate: - Summary record of the 84th Session of the Committee for Scientific and Technological Policy [DSTI/STP/M(2004)3, paragraph 34]

- Summary Record of the 78th Session of the Committee for Scientific and Technological Policy [DSTI/STP/M(2002)1]

\section{Extracts from documents [DSTI/STP/M(2004)3, paragraph 34, and DSTI/STP(2004)16]}

$“ \cdots$

The Committee:

Agreed to provisionally approve the CSTP Working Parties' new mandates pending the Council's decision on the CIBE/CSTP merger."

\section{"MANDATE OF THE WORKING PARTY ON BIOTECHNOLOGY}

1. The Group will advise upon emerging policy-relevant issues of science, technology and innovation related to biotechnology including, as appropriate, their social and economic implications, with a view to assisting the development, application and diffusion of products, processes, infrastructure and services which, through industrial production, environmental protection, health care and health promotion, will contribute to sustainable economic growth and development, and human welfare.

2. This should be achieved by: encouraging the international harmonisation of science-based policies, principles and concepts; facilitating scientific and technological co-operation, capacity-building and exchange; taking an appropriate role in debate with society including by promoting education and the public understanding of the opportunities and risks associated with advances in biotechnology, and informing and assisting the work of policy makers in Member countries.

3. The Group will report to the Committee for Scientific and Technological Policy (CSTP), and will keep other Committees or their subsidiary bodies informed on the progress of work relating to their interests. It will also seek to work co-operatively with such bodies, where deemed mutually 
beneficial. The Internal Co-ordination Group for Biotechnology will also be consulted and informed about the work of the Group, with a view to the avoidance of duplication and the promotion of synergy and joint activities, where appropriate. Communication and co-operation should also extend, where relevant, to other international organisations.

4. When and where appropriate, and having identified appropriate activities, the Group shall seek through various forms of outreach activities to make known and extend the influence and impact of OECD work on biotechnology beyond Member countries, and so far as practicable take this wider context into account in the preparation and execution of its work.

5. In pursuance of its aims, the Group will endeavour to set strategic future directions for successive Programmes of Work from which to set clear, defined and costed objectives for work in which OECD activity adds value.

6. The Mandate shall run from 1 January 2005 to 31 December 2009, subject to modification by decision of the CSTP; with a mid-term review to assess the value, impact and effectiveness of the work of the Group." 
Chair:

Vice-Chair:

Members:

Observers:

Date of creation:

Duration:
Mr. Alexandre Quintanilha

Mr. Hiroshi Yoshikura

Open to all Member countries

China

Israel

Russian Federation

South Africa

February 1995

31st December 2009
(Portugal)

(Japan)

Mandate: - Summary Record of the 2nd Session of the Working Party on Biotechnology [DSTI/STP/BIO/M(95)1]

- In 1998, following the review undertaken by Mr. Vinde [CE(98)3], in line with the recommendation on standardised terminology, the Ad hoc Group was renamed Working Group on Human-Health-Related Biotechnologies.

\section{Extract from document [DSTI/STP/BIO/M(95)1]}

"35. It was agreed to establish an Ad hoc Task Force on Human-health-related Biotechnologies to address the economic project, the subject of transgenic animals, and the general issue of priorities for WPB work in health care." 
Chair:

Vice-Chairs:

Members:

Observers:

Date of creation:

Duration:
Mr. John Jaworski

Mr. Yukio Kawauchi

Mr. Oliver Wolf

Open to all Member countries

China

Israel

Russian Federation

South Africa

February 1998

31st December 2006
(Canada)

(Japan)

(European Commission)

Mandate: Summary Record of the 6th Session of the Working Party on Biotechnology [DSTI/STP/BIO/M(98)2]

\section{Extract from document [DSTI/STP/BIO/M(98)2]}

"16. The Secretariat and the Chairman of the Ad Hoc Task Force on Biotechnology for Clean Industrial Products and Processes, Professor Alan Bull, presented the final report, DSTI/STP/BIO(98)2, with its Annex and the amendments as finalised at the meeting on 19-20 February of the Task Force.

17. The WPB expressed strong appreciation for the quality and timeliness of the report, and agreed to recommend it to CSTP for declassification, subject to incorporation of modifications received so far, and a 5 March deadline for final comments. The WPB underlined the need for a "Policy Booklet", to be submitted to the Ad Hoc Task Force for declassification, and other effective diffusion, including a press release and use of Internet.

18. Canada proposed to initiate and lead a follow-up activity on "Biotechnology for Sustainable Industrial Development", perhaps by a procedure similar to that used in the Megascience Forum. The proposal received strong support." 
TASK FORCE ON BIOLOGICAL RESOURCE CENTRES

Chair:

Vice-Chairs:

Members:

Observers:

Date of creation:

Duration:
Mr. Louis Réchaussat

Mr. John Jaworski

Mr. Hideaki Sugawara

Mr. David Smith

Open to all Member countries

China

Israel

Russian Federation

South Africa

February 2001

31st December 2006
(France)

(Canada)

(Japan)

(United Kingdom)

Mandate: Summary Record of the 10th Session of the Working Party on Biotechnology [DSTI/STP/BIO/M(2001)2]

\section{Extract from document [DSTI/STP/BIO/M(2001)2]}

\section{“ITEM 7: BIOLOGICAL RESOURCE CENTRES}

$(\ldots)$

23. There was considerable WPB support for follow-up activity on BRCs addressing the five goals identified. Clear milestones were required and participation by GBIF would be useful as well as that of appropriate centres from non-OECD countries and representatives of other relevant international initiatives, such as the CBD.

24. The WPB agreed to the creation of a follow-up Task Force with a two-year work programme, with an additional preparatory period to agree priorities and milestones and to shape the detail of the work." 


\section{OECD GLOBAL SCIENCE FORUM}

Officer:

Mr. Hermann-Friedrich Wagner

(Germany)

Vice-Chairs:

Mr. Grahame Cook

Mr. Jørgen Kjems

(Australia)

Mr. Dominique Goutte

(Denmark)

Mr. Alessandro Bettini

(France)

Mr. Hiroshi Nagano

(Italy)

(Japan)

Mr. Leo Le Duc

(Netherlands)

Mr. Paul Williams

(United Kingdom)

Ms. Kathie Olsen

(United States)

Members:

Australia
Austria
Belgium
Canada
Czech Republic
Denmark
Finland
France
Germany
Greece
Hungary
Ireland
Italy
Japan
Korea

Mexico

Netherlands

New Zealand

Norway

Poland

Portugal

Slovak Republic

Spain

Sweden

Switzerland

Turkey

United Kingdom

United States

European Commission

$\begin{array}{ll}\text { Observers: } & \text { China } \\ & \text { Israel } \\ & \text { Russian Federation } \\ & \text { South Africa }\end{array}$

Date of creation: June 1992

Duration:

31st January 2009

Mandate: - Summary of the Special Session of the Committee for Scientific and Technological Policy held on 30 April 1999 [DSTI/STP/M(99)2]

- Summary Record of the $82^{\text {nd }}$ Session of the Committee for Scientific and Technological Policy, held on 12 December 2003 [DSTI/STP/M(2003)3]

\section{Extract from document [DSTI/STP/M(2003)3, paragraph 16]}

16. The Committee:

i. Noted the current GSF mandate contained in document DSTI/STP/MS(99)3.

ii. Expressed its strong support for the work carried out by the Global Science Forum

iii. Agreed to extend the GSF mandate, without modification of the text, for a period of five years as of 1 February 2004. 
“..

2. The Committee considered that:

a) Basic and applied research in the physical, life and social sciences constitute an essential input to the development and performance of OECD knowledge-based economies.

b) Decision-makers increasingly seek science-based information and advice on problems in critical areas such as health, environmental stewardship and sustainable development.

c) The importance of science policy is therefore increasing, both in its own right, and in connection with other governmental responsibilities.

d) In certain scientific and technological fields, the scope and scale of new initiatives and facilities are such that they can only be achieved through international or interregional collaboration, due to the high cost and complexity of the needed infrastructure, and the worldwide distribution of resources, data and expertise.

e) International consultations are therefore often needed in scientific areas where other mechanisms do not already exist, to address specific near- and mid-term science policy issues, and to explicitly identify opportunities for international co-operation.

3. The Committee noted a statement by the Deputy Director of the Directorate for Science, Technology and Industry, Mr. Oborne, who emphasised that the Secretariat was suggesting a 5-year mandate for the proposed Forum with the understanding that:

i) Any country could withdraw before the end of the mandate.

ii) The Committee could abolish the Forum before the end of the 5-year period if it so wished.

iii) The evaluation process would be undertaken between the fourth and the fifth year and be designed by the Forum in consultation with the Committee.

4.

the light of the foregoing considerations, of the relevant discussions of the Megascience Forum, and of Mr. Oborne's statement, the Committee agreed to establish an OECD Global Science Forum, which would succeed and replace the Megascience Forum, with the mandate contained in Annex 1 to the present record."

\section{ANNEX 1}

\section{“MANDATE OF THE OECD GLOBAL SCIENCE FORUM}

The OECD Global Science Forum shall be a venue for consultations among senior science policy officials of the OECD Member countries, leading to findings and recommendations for action on high-priority science policy issues that require international consultations and/or co-operation, and, whenever possible, identifying opportunities for collaboration on major scientific undertakings. The OECD Global Science Forum shall build on the accomplishments and procedures of the Megascience Forum from 1992 to 1998, with more flexible working mechanisms, and a broader scope including issues at the intersection of science and other public policy domains. As in the Megascience Forum, substantive work will be performed by representatives of governments, with the OECD Secretariat playing a facilitating and co-ordinating role. 
Through its deliberations and activities, the OECD Global Science Forum shall assist Members in the formulation and implementation of their science policies by:

- Exploring opportunities for new or enhanced international co-operation in selected scientific areas.

- Defining international frameworks for vital national or regional science policy decisions.

- Addressing the scientific dimensions of issues of global concern.

The Forum's principal customers will be the government science policy officials who will bring issues forward for consultation. The Forum shall regularly report to the Committee on the progress of its work, its findings, and new topics and activities that are being considered for incorporation into its work programme. At the request of the Committee, it may undertake work on specific issues, for example, reviews and analyses of current policies, practices and emerging challenges. It shall maintain close working relationships with relevant bodies of the OECD and other international organisations. The OECD Global Science Forum shall define its operating procedures, taking into account the experience and relevant discussions of the Megascience Forum. To ensure that the Forum's work attracts the broad support of delegations, and complements that of the Committee, the following criteria should be met before any new activity is undertaken:

- $\quad$ Specificity -- A specific challenge, problem, opportunity or programme area must be identified - one that concerns international scientific co-operation, and requires a structured international consultation with the involvement of governmental officials.

- Relevance -- There must exist significant near- or mid-term decisions and actions by governments that would be facilitated by the activity.

- Workload -- A fixed time interval, as well as the type of activity should be specified (workshop, working group, study, structured discussion by the Forum, etc.). The resources required from the OECD Secretariat and the Member delegations should be described.

- Commitment -- There must be a high level of interest among Member countries, including broad geographic representation among the OECD membership. One lead country must be willing to provide the needed leadership and resources. There must be a prospect for participation by the appropriate governmental representatives, and scientific experts.

- Inclusiveness -- Potential involvement of non-OECD countries, international bodies, and other OECD committees must be considered to maximise opportunities for productive interactions, and to avoid unnecessary duplication of effort.

The Mandate of the OECD Global Science Forum shall remain in force until 1 February 2004, subject to the renewal of the mandate of the Committee by the Council, unless the Committee decides otherwise. An evaluation exercise will be conducted prior to the end of the mandate period. Approximately half-way into that period, the extent and format of the evaluation will be decided by the Global Science Forum, with the concurrence of the CSTP." 


\section{AD HOC WORKING GROUP ON STEERING AND FUNDING OF RESEARCH INSTITUTIONS}

Chair:

Ms. Sveva Avveduto

(Italy)

Vice-Chairs:

Mr. William Thorn

Mr. Anders Bjørneboe

(Australia)

Mr. Joel Lelièvre

(Denmark)

Ms. Sveva Avveduto

(France)

(Italy)

Mr. Yuji Sakakibara

(Japan)

Ms. Yukiko Miura

(Japan)

Mr. Jacek Mazur

(Poland)

Members:

Open to all Member countries

Observers:

China

Israel

Russian Federation

South Africa

Date of creation:

1st March 2000

Duration:

31st December 2009

Mandate : Summary record of the 84th Session of the Committee for Scientific and

Technological Policy [DSTI/STP/M(2004)3, para. 34] and [DSTI/STP(2004)24]

Summary record of the 74th Session of the Committee for Scientific and

Technological Policy [DSTI/STP/M(2000)1, para. 13]

Extract from documents [DSTI/STP/M(2004)3 para. 34 and DSTI/STP(2004)24]

$“ \ldots$

"The Committee:

“Agreed to provisionally approve the CSTP Working Parties' new mandates pending the Council's decision on the CIBE/CSTP merger.

\section{MANDATE OF THE AD HOC WORKING GROUP STEERING AND FUNDING OF RESEARCH INSTITUTIONS (SFRI)}

1. The main objectives of the ad hoc Working Group will be to exchange information on and to review the main institutional, regulatory, and management issues facing governments as they strive to foster a diverse and mobile workforce for science and technology. Specific issues to be addressed include:

- $\quad$ Monitoring supply and demand for S\&T graduates and PhDs. 
- Comparing, at international level, factors that affect the attractiveness and prospects of research careers.

- Contribute to work on raising the attractiveness of science at all stages of education.

- $\quad$ Analysing the participation of women in S\&T education and research careers.

- Analysing trends, key drivers and policies of international mobility of students and personnel in S\&T.

- Contribute to the improvement of existing data on human resources.

2. As required by the Committee, the Working Group will continue to carry out work on the funding of research and address issues related to the evaluation of research institutions.

3. The Group will implement its activities through the provision and exchange of information on member countries' practices and policy initiatives with a view to identifying good practices and possible reforms.

4. The ad hoc Working Group will undertake its work in close co-operation with other relevant Working Parties of CSTP (TIP, Global Science Forum, NESTI) and other OECD bodies (EDU/IHME/CERI) in order to increase the benefits to their respective activities and to avoid duplication of effort. It will also liaise with other relevant international organisations (e.g. UNESCO, European Commission) as appropriate.

5. The Working Group will report regularly to the CSTP so that the value, impact and effectiveness of its work can be reviewed and assessed, and the CSTP can decide on the duration of the Working Group in due time." 



\section{COMMITTEE FOR INFORMATION, COMPUTER AND}

COMMUNICATIONS POLICY

Chair:

Vice-Chairs:

Members:

Observers:

Date of creation:

Duration:
Mr. Hugo Parr

Mr. Richard Simpson

Ms. Kristiina Pietikainen

Mr. Benoît Blary

Mr. Ervin Kajzinger

Mrs. Daniela Battisti

Mr. Hitoshi Aida

Mr. Mark Esseboom

Mr. R. C. Beaird
(Norway)

(Canada)

(Finland)

(France)

(Hungary)

(Italy)

(Japan)

(Netherlands)

(United States)

Open to all Member countries

Israel

Russian Federation

Singapore

Council of Europe

1st April 1982

31st December 2008

Mandate: - Resolution of the Council concerning the Terms of Reference of the Committee for Information, Computer and Communications Policy [C(99)13/FINAL]

- Mandate extended by Council during its $1078^{\text {th }}$ session on 26 February 2004 [C/M(2004)4 and C(2004)7 and CORR1]

- Mandate modified by Council during its $1107^{\text {th }}$ session on 10 March 2005 [C/M(2005)6, Item 68 and C(2005)26]

\section{$\underline{\text { Resolution of the Council [C(2005)26] }}$}

THE COUNCIL,

Having regard to Articles 1 and 2 of the Convention of the Organisation for Economic Co-operation and Development of 14th December 1960;

Having regard to the Resolution of the Council of 27th January 1994 concerning the Terms of Reference of the Committee for Information, Computer and Communications Policy [C(93)180/FINAL];

Having regard to the continuing need for a consultative mechanism within the OECD whereby information, computer and communications policy problems of a national and international nature can be examined by Member countries and reported to the Council;

Having regard to the Conclusions of the October 1998 Ottawa Ministerial Conference "A Borderless World: Realising the Potential of Global electronic Commerce" [SG/EC(98)14/FINAL], in particular to the OECD Action Plan for Electronic Commerce which was endorsed by Ministers [SG/EC(98)9/FINAL], and to the leading role to be played by the Committee for Information, Computer and Communications Policy in the follow-up to this Conference; 
Having regard to the Rules of Procedure of the Organisation;

DECIDES:

I.

TERMS OF REFERENCE OF THE COMMITTEE FOR INFORMATION, COMPUTER AND COMMUNICATIONS POLICY

1. The Committee for Information, Computer and Communications Policy shall be responsible for examining policy issues arising from the development and application of technologies in the field of information, computer and communications systems and services, such as electronic business and information infrastructure issues, including the impact of such issues on the economy and on society in general, and for strengthening co-operation in this field between the Member countries and, as appropriate, between Member countries and non-Member countries.

2. The Committee shall, in particular, be responsible in this field for:

a) Promoting exchanges of experience among Member countries on the development and application of technologies in the field of information, computer and communications systems and networks and services as well as on national and international policies.

b) Analysing developments, such as convergence, information, computer and communication services, and calling the attention of Member governments to the major implications of such developments.

c) Facilitating the development of policies for information, computer and communications policy at the national and international level, information and communication networks, electronic business, digital content, and building trust by enhancing security of information systems and networks and privacy protection.

d) Fostering co-operation among Member countries and as appropriate, co-ordination of their policies.

3. The Committee shall maintain close working relationships with other relevant bodies of the Organisation, and other international organisations active in the field of information, computer and communications policy as well as with regional bodies. The Committee shall also develop, as appropriate, partnerships with business, trade unions and public interest groups.

4. The Terms of Reference of the Committee for Information, Computer and Communications Policy shall remain in force until 31 December 2008, unless the Council decides otherwise. 


\begin{tabular}{|c|c|c|}
\hline Chair: & Mr. Dietmar Plesse & (Germany) \\
\hline Vice-Chairs: & $\begin{array}{l}\text { Mr. Simon Bryant } \\
\text { Mr. Nicolas Toure } \\
\text { Mr. Tsuyoshi Okazaki } \\
\text { Ms. Christina Speck }\end{array}$ & $\begin{array}{l}\text { (Australia) } \\
\text { (France) } \\
\text { (Japan) } \\
\text { (United States) }\end{array}$ \\
\hline Members: & \multicolumn{2}{|c|}{ Open to all Member countries } \\
\hline Observers: & \multicolumn{2}{|l|}{$\begin{array}{l}\text { Israel } \\
\text { Singapore }\end{array}$} \\
\hline & \multicolumn{2}{|c|}{ International Telecommunication Union (ITU) } \\
\hline Date of creation: & \multicolumn{2}{|l|}{ 24th March 1988} \\
\hline Duration: & \multicolumn{2}{|l|}{ 31st December 2006} \\
\hline
\end{tabular}

Mandate : - Summary Record of the 35th Session of the ICCP Committee held on 4-5 March 1999 [DSTI/ICCP/M(99)1]

- $\quad$ Summary Record of the 40th Session of the ICCP Committee held on 11-12 October 2001 [DSTI/ICCP/M(2001)2]

- $\quad$ Summary Record of the 45th Session of the ICCP Committee held on 2-3 October 2003 [DSTI/ICCP/M(2003)2]

- $\quad$ Summary Record of the 47th Session of the ICCP Committee held on 20-21 October 2004 [DSTI/ICCP/M(2004)2]

\section{Extract from document [DSTI/ICCP/M(2004)2]}

"Item 8. The Committee decided to maintain its current structure of four working parties, and to extend the mandates with the existing terms of reference for the duration of the PWB 2005-6, i.e. until 31/12/2006."

\section{Extract from document [DSTI/ICCP/M(2003)2]}

"Item 13. The Committee decided to extend the mandates of its four Working Parties until 1 January 2005."

\section{Extract from document [DSTI/ICCP/M(2001)2]}

"29. The Committee agreed to extend until 1 March 2004 the mandates of its four Working Parties."

\section{Extracts from document [DSTI/ICCP/M(99)1]}

"7. The Committee: 
ii) adopted the proposed terms of reference of the Working Party on Telecommunication and Information Services (WPTISP) contained in Annex 2 to the present record (which incorporates the editorial amendment proposed by the Delegate of the United States and approved by the Committee);"

\section{ANNEX 2}

\section{"Working Party on Telecommunication and Information Services (WPTISP)}

\section{Terms of Reference}

The terms of reference of the Working Party on Telecommunication and Information Services (WPTISP) shall be:

1. To promote exchanges of experience among Member countries and review recent developments in the field of telecommunications and information policy, taking into account the deployment of the new Global Information Infrastructure and the emergence of a Global Information Society.

2. To explore alternative goals and strategies for telecommunications and information sectors to enhance a common understanding of policies and increased international co-operation.

3. To analyse the economic and social implications of changing telecommunication market structures, including the Internet, and information and computer services based thereon; to analyse the implications of the interrelationships between electronic commerce and telecommunications; to analyse the policy and economic impact of convergence in the communications and information sectors.

4. To analyse trade-related issues in telecommunications and information services, and promote international co-operation in this field.

5. The Working Party will undertake its work in close co-operation with other bodies of the Organisation and other international Organisations, in order that all parties can gain mutual advantage from the better understanding achieved, and in order to avoid duplication.

6. The Working Party will undertake work as requested by the ICCP Committee, and submit on a regular basis the results of its work for review by this Committee.

The terms of reference of the Working Party on Telecommunication and Information Services shall remain in force until 31 December 2006, unless the ICCP Committee decides otherwise." 


\section{WORKING PARTY ON THE INFORMATION ECONOMY (WPIE)}

Chair:

Vice-Chairs:

Members:

Observers:

Date of creation:

Duration:
Mr. Jean-Jacques Sahel

Ms. Catherine Peters

Mr. Antti Eskola

Mrs. Daniela Battisti

Mr. Sukkyun Chung

Ms. Doreen McGirr
(United Kingdom)

(Canada)

(Finland)

(Italy)

(Korea)

(United States)

Open to all Member countries

Israel

Singapore

20th October 1993

31st December 2006

Mandate : - Summary Record of the 35th Session of the ICCP Committee held on 4-5 March 1999 [DSTI/ICCP/M(99)1]

- Summary Record of the 40th Session of the ICCP Committee held on 11-12 October 2001 [DSTI/ICCP/M(2001)2]

- Summary Record of the 45th Session of the ICCP Committee held on 2-3 October 2003 [DSTI/ICCP/M(2003)2]

- Summary Record of the 47th Session of the ICCP Committee held on 20-21 October 2004 [DSTI/ICCP/M(2004)2]

\section{Extract from document [DSTI/ICCP/M(2004)2]}

"Item 8. The Committee decided to maintain its current structure of four working parties, and to extend the mandates with the existing terms of reference for the duration of the PWB 2005-6, i.e. until 31/12/2006."

\section{Extract from document [DSTI/ICCP/M(2003)2]}

"Item 13. The Committee decided to extend the mandates of its four Working Parties until 1 January 2005."

\section{Extract from document [DSTI/ICCP/M(2001)2]}

"29. Working Parties."

The Committee agreed to extend until 1 March 2004 the mandates of its four

\section{Extracts from document [DSTI/ICCP/M(99)1]}

"7. The Committee: 
iii) adopted the proposed terms of reference of the Working Party on the Information Economy (WPIE) contained in Annex 3 to the present record (which incorporates the editorial amendment proposed by the Delegate of the United States and approved by the Committee);"

\section{ANNEX 3}

"Working Party on the Information Economy (WPIE)

Terms of Reference

The Working Party on the Information Economy (WPIE) shall be responsible for:

1. analysing the policy frameworks for the information economy required to strengthen economic growth, productivity, employment and industrial competitiveness in conjunction with the deployment of the new Global Information Infrastructure, and the emergence of a Global Information Society, and electronic commerce.

2. reviewing and evaluating the economic and social implications of the development, diffusion and use of information and communication technologies, products and services, and electronic commerce, including content, and their applications, particularly in light of their policy implications.

3. submitting, for review by the ICCP Committee, analysis of factors which encourage the usage of information and communications technologies, products and services, and electronic commerce, including content, and their applications, in the various sectors of the economy and society; and to develop appropriate methods and tools for measurement and international comparison.

4. undertaking work as requested by the ICCP Committee and submitting the results of its work on a regular basis for review by the Committee.

5. establishing co operative and productive relationships with other relevant bodies within and outside the OECD, including non-member countries.

The terms of reference of the Working Party on the Information Economy shall remain in force until 31 December 2006, unless the ICCP Committee decides otherwise." 


\section{WORKING PARTY ON INFORMATION SECURITY AND PRIVACY (WPISP)}

Chair:

Vice-Chairs:

Members:

Observers:

Date of creation:

Duration:
Mr. Peter Ferguson

Mr. Keith Besgrove

Mr. Mikael Kiviniemi

Mr. Masao Horibe

Mr. Tai Myoung Chung

Mrs. Katarina De Brisis

Mr. Geoffrey Smith

Mr. Jamie Estrada
(Canada)

(Australia)

(Finland)

(Japan)

(Korea)

(Norway)

(United Kingdom)

(United States)

Open to all Member countries

Israel

Singapore

Council of Europe

October 1995

31st December 2006

Mandate : - Summary Record of the 35th Session of the ICCP Committee held on 4-5 March 1999 [DSTI/ICCP/M(99)1]

- Summary Record of the 40th Session of the ICCP Committee held on 11-12 October $2001[\mathrm{DSTI} / \mathrm{ICCP} / \mathrm{M}(2001) 2]$

- Summary Record of the 45th Session of the ICCP Committee held on 2-3 October 2003 [DSTI/ICCP/M(2003)2]

- Summary Record of the 47th Session of the ICCP Committee held on 20-21 October 2004 [DSTI/ICCP/M(2004)2]

\section{Extract from document [DSTI/ICCP/M(2004)2]}

"Item 8. The Committee decided to maintain its current structure of four working parties, and to extend the mandates with the existing terms of reference for the duration of the PWB 2005-6, i.e. until 31/12/2006."

\section{Extract from document [DSTI/ICCP/M(2003)2]}

"Item 13. The Committee decided to extend the mandates of its four Working Parties until 1 January 2005."

\section{Extract from document [DSTI/ICCP/M(2001)2]}

"29. The Committee agreed to extend until 1 March 2004 the mandates of its four Working Parties."

\section{Extracts from document [DSTI/ICCP/M(99)1]}


"7. The Committee:

ii) adopted the proposed terms of reference of the Working party on Information Security and Privacy (WPISP) contained in Annex 4 to the present record;"

ANNEX 4

"Working party on Information Security and Privacy (WPISP) Terms of Reference

The terms of reference of the Working Party on Information Security and Privacy (WPISP) shall be:

1. To exchange experience among Member countries related to security of information and communications systems, and protection of personal data and privacy in the Global information infrastructure (GII)/Global information society (GIS), benefiting from the unique membership of the Organisation;

2. To monitor and analyse developments and trends in security of information and communications systems, and protection of personal data and privacy, in Member and non-Member countries, particularly in those areas which might benefit from more common understanding of various approaches; and

3. To develop and propose policy options for security of information and communications systems, and protection of personal data and privacy, particularly in areas in which there is an increased need for international co-operation.

4. To promote the objectives of the relevant OECD Recommendations and Declarations.

The Group will undertake work as requested by the Committee for Information, Computer and Communications Policy (ICCP) and will submit on a regular basis to the ICCP Committee the results of its work.

The Group will undertake its work in close co-operation with other relevant bodies of the Organisation and with other international organisations, in order to increase awareness of the views of Member countries and avoid duplication of effort.

The terms of reference of the Working Party on Information Security and Privacy shall remain in force until 31 December 2006, unless the ICCP Committee decides otherwise." 


\title{
WORKING PARTY ON INDICATORS FOR THE INFORMATION SOCIETY (WPIIS)
}

Chair:

Ms. Patricia Buckley

Mr. Daniel April

Mrs. Lea Parjo

Mr. Marc Aufrant

Mr. Tony Clayton
(United States)

(Canada)

(Finland)

(France)

(United Kingdom)

Members:

Open to all Member countries

Observer:

U.N. Conference on Trade and Development (UNCTAD)

\author{
Israel \\ Russian Federation \\ Singapore
}

Date of creation: $\quad$ March 1999

Duration:

31st December 2006

Mandate : - Summary Record of the 35th Session of the ICCP Committee held on 4-5 March 1999 [DSTI/ICCP/M(99)1]

- $\quad$ Summary Record of the 40th Session of the ICCP Committee held on 11-12 October 2001 [DSTI/ICCP/M(2001)2]

- $\quad$ Summary Record of the 45th Session of the ICCP Committee held on 2-3 October 2003 [DSTI/ICCP/M(2003)2]

- $\quad$ Summary Record of the 47th Session of the ICCP Committee held on 20-21

October 2004 [DSTI/ICCP/M(2004)2]

\section{Extract from document [DSTI/ICCP/M(2004)2]}

"Item 8. The Committee decided to maintain its current structure of four working parties, and to extend the mandates with the existing terms of reference for the duration of the PWB 2005-6, i.e. until 31/12/2006."

\section{Extract from document [DSTI/ICCP/M(2003)2]}

"Item 13. The Committee decided to extend the mandates of its four Working Parties until 1 January 2005."

\section{Extract from document [DSTI/ICCP/M(2001)2]}

"29. Working Parties."

The Committee agreed to extend until 1 March 2004 the mandates of its four

\section{Extracts from document [DSTI/ICCP/M(99)1]}

"7.

The Committee:

iv) adopted the proposed terms of reference of the Working Party on Indicators for the Information Society (WPIIS) contained in Annex 5 to the present record." 


\section{ANNEX 5 \\ "Working Party on Indicators for the Information Society (WPIIS) Terms of Reference}

a)

The Working Party will monitor, supervise, direct and co-ordinate the statistical work and contribute to the development of indicators and quantitative analyses needed to meet the requirements of the Information, Computer and Communications Policy Committee and its subsidiary bodies. More specifically, the Working Party will:

i) Ensure the continued improvement of the methodology for the collection of internationally comparable data for measuring the supply and demand for, and impacts of, information and communication infrastructures, related services, content and applications like electronic commerce. This may entail the development of manuals produced by the Group.

ii) Assist in developing and interpreting new and existing indicators which aid formulating policies, monitoring progress, assessing the effectiveness of regulatory reform, appraising applications and impacts and identifying various obstacles to diffusion and use of information and communication infrastructures, related services and content. These should be undertaken in the light of policy changes or other special characteristics of their countries and advise the Committee on the technical validity of reports based on such indicators.

b) The Working Party will, when required, assist the other subsidiary bodies of the ICCP Committee in the development of analytical and quantitative analyses on related issues such as information security and privacy, assessing the effectiveness of regulatory reform, appraising applications and impacts and identifying various obstacles to diffusion and use of information and communication infrastructures, related services and content.

c) The Working Party will seek the maximum practicable conformity of its own work with the statistical work undertaken by other parts of the OECD; and also with the work on indicators for the information society undertaken by other competent international bodies.

d) The Working Party will co-operate, in particular, with other OECD statistical subgroups and working parties in dealing with broader statistical issues connecting industrial, science and technology activities.

e) The Working Party will act as a clearing house through which Member countries can exchange information and experience on methods of collection, compilation, analysis and presentation of data which they use as indicators for the information society.

The Terms of Reference of the Working Party on Indicators for the Information Society shall remain in force until 31 December 2006, unless the ICCP Committee decides otherwise." 


\section{TASK FORCE ON SPAM}

Chair:

Mr. Tom Dale

(Australia)

Members:

Open to all Member countries

Observers:

Israel

Russian Federation

Singapore

Council of Europe

International Telecommunication Union (ITU)

Date of creation:

8th July 2004

Duration:

8th July 2006

Mandate: Decision of the Council approved at its 1091st session held on 8 July 2004

[C/M(2004)17, Item 218 and C(2004)102/REV1]

\section{Extract of Summary Record [C/M(2004)17, item 218]}

"THE COUNCIL

b) approved the creation, until 8 July 2006, of the Task Force on Spam and endorsed its method of work as set out in paragraphs 5 to 9 of C(2004)102/REV1;

c) authorised the participation of Israel, the Russian Federation, Singapore, the Council of Europe and the International Telecommunication Union as observers in the Task Force on Spam."

\section{Annex of document [C(2004)102/REV1]}

\section{Terms of Reference of the Task Force on Spam}

The Task Force on Spam is a joint subsidiary body of the Committee for Information, Computer and Communications Policy (ICCP) and the Committee on Consumer Policy (CCP). Its Terms of Reference are:

- To study, document and promote the range of existing and emerging anti-spam strategies, across all sectors, encompassing regulatory strategies, technologies, enforcement arrangements and strategies, and education and awareness-raising activities and materials.

- To develop and promote an anti-spam "tool-kit" to facilitate the development and growth of anti-spam strategies, arrangements and solutions, and to facilitate international co-operation against spam.

- To build upon work already done by OECD, the private sector, civil society, and other international organisations. 
- To devise a public awareness strategy for OECD and a strategy for OECD outreach to share experiences with non-Member economies in order to support global efforts to combat spam.

The Terms of Reference of the Task Force on Spam shall expire on 8 July 2006. The final deliverable will be a report to the ICCP and CP committees summarising the recommended package of policies and measures to combat the global problem of spam. 


\section{COMMITTEE ON CONSUMER POLICY}

Chair:

Vice-Chairs:

Members:

Date of creation:

Duration:
Mr. Michael Jenkin

Mr. Steve French

Ms. Anja Peltonen

Mr. André Longuet Des Digueres

Mr. Koichi Fujisaki

Ms. Patricia Ruiz Velasco

Mr. Lee Peeler
(Canada)

(Australia)

(Finland)

(France)

(Japan)

(Mexico)

(United States)

Open to all Member countries

12th November 1969

31st December 2009

Mandate: - Resolution of the Council concerning the renewal and modification of the mandate of the Committee on Consumer Policy, adopted on 10 November 2004 [C(2004)170 and $\mathrm{C} / \mathrm{M}(2004) 24$, item 309]

\section{Resolution of the Council [C(2004)170]}

\section{THE COUNCIL,}

Having regard to the Rules of Procedure of the Organisation;

Having regard to the Resolution of the Council of 12 November 1969 establishing a Committee on Consumer Policy [C(69)143];

Having regard to the Resolutions of the Council of 18 July 1972, 22 July 1977, 1 October 1982, 10 July 1987, 25 June 1992, 18-19 and 22-23 December 1997, 10 December 1998 and 26 November 2001 concerning the continuation of the Committee on Consumer Policy [C(72)132(Final), $\quad$ C(77)134(Final), $\quad$ C(82)121(Final), $\quad$ C(87)116(Final), $\quad$ C(92)116/FINAL, C(97)197/FINAL, C(98)199/FINAL and C(2001)239/REV1];

Having regard to the conclusions of the October 1998 Ottawa Ministerial conference "A Borderless World: Realising the Potential of Global Electronic Commerce", and in particular to the Ministerial Declaration on Consumer Protection in the Context of Electronic Commerce adopted by Ministers at this Conference [Annex 2 to C(98)177], and to the OECD Action Plan for Electronic Commerce which was endorsed by Ministers, SG/EC(98)10/REV5];

Having regard to the Recommendation of the Council Concerning Guidelines for Consumer Protection in the Context of Electronic Commerce [C(99)184/FINAL];

Having regard to the Recommendation of the Council Concerning Guidelines for Protecting Consumers from Fraudulent and Deceptive Commercial Practices Across Borders [C(2003)116];

Considering the economic and social importance of a broad-based consumer policy in Member countries and the latter's close relationship with general economic and trade policies;

Considering the need to minimise economic costs to consumers and to facilitate the integration of consumer policy considerations into economic and other policy areas; 
Considering the need to improve the functioning of markets, encourage the development of a global marketplace for consumers, including through the use of new electronic media, and to provide effective protection to consumers;

OECD;

Considering the importance of collaborating with other relevant subsidiary bodies of the

Considering that the implementation of such a policy would be encouraged by exchanges of information and experience, discussions, and law enforcement and policy co-operation between Member countries, as well as co-operation with other international organisations and non-Member economies;

Consumer Policy:

On the proposal of the Secretary-General after consultation with the Committee on

\section{DECIDES:}

I. Terms of Reference

The terms of reference of the Committee on Consumer Policy are:

1. To examine questions relating to consumer policy and law in Member countries and within international and regional organisations and to contribute to the further development and strengthening of co-operation between Member countries in policy development and law enforcement.

2. To examine and help develop, in particular, consumer trust in the global digital economy, to participate in and encourage the development of the principles which should govern an efficient, transparent and fair global marketplace for consumers, and to develop mechanisms for the implementation of these principles and for the effective enforcement of consumer laws on line and across borders.

3. To examine issues of consumer policy and safety, particularly those concerning international trade or the development of a global marketplace for consumers.

4. To collaborate closely with other relevant subsidiary bodies of the OECD.

5. To consult with the advisory bodies to OECD, BIAC and TUAC, consumer organisations such as Consumers International, the private sector, academia and other international organisations.

6. To encourage the development and use of relevant quantitative information in consumer policy deliberations, to facilitate overall policy coherence through the inclusion of consumer policy considerations in other policy areas, and to engage in outreach to non-member economies.

II. Review of terms of reference

The terms of reference of the Committee on Consumer Policy shall expire on 31 December 2009, unless the Council decides otherwise.

III. Amendment to the Annex to the Rules of Procedure of the Organisation

Paragraph 23 of the Annex to the Rules of Procedure of the Organisation shall be amended as follows: Committee on Consumer Policy: its terms of reference are defined in the Resolution of the Council annexed to document C(2004)170." 


\section{TASK FORCE ON SPAM}

Chair:

Mr. Tom Dale

(Australia)

Members:

Open to all Member countries

Observers:

Israel

Russian Federation

Singapore

Council of Europe

International Telecommunication Union (ITU)

Date of creation:

8th July 2004

Duration:

8th July 2006

Mandate: Decision of the Council approved at its 1091st session held on 8 July 2004

[C/M(2004)17, Item 218 and C(2004)102/REV1]

\section{Extract of Summary Record [C/M(2004)17, item 218]}

"THE COUNCIL

b) approved the creation, until 8 July 2006, of the Task Force on Spam and endorsed its method of work as set out in paragraphs 5 to 9 of C(2004)102/REV1;

c) authorised the participation of Israel, the Russian Federation, Singapore, the Council of Europe and the International Telecommunication Union as observers in the Task Force on Spam."

\section{Annex of document [C(2004)102/REV1]}

\section{Terms of Reference of the Task Force on Spam}

The Task Force on Spam is a joint subsidiary body of the Committee for Information, Computer and Communications Policy (ICCP) and the Committee on Consumer Policy (CCP). Its Terms of Reference are:

- To study, document and promote the range of existing and emerging anti-spam strategies, across all sectors, encompassing regulatory strategies, technologies, enforcement arrangements and strategies, and education and awareness-raising activities and materials.

- To develop and promote an anti-spam "tool-kit" to facilitate the development and growth of anti-spam strategies, arrangements and solutions, and to facilitate international co-operation against spam.

- To build upon work already done by OECD, the private sector, civil society, and other international organisations. 
- To devise a public awareness strategy for OECD and a strategy for OECD outreach to share experiences with non-Member economies in order to support global efforts to combat spam.

The Terms of Reference of the Task Force on Spam shall expire on 8 July 2006. The final deliverable will be a report to the ICCP and CP committees summarising the recommended package of policies and measures to combat the global problem of spam. 


\section{Chairs:}

Vice-Chairs:

\author{
Mr. Jörgen Rosted \\ Mr. Matti Pietarinen \\ Mrs. Agnès Arcier \\ Mr. Toshinori Kobayashi \\ Mr. Theo Roelandt \\ Mr. Ken Warwick \\ Ms. Jane Corwin
}

(Denmark)

(Finland)

(France)

(Japan)

(Netherlands)

(United Kingdom)

(United States)

Members:

Open to all Member countries

Observer:

Israel

Date of creation:

25th January 2001

Duration:

30th April 2006

\section{Resolution of the Council [C(2001)7]}

\section{THE COUNCIL}

Having regard to Articles 1 and 2 of the Convention on the Organisation for Economic Co-operation and Development of 14 December 1960.

Having regard to the Resolution of the Council C(70)133(final) of 29 September 1970 concerning the Activities of the Organisation in the Fields of Industry and Energy and amending the Rules of Procedure of the Organisation, as amended by the Resolution of the Council C(73)235(Final) of 4 December 1973.

Having Regard to the report of the Task Force mandated for the Evaluation of the Industry Committee [CE(2000)9/REV1], to the Report of the chairman of the Executive Committee to the Council on the discussion of this report [C(2000)140], and to the report by the Industry committee on its evaluation [CE(2001)2].

Having regard to the Rules of Procedure of the Organisation.

\section{DECIDES:}

1. In order to pursue its activities in the field of industry, the Organisation shall have at its disposal a Committee on Industry and Business Environment (CIBE).

2. a) The Committee on Industry and Business Environment shall have overall responsibility for the Organisation's work in the field of industry. Through sector- and firm-level analyses, it will complement macro-level analyses done by other bodies of the Organisation. Where appropriate, the Committee shall discuss the industrial aspects of questions dealt with by other bodies of the Organisation, take into consideration the results of their work and undertake joint projects.

2. b) The Committee on Industry and Business Environment shall study and discuss issues and other matters in the field of industry which require co-operation and consultation among 
Member Governments in a manner which encourages high-level dialogue and publication of analytical work. To this end, the Committee shall examine major developments and trends in industry, the industrial policies of Member Governments, and problems of industrial adaptation. The scope of the Committee's work will include micro-level analysis of industry, sectors and firms including manufacturing and services sectors, large firms and small and medium-sized enterprises (SMEs), and at national and global levels. A main area for analysis will be improving the business environment to foster entrepreneurship, investment, innovation and growth in knowledge-based economies. This will include assessment of the contributions of new forms of work organisation and flexible enterprises to industrial competitiveness. The work of the Committee will have three main dimensions:

- Economic analysis and theme reviews focusing on improving the business environment and the conditions for industrial competitiveness.

- Policy analysis to identify the implications for public policy and best policy practices in Member countries; and

- Active involvement and links to the horizontal programmes of the Organisation.

2. c) The Committee on Industry and Business Environment shall propose to the Council, wherever possible, conclusions which could be brought to the attention of Member countries, or decisions or recommendations which might be adopted. The Committee will organise Business and Industry Policy Forums to explore timely issues with the private sector and to develop policy recommendations. The Committee will also consult with, as appropriate, representatives of business, trade unions and public interest groups.

3. Where possible, Member Governments shall appoint to the Committee on Industry and Business Environment high-ranking officials concerned with co-ordination of policies in the fields of industry in their own countries.

4. For the purpose of its activities in the fields of industry, the Organisation shall periodically collect all relevant statistics and other information; in principle, these data will be assembled by the Secretariat and published on the responsibility of the Secretary-General.

5. The terms of reference of the Committee on Industry and Business Environment will remain in force for a period of five years, unless the Council decides otherwise.

6. The Council Resolutions of 29 September 1970 and 4 December 1973 are hereby repealed.

7. Paragraph 22 of the Annex to the Rules of Procedure shall be amended as follows:

22. "Committee on Industry and Business Environment: its terms of reference are defined in the Resolution of the Council C(2001)7/FINAL."

Extract of the Summary record [C/M(2005)25, item 324]

"THE COUNCIL

b) Agreed that the mandate of the Committee on Industry and Business Environment as set out in Council Resolution C(2001)7, is extended to 30 April 2006 unless the Council decides otherwise." 


\section{WORKING PARTY ON SMES AND ENTREPRENEURSHIP}

Chair:

Vice-Chairs:

Members:

Observers:

Date of creation:

Duration:
Mr. Roger Wiggelsworth

Mr. Bob Pegler

Ms. Annukka Lehtonen

Mr. Serge Boscher

Mr. Efstathios Zafrantzas

Mrs. Loredana Gulino

Mr. Iván Ornelas Diaz

Mr. Christian Weber
(New Zealand)

(Australia)

(Finland)

(France)

(Greece)

(Italy)

(Mexico)

(Switzerland)

Open to all Member countries

Israel

Inter-American Development Bank (IADB)

31st March 1993

30th April 2006

\section{Extract from document [DSTI/IND/M(2005)1, Item 9$]$}

"The Committee agreed to renew the mandate of its Working Party on SMEs and Entrepreneurship, with unchanged terms of reference, to the end of April 2006, subject to the extension of CIBE's own mandate by the Council."

\section{Extracts from document [DSTI/IND/M(2002)1, Item 12 and Annex 2]}

"The Committee agreed to change the name of the Working Party on Small and Medium-Sized Enterprises into Working Party on SMEs and Entrepreneurship, and to renew its mandate until 24 January 2006 with the revised terms of reference set out in Annex 2 to the present record."

\section{ANNEX 2}

\section{Mandate of the Working Party on SMEs and Entrepreneurship}

1. The Working Party on SMEs and Entrepreneurship is entrusted with examining the nature and scale of issues and policies at the national and international levels pertaining to SMEs (including micro-enterprises) and entrepreneurship. This task will be accomplished through discussions within the Working Party, through research projects and through horizontal co-operation with relevant bodies in the OECD, in particular in the framework of OECD horizontal projects. The Working Party shall make available to OECD governments, and when appropriate non-OECD governments, and to other Committees of the Organisation, information and advice on these issues and on measures and policies for dealing with them. 
2. The Working Party is entrusted with fostering the implementation of the recommendations contained in the Bologna Charter in the context of the follow-up to the June 2000 Bologna Ministerial Conference on SMEs (known as the "Bologna Process"). The Ministerial mandate expressed in the Charter provides a framework for the Working Party to continue its core activities and deepen its work on issues of importance for SMEs to increase their competitiveness in the context of globalisation, in particular electronic commerce, innovation and entrepreneurship, including women's entrepreneurship, networking and clusters, and a cross-cutting theme: financing. In addition, it should enhance the outreach dimension of its work and co-operation with relevant international and regional bodies.

3. With regard to entrepreneurship, defined in this context as the pre-start-up, start-up and early post start-up phases of business, the Working Party shall give due attention to issues and policies relating to this theme at the national level, including the role played by framework conditions for a business environment (e.g. regulatory, innovation, competition, taxation issues) conducive to "sustainable" growth, and the uptake and use of information and communications technologies (ICT). It will act in close collaboration with the TDS/LEED Programme with regard to the territorial/local level, and in co-operation with other OECD bodies as appropriate.

4. The Working Party shall continue its core activities in the following areas:

- It shall produce every second year a comprehensive report that provides an integrated assessment of trends in entrepreneurship and SME policies in Member countries, including selected thematic and quantitative analyses, as well as policy recommendations based on best practices.

- The Working Party shall act as a clearing house through which OECD (and when relevant, non-OECD) countries can exchange information and experience on SME and entrepreneurship issues, policies and programmes, especially with regard to areas of interest, topical developments and areas identified by the Committee on Industry and Business Environment (CIBE) or the OECD Council as being of particular relevance to the OECD.

- The Working Party shall undertake a critical and comparative assessment of best practice policies for SMEs and entrepreneurship adopted by OECD countries, and where appropriate, non-OECD countries, and make these available to the CIBE and to Member governments. Linkages will be established with the CIBE Benchmarking Project when appropriate.

- In accordance with the recommendations of the 2nd Conference on Women Entrepreneurs in SMEs, and the OECD Ministerial Communique of May 2001, the Working Party shall consolidate and mainstream its work on women's entrepreneurship, by considering and addressing related issues throughout its work programme, and by undertaking targeted studies when appropriate and resources permit.

5. The Working Party shall give special consideration to:

- The increasingly important role that SMEs, including innovative start-ups, play in job creation and growth.

- The need for financing options for SMEs, in particular for knowledge-based enterprises, which take account of their particular financing challenges (e.g. evaluation of intangible assets).

- The demand for increasing emphasis on the development of management skills to support the growth of firms in an innovative, knowledge-based economy.

- The globalisation of economic activities, including the increasing participation of SMEs in the global marketplace and the incorporation of electronic commerce into business strategies, and its implications for SMEs. 
- The improvement and development of SME and firm-level statistics, in co-operation with the OECD (e.g. Statistical Working Party of the CIBE) and the appropriate national and international bodies.

6. The Working Party shall seek to enhance co-operation with non-OECD countries (in particular those who adopted the Bologna Charter) on issues related to the Bologna Process to address these issues in the most effective way. In addition, the Working Party will seek to strengthen co-operation with international institutions and regional economic bodies in order to avoid unnecessary duplication in its activities and improve its effectiveness. When appropriate and resources permit, and as approved by the $\mathrm{CCN}$, the following outreach and liaison mechanisms can be implemented:

- Co-operation and information-sharing among OECD and non-OECD countries, as well as regional initiatives to promote information exchange among non-OECD countries, in cooperation with the OECD bodies undertaking Enterprise Development activities, as appropriate.

- Deepening of multilateral exchange and the establishment or strengthening of co-operation with relevant international organisations/institutions and regional bodies, including APEC, CEI, ILO, UNCTAD, UNIDO, the World Bank and regional development banks such as the Inter-American Development Bank (IADB).

7. The Working Party shall seek to involve, where appropriate and in accordance with the Council guidance all relevant stakeholders, aiming at a more effective dialogue in the development of SME and entrepreneurship policy.

8. The Working Party shall submit every second year a draft work programme to the CIBE. The Working Party will also report annually to the CIBE on the main results of its work, in particular the related policy recommendations, in line with its terms of reference.

9. The terms of reference of the Working Party on SMEs and Entrepreneurship shall remain in force until 30 April 2006, unless the CIBE or the Council decides otherwise." 


\section{WORKING PARTY ON STATISTICS (SWIC)}

Chair:

Vice-Chairs:

Members:

Observer:

Date of creation:

Duration:
Mr. Kazuyuki Motohashi

Mr. Dean Parham

Mr. Hans-Olof Hagen

Mr. Ron Jarmin

Open to all Member countries

Israel

International Labour Organization (ILO)

International Monetary Fund (IMF)

U.N. Conference on Trade and Development (UNCTAD)

U.N. Economic Commission for Europe (ECE)

U.N. Industrial Development Organisation (UNIDO)

World Bank

World Trade Organization (WTO)

2nd March 1971

30th April 2006
(Japan)

(Australia)

(Sweden)

(United States)

Mandate : - Mandate of the Working Party on Statistics of the Industry Committee [DSTI/IND(97)7, Annex 1]

- Summary Record of the 98th Session of the Industry Committee [DSTI/IND/M(2000)2, § 15]

- Summary Record of the 104th Session of the Committee on Industry and Business Environment [DSTI/IND/M(2003)2] and document [DSTI/IND(2003)24]

- Summary Record of the $107^{\text {th }}$ Session of the Committee on Industry and Business Environment [DSTI/IND/M(2005)1] and document [DSTI/IND(2003)24]

\section{Extract from document [DSTI/IND(2003)24]}

a) The Working Party will supervise, direct and co-ordinate all the statistical work and contribute to the development of indicators and quantitative analyses needed to meet the requirements of the Committee on Industry and its subsidiary bodies. More specifically, the Working Party will:

i) contribute to the development of analytical and quantitative analyses that follow from concerns with such matters as:

- the changing nature of the firm as its activities become progressively globalised, including the changing character of production and capital formation;

- the role of innovation and its bearing on international competitiveness;

- the role of small and medium-sized enterprises;

ii) facilitate the development and improvement of internationally comparable methodologies and the timely availability of statistical series and indicators to 
monitor short-term and structural change and to assess economic performance and policy outcomes;

iii) contribute, in co-operation with other OECD subsidiary bodies, to the development of indicators that describe the links between technology and enterprise performance and competitiveness;

b) The Working Party will seek the maximum practicable conformity of its own work with the statistical work undertaken by other parts of the OECD and by other competent international and supranational organisations such as the UN Statistics Division and Eurostat;

c) Finally, the Working Party will act as a forum in which Member countries would exchange information and experience on new methods of collection, compilation, analysis, presentation of data and development of new indicators in the field of industrial statistics."

\section{Extract from document [DSTI/IND/M(2005)1]}

The Committee agreed to renew the mandate of its Working Party on Statistics (SWIC), with unchanged terms of reference, to the end of April 2006, subject to the extension of CIBE's own mandate by the Council." 

Chair:

Vice-Chairs:

Members:

Observers:
Mr. Bruce Carlton

Mr. Jerry Rysanek

Mrs. Ann Dilling

Mr. Ok In Baek

Open to all Member countries

Chile

Estonia

Latvia

Romania

Russian Federation

30th September 1961

31st December 2008
(United States)

(Canada)

(Denmark)

(Korea)

Date of creation:

Duration:

Mandate: - Paragraph 34 of the Report of the Preparatory Committee

- Council Decision regarding a Sunset Clause for all Committees [C/M(2004)5, item

75] entered into force on 22 April 2004 [C/M(2004)10, item 143, IV, c)]

\section{Paragraph 34 of the Report of the Preparatory Committee}

"34. The Preparatory Committee recommend the creation of a Maritime Transport Committee which shall be responsible for keeping the Organisation informed of significant developments in the field of maritime transport. The Committee shall also be responsible for consultations concerning the policies of Members and may submit recommendations to the Council in cases where this appears appropriate. The reports and/or recommendations of the Maritime Transport Committee should where appropriate be submitted to the relevant bodies of the Organisation for comment prior to submission to the Council." 

Chair:

Members: ${ }^{1}$

Observers: ${ }^{2}$

Date of creation:

Duration:
Mr. Hans Colliander

Australia
Austria
Belgium
Canada
Czech Republic
Denmark
Finland
France
Germany
Greece
Hungary
Italy
Japan
Korea
Luxembourg

Bulgaria

Malaysia

South Africa

Chinese Taipei

Participating Countries:

China

India

Russian Federation

Ukraine

26th October 1978

31st December 2008
Mexico

Netherlands

Norway

Poland

Portugal

Slovak Republic

Spain

Sweden

Switzerland

Turkey

United Kingdom

United States

European Commission

Brazil

Romania

Mandate: - Decision of the Council establishing a Steel Committee [C(78)171(Final)]

- Minutes of the 501st Meeting of the Council [C/M(79)22(Final)]

- Minutes of the 582nd Meeting of the Council [C/M(83)6(Final)]

- Council Decision regarding a Sunset Clause for all Committees [C/M(2004)5, item 75] entered into force on 22 April 2004 [C/M(2004)10, item 143, IV, c)]

Decision of the Council $[\mathrm{C}(78) 171$ (Final) $]$ as amended by documents [C/M(79)22(Final), Item 231 (b) and C/M(83)6(Final), Item 51 (b)]

THE COUNCIL,

\footnotetext{
1 In February 2006, Council agreed to invite China, India, the Russian Federation and Ukraine to participate as full participants in the work of the Steel Committee.

2 In February 2006, Council agreed to invite Argentina, Egypt and Kazakhstan to participate as regular observers in the work of the Steel Committee until December 2007.
} 
Having regard to the Convention on the Organisation for Economic Co-operation and Development of 14th December 1960 (hereinafter referred to as the "Convention") and, in particular, Articles 5 a), 6, 12, 13 and 20 thereof;

Having regard to the Rules of Procedure of the Organisation;

Having regard to the Financial Regulations of the Organisation and, in particular, Articles 5 and 14(b) thereof;

Having regard to the Communiqué approved by the Council meeting at Ministerial Level on 15th June 1978 and, in particular, Annex II thereof [C(78)96(Final)];

Considering that the Ad Hoc Working Group on the Steel Industry has reached the conclusion that a Steel Committee should be established within the framework of the Organisation under Part II of the Budget and that a number of Member countries as well as the European Communities have expressed their intention to participate therein;

Noting that the Member countries participating in the proposed

Committee and the European Communities agree as initial commitment to the multilateral guidelines set out in Paragraph 6 of the Annex hereto;

\section{DECIDES:}

\section{Article 1}

In order to seek solutions to the problems experienced by the Steel Industry and achieve the objectives set out in the Annex, a Steel Committee (hereinafter referred to as the "Committee") is established within the framework of OECD and shall have the functions and the initial work programme set out in the Annex.

Article 2

a)

Participants in the Committee shall be:

i) Australia, Austria, Belgium, Canada, Denmark, Finland, France, Germany, Greece, Ireland, Italy, Japan, Luxembourg, the Netherlands, Norway, Portugal, Spain, Sweden, Switzerland, Turkey, the United Kingdom, the United States and the European Communities,

ii) Any other Member country of the Organisation which decides to participate in the Committee at a later stage, and

iii) Any non-Member country which becomes a participant in the Committee in conformity with the provisions of paragraph $b$ ).

b) The Committee shall, if the OECD Member countries participating therein so decide, propose to the Council that a non-Member country with substantial steel interests should be invited to become a participant in the Committee. In making such a proposal the Committee must be satisfied that the non-Member country has agreed and is able to undertake the same commitments, as appropriate, with regard to the Committee's work as the OECD Member countries which participate therein and that its participation in the Committee would contribute to achieving the objectives of the Committee. Such proposal shall specify the relevant provisions in respect of the non-Member country's participation in the Committee's work.

Article 3

Expenditure required for the functioning of the Committee shall be defrayed from the appropriations authorised for that purpose under Part II of the Budget of the Organisation. The 
Committee shall prepare each year a Programme of Work and this with the corresponding budgetary proposals shall be submitted by the Secretary-General to the Council.

\section{Article 4}

The Committee may make proposals to the Council on any matter within its terms of reference and, at the request of the Council or on its own initiative, the Committee may submit other communications to the Council. The Committee shall also make an annual report to the Council on its activities.

Article 5

a) The provisions of the Rules of Procedure of the Organisation shall apply to the Committee to the extent that this Decision does not derogate therefrom.

b) The Committee may make recommendations to participants within the scope of its terms of reference.

c) The Annex to the Rules of Procedure is amended by the insertion of a new paragraph as follows:

"26. Steel Committee. Its terms of reference are defined in the Decision of the Council establishing a Steel Committee [C(78)171(Final)]."

Article 6

This Decision and the Annex shall take effect on 26th October 1978.

$\underline{\text { Annex }}$

\section{PROBLEMS}

1. The world's steel industry is experiencing serious difficulties of both a cyclical and structural nature. These difficulties are widespread and are characterized by:

- Persistent excess capacity;

- An exceptionally low level of demand;

- Unjustifiably low prices on world markets;

- Marked changes in traditional trade patterns;

- Major dislocations of labour, frequently in areas already experiencing high unemployment;

- Depressed financial performance among producers, which holds down investments needed for modernisation and rationalisation of plants;

- Increasing governmental intervention in steel supply and demand, especially with foreign trade.

2. In virtually all major steel-producing nations, steel occupies a central place in the national economy. In a number of major areas, the magnitude of structural problems confronting the steel sector and resultant social and economic implications of the necessary structural adjustments are substantial.

3. The interrelationship of developments in the steel sectors from country to country and the potential that unilateral actions and policies can aggravate the problems of others have become 
clear. The convergence of cyclical problems among many nations serves to intensify the problems faced by each. There is general recognition that there may well be recurring cyclical differences.

\section{OBJECTIVES}

4. In view of these difficulties, governments need to work closely together in order to:

- Ensure that trade in steel will remain as unrestricted and free of distortion as possible. Restrictive actions should be avoided and, where necessary, strictly limited in scope and time, and in conformity with GATT rules; ${ }^{1}$

- Encourage reduction of barriers to trade;

- Enable governments to act promptly to cope with crisis situations in close consultation with interested trading partners and in conformity with agreed principles;

- Facilitate needed structural adaptations that will diminish pressures for trade actions and promote rational allocation of productive resources with the aim of achieving fully competitive enterprises;

- Ensure that measures affecting the steel industry are consistent to the extent possible with general economic policies and take into account implications for related industries, including steel- consuming industries;

- Avoid encouraging economically unjustified investments which recognizing legitimate development needs;

- Facilitate multilateral co-operation consistent with the need to maintain competition, to anticipate and, to the extent possible, prevent problems.

\section{COMMITTEE FUNCTIONS}

5.

The Steel Committee will meet regularly and additionally as required to:

1. Continuously follow national, regional and world supply and demand conditions in steel and closely related industries, including steel-consuming industries, with a view to identifying potential problems and implications and making assessments and forecasts available to all interested parties;

2. Continuously follow the evolution of national, regional and world steel industries with regard to employment, profits, investments, capacity, input costs, productivity, and other aspects of viability and competitiveness;

3. Develop common perspectives regarding emerging problems or concerns in the steel sector and establish, where appropriate, multilateral objectives or guidelines for government policies;

4. Regularly review and assess government policies and actions in the steel sector in the light of the current situation, agreed multilateral objectives and guidelines and the GATT and other relevant international agreements;

5. Identify deficiencies and gaps in existing data needed by the Committee with a view to improving national inputs to the Committee and cross-national comparability of data.

\footnotetext{
1 It is noted that references to GATT rules and provisions in this Annex do not alter the rights and obligations under the GATT of individual participants which are contracting parties to the GATT nor confer by implication equivalent rights or obligations on participants which are not contracting parties to the GATT.
} 


\section{INITIAL COMMITMENTS}

6. Participants in the Steel Committee agree to the following multilateral guidelines:

A. With respect to steel crisis trade actions:

1. No actions should be inconsistent with GATT provisions;

2. When actions are necessary they should be as limited and temporary as practicable and appropriate to the causes which led to their introduction;

3. All actions ${ }^{1}$ taken by participants should be reported promptly to the Steel Committee and, in conformity with GATT rules, to the GATT. The status and rationale for maintaining such actions should be reported periodically to the Steel Committee. Participants agree to consult on any trade action of interest to another participant;

4. When taking action under domestic law and procedures to deal with serious difficulties of its industry, a participant shall take into account the concerns of trading partners that traditional trade flows established under normal conditions of competition not be severely disrupted;

5. Price guidelines should be in conformity with the international Anti-Dumping Code and are appropriate only during crisis periods of substantial excess capacity in exporting countries, widespread price-cutting by many exporters over many products in the importing market or on world markets, and depressed domestic industry conditions such as low capacity utilisation, profits, sales, investments and employment. Such actions should be expeditiously removed or liberalised as conditions improve.

6. Such price guidelines should neither exceed the lowest normal prices in the supplying country or countries where normal conditions of competition are prevailing, nor exceed the sums of the full costs of production (including overheads) and profit, as determined over a reasonable period of recent time, in the supplying country or countries delivery costs to the importing market and import duties may be included in the event that price guidelines are established on a delivered basis.

B. Participants in the Steel Committee recall their determination to abstain from destructive competition in official support of export credit; they agree that their policies in the field of export credits for steel plant and equipment will be fully consistent with the Arrangement on Guidelines for Officially Supported Export Credits and contribute to the avoidance of competitive subsidisation of such exports.

C. Participants, recalling the general orientations for adjustment policies adopted as part of the Communiqué of the June 1978 Meeting of the Council at Ministerial level, agree that domestic policies to sustain steel firms during crisis periods should not shift the burden of adjustment to other countries and thus increase the likelihood of restrictive trade actions by other countries (e.g. by artificially stimulating exports or by artificially displacing imports). Further, as a general rule, domestic measures should not prevent marginal facilities from closing in those instances where the facilities cannot become commercially viable within a reasonable period of time.

D. Participants in the Steel Committee agree to make every effort to provide effective programmes for steel worker readaptation away from facilities affected by structural adjustments into alternative employment. To this end, they will periodically exchange information on the effectiveness of policies and programmes to assist steel workers and communities.

1 It is understood that these include all safeguard measures subject to the reporting requirements under the GATT. 
E. Any action to restrict trade in steel-making materials should be reported promptly to the Steel Committee and be subject to consultation with affected parties.

\section{INITIAL WORK PROGRAMME}

7. With respect to the commitments agreed in this Resolution the Steel Committee should promptly undertake an examination of government policies affecting the steel sector in the following areas:

1. Evolution of trade flows and the impact on them of government measures;

2. Guidelines for steel trade actions;

3. Adaptation of production structure through modernisation, closures and reconversions;

4. Readaptation of labour;

5. Domestic policies to sustain steel production and stimulate steel demand in times of crisis;

6. Domestic pricing and supply;

7. Government export credits for steel plant and equipment.

The Committee will continue the work initiated in the Ad Hoc Steel Group and may undertake examinations in other areas as deemed appropriate by the participants." 


\title{
COUNCIL WORKING PARTY ON SHIPBUILDING
}

Chair:

Members:

Observers:

Date of creation:

Duration:
Mr. Wilhelm Jaggi

(Switzerland)

Open to all Member countries

\author{
Croatia \\ Romania \\ Russian Federation
}

24th May 1966

31st December 2008

Mandate: - Resolution of the Council concerning the terms of reference of an ad hoc Working Party on Shipbuilding as amended [C(66)57; C(67)104(Final); C(70)165(Final); C(73)214(Final) and C(89)122(Final)]

- Council Decision regarding a Sunset Clause for all Committees [C/M(2004)5, item 75] entered into force on 22 April 2004 [C/M(2004)10, item 143, IV, c)]

\section{Resolution of the Council [C(66)57], as amended by the resolutions mentioned above}

THE COUNCIL,

Having regard to the Report of 24th July 1965, by its ad hoc Working Party on Shipbuilding, which defines several fields as being most suitable for joint governmental consideration [C(65)86];

Noting the Progress Report of 29th October 1965, on Terms of Credit for Sales of Ships [C(65)111] by the Trade Committee's Group on Export Credits and Credit Guarantees;

Having regard to the objectives of the Organisation and in view of the fact that all major shipbuilding countries are Members thereof;

I. DECIDES to set up an ad hoc Working Party in which Belgium, Denmark, Finland, France, Germany, Greece, Ireland, Italy, Japan, the Netherlands, Norway, Spain, Sweden, the United Kingdom, the United States and the Commission of the European Communities are to be represented.

II. INSTRUCTS the Working Party to commence work without delay and to:

a) Work out, in the light of the Reports referred to above and having due regard to social and other relevant conditions in individual Member countries, recommendations directed to a progressive reduction of the factors which distort normal competitive conditions in the shipbuilding industry;

b) Keep, in the meantime, the situation in the shipbuilding industry under review.

III. REQUESTS the Working Party to complete its tasks as soon as possible. 


\section{SUB-GROUP ON SUPPLY AND DEMAND}

Chair:

Mr. Richard J. Domokos

(Canada)

Members:

Open to all Member countries

Date of creation:

1st June 1972

Duration:

31st December 2008

Mandate: $\quad$ - Action Reminder on the 17th Session of the Working Party on 22nd-23rd June 1972 [C/NP6(72)17]

- Secretariat's suggestions for Monitoring the supply and demand situation in the Shipbuilding Industry [C/WP6(72)13]

\section{Extract from document [C/NP6(72)17]}

\section{"Paragraph 2}

c) Secretariat's suggestion for monitoring the supply and demand situation [C/NP6(72)13]

The Working Party examined the suggestion put forward by the Secretariat and decided to set up an ad hoc Sub-group for the purpose of working out, on the basis of these suggestions, ways and means for the Working Party to go about monitoring the supply and demand situation. The mandate of the Sub-group would consist of the tasks described in paragraph $16 \mathrm{~b}$ ) of the document under examination. The Working Party decided that the questionnaires mentioned in $16 \mathrm{c})$ should not be issued until the sub-group had examined them together with replies received from previous issues. With reference to item d) of this paragraph 16, the Working Party considered that it was certainly desirable to exchange information, but would take a final decision on the subject in the light of the sub-group's report. The sub-group should meet in early autumn, if possible before the end of September, and report to the Working Party at its 18th session in November.

The Working Party considered that the advice of experts from the industry would be of value to the sub-group; Delegates to this sub-group could therefore be accompanied, at the discretion of individual Delegations, by such advisers."

\section{Extract from document [C/NP6(72)13]}

\section{"Paragraph 16}

16. Activities envisaged under paragraph IV of the Draft Resolution should be developed in a pragmatic way. In order to make it possible for the Working Party to take them in hand efficiently in parallel with the implementation of the Comprehensive Arrangement, it should, at least at the beginning, base its monitoring on existing studies and information, improved and adapted as required by this task. To this end the Working Party should consider at its 17 th session the following matters:

a) Arrangements for a consultation of experts in the early autumn of 1972; the form which it should take (ad hoc meeting, setting up of an ad hoc sub-group); desirability or otherwise of the participation of industry representatives; 
b) Tasks to be given to the experts, including:

- Choice of studies on demand prospects to be used; proposals for their improvement and arrangements for an updated version to be available in spring 1973;

- Means and methods for permanently keeping under review medium and long-term demand prospects for the purposes of the Comprehensive Arrangement (studies to be made; improvements and creation of reliable basic data; exchange of information);

- Examination of latest information on individual yards, its improvement and complementary information needed for systematic reviews of current and future trends in supply;

- Examination of information on the current situation; its improvement and methods enabling the Working Party to assess the current overall situation in shipbuilding and its prospects;

c) Authorisation for the immediate issue of questionnaires on the facilities of individual yards and on employment in countries' shipbuilding industries;

d) Desirability and feasibility of an exchange of information on yards' expansion projects." 

EMPLOYMENT, LABOUR AND SOCIAL AFFAIRS 

Chair:

Vice-Chairs:

Members:

Observers:

Date of creation:

Duration:
Ms. Annie Fouquet

Ms. Jennifer Taylor

Mr. François Weldon

Ex officio

Mr. Rolf Myhrman

Ms. Dagmar Feldgen

Ex officio

Mr. Paolo Sestito

Ex officio

Ms. Agnieszka Chlon-Dominczak

Mr. Jaime Hevia Ruiz
(France)

(Australia)

(Canada)

(Finland)

(Germany)

(Italy)

(Poland)

(Spain)

Open to all Member countries

Russian Federation

Council of Europe

International Labour Organization (ILO)

30th September 1961

31st December 2008

Mandate: - Paragraph 35 of the Report of the Preparatory Committee

- Minutes of the 543rd Meeting of the Council [C/M(81)15(Final)]

- Minutes of the 761st meeting of the Council [C/M(91)14/FINAL]

- Council Decision regarding a Sunset Clause for all Committees [C/M(2004)5, item 75] entered into force on 22 April 2004 [C/M(2004)10, item 143, IV, c)]

\section{Paragraph 35 of the Report of the Preparatory Committee}

"35. The Preparatory Committee recommend the creation of a Manpower Committee to deal with manpower questions connected with the general objectives of the Organisation and those social questions which are closely linked with manpower problems. This Committee would also continue the work of the OEEC in connection with manpower movements in Europe. The Committee could, if the Council so instructed it, carry out certain operational tasks."

\section{Extract from the Minutes of the Council [C/M(81)15(Final) Item 154 i)]}

\section{"THE COUNCIL} $\cdots$

(154) i) noted that overall programme co-ordination of the work of the Organisation in the field of manpower, social affairs and education will be ensured, when appropriate, by joint meetings of the Bureaux of the bodies concerned as well as by the setting up on an ad hoc basis of Joint Working Parties." 
Extract from the Minutes of the Council [C/M(91)14 FINAL Item $130 \mathrm{~b})]$

\section{"THE COUNCIL}

(130) b) agreed that the Manpower and Social Affairs Committee shall in future be called "The Employment, Labour and Social Affairs Committee" and instructed the Secretary-General to issue the necessary amendment to paragraph 19 of the Annex to the Rules of Procedure." 


\section{WORKING PARTY ON MIGRATION}

Chair:

Vice-Chairs:

Members:

Observers:

Date of creation:

Duration:
Ms. Dagmar Feldgen

(Germany)

Ms. Elizabeth Ruddick

Ms. Brigitte Frenais-Chamaillard

Mr. Luca Einaudi

Ms. Su Kyoung Sim

Mr. Jan Verboom

Ms. Eva Haagensen

Open to all Member countries

Council of Europe

International Labour Organization (ILO)

International Organisation for Migration (OIM)

U.N. High Commissioner for Refugees (UNHCR)

9th February 1967

31st December 2010
(Canada)

(France)

(Italy)

(Korea)

(Netherlands)

(Norway)

Mandate: - Summary record of the $1125^{\text {th }}$ Session of the Council $[C / M(2005) 24$, item 315] and documents [C(2005)121 and ADD1].

\section{Annex to document [C(2005)121]}

\section{Terms of reference of the Working Party on Migration}

1. The Working Party on Migration shall:

a) serve as a forum for OECD Member countries to exchange information on national policies and practices and discuss matters related to migration, with emphasis on labour market and other economic and social aspects;

b) systematically collect, review and disseminate information, using the Continuous Reporting System on Migration (SOPEMI), on migratory trends as well as statistical data and policies and practices of Member countries and, to the extent feasible, of relevant non-Member countries;

c) initiate work on the economic, demographic, and social causes and consequences of migration in sending and receiving countries and discuss the results of this work and its wide-ranging policy implications;

d) evaluate and develop, on the basis of analytical work, policy options which would facilitate decisions by OECD Member countries to respond to the challenges and opportunities of international migration, including the integration and insertion of migrants and their children in the economy and society at large;

e) encourage and facilitate co-operation among sending and receiving countries by providing information and policy analysis that will assist them in assessing and managing migration flows to their mutual benefit; 
f) promote co-operation among the bodies of the Organisation dealing with work related to migration, and maintain regular contacts and co-operation with other International Organisations, as appropriate.

2. The procedure adopted by the Council in 1979 and confirmed in 1988 [C(88)32] according to which the Working Party is instructed "to report to the Council... at regular intervals, as required, such reports to be transmitted through the [Manpower and Social Affairs Committee] Employment, Labour and Social Affairs Committee, which may formulate comments thereon as appropriate" $[\mathrm{C} / \mathrm{M}(79) 5$, Item 65] remains unchanged. 


\section{WORKING PARTY ON THE ROLE OF WOMEN IN THE ECONOMY 1}

Chair:

Vice-Chairs:

Members:

Observers:

Date of creation:

Duration:
(..)

$(\ldots)$

Open to all Member countries

International Labour Organization (ILO)

Council of Europe

11th July 1974

31st December 2008

Mandate : - $\quad$ Minutes of the 614th Meeting of the Council [C/M(84)18(Final)]

- Mandate of the Working Party on the Role of Women in the Economy [C(84)166, Annex 1]

\section{Extract from document [C/M(84)18(Final), Item 234]}

\section{"THE COUNCIL}

a) noted the Note by the Secretary-General [C(84)166 and Corrigendum 1] ;

b) adopted the Mandate of the Working Party on the Role of Women in the Economy as proposed by the Manpower and Social Affairs Committee (Annexe 1) ${ }^{2}$;

c) invited the Working Party on the Role of Women in the Economy to report in writing to the Council before the end of 1987 and at regular intervals thereafter as required, such reports to be transmitted through the Manpower and Social Affairs Committee which may formulate comments on issues within its competence."

\section{Extract from document [C(84)166, Annex 1]}

"Bearing in mind the objectives enunciated in the 1980 Declaration of the high-level Conference on Policies for the Employment of Women at the 1984 Report on the Integration of Women in the Economy prepared by the Working Party on the Role of Women in the Economy, the functions of the Working Party will be:

a) to monitor progress, identify obstacles, assess effectiveness and develop strategies for promoting the policies identified in the 1980 Declaration;

\footnotetext{
1 No meeting scheduled in 2006.

2

Now called Employment, Labour and Social Affairs Committee
} 
b) to identify and provide advice through the Manpower and Social Affairs Committee on the policy implications of any work within the OECD as a whole which has implications for the economic and social position of women;

c) to advise the Manpower and Social Affairs Committee of the work it would propose and, on the basis of the annual programme of work of the Organisation, undertake substantive studies and reviews of policies and issues in order to develop their policy implications for Member countries." 


\section{WORKING PARTY ON EMPLOYMENT}

Chair:

Mr. Kenneth Swinnerton

(United States)

Vice-Chair:

Dr. Joyup Ahn

(Korea)

Members:

Open to all Member countries

Date of creation:

6th July 1976

Duration:

December 2008

Mandate: Record of the 44th Meeting of the Manpower and Social Affairs Committee ${ }^{1}$ [MAS/M(76)3]

\section{Extract from document [MAS/M(76)3, paragraph 29]}

\section{"THE COMMITTEE}

ii) as regards paragraph 1-7 of MAS(76)10, approved the draft terms of reference for the reconstitution of the Working Party on Employment circulated during the meeting, as amended in the discussion and attached at Annex A hereto."

\section{Annex A to document [MAS/M(76)3]}

\section{"TERMS OF REFERENCE}

\section{WORKING PARTY ON EMPLOYMENT}

1. The Working Party will be responsible to the Employment, Labour and Social Affairs Committee for following up the implementation of the 1976 Recommendation on a General Employment and Manpower Policy, and other assignments enumerated below:

i) With respect to the Report on the 1976 Recommendation, due not later than 31st March 1977, and subsequently at intervals to be determined by the Manpower and Social Affairs Committee:

a) The maintenance and up-dating of the "inventory" of employment and manpower measures, including the classification and format of presentation of the "inventory";

b) The preparation of reports on the quantification of the measures in financial and manpower terms, as an element in the evaluation of the implementation of policies on a Member country basis;

\footnotetext{
1 Now called the Employment, Labour and Social Affairs Committee
} 
c) The format and content of the Report to be submitted by Member countries on the implementation of the 1976 Recommendation.

ii) The selection of specific manpower and employment measures for evaluation of experience in selected countries, and reporting the results of such evaluations;

iii) The periodic review and assessment of the changing employment situation facing Member countries and the employment and manpower policy responses appropriate to the current situation;

iv) Analysis and evaluation of the implications of the medium-term growth strategy approved by the Council of Ministers for the implementation of the 1976 Recommendation, including preparation of a Report to the Manpower and Social Affairs Committee in co-operation with other relevant bodies of the Organisation;

v) Investigations and analyses as required from time to time on specific issues which are of particular concern (these can include, inter alia, the concept of full employment, the extent and character of structural unemployment and its policy implications, the effects of particular policies on labour market behaviour, and the co-ordination of income support policies and selective employment and manpower policies).

2. The Working Party will report its analyses, evaluations and conclusions to the Manpower and Social Affairs Committee on a periodic basis as required. In particular, it will report to the next meeting of the Manpower and Social Affairs Committee on the implementation of Item i); on progress made on (tem ii), iv) and v), and will present a report on Item iii)." 


\section{WORKING PARTY ON SOCIAL POLICY}

Chair:

Vice-Chairs:

Members:

Observers:

Date of creation:

Duration:
Mr. François Weldon

Mr. Raffaele Tangorra

Mr. Yutaka Iwabuchi

Ms. Agnieszka Chlon-Dominczak

Mr. John Hoff

Open to all Member countries

Council of Europe

International Labour Organization (ILO)

International Social Security Association (ISSA)

World Health Organization (WHO)

14th December 1983

31st December 2008
(Canada)

(Italy)

(Japan)

(Poland)

(United States)

Mandate: - Renewal of the mandate [DELSA/ELSA(2004)10] approved by the Employment, Labour and Social Affairs Committee as of 1st January 2005 for a period of four years, document [DELSA/ELSA/M(2004)2] at its $105^{\text {th }}$ Session on 22-23 November 2004.

- Record of the 60th Meeting of the Manpower and Social Affairs Committee [MAS/M(83)2]. This mandate was renewed by the Committee at its 69th and 75th Meetings [MAS/M(87)1, MAS/M(89)3] and by the Employment, Labour and Social Affairs Committee at its $81 \mathrm{st}, 87^{\text {th }}, 93 \mathrm{rd}$ and 99 th meetings [DEELSA/ELSA/M(2001)2].

\section{Extract from document [DELSA/ELSA/M(2004)2, item 4]}

7. On the proposal of the President, the Committee:

ACCEPTED the revisions proposed by the Chair of the Working Party; and

APPROVED the proposal to renew the mandate of the Working Party on Social Policy to $31^{\text {st }}$ December 2008, noting that, if the outcomes of the Social Policy Ministerial so required, the Committee would be asked to reconsider the terms of reference of the Working Party at a later date.

\section{Annex to document [DELSA/ELSA(2004)10]}

\section{Terms of Reference of the Working Party on Social Policy}

1. The Working Party will address those issues of social policy which arise in the context of demographic, social and economic changes in the Member countries, bearing in mind the effective functioning of labour markets. It will, on behalf of the Committee, develop a framework for the assessment of social policy and oversee the development of a comprehensive data base enabling comparative trends to be tracked. 
2. To achieve these goals, the Working Party will supervise, on behalf of the Committee, the implementation of activities on social policy issues allocated to the Committee in the Programme of Work and Budget of the Organisation.

3. The Working Party will contribute to and comment on studies and analyses undertaken for the Employment, Labour and Social Affairs Committee on the above topics and, in view of the specialised expertise from Member countries, may authorise the Secretariat to convene ad hoc meetings of national experts from time to time on specialised topics for the consideration of the Working Party and the Committee.

4. The Working Party will collaborate with other Committees and Groups through horizontal projects and exchanges of views wherever such work appears likely to be fruitful. 


\section{GROUP ON HEALTH}

\section{Co-Chairs:}

Vice-Chairs:

Members:

Observers:

Date of creation:

Duration:
Ms. Jane Halton

Mr. Roel Bekker

Mr. Raimo Jämsén

Mr. Likurgus Liaropoulos

Mr. Yutaka Iwabuchi

Mr. Eduardo Gonzalez Pier

Mr. Gaudenz Silberschmidt

Mr. John Hoff

Open to all Member countries

Council of Europe

International Social Security Association (ISSA)

World Health Organization (WHO)

1st January 2005

31st December 2006
(Australia)

(Netherlands)

(Finland)

(Greece)

(Japan)

(Mexico)

(Switzerland)

(United States)

Mandate: - Resolution of the Council renaming the Ad Hoc Group on Health as the Group on Health and revising its mandate as indicated in Annex to document [C(2004)172/REV2], approved at its 1100th session on 9 December 2004 [C/M(2004)26, item 328].

\section{Annex to the Resolution of the Council [C(2004)172/REV2}

"1. The Group on Health will have the following responsibilities:

a) Provide a forum for Member countries to share views and experiences on, and consider responses to, health issues and challenges.

b) Encourage co-operation among Member countries in developing health accounts on a consistent basis, in other data and information sharing.

c) Develop and promulgate health care indicators, and standardised, comparable sets of data and statistics, as a basis for joint research and analysis assessing the performance of OECD health care systems.

d) Assess options for sustainable financing of efficient health care systems.

e) Assess the health care performances of Member countries in relation to their national and international policies and commitments in accordance with current procedures and practices.

f) Promote the sharing with non-Members of the health care data systems and the expertise, information and experience which reside in Member countries.

g) Ensure that the views and expertise of non-government institutions are drawn upon in the conduct of OECD's health work, utilising, inter alia, the Business and Industry Advisory Committee to the OECD (BIAC), the Trade Union Advisory Committee to the 
OECD (TUAC) and contacts with relevant non-governmental organisations, including organisations representing patients and health professionals.

2. Advise the Council on appropriate priorities for work on health.

3. Steer and review the progress of work and its financial status.

4. In the pursuit of these objectives, the Group shall maintain close working relationships with other relevant bodies of the Organisation, seeking to ensure that health issues are fully addressed in the overall work of the OECD, in a well-coordinated and horizontal manner.

5. The Group shall also maintain, as appropriate, and in conformity with the OECD Convention and Rules of Procedures, relations with other international organisations, particularly the WHO, seeking to achieve non-duplicative, co-ordinated and complementary work programmes in areas of shared interest and mutual benefit, conducting joint projects where appropriate and ensuring that the experience and expertise of other bodies is appropriately incorporated into the Group's health work." 
ENTREPRENEURSHIP, SMESAND LOCAL DEVELOPMENT 



\section{Chair:}

Vice-Chairs:

Bureau Members:
Mr. Jean-François Rocchi

Members:

Date of creation:

Duration:

\section{2nd July 1982}

31st December 2010
Mrs. Cate McKenzie

Mr. Jan Hendeliowitz

Ms. Ann Van Den Cruyce

Mr. John Atherton

Mr. Paavo Saikkonen

Mr. Michele Dau

Mr. Piotr Stronkowski

$\begin{array}{ll}\text { Australia } & \text { Poland } \\ \text { Austria } & \text { Portugal } \\ \text { Belgium } & \text { Slovak Republic } \\ \text { Canada } & \text { Spain } \\ \text { Czech Republic } & \text { Sweden } \\ \text { Denmark } & \text { Switzerland } \\ \text { Finland } & \text { Turkey } \\ \text { France } & \text { United Kingdom } \\ \text { Greece } & \text { United States } \\ \text { Hungary } & \text { European Commission } \\ \text { Ireland } & \text { Chile } \\ \text { Italy } & \text { Latvia } \\ \text { Mexico } & \text { Lithuania } \\ \text { New Zealand } & \text { Romania } \\ \text { Norway } & \text { Slovenia }\end{array}$

European Bank for Reconstruction and Development (EBRD) /Central European Initiative (CEI) Inter-American Development Bank (IADB)

(Australia)

(Denmark)

(Belgium)

(Canada)

(Finland)

(Italy)

(Poland)

Poland

Slovak Republic

Sweden

Switzerland

United Kingdom

United States

European Commission

Chile

Lithuania

Romania

Slovenia

Mandate: Decision of the Council concerning the Co-operative Action Programme on Local Economic and Employment Development (LEED) approved at its 1106th session on 24 February 2005 [C/M(2005)5, Item 50 and C(2004)151/REV1]

\section{Extract of the summary record [C/M(2005)5, Item 50]}

"THE COUNCIL

b) adopted the draft Decision of the Council concerning the Co-operative Action Programme on Local Economic and Employment Development as set out in Annex 1 to the document C(2004)151/REV1." 


\section{THE COUNCIL,}

Having regard to the Convention on the Organisation for Economic Co-operation and Development of 14th December 1960 and, in particular, Articles 1 a), 5 a), 9 and 20 thereof;

Having regard to the Rules of Procedure of the Organisation;

Having regard to the Financial Regulations of the Organisation;

Having regard to the Decision of the Council of 24 February 2000 concerning the Cooperative Action Programme on Local Economic and Employment Development [C(2000)16(FINAL) as amended by $\mathrm{C}(2001) 303$ \& CORR1; C/M(2001)26];

Having regard to the document on the Renewal of the Mandate of the Co-operative Action Programme on Local Economic and Employment Development and the opinion of the Directing Committee of the Programme [C(2004)151/REV1, Annex 2];

Considering that the Governments of Australia, Austria, Belgium, Canada, the Czech Republic, Denmark, Finland, France, Greece, Hungary, Ireland, Italy, Latvia, Lithuania, Mexico, New Zealand, Norway, Poland, Portugal, the Slovak Republic, Slovenia, Spain, Sweden, Switzerland, Turkey, the United Kingdom, the United States, as well as the European Commission, the World Bank, the European Bank for Reconstruction and Development (EBRD) together with the Central European Initiative (CEI), and the Inter-American Development Bank (hereinafter referred to as the "Participants") have formally expressed their willingness to participate in a Co-operative Action Programme on Local Economic and Employment Development;

On the proposal of the Secretary-General;

\section{DECIDES:}

\section{Article 1}

\section{DEFINITION OF THE PROGRAMME}

a) The Co-operative Action Programme on Local Economic and Employment Development, established within the framework of the Organisation, is hereby maintained.

b) The main objectives of the Programme shall be:

i) To improve the quality of local labour market and social policies, through continuous monitoring and assessment of current practices;

ii) to promote the exchange of experience and information and the diffusion of innovation in local economic, employment and entrepreneurship development.

iii) to provide assistance for Member countries, to support exchanges with nonmember economies and to serve as a critical link between the OECD and local authorities.

c) A programme of work shall be adopted by the Council and implemented by the Secretary-General. The programme of work may include activities to be financed in part from voluntary contributions from public institutions and grants from private foundations.

Article 2

\section{COMPOSITION OF THE DIRECTING COMMITTEE}


a) Each Participant shall appoint at least one representative to the Directing Committee. Representatives to the Directing Committee of the Programme (hereinafter referred to as the "Directing Committee") should be chosen by virtue of their responsibilities in matters relating to Local Economic and Employment Development.

b) Participants may appoint experts to assist their representatives and the Directing Committee.

c) The Directing Committee shall appoint from among its members, a Bureau consisting of at least the Chairman and two Vice-Chairmen. Bureau members shall be appointed for a maximum of five years (two mandates of two years and a half).

\section{Article 3}

\section{FUNCTIONS OF THE DIRECTING COMMITTEE}

a) The Directing Committee shall be competent to consider all questions related to the carrying out of the Programme.

b) Each biennium the Directing Committee shall submit to the Council for adoption the draft programme of work.

c) The Directing Committee shall submit a summary activity report each year to the Council.

\section{Article 4}

\section{FINANCING OFEXPENDITURE}

a) The expenditure arising from the implementation of the Programme shall be charged against the appropriations authorised for it under Part II of the Budget of the Organisation.

b) The above-mentioned appropriations shall be financed by special contributions paid by the Participants, voluntary contributions and grants.

c) The Directing Committee shall submit to the Council for adoption the annual estimates of expenditure and of income for the Programme.

\section{Article 5}

\section{RELATIONS WITH OTHER INSTITUTIONS}

In order to further the objectives of the Programme the Secretary-General may establish appropriate working relations, in agreement with a Member government, with a national institution concerned with local economic development and employment creation. Such relations may include the encouragement, promotion or assistance of activities of such institutions. The same arrangements may be applicable to other international organisations with a view to strengthening international co-operation in relation to job creation and local development. Furthermore, collaboration will be pursued in areas of synergy between the LEED Programme and the many OECD Directorates and Committees.

\section{Article 6 \\ PARTICIPANTS}

a) The Participants shall be the Member countries and non-OECD economies and invited international organisations listed in the Preamble. 
b) Any Member country of the Organisation the Government of which does not participate in the present Decision may participate in it by addressing a notification to the Secretary-General to this effect.

c) Subject to approval by the OECD Council and the LEED Directing Committee, nonMember economies and international organisations may be invited to participate in the Programme as full participants.

Article 7

\section{DURATION}

This Decision repeals the Decision of 24 February 2000, referred to above, and shall terminate on 31st December 2010, unless the Council decides otherwise. 


\section{TOURISM COMMITTEE}

Chair:

Vice-Chairs:

Members:

Observers:

Date of creation:

Duration:
Mr. Peter Keller

Ms. Angelika Liedler

Ms. Chantal Péan

Mr. Lars Erik Jønsson

Mr. Naoki Fujii

Mr. Gabriel Szekeli

Ms. Helen Marano
(Switzerland)

(Austria)

(Canada)

(Denmark)

(Japan)

(Mexico)

(United States)

Open to all Member countries

Council of Europe

World Bank

30th September 1961

31st December 2008

Mandate: - Paragraph 33, part I of the Report of the Preparatory Committee

- Council Decision regarding a Sunset Clause for all Committees [C/M(2004)5, item 75] entered into force on 22 April 2004 [C/M(2004)10, item 143, IV, c)]

\section{Extract of the Report of the Preparatory Committee}

"33. The Preparatory Committee recommends that co-operation in the field of tourism should be continued. To this effect the present structure should be reviewed and adapted in the light of future requirements." 


\section{STATISTICAL WORKING PARTY}

Chair:

Vice-Chairs:

Members:

Date of creation:

Duration:
Mr. Peter Laimer

Mr. Scott Meis

Mr. Laurent Vassille

Mr. Ulrich Spörel

Ms. Natalia Rodriguez Salmones

Ms. Helen Marano

Open to all Member countries

January 1971

31st December 2008
(Austria)

(Canada)

(France)

(Germany)

(Spain)

(United States)

Mandate: Consideration of the Mandate of the Statistical Working Party [DSTI/DOT/TOU(98)8] approved by the Tourism Committee at its $69^{\text {th }}$ session on 11-12 June 1998 [DSTI/DOT/TOU/M(98)1]

\section{Extract of document [DSTI/DOT/TOU(98)8]}

ANNEX I

$" \ldots$

- $\quad$ "To provide a forum for discussion and exchange of information by statisticians of current issues concerning the development of tourism statistics.

- To assist the Tourism Committee in its task on the evaluation and analysis of market developments and prospects, taking into account policymakers' needs to have good quality information available in order to be in a position to assess the different options, make decisions, implement them and appraise performances.

- In order to provide policymakers, researchers and tourist industries with a reference instrument enabling them to assess the importance of tourism in OECD countries, develop a tourism satellite account using the concepts and principles of the System of National Accounts. Encourage all forms of co-operation with other international organisations' work in related fields. Keep up an on-going dialogue with representatives of the private sector. Monitor the work undertaken by the Group of Expert on Tourism Satellite Accounts and, if necessary, review the Group's mandate.

- At the same time, continue to collect, analyse and diffuse timely data on the tourism economic accounts, on the basis of the concept adopted in 1991 (Manual on Tourism Economic Accounts, OECD, 1991).

- Contribute to the harmonisation of tourism-related statistical systems in Member countries and to the integration of new statistical systems (System of National Accounts 1993, classification systems, definitions and recommendations concerning tourism statistics, etc.) in tourism statistics. To this end, encourage all forms of co-operation with other international organisations' work in related fields. Keep up an on-going dialogue with representatives of the private sector.

- $\quad$ Place special emphasis on defining and measuring tourism-related employment from both the quantitative and the qualitative points of view. Develop a methodological framework for the OECD countries for the purpose of collecting detailed information on employment in tourist industries and on tourism's role in job creation. Ensure that this approach is consistent with 
other methodological work in progress, in particular the Tourism Satellite Account for OECD countries.

- Assemble statistics and ensure the comparability and comprehensiveness of such material in conformity with international standards; participate in the elaboration of standards, where and when appropriate.

- $\quad$ Perform other tasks on request by the Tourism Committee"." 

EDUCATION 

Chair:

Bureau Members:

Members:

Observers:
Mr. Torben Kornbech Rasmussen

Ms. Nadine Prost

Ms. Veronika Pahl

Mr. Dimitris Glaros

Mr. Hyung Yeel Koh

Mr. Hans-Åke Öström

Open to all Member countries

Chile
Estonia
Israel
Russian Federation
Slovenia
Council of Europe
22nd July 1970
31st December 2006
Date of creation:

Duration:
(Denmark)

(France)

(Germany)

(Greece)

(Korea)

(Sweden)

Mandate: - Resolution of the Council Terminating the Mandate of the Committee for Scientific and Technical Personnel and Establishing an Education Committee [C(70)134]

- Minutes of the 226th, 423rd and 543rd Meetings of the Council [C/M(70)21(Final); C/M(76)15, Part I (Final); C/M(81)15(Final)]

- This mandate has been renewed by the Council at its 647 th, 761 st, 880 th and 1010th Sessions [C(86)108/Final; C(91)62/FINAL; C(96)102/FINAL ; C/M(2001)16 and $\mathrm{C}(2001) 180]$

\section{Resolution of the Council [C(2001)180 Annex 3]}

"THE COUNCIL,

Having regard to Articles 1 and 2 of the Convention on the Organisation for Economic Co-operation and Development of 14th December 1960; Annex there to;

Having regard to the Rules of Procedure of the Organisation and, in particular, to the

Having regard to the Resolution of the Council of 22nd July 1970, establishing an Education Committee [C(70)134];

Having regard to the Resolution of the Council of 24th July 1981, concerning the Renewal of the Mandate of the Education Committee [C/M(81)15(Final), Item 154 b, h and i)];

Having regard to the Resolution of the Council of 27 June 1996 concerning the Renewal of the Mandate of the Education Committee [C(96)102/FINAL];

Having regard to the Note by the Secretary-General concerning the Renewal of the Mandate of the Education Committee, of the Programme on Educational Research and Innovation, of the Decentralised Project on Institutional Management in Higher Education (IMHE) the 
Decentralised Programme on Educational Building (PEB) and the Decentralised Programme for International Student Assessment (PISA); [C(2001)180],

\section{RESOLVES:}

The Mandate of the Education Committee is hereby renewed for a further period of five years as from 1st January 2002."

\section{Mandate of the Education Committee - Extract from [C(2001)81]}

The Education Committee is responsible for:

i) Evaluating prospects and policies for educational growth and development to meet individual, social, cultural and economic objectives, taking into account the need for optimal allocation and efficient management of the total resources for learning;

ii) Exchanging information and promoting international co-operation among member countries and, where relevant, with non-member countries on the problems identified under i) above."

\section{Participation in the Education Committee - Extract from [C/M(70)21(Final), Item $210 \mathrm{~b}$ )]}

Member governments should, whenever possible appoint to the Education Committee senior officials with direct responsibility for advising their governments on general education policy and the allocation of educational resources. 


\section{INDICATORS OF EDUCATION SYSTEMS STRATEGIC MANAGEMENT GROUP (INESSMG)}

Chair:

Members:

Date of creation:

Duration:
Mr. Gaby Hostens

Education Committee

Mr. Melvin Brodsky

ELSA Committee

Mr. Mats Ekholm

CERI Governing Board

Mr. Masayuki Inoue

CERI Governing Board

Ms. Frances Kelly

Education Committee

Mr. Josef Neumuller

Education Committee

Mr. Claude Sauvageot

CERI Governing Board

Mr. Paolo Sestito

ELSA Committee

Mr. Joern Skovsgaard

Education Committee

Mr. William Thorn

CERI Governing Board

Mr. Ryo Watanabe

PISA Board of Participating Countries

1st May 2001

31st May 2006
(Belgium)

(United States)

(Sweden)

(Japan)

(New Zealand)

(Austria)

(France)

(Italy)

(Denmark)

(Australia)

(Japan)

Mandate: - Decision of the Education Committee [DEELSA/ED/M(2000)2, paragraph 18]

- Decision of the CERI Governing Board [CERI/CD/M(2000)2, paragraph 42]

- Document [DEELSA/ELSA/ED/CERI/CD(2001)1, Annex 1, paragraph 1]

Extract from the Decision of the Education Committee [DEELSA/ED/M(2000)2, paragraph 18]

"On the proposal of the President, the Education Committee:

SUPPORTED the idea of more strategic and transparent management of INES and, in particular, the proposal to set up a Strategic Management Group to replace the existing INES Steering Group and the proposal to elect four delegates from the Education Committee, four from the CERI Governing Board and two from the Employment, Labour and Social Affairs Committee. "

Extract from the Decision of the CERI Governing Board [CERI/CD/M(2000)2, paragraph 42]

"On the proposal of the President, the CERI Governing Board: 
SUPPORTED the proposal to set up a Strategic Management Group to replace the existing INES Steering Group and the proposal to elect four delegates from the Education Committee, four from the CERI Governing Board and two from the Employment, Labour and Social Affairs Committee and NOTED that elected members of the SMG could be accompanied by experts if necessary."

\section{Extract of document [EDU/INES/SMG(2005)5, paragraph 2]}

"2. The function of the Strategic Management Group is to make recommendations to Joint Sessions of the Education Committee and CERI Governing Board covering the strategic management of INES. To this end the Group will:

- $\quad$ within the framework of the priorities set by OECD Education Ministers, the specific objectives agreed at the Tokyo INES General Assembly and further broad guidance from countries such as that provided by the Dublin meeting on 6-8 February 2003, make recommendations on the priorities for INES work within agreed resources. Over time, this prioritisation will adapt to the changing needs of Member countries.

- in this context, have the possibility to make recommendations on:

the improvement in the quality of existing indicators;

the development of new data sources and new indicators;

the dissemination of INES outputs;

the analytic work using INES data;

the relative priority of work under the previous four headings.

- keep under review the resources, structures and working arrangements of INES, and make necessary recommendations to ensure that the INES programme of work is well managed and effectively prioritised within the resources available, taking account of related activities in other bodies;

- act as an intermediary between Networks and Joint Sessions, making recommendations to Joint Sessions with respect to the acceptability of proposals advanced by Networks, and initiating proposals to Joint Sessions on particular items which might be included in the work programmes of Networks;

- while recognising that the management and development of PISA is primarily a matter for the PISA Governing Board, ensure that appropriate linkages are made between PISA and other INES developments, and that any relevant concerns are brought to the attention of the PISA Governing Board." 


\section{CENTRE FOR EDUCATIONAL RESEARCH AND INNOVATION GOVERNING BOARD (CERI)}

\section{Chair:}

Participation in the work: ${ }^{1}$
Mr. Gabor Halász

Ms. Wendy Jarvie

Ms. Elsa Hackl

...

Ms. Rachel Bard

Mr. Jiri Kotasek

Mr. Joern Skovsgaard

Mr. Reijo Laukkanen

Mr. Claude Sauvageot

Mr. Klaus Luther

Mr. Sigurjón Mýrdal

Mr. Gearoid O'Conluain

Mr. Felice Rizzi

Mr. Masayuki Inoue

Ms. Sylvia Ortega Salazar

Ms. Anneke Boot

Ms. Frances Kelly

Mr. Petter Skarheim

Mr. Jerzy Wisniewski

Mr. Fernando Adão-da-Fonseca

Mr. Peter Plavcan

Mr. José Pérez Iruela

Mr. Mats Ekholm

Mr. Stefan C. Wolter

Mr. Ibrahim Ozdemir

Mr. Richard Bartholomew

Mr. Grover J. Whitehurst
(Hungary)

(Australia)

(Austria)

(Belgium)

(Canada)

(Czech Republic)

(Denmark)

(Finland)

(France)

(Germany)

(Greece)

(Iceland)

(Ireland)

(Italy)

(Japan)

(Korea)

(Mexico)

(Netherlands)

(New Zealand)

(Norway)

(Poland)

(Portugal)

(Slovak Republic)

(Spain)

(Sweden)

(Switzerland)

(Turkey)

(United Kingdom)

(United States)

Observers: $\quad$ Chile

Israel

Date of creation:

28th July 1967

Duration:

31st December 2006

Mandate: - Decision of the Council concerning a Programme on Educational Research and Innovation, adopted by the Council at its 543rd Meeting [C(81)53(Final)]. Article 4 b) amended by Council on 7 February 1997 [C/M(97)4, item 56 b)]

- This mandate was renewed by the Council at its 647 th, 761st, 880th and 1010th sessions [C(86)120; C(91)112; C(96)138/FINAL; C/M(2001)16 and C(2001)180]

Decision of the Council [C(81)53(Final)] as amended by Council on 7 February 1997

"THE COUNCIL,

\footnotetext{
1 The European Commission participates by virtue of the Supplementary Protocol No.1 to the Convention on the OECD
} 
Having regard to the Convention on the Organisation for Economic Co-operation and Development of 14th December 1960, and, in particular, Articles 2 b), 5 a), 9, 12 and 20 thereof;

Having regard to the Financial Regulations of the Organisation and, in particular, to Articles 5, 10, $14 \mathrm{~b}$ ) and $16 \mathrm{~b}$ ) thereof;

Having regard to the Decision of the Council of 20th July 1976, concerning the Programme on Educational Research and Innovation [C(76)153];

On the proposal of the Secretary-General;

DECIDES:

Article 1

\section{PROGRAMME}

a) With a view to meeting, by means of the joint action of the Member countries, certain needs for educational research and innovation, the Council shall, for a period of five years as from 1st January 1982, adopt each year a Programme on Educational Research and Innovation (hereinafter called the "Programme") in the context of the economic and social objectives of Member countries.

b) Within this context, the main objectives of the Programme shall be:

i) to promote and support the development of research activities in education and undertake such research activities where appropriate;

ii) to promote and support pilot experiments with a view to introducing and testing innovations in the educational system;

iii) to promote the development of co-operation between Member countries in the field of educational research and innovation.

c) The Programme may include Special Activities to be financed in whole or in part from voluntary contributions by public institutions or grants from private institutions.

Article 2

\section{CENTRE FOR EDUCATIONAL RESEARCH AND INNOVATION}

a) A centre for Educational Research and Innovation (hereinafter called the "Centre") is hereby established within the framework of the Organisation.

b) The task of the Centre shall be to draw up and carry out the Programme.

Article 3

\section{STRUCTURE}

The task assigned to the Centre shall be carried out by the Secretariat of the Centre under the authority of the Secretary-General, in accordance with the decisions of the Council and those of the Governing Board of the Centre (hereinafter called the "Governing Board") within its field of competence.

Article 4

\section{COMPOSITION OF THE GOVERNING BOARD}

a) The Governing Board shall be composed of one national expert in the field of competence of the Centre from each of the countries participating in the Programme.

b) After consultation with the participating Member countries, the Secretary-General shall propose the membership of the Governing Board to the Council. The Council will nominate members for a period of 30 months. (As amended by Council on 7 February 1997 [C/M(97)4, item 56 b)]). 
c) The Chairman of the Governing Board shall be designated by the Council from amongst the members of the Governing Board.

d) The Chairman of the Education Committee or a Vice-Chairman may attend meetings of the Governing Board.

e) The Governing Board shall establish an Executive Group of not more than six of its members. The Secretary-General or the Executive Group may invite not more than three technical advisers to take part in the discussions of the Executive Group.

Article 5

\section{FUNCTIONS OF THE GOVERNING BOARD}

a) The Governing Board shall be concerned with all matters in the field of competence of the Centre. In particular, each year it shall prepare and approve by a two-thirds majority vote the draft Programme for the following year.

b) The Governing Board shall be assisted by the Executive Group in the preparation and supervision of the programme.

c) The Executive Group shall be responsible for liaison with the Education Committee, the Employment, Labour and Social Affairs Committee and the Committee for Scientific and Technological Policy.

d) The Governing Board shall, by unanimous vote, adopt any necessary Regulations and Rules for the application of this Article.

Article 6

\section{EXECUTION OF THE PROGRAMME}

a) The Programme, including the Special activities, shall be carried out by means of general projects and/or joint projects.

b) The general projects shall be carried out by the Centre and may be financed entirely by the Centre, with the exception of travelling expenses and daily subsistence of experts and participants designated by the participating countries.

c) The joint projects shall be carried out jointly by the Centre and one or several participating countries, or institutions in the participating countries in agreement with the National Authorities. The contributions of the Centre to joint projects shall be defined in the Programme and Budget of the Organisation and shall not exceed one half of the expenditure involved. They may take the form of advisory services, research work done by the Secretariat and/or a financial contribution in exceptional cases.

Article 7

\section{STAFF OF THE CENTRE}

a) The staff of the Centre shall form part of the Secretariat of the Organisation.

b) Consultants to the Centre may be appointed for a period exceeding that provided in Regulation 2 b) of the Regulations and Rules for Council Experts and Consultants of the Organisation.

Article 8

\section{BUDGET OF THE CENTRE}

a) The expenditure of the Centre shall be charged against the appropriations authorised for it under Part II of the Budget of the Organisation.

b) The Governing Board shall, by a two-thirds majority decision, submit the annual estimates of expenditure of the Centre to the Council for adoption. 
c) Notwithstanding the provisions of Article $14 \mathrm{~b}$ ) of the Financial Regulations, the Secretary-General may accept any voluntary contribution or grant not exceeding FF 1000000 in respect of Special Activities referred to in Article $1 \mathrm{c}$ ) above which have been included in the approved Programme.

d) Notwithstanding the provisions of Article $16 \mathrm{~b}$ ) of the Financial Regulations of the Organisation, appropriations in respect of the Special Activities referred to in Article $1 \mathrm{c}$ ) above, for which no commitment has been entered into before the end of the Financial Year for which they were appropriated, shall be automatically carried forward to the budget for the ensuing year by decision of the Secretary-General.

Article 9

\section{RELATIONS WITH OTHER INSTITUTIONS}

The Centre may establish such working relations as may be appropriate to facilitate the accomplishment of its tasks with other international organisations and, in agreement with the National Authorities, with national institutions concerned with educational research and innovation. Such working relations should in particular allow the Centre to take full advantage of the work of these organisations and institutions. Such working relations should be established taking into account the applicable Acts of the Organisation. In order to accomplish its purposes, the Centre may also encourage, promote and assist the activities of other institutions and organisations.

Article 10

\section{PARTICIPATING COUNTRIES}

The countries participating in this Programme are: Australia, Austria, Belgium, Canada, Czech Republic, Denmark, Finland, France, Germany, Greece, Hungary, Iceland, Ireland, Italy, Japan, Korea, Luxembourg, Mexico, the Netherlands, New Zealand, Norway, Poland, Portugal, Slovak Republic, Spain, Sweden, Switzerland, Turkey, the United Kingdom, the United States.

\section{Article 11}

\section{REVIEW}

This Decision shall terminate on 31st December 2006, unless the Council decides otherwise.

\section{Article 12}

\section{TITLE}

This Decision shall replace the Decision of the Council of 20th July 1976 [C(76)153]. It shall be known as the "Rules for the Implementation of the Programme on Educational Research and Innovation".

\section{Extract from document [C/M(81)15(Final)], Item $154 \mathrm{~g}), \mathrm{h})$ and i)}

\section{"THE COUNCIL}

g) agreed to the following interpretations:

Article $4 \mathrm{~b}$ ) The Secretary-General will consult each participating country by inviting nominations for the Governing Board from the country concerned. The Secretary-General and Delegations will take into account the need to ensure within the Governing Board a balance between government officials, educational scientists and national experts in charge of educational development programmes. 
Article $4 \mathrm{c}$ ) The term of office of the Chairman of the Governing Board shall be identical with his term of office as a member of the Governing Board.

h) noted that programme co-ordination between the Education Committee and the Centre for Educational Research and Innovation will be achieved through a single two-part programme, and agreed that the Chairman of the Governing Board of CERI may attend meetings of the Education Committee;

i) noted that overall programme co-ordination of the work of the Organisation in the field of manpower, social affairs and education will be ensured, when appropriate, by joint meetings of the Bureaux of the bodies concerned as well as by the setting up on an ad hoc basis of Joint Working Parties."

\section{Extract from document $[\mathrm{C} / \mathrm{M}(2001) 16$, Item $254 \mathrm{a})$ and c)}

"THE COUNCIL,

a) noted document $\mathrm{C}(2001) 180$ and endorsed the proposals concerning the renewal of the Mandates of [...] the Centre for Educational Research and Innovation (CERI), ...

c) adopted the draft Decision of the Council concerning the Renewal of the Mandate of the Centre for Educational Research and Innovation (CERI) as set out in Annex 4 to document C(2001)180;"

\section{Decision of the Council [C(2001)180, Annex 4]}

\section{"THE COUNCIL,}

Having regard to the Convention on the Organisation for Economic Co-operation and Development of 14th December 1960, and, in particular, Articles 2 b), 5 a), 9, 12 and 20 thereof;

Having regard to the Financial Regulations of the Organisation and, in particular, to Articles 5, 10, $14 \mathrm{~b}$ ) and $16 \mathrm{~b}$ ) thereof;

Having regard to the Decision of the Council of 24th July 1981, concerning a Programme on Educational Research and innovation [C(81)53(Final)];

Having regard to the Decision of the Council of 27 June 1991 concerning the Renewal of the Programme on Educational Research and Innovation [C(91)112];

Having regard to the Decision of the Council of 27 June 1996 concerning the Renewal of the Programme on Educational Research in and Innovation [C(96)138/FINAL];

Having regard to the Note by the Secretary-General concerning the renewal of the Mandate of the Education Committee, of the Programme on Educational Research and Innovation, of the decentralised Project on Institutional Management in Higher education (IMHE) and of the Decentralised Programme on Educational Building (PEB) and the Decentralised Programme for International Student Assessment [C(2001)180];

\section{DECIDES:}

The provisions of the Decision of the Council of 24th July 1981 [C(81)53(Final)] referred to above shall be applicable for a further period of five years as from 1st January 2002." 


\section{CERI EXECUTIVE GROUP}

Members:

Ms. Rachel Bard

Mr. Richard Bartholomew

Mr. Gabor Halász

Mr. Masayuki Inoue

Mr. Reijo Laukkanen

Mr. Stefan C. Wolter

12th May 1971

Date of creation:

Duration:
(Canada)

(United Kingdom)

(Hungary)

(Japan)

(Finland)

(Switzerland)

Mandate: Decision of the Council concerning a Programme on Educational Research and Innovation, adopted by the Council at its 543rd meeting [C(81)53(Final); and $\mathrm{C} / \mathrm{M}(81) 15$ (Final)]

\section{Extracts from the Decision of the Council [C(81)53(Final)}

\section{"Article 4}

e) The Governing Board shall establish an Executive Group of not more than six of its members. The Secretary-General or the Executive Group may invite not more than three technical advisers to take part in the discussions of the Executive Group.

\section{$\underline{\text { Article } 5}$}

b) The Governing Board shall be assisted by the Executive Group in the preparation and supervision of the Programme.

c) The Executive Group shall be responsible for liaison with the Education Committee, the Employment, Labour and Social Affairs Committee and the Committee for Scientific and Technology Policy."

\section{Extract from document [C/M(81)15(Final) Item $154 \mathrm{~g})]$}

\section{"THE COUNCIL}

g) agreed to the following interpretations:

"Article 4 e) The members of the Executive Group will be appointed for one year. The Governing Board will ensure a certain rotation of membership so that the maximum of its members will take part in the work of the Executive Group." 


\section{INDICATORS OF EDUCATION SYSTEMS STRATEGIC MANAGEMENT GROUP (INESSMG)}

Chair:

Members:

Date of creation:

Duration:
Mr. Gaby Hostens

Education Committee

Mr. Melvin Brodsky

ELSA Committee

Mr. Mats Ekholm

CERI Governing Board

Mr. Masayuki Inoue

CERI Governing Board

Ms. Frances Kelly

Education Committee

Mr. Josef Neumuller

Education Committee

Mr. Claude Sauvageot

CERI Governing Board

Mr. Paolo Sestito

ELSA Committee

Mr. Joern Skovsgaard

Education Committee

Mr. William Thorn

CERI Governing Board

Mr. Ryo Watanabe

PISA Board of Participating Countries

1st May 2001

31st May 2006
(Belgium)

(United States)

(Sweden)

(Japan)

(New Zealand)

(Austria)

(France)

(Italy)

(Denmark)

(Australia)

(Japan)

Mandate: - Decision of the Education Committee [DEELSA/ED/M(2000)2, paragraph 18]

- Decision of the CERI Governing Board [CERI/CD/M(2000)2, paragraph 42]

- Document [DEELSA/ELSA/ED/CERI/CD(2001)1, Annex 1, paragraph 1]

Extract from the Decision of the Education Committee [DEELSA/ED/M(2000)2, paragraph 18]

"On the proposal of the President, the Education Committee:

SUPPORTED the idea of more strategic and transparent management of INES and, in particular, the proposal to set up a Strategic Management Group to replace the existing INES Steering Group and the proposal to elect four delegates from the Education Committee, four from the CERI Governing Board and two from the Employment, Labour and Social Affairs Committee. "

Extract from the Decision of the CERI Governing Board [CERI/CD/M(2000)2, paragraph 42]

"On the proposal of the President, the CERI Governing Board: 
SUPPORTED the proposal to set up a Strategic Management Group to replace the existing INES Steering Group and the proposal to elect four delegates from the Education Committee, four from the CERI Governing Board and two from the Employment, Labour and Social Affairs Committee and NOTED that elected members of the SMG could be accompanied by experts if necessary."

\section{Extract of document [EDU/INES/SMG(2005)5, paragraph 2]}

"2. The function of the Strategic Management Group is to make recommendations to Joint Sessions of the Education Committee and CERI Governing Board covering the strategic management of INES. To this end the Group will:

- $\quad$ within the framework of the priorities set by OECD Education Ministers, the specific objectives agreed at the Tokyo INES General Assembly and further broad guidance from countries such as that provided by the Dublin meeting on 6-8 February 2003, make recommendations on the priorities for INES work within agreed resources. Over time, this prioritisation will adapt to the changing needs of Member countries.

- in this context, have the possibility to make recommendations on:

the improvement in the quality of existing indicators;

the development of new data sources and new indicators;

the dissemination of INES outputs;

the analytic work using INES data;

the relative priority of work under the previous four headings.

- keep under review the resources, structures and working arrangements of INES, and make necessary recommendations to ensure that the INES programme of work is well managed and effectively prioritised within the resources available, taking account of related activities in other bodies;

- act as an intermediary between Networks and Joint Sessions, making recommendations to Joint Sessions with respect to the acceptability of proposals advanced by Networks, and initiating proposals to Joint Sessions on particular items which might be included in the work programmes of Networks;

- while recognising that the management and development of PISA is primarily a matter for the PISA Governing Board, ensure that appropriate linkages are made between PISA and other INES developments, and that any relevant concerns are brought to the attention of the PISA Governing Board." 


\section{INSTITUTIONAL MANAGEMENT IN HIGHER EDUCATION GOVERNING BOARD (IMHE)}

Chair:

Vice-Chairs:

Members: ${ }^{1}$

Observers:

Date of creation:

Duration:
Ms. Marijk van der Wende

(Netherlands)

Mr. Serge Bodson

Mr. José-Ginés Mora

Mr. Kari Suokko

Mr. Malcolm D. Winton

Australia
Austria
Belgium
Canada
Czech Republic
Denmark
Finland
France
Germany
Greece
Hungary
Iceland
Ireland
Italy

Brazil

China

Estonia

Hong Kong, China

Israel

Latvia
(Belgium)

(Spain)

(Finland)

(United Kingdom)

Japan

Korea

Mexico

Netherlands

New Zealand

Norway

Poland

Portugal

Slovak Republic

Spain

Sweden

Switzerland

Turkey

United Kingdom

Lithuania

Pakistan

Russian Federation

Slovenia

South Africa

20th July 1976

31st December 2006

Mandate: - Decision of the Council [C(76)75(Final)] of 20 July 1976.

- This mandate was renewed by the Council at its 880th and 1010th sessions [C(96)139/FINAL; C/M(2001)16 and C(2001)180].

\section{Resolution of the Council [C(76)75(Final)]}

"THE COUNCIL,

Having regard to Articles 5(a) and 20 of the Convention on the Organisation for Economic Co-operation and Development of 14th December 1960;

Having regard to the Financial Regulations and the Financial Rules of the Organisation;

\footnotetext{
1 The members of IMHE include government departments, higher education institutions and other organisations involved in higher education. Depending on their number, the members in each country elect one or two representatives to the Directing Group, who serve as full members in the case of OECD Member countries, or as observers in the case of non-member countries.
} 
Having regard to the Decision of the Council of 28th November, 1972, on Management of Decentralised Projects in the Field of Activities of the Centre for Educational Research and Innovation, as amended [C(72)222(Final); C(74)167(Final)];

Having regard to the Decision of the Council of 20th July 1976 concerning a Programme on Educational Research and Innovation [C(76)153];

Considering that a number of Member countries have expressed their interest in the implementation of certain Activities launched by the Centre for Educational Research and Innovation and continued as decentralised projects;

On the proposal of the Secretary-General,

\section{DECIDES:}

1. (a) The Secretary-General is authorised to hold in a separate account of the Organisation, up to $31^{\text {st }}$ December, 1979 , the funds constituted for the purpose of the Decentralised Project No. 2 - Programme on Institutional Management in Higher Education. These funds shall include the special contributions of Member countries or national institutions participating in the decentralised project and the grants from private institutions previously accepted by the Directing Group provided for in paragraph 3 below:

(b) Proposals made by the Directing Group for expenditure to be charged against this separate account shall be examined by the Budget Committee which shall address its comments to the Directing Group and shall refer to the Council any question which cannot be settled by agreement with the Directing Group.

2. The Secretary-General is authorised to incur the expenditure necessary to carry out this activity pursuant to the Financial Regulations and the Financial Rules of the Organisation, up to the limit of the amounts of the separate account provided for above.

3. There is hereby established a Directing Group responsible for supervising the above-mentioned decentralised project, which shall be composed of representatives of the participating countries or institutions."

\section{Extract from document [C/M(2001)16, Item 254 a) and d)]}

\section{"THE COUNCIL}

a) noted document $\mathrm{C}(2001) 180$ and endorsed the proposals set out in it concerning the renewal of the mandate of [...] the Decentralised Programme on Institutional Management in Higher education (IMHE), ...

d) Adopted the draft Decision of the Council concerning the Renewal of the Decentralised Programme on Institutional Management in Higher Education (IMHE), as set out in Annex 5 to document C(2001)180;"

\section{Decision of the Council [C(2001)180, Annex 5]}

THE COUNCIL,

Having regard to Articles 5 a) and 20 of the Convention on the Organisation for Economic Co-operation and Development of 14 December 1960;

Having regard to the Financial Regulations and the Financial Rules of the Organisation; 
Having regard to the Decision of the Council of 20 July 1976 concerning a Decentralised Project on Institutional Management in Higher Education [C(76)75(Final)];

Having regard to the Decision of the Council of 27 June 1996 concerning the renewal of the Decentralised Programme on Institutional Management in Higher Education [C(96)139/FINAL];

Having regard to the Decision of the Council of 27 June 1996 concerning the renewal of the Programme on Educational Research and Innovation [C(96)138/FINAL];

Having regard to the Note by the Secretary-General concerning the Renewal of the Mandates of the Education Committee, the Centre for Educational Research and Innovation, the Decentralised Programme on Institutional Management in Higher Education (IMHE), the Decentralised Programme on Educational Building (PEB), and the Decentralised Programme for International Student Assessment [C(2001)180];

Considering that Members participating in the Institutional Management in Higher Education have agreed to pursue their co-operation;

\section{DECIDES:}

The provisions of the Decision of the Council of 20 July 1976 referred to above [C(76)75(Final)] shall be applicable for a further period of five years from 1 January 2002." 

Chair:

Vice-Chairs:

Members:

Date of creation:

Duration:
Mr. Mukund Patel

Mr. Martin Heffernan

Mr. Bernard Mernier

Australia

Austria

Greece

Hungary

Iceland

Ireland

Korea

Mexico
(United Kingdom)

(Ireland)

(Belgium)

New Zealand

Portugal

Slovak Republic

Spain

Switzerland

Turkey

United Kingdom

29th June 1971

31st December 2006

Mandate: - Decision of the Council on the Management of Activities in the Field of Educational Building [C(79)234(Final)] of the 18 December 1979.

- $\quad$ This mandate has been renewed by Council at its $543^{\text {rd }}, 606^{\text {th }}, 880^{\text {th }}, 1010^{\text {th }}$, $1044^{\text {th }}$ and $1100^{\text {th }}$ Sessions $[\mathrm{C} / \mathrm{M}(81) 15$ (Final); C/M(84)10(Final); C/M(96)15; C/M(2001)16; C/M(2002)24; C/M(2004)26, C(2002)237, C(2002)237/CORR1 and $\mathrm{C}(2004) 187]$

\section{Extract of the Decision of the Council [C(2004)187]}

"THE COUNCIL,

Considering that Member countries and associate members participating in the Decentralised Programme on Educational Building have agreed to pursue their co-operation;

Noting the desirability of increased connection between the programme of work for the Decentralised Programme on Educational Building and the programmes of work of the Education Committee and the Centre for Educational Research and Innovation;

Noting the desirability of increased membership in and increased funding for the Decentralised Programme on Educational Building;

Having regard to the Decision of the Council of 9 April 2004 on Harmonisation of Names of Part II Subsidiary Bodies Supported by the Directorate for Education [C(2004)72; C/M(2004)13];

\section{DECIDES:}

I. The provisions of the Decision of the Council of 12 July 1984 referred to above [C(84)61(Final)] shall be applicable for a further period of two years from 1 January 2005. 
II. The reference in any existing OECD instrument to the "Programme on Educational Building Steering Committee" shall be read as a reference to "The Programme on Educational Building Governing Board"."

\section{Extract of the Decision of the Council [C(79)234(Final)]}

\section{"THE COUNCIL,}

\section{DECIDES:}

1. (a) The Secretary-General is authorised to hold in a separate account of the Organisation, up to 31st December 1981, the funds constituted for the purpose of the Decentralised Programme on Educational Building. These funds shall include the contributions of Member countries participating in the Decentralised Programme;

(b) Proposals made by the Steering Committee for expenditure to be charged against this separate account shall be examined by the Budget Committee which shall address its comments to the Steering Committee and shall refer to the Council any question which cannot be settled by agreement with the Steering Committee.

2. The Secretary-General is authorised to incur the expenditure necessary to carry out this Programme pursuant to the Financial Regulations and the Financial Rules of the Organisation up to the limit of the amounts of the separate account provided for above.

3. There is hereby established a Steering Committee responsible for supervising the above-mentioned Decentralised Programme, which shall be composed of representatives of the participating countries.

4. This Decision shall replace the Decision of the Council of 29th June 1971, referred to above, with effect from 1st January 1980." 


\section{Chair:}

Vice-Chairs:

\section{Members:}

\section{Participating Countries:}

Date of creation:

Duration:
Mr. Ryo Watanabe

Ms. Dianne Pennock

Mr. Gérard Bonnet

Ms. Anita Wester

Open to all Member countries
(Japan)

(Canada)

(France)

(Sweden)
Latvia

Lithuania

Macau China

Qatar

Romania

Russian Federation

Serbia and Montenegro

Slovenia

Chinese Taipei

Thailand

Tunisia

Uruguay

Kyrgyzstan

26th September 1997

31st December 2006

Mandate: - Decision of the Council concerning a Decentralised Programme for Producing Indicators of Student Achievement, adopted by the Council at its 909th Meeting [C(97)176/FINAL; C/M(97)20/FINAL].

- $\quad$ This mandate has been renewed by the Council at its 1010th Session [C/M(2001)16 and C(2001)180]

\section{Decision of the Council [C(97)176/FINAL]}

"THE COUNCIL,

Having regard to articles 5 a) and 20 of the Convention on the Organisation for Economic Co-operation and Development of 14 December 1960;

Having regard to the Financial Regulations and the Financial Rules of the Organisation;

Considering that the Member countries listed in document $C(97) 176$ have agreed to participate in a Programme for Producing Student Achievement Indicators on a Regular Basis;

On the proposal of the Secretary-General ;

DECIDES: 
1. The Secretary-General is authorised to implement a decentralised Programme for Producing Student Achievement Indicators on a Regular Basis. The mandate for this Programme shall extend until 31 December 2001.

2. The participating countries are those OECD Member Countries which have notified the Secretary-General of their intention to participate by the commencement of the Programme and, thereafter, at the entry points specified in document DEELSA/ED/CERI/CD(97)4.

3. There is hereby established a Board of Participating Countries responsible for supervising the above-mentioned decentralised Programme, which shall be composed of representatives of the participating countries. The operating rules of the Board of Participating Countries are those outlined in the Appendix [Annex 1 to document DEELSA/ED/CERI/CD(97)7].

4. The Secretary-General is authorised to hold in a separate account of the Organisation, up to 31 December 2001, the funds constituted for the purpose of the decentralised Programme. These funds shall include the contributions of participating countries in the decentralised Programme, as well as the voluntary contributions and grants accepted by the Board of Participating Countries, in respect of the activities included in the Programme.

5. The Board of Participating Countries of the Programme shall establish a proposed budget authorising expenditure to be charged against this separate account. The proposed budget shall be examined by the Budget Committee which shall address its comments to the Board of Participating Countries and shall refer to the Council any questions which cannot be settled by agreement with the Board of Participating Countries of the Programme. The budget shall be deemed adopted at the end of this procedure. It shall empower the Secretary-General, pursuant to the Financial Regulations and the Financial Rules of the Organisation, to commit and authorise expenditures and, up to the limit of the amounts of the separate account provided for above, to make all authorised payments necessary to carry out the Programme.

6. The costs of the Programme shall be borne by the participating countries and shall be apportioned among them according to the operating rules of the Board of Participating Countries mentioned above.

7. While the budget of the decentralised Programme is not part of the OECD's budget, the Secretary-General is authorised by the Council to exercise management responsibilities and financial control over the operations of the Programme.

8. Appropriations for which no commitment has been entered into before the end of the Financial Year for which they were appropriated shall be automatically carried forward to the budget for the ensuing year by decision of the Secretary-General."

\section{Extract from document [C(M)2001)16, Item 254 a) and f]}

\section{"THE COUNCIL}

a) noted document $\mathrm{C}(2001) 180$ and endorsed the proposals set out in it concerning the renewal of the mandate of [...] the Decentralised Programme for International Student Assessment (PISA);

f) adopted the draft Decision of the Council concerning the Renewal of the Decentralised Programme for International Student Assessment (PISA), as set out in Annex 7 to document C(2001)180." 


\section{Decision of the Council [C(2001)180 Annex 7]}

\section{"THE COUNCIL,}

Having regard to Articles 5 a) and 20 of the Convention on the Organisation for Economic Co-operation and Development of 14 December 1960;

Having regard to the Financial Regulations and the Financial Rules of the Organisation;

Having regard to the Decision of the Council of 26 September 1997 to establish a Decentralised Programme for Producing Indicators on Student Achievement on a Regular Basis [C(97)176/FINAL], with an initial mandate to 31 December 2001 and now referred to as the Programme for International Student Assessment (PISA);

Having regard to the Note by the Secretary-General concerning the Renewal of the Mandates of the Education Committee, the Centre for Educational Research and Innovation, the Decentralised Programme on Institutional Management in Higher Education (IMHE), the Decentralised Programme on Educational Building (PEB), and the Decentralised Programme for International Student Assessment [C(2001)180];

Considering that Member countries and non-Members participating in the Decentralised Programme for International Student Assessment have agreed to pursue their co-operation;

\section{DECIDES:}

The provisions of the Decision of the Council of 26 September 1997 referred to above [C(97)176/FINAL] shall be applicable for a further period of five years from 1 January 2002. 


\section{PISA STRATEGIC DEVELOPMENT GROUP}

Chair:

Members:

Date of creation:

Duration: $\ldots$

Open to all Member countries
(...)

(United Kingdom)

(France)

(Austria)

(Mexico)

(United States)

(Norway)

(Japan)

(New Zealand)

9th October 2002

31st December 2006

Mandate : - Mandate agreed by the Board of Participating Countries (now called Programme for International Student Management Governing Board) on the 9 October 2002 [DEELSA/PISA/BPC/M(2002)2/REV1 and DEELSA/PISA/BPC(2002)14]

\section{Extract of DEELSA/PISA/BPC(2002)14}

\section{"Role of the PISA Strategic Development Group}

3. The role of the PISA Strategic Development Group (SDG) is to advise the BPC:

- In the short term, on the revision and finalisation of the PISA 2003 context questionnaires in the light of the BPC's policy objectives and the field trial results as well as on the establishment of an analysis and reporting plan for PISA 2003.

- In the medium term, on the establishment of a broader analytic agenda for PISA that would extend across the various future survey cycles, with each survey cycle emphasising the examination of specific policy themes.

- In the long term, in consultation with the INES Network A, on the strategic design and development of PISA, including the balance between the PISA assessment and questionnaire components and the exploration of alternative data collection means and methods. PISA 2000 and 2003 provide 120 minutes for the assessment of student knowledge and skills and devote 30 minutes to the collection of background data. Does this balance serve PISA objectives effectively and, if not, how can and should it be revised, taking into account the need to establish reliable trend data across successive survey cycles? In addition, assessment methodologies other than traditional paper-and-pencil tests are beginning to evolve and PISA needs to explore to what extent these methods might serve PISA objectives. This may include the use of computer-delivered assessments but it may also include other means to obtain student, teacher and school-level background data, including computer-assisted telephone interviews, face-to-face interviews and video-based studies.

- In the long term, on feeding work of the Network A/C Task Force on teaching and learning into the design and terms of reference for PISA. 
4. The PISA SDG takes an advisory role vis a vis the BPC which will retain decisionmaking responsibility on these matters. Furthermore, all aspects requiring input from national authorities will be dealt with through the BPC rather than through the PISA SDG which will take an international perspective in its work.

\section{Composition of the PISA Strategic Development Group}

5. The PISA SDG will be established from among the members of the BPC on a volunteering basis, seeking a broad representation of OECD countries. Members will serve for renewable terms of 18 months and the BPC will regularly review the composition of the group in light of changing priorities in the work programme. The PISA SDG will elect its chair. The group will be supported by the OECD Secretariat which will also convene and organise its meetings." 

FOOD, AGRICULTURE AND FISHERIES 



\title{
COMMITTEE FOR AGRICULTURE (COAG)
}

Chair:

Vice-Chairs:

Members:

Observers:

Date of creation:

Duration:
Ms. Suzanne Vinet

Mr. Gejza Blaas

Mr. Dae Geun Kim

Mr. Christian Ligeard

Open to all Member countries

Argentina
Brazil
Chile

Council of Europe

U.N. Food and Agricultural Organization (FAO)

World Trade Organization (WTO)

30th September 1961

31st December 2008
(Canada)

(Slovak Republic)

(Korea)

(France)

\begin{abstract}
Mandate: - Paragraphs 21, 22, 23, 26 and 89 of the Report of the Preparatory Committee
- Council Decision regarding a Sunset Clause for all Committees [C/M(2004)5, item 75] entered into force on 22 April 2004 [C/M(2004)10, item 143, IV, c)]
\end{abstract}

\section{Extract of the Report of the Preparatory Committee}

\section{"Agriculture and Fisheries}

21. The Preparatory Committee agrees that the activities of the Organisation concerning agriculture and fisheries should be strengthened and closely integrated with the Organisation's other activities in pursuit of the objectives of the Convention.

22. With regard to agriculture, the Preparatory Committee recommends the creation of a committee responsible to the Council to consider, advise and make recommendations to the Organisation on agricultural problems and policies pertinent to the objectives of the Convention.

23. The Committee shall meet at Ministerial level in order to examine major problems in the agricultural sector, including those connected with other aspects of the Organisation's work.

26. The Committee may be authorised by the Council to assume operational tasks.

89

89. As a result of the review of the Acts in this sector, the Committee recommend that the following activities should continue to feature in the programme of work to be carried out by the agricultural body or bodies of the Organisation, without, however, excluding the possibility that other activities might be added at a later stage in the light of directives resulting from new requirements:

a) Confrontation and consultations on agricultural, food and fishery policies under their different aspects with a view to promoting the harmonious development of these 
policies among Member countries in accordance with the objectives of the Organisation and the undertakings entered into under the Convention;

b) Examination of the overall situation of agriculture and fisheries in Member countries and of the prospects including examination of the trend of supply and demand;

c) Study of the possibilities for improving the marketing and distribution of agricultural, fishery and food products with a view to determining measures which could be adopted nationally and internationally; similar studies in the field of means of production;

d) Surveys of the market situation for the main agricultural and fishery products and formulation, in co-operation where necessary with the Trade Committee, of proposals for remedial measures in the event of market difficulties;

e) Examination in liaison and co-operation with the Trade Committee of trade problems directly connected with agricultural and fishery policies and falling within the mandate of the Organisation in trade matters as described in this Report;

f) Assistance in the agricultural field to the economic, trade and technical activities of other bodies of the Organisation in implementing the aims of the Organisation concerning countries, or in special cases, areas in process of economic development;

g) Practical work designed to promote a better use of production factors and to promote technical progress in the sectors of agriculture and fisheries including marketing and distribution. The nature and extent of such activities and the way in which they will be performed will be decided later. Insofar as they have budgetary implications appropriate rules will be drawn up in accordance with the principles agreed in Part I, paragraph 39." 


\section{JOINT WORKING PARTY ON AGRICULTURE AND TRADE}

$\begin{array}{lll}\text { Chair: } & \text { Mr. Craig Burns } & \text { (Australia) } \\ \text { Vice-Chair: } & \text { Ms. Cornelia Berns } & \text { (Germany) } \\ \text { Members: } & \text { Open to all Member countries } \\ \text { Observers: } & \begin{array}{l}\text { Argentina } \\ \text { Brazil } \\ \text { Chile }\end{array} \\ & \text { World Trade Organization (WTO) } \\ \text { Date of creation: } & \text { 6th June 1962 } \\ \text { Duration: } & \text { 31st December } 2008\end{array}$

Mandate: Joint Working Party on Agriculture and Trade Terms of Reference [AGR/CA/M(2000)1] and [TD/TC/M(2000)1]

\section{Extract from document [COM/AGR/CA/TD/TC(2000)7/REV1]}

“6. $\quad$...The 1998 Ministerial Mandate defines the overall context of the policy dimensions related to trade and agriculture. The programmes of work to be derived from the new mandate for the JWP will be fully consistent with the 1998 Ministerial Mandate.

7. Against this background, it is proposed to define the mandate in a short and relatively open and general manner, while reflecting ongoing and planned work, in particular the work programme defined by the Agriculture and Trade Committees for 1999/2000 and that under discussion for $2001 / 2002$. It is also proposed to simplify and shorten its name to The Joint Working Party on Agriculture and Trade. The mandate would read as follows:

"The Joint Working Party on Agriculture and Trade is to provide analytical support to the process of agricultural trade liberalisation by

1. analysing actual and projected effects of agricultural trade liberalisation;

2. examining ongoing and new agricultural trade and trans-boundary policy issues and their impacts;

3. examining the trade effects of agricultural support policies and regulatory frameworks;

4. analysing the characteristics of effective policies that are minimally trade distorting.

It is proposed that the life of the JWP is open-ended, but with review of the mandate at five-year intervals." "

\footnotetext{
1 The election of the 2006 Bureau will take place in May 2006.
} 


\section{JOINT WORKING PARTY ON AGRICULTURE AND THE ENVIRONMENT}

Chair:

Vice-Chairs:

Members:

Observer:

Date of creation:

Duration:
Ms. Katherine Smith

Mr. Chang-Gil Kim

Mr. Grant King

Mr. Frode Lyssandtrae

Ms. Annalisa Zezza

Open to all Member countries

U.N. Food and Agricultural Organization (FAO)

January 1993

31st January 2009
(United States)

(Korea)

(New Zealand)

(Norway)

(Italy)

Mandate: - Mandate agreed by the Committee for Agriculture at its session on 28-29 November $2000[\mathrm{AGR} / \mathrm{CA}(2000) 8]$ and by EPOC (under the written procedure) until the end of January 2004, under the name of "Joint Working Party on Agriculture and the Environment."

- New mandate agreed by Committee for Agriculture in December 2003, and by the EPOC by written procedure in January 2004 [AGR/CA(2003)14]

\section{Extract from document $[\mathrm{AGR} / \mathrm{CA}(2003) 14]$}

\section{“Objectives}

The Joint Working Party on Agriculture and the Environment will provide a forum to exchange information, identify and analyse the implications for achieving environmentally sustainable agriculture of policies and market approaches in the context of technological change, agricultural policy reform and multilateral trade and environmental agreements, and communicate the results to the wider public."

\section{Terms of reference}

The Joint Working Party will:

- Identify and analyse policy relevant domestic and trans-boundary issues at the interface between agriculture and the environment in both OECD and, where relevant, nonOECD countries; quantify the relationships between agriculture and the environment, including in a forward-looking perspective; monitor and evaluate policy measures and actions addressing environmental issues in agriculture; and provide guidance on an integrated and coherent approach for agricultural and environmental policies to help achieve sustainable agriculture.

- Undertake the analysis of agricultural and environmental issues of relevance to policy makers; in particular to: co-ordinate, undertake and review relevant work mandated by the two parent Committees; co-ordinate, receive reports and review relevant on-going and proposed work carried out elsewhere in the OECD; advise and report to the parent Committees on new and emerging problems and major issues with respect to agrienvironment relationships; identify successful policies and courses of action at national and international levels; and identify new initiatives for consideration by the appropriate bodies of the Organisation. 
- Co-operate and liaise with other competent bodies in the OECD, and ensure appropriate co-ordination with other relevant international organisations, in particular the Food and Agricultural Organisation of the United Nations, the United Nations Environment Programme and the Commission on Sustainable Development and the Convention on Biological Diversity, and with relevant non-governmental organisations, representing the farming, agro-food industry, and environmental interests; strengthen efforts to present and communicate the work to relevant organisations, the media and wider public.

\section{Mode of operation}

The Joint Working Party, comprised of agriculture and environment representatives from OECD governments and supported by expert groups and workshops as considered necessary, will meet twice yearly until the end of the mandate of 5 years, with a review of the work at the end of 3 years to provide guidance for the remaining 2 years.

The Bureau of the Joint Working Party will be elected each year, composed of a chair and at least two vice chairs to ensure a balanced representation of both agricultural and environmental interests.

Other Committees of the Organisation could be represented through their respective OECD Directorates at meetings of the Joint Working Party to gather information, and to raise issues and make suggestions, as appropriate.

The Committee for Agriculture and the Environment Policy Committee delegate the declassification of documents to the Joint Working Party, but retain the possibility to take a final decision on the declassification of documents.

The Joint Working Party will regularly report to both the Committee for Agriculture and the Environment Policy Committee, through written reports or oral presentations." 


\section{WORKING PARTY ON AGRICULTURAL POLICIES AND MARKETS (APM)}

Chair:

Vice-Chair:

Members:

Observers:
Mr. Ancel Van Royen

Ms. Laurie Knight

Open to all Member countries

Argentina

Brazil

Chile
(Netherlands)

(New Zealand)

Council of Europe

U.N. Food and Agricultural Organization (FAO)

World Food Council

World Trade Organization (WTO)

Date of creation:

30th September 1987

Duration:

31st December 2008

Mandate: Memorandum of the 98th Session of the Committee for Agriculture [AGR/M(88)2]

\section{Extract from document $[\mathrm{AGR} / \mathrm{M}(88) 2$, Annex $]$}

"The Working Party on Agricultural Policies and Markets will undertake the preparatory studies required for the work of the Committee for Agriculture in accordance with the priorities as defined in the programme of work and report to the Committee for Agriculture. Its functions will cover in particular the following areas:

i) Monitoring of agricultural policies, markets and trade, and of the implementation of the various principles and actions related to agriculture as defined in the Ministerial communiqués;

ii) Discussion of all aspects of the development of analytical tools, including particularly PSE/CSE work and related analysis and modelling exercises, with a view to deepening the analysis and updating and improving these tools;

iii) Preparation and review of any special studies related to the various means and instruments which could contribute to the achievement of the objectives of agricultural policy reform. This work would also include such aspects as inter-sectoral linkages, monetary developments, and the relationships between agriculture and the rest of the economy;

iv) Discussion and co-ordination of the work and reports of the commodity groups (Cereals, Feeds and Sugar, Meat and Dairy Products and Fruit and Vegetables), the purpose of which is to highlight the main trends and outlook in the short to medium term, to identify the problems likely to emerge, and to indicate the effects of government measures on market balance and production structures;

For the activities i) and ii) mentioned above, the Working Party on Agricultural Policies and Markets will work in co-operation with the Joint Working Party Agriculture/Trade to the extent that issues related to agricultural trade are included in those activities." 


\section{GROUP ON CEREALS, ANIMAL FEEDS AND SUGAR}

Chair:

Vice-Chairs:

Members:

Observers:

Date of creation:

Duration:
Mr. Terry Sheales

Mr. Georges Waskiel

Mr. Jorge Rueda Sousa

Open to all Member countries

Argentina

Brazil

Chile

Russian Federation

Council of Europe

U.N. Food and Agricultural Organization (FAO)

World Food Council

World Trade Organization (WTO)

26th November 1980

31st December 2008
(Australia)

(France)

(Mexico)

Mandate: Memorandum of the 98th Session of the Committee for Agriculture [AGR/M(88)2]

\section{Extract from document $[A G R / M(88) 2$, Annex]}

$"$

- To review the current situation for cereals, feeds and sugar, as well as their substitute products;

- To examine the short and principally medium-term outlook and identify policy issues relevant to these commodities; analyse and assess the impacts of these outlook and policy issues, including on other agricultural commodities and the general economy;

- To undertake studies as may be requested from time to time by the Committee for Agriculture;

- To report on all these matters to the Working Party on Agricultural Policies and Markets." 


\section{GROUP ON MEAT AND DAIRY PRODUCTS}

Chair:

Vice-Chairs:

Members:

Observers:

Date of creation:

Duration:
Mr. Matthias Reeh

Mr. Pierre Charlebois

Mr. Hiroo Shimamori

Open to all Member countries

Argentina

Brazil

Chile

Russian Federation

Council of Europe

U.N. Food and Agricultural Organization (FAO)

World Food Council

World Trade Organization (WTO)

3rd June 1987

31st December 2008
(Austria)

(Canada)

(Japan)

Mandate: Memorandum of the 98th Session of the Committee for Agriculture [AGR/M(88)2]

\section{Extract from document $[A G R / M(88) 2$, Annex]}

$"$

- To review the current market situation for meat and dairy products, as well as their substitute products;

- To examine the short and principally medium-term outlook and identify policy issues relevant to these commodities; analyse and assess the impact of these outlook and policy issues, including on other agricultural commodities and the general economy;

- To undertake studies as may be requested from time to time by the Committee for Agriculture;

- To report on all these matters to the Working Party on Agricultural Policies and Markets." 


\section{PLENARY MEETING OF THE OECD SCHEME FOR THE APPLICATION OF INTERNATIONAL STANDARDS FOR FRUIT AND VEGETABLES}

Chair:

Vice-Chairs:

Members:

Observers:

Date of creation:

Duration:
Ms. Viera BARICICOVA

Mr. Ulrike Bickelmann

Mr. Pierre Schauenberg

Austria

Belgium

Finland

France

Germany

Greece

Hungary

Ireland

Italy

Luxembourg

Netherlands

New Zealand
(Slovak Republic)

(Germany)

(Switzerland)

Poland

Slovak Republic

Spain

Sweden

Switzerland

Turkey

Bulgaria

Israel

Morocco

Romania

South Africa

Confederation of Importers and Marketing Organisations in Europe for Fresh Fruit and Vegetables (CIMO)

European Union of the Fruit and Vegetable Wholesale, Import and Export Trade (EUCOFEL)

Liaison Committee for Mediterranean Citrus Fruit Culture (CLAM)

Liaison Committee for the Promotion of Tropical Fruit and Out-ofseason Vegetables Derived from ACP Countries (COLEACP)

U.N. Economic Commission for Europe (ECE)

U.N. Food and Agricultural Organization (FAO)

20th February 1962

Unspecified

Mandate: Decision of the Council revising the OECD "Scheme" for the application of international standards for fruit and vegetables [C(99)10/FINAL]

\section{Extract from the Decision of the Council [C(99)10/FINAL]}

$" \ldots$

On the proposal of the Committee for Agriculture;

THE COUNCIL,

I. DECIDES:

1. The OECD "Scheme" for the Application of International Standards for Fruit and vegetables (hereinafter called the "Scheme") is revised pursuant to the provisions of this Decision.

2. The "Scheme" has as its primary objectives: 
- to promote the establishment of one single international grade standard setting body and,

- in the interim, to facilitate the implementation and harmonisation of international grade standards activities. Hence, the "Scheme" shall:

a) facilitate the international harmonisation and adaptation of grade standards, standardisation of packaging and development of palletisation to present production, trade and marketing conditions;

b) review the operation and progress of its activities at Plenary Meetings of the national representatives appointed by their Governments to be responsible for its implementation (hereafter called the "Plenary Meeting");

c) promote uniform quality control procedures and the use of the model control certificate;

d) set up meetings of officers in charge of national control services;

e) propose new standards and revisions to those which are the subject of Annex I to this Decision;

f) develop the "Scheme's" operational guidelines;

g) study conditions and quality assurance operations, taking into account new methods of marketing, to ensure consumer interest in product quality is addressed.

3. The "Scheme" may establish Produce Working Groups, which are subsidiary bodies of the Plenary Meeting for the development and preparation of explanatory guidelines for the various standards.

4. The standards adopted by the United Nations Economic Commission for Europe, once approved by the Plenary Meeting, shall be applied under the "Scheme" to the products specified in Annex I to this Decision, at the export stage, when these products enter into international trade between countries participating in the "Scheme".

5. Each time a new standard is approved, each country participating in the "Scheme" willing to conform thereto shall inform the Secretary-General within a period of six months. Once a standard has been approved, participating countries willing to conform thereto may inform the Secretary-General at any time.

6. The Secretary-General shall bring to the attention of participating countries of the "Scheme" all notifications and information conveyed within the framework of the "Scheme".

7. Participating countries are obliged to establish within three years of joining the "Scheme", an export quality control of the produce in accordance with the guidelines set out in annex II of this Decision, by virtue of which they participate in the "Scheme".

8. Participation in the "Scheme" shall be open to any member of the United Nations or one of its specialised agencies or the World Trade Organization which desire to participate therein as regards all or some of the produce concerned and is willing, as an exporting country, to conform with the standards referred to in paragraph 5 and, as an importing country, to recognise them as standards which are to be applied to exported fruit and vegetables produced in the country of origin. Any country desiring to participate in the "Scheme" shall notify the Secretary-General indicating the institution responsible for quality control and a contact person. 
9. Any participating country can withdraw from the "Scheme" by giving no less than twelve months' notice in writing to the Secretary-General.

10. The Secretariats of the:

- United Nations Economic Commission for Europe,

- Joint FAO/WHO Food Standards Programme of the United Nations,

- Confederation of Importers and Marketing Organisations in Europe of Fresh Fruit and Vegetables (CIMO),

- Liaison Committee for Mediterranean Citrus Fruit Culture (CLAM),

- Liaison Committee for the Promotion of Tropical Fruits and Out-of-Season Vegetables derived from ACP Countries (COLEACP),

- European Union of the Fruit and Vegetable Wholesale, Import and Export Trade (EUCOFEL),

shall be invited to be represented as observers at the Plenary Meeting and its Produce Working Groups.

11. Other International Organisations or Non Governmental Organisations which have responsibilities in the sector covered by the "Scheme" may be invited to designate an ad-hoc observer or an expert to sessions of the Plenary Meetings of the "Scheme" or its Produce Working Groups.

\section{$(\ldots)$}

II. DECIDES that the countries which, at the adoption of the present Decision, already participated in the "Scheme" as revised by the Decision of the Council C(92)184/FINAL, shall participate in the "Scheme" established by this Decision subject to a notification to the contrary to the Secretary-General within three months following the adoption of the present Decision.

III. DECIDES that within a period of six months after the adoption of this Decision, the participating countries shall inform the Secretary-General of the standards currently in force with which they are willing to conform.

IV. INSTRUCTS the Committee for Agriculture to report to the Council, when appropriate, on the operation of the "Scheme", to submit to the Council, where necessary, proposals for its modification.

V. DECIDES that the Decision of the Council of 18 December 1992 referred to above is repealed and replaced by this Decision.

$(\ldots)$

\section{ANNEX II}

OPERATIONAL FRAMEWORK FOR THE CONTROL OF THE QUALITY OF PRODUCE EXPORTED UNDER THE "SCHEME"

I. OPERATIONAL FRAMEWORK CONCERNING QUALITY CONTROL 
1. The purpose of the control is to ascertain that the quality and classification of the produce exported are in conformity with the standards applied under the "Scheme".

2. Control operations are to be carried out according to the guidelines set out in Section II below by the control service authorised by each country participating in the "Scheme" to issue the control certificate comparable to the model set out in Appendix I to this Annex. Its use is described in the explanatory note appearing in Appendix II to this Annex.

3. The purpose of the control certificate is to attest that the appropriate control service has verified, according to the methods set out hereafter in section II of this Annex, that the consignment in question conforms with the standard applied under the "Scheme" at the time of inspection. That service is responsible to the corresponding services of importing countries participating in the "Scheme" for the statements attesting quality in the control certificate." 
ANNUAL MEETING OF REPRESENTATIVES OF THE NATIONAL DESIGNATED AUTHORITIES FOR THE IMPLEMENTATION OF THE OECD SCHEMES FOR THE VARIETAL CERTIFICATION

\section{OF SEED MOVING IN INTERNATIONAL TRADE}

Chair:

Mr. Michael Scheffel

(Canada)

Vice-Chairs:

Mr. Leopold Girsch

Mr. Chagema John Kedera

(Austria)

(Kenya)

Date of creation:

30th January 1962 (OEEC 30th May 1958)

Duration:

Unspecified

\section{Mandate:}

There is no mandate setting up the Annual Meeting for the Seed Schemes as a whole. The seven Schemes, which make up the "Seed Schemes", each have specific country participation.

The latest Decision of the Council revising the OECD Schemes for the Varietal Certification or the Control of Seed Moving in International Trade is [C(2000)146/FINAL] and was approved during the Council meeting held on 28 September 2000 [C/M(2000)22, Item 280]. It has been subsequently amended by Council: [C(2003)18 and C/M(2003)4, Item 83]; [C(2003)23 and $\mathrm{C} / \mathrm{M}(2003) 8$, Item 129]; [C(2004)97 and C/M(2004)14, Item 199]; [C(2005)38 and C/M(2005)12, Item 148] and [C(2005)171 and $C / M(2006) 1$, Item 10]. 
Members:

Observers: ${ }^{1}$

Australia
Austria
Belgium
Canada
Czech Republic
Denmark
Finland
France
Germany
Greece
Hungary
Iceland
Ireland
Italy
Japan
Luxembourg
Mexico
Netherlands
New Zealand
Norway
Poland
Portugal
Slovak Republic
Spain
Sweden
Switzerland

Turkey

United Kingdom

United States

Argentina

Bolivia

Brazil

Bulgaria

Chile

Croatia

Cyprus

Egypt

Estonia

Israel

Kenya

Latvia

Lithuania

Morocco

Romania

Serbia and Montenegro

Slovenia

South Africa

Tunisia

Uganda

Uruguay

Zimbabwe

African Seed Trade Association (AFSTA)

Asia and Pacific Seed Association (ASPA)

Association of Official Seed Analysts (AOSA)

Association of Official Seed Certifying Agencies (AOSCA)

Eastern European Seed Network (EESNET)

European and Mediterranean Plant Protection Organization (EPPO)

European Association for Research on Plant Breeding (EUCARPIA)

European Seed Association (ESA)

Federation of Latin American Seed Associations

Inter-American Institute for Cooperation on Agriculture (IICA)

International Center for Agricultural Research in the Dry Areas

(WANA/ICARDA)

International Federation of Agricultural Producers (IFAP)

International Institute for Research in Sugar Beet (IIRB)

International Plant Genetic Resources Institute (IPGRI)

International Seed Testing Association (ISTA)

International Seed Trade Federation (FIS)

International Union for the Protection of New Varieties of Plants

(UPOV)

Latin American Integration Association (ALADI)

U.N. Food and Agricultural Organization (FAO)

West Asia and North Africa Seed Network (W.A.N.A)

\footnotetext{
1 Note: The Director-General of WIPO (World Intellectual Property Organization) is the Secretary General of UPOV.
} 
Date of creation:

Duration: 30th January 1962 (OEEC 30th May 1958)

Unspecified 
SCHEME FOR CRUCIFER SEED AND OTHER OIL OR FIBER SPECIES

Members:

Observers: ${ }^{1}$

Australia
Austria
Belgium
Canada
Czech Republic
Denmark
Finland
France
Germany
Greece
Hungary
Iceland
Ireland
Italy
Japan
Luxembourg
Mexico
Netherlands
New Zealand
Norway
Poland
Portugal
Slovak Republic
Spain
Sweden
Switzerland

Turkey

United Kingdom

United States

Argentina

Bolivia

Brazil

Bulgaria

Chile

Croatia

Cyprus

Egypt

Estonia

Israel

Kenya

Lithuania

Morocco

Romania

Russian Federation

Serbia and Montenegro

Slovenia

South Africa

Tunisia

Uganda

Uruguay

Zimbabwe

African Seed Trade Association (AFSTA)

Asia and Pacific Seed Association (ASPA)

Association of Official Seed Analysts (AOSA)

Association of Official Seed Certifying Agencies (AOSCA)

Eastern European Seed Network (EESNET)

European and Mediterranean Plant Protection Organization (EPPO)

European Association for Research on Plant Breeding (EUCARPIA)

European Seed Association (ESA)

Federation of Latin American Seed Associations

Inter-American Institute for Cooperation on Agriculture (IICA)

International Center for Agricultural Research in the Dry Areas

(WANA/ICARDA)

International Federation of Agricultural Producers (IFAP)

International Institute for Research in Sugar Beet (IIRB)

International Plant Genetic Resources Institute (IPGRI)

International Seed Testing Association (ISTA)

International Seed Trade Federation (FIS)

International Union for the Protection of New Varieties of Plants

(UPOV)

Latin American Integration Association (ALADI)

U.N. Food and Agricultural Organization (FAO)

West Asia and North Africa Seed Network (W.A.N.A)

\footnotetext{
1 Note: The Director-General of WIPO (World Intellectual Property Organization) is the Secretary General of UPOV
} 
Date of creation:

Duration: 30th January 1962 (OEEC 30th May 1958)

Unspecified 
Members:

\section{Observers: ${ }^{1}$}

\footnotetext{
1 Note: The Director-General of WIPO (World Intellectual Property Organization) is the Secretary General of UPOV.
}

United Kingdom
United States
Albania
Argentina
Bolivia
Brazil
Bulgaria
Chile
Croatia
Egypt
Estonia
Israel
Kenya
Kyrgyzstan
Latvia
Lithuania
Morocco
Romania
Russian Federation
Serbia and Montenegro
Slovenia
Tunisia
Uganda
Uruguay
Zimbabwe

African Seed Trade Association (AFSTA)

Asia and Pacific Seed Association (ASPA)

Association of Official Seed Analysts (AOSA)

Association of Official Seed Certifying Agencies (AOSCA)

Eastern European Seed Network (EESNET)

European and Mediterranean Plant Protection Organization (EPPO)

European Association for Research on Plant Breeding (EUCARPIA)

European Seed Association (ESA)

Federation of Latin American Seed Associations

Inter-American Institute for Cooperation on Agriculture (IICA)

International Center for Agricultural Research in the Dry Areas

(WANA/ICARDA)

International Federation of Agricultural Producers (IFAP)

International Institute for Research in Sugar Beet (IIRB)

International Plant Genetic Resources Institute (IPGRI)

International Seed Testing Association (ISTA)

International Seed Trade Federation (FIS)

International Union for the Protection of New Varieties of Plants

(UPOV)

Latin American Integration Association (ALADI)

U.N. Food and Agricultural Organization (FAO)

West Asia and North Africa Seed Network (W.A.N.A) 
Date of creation:

Duration: 30th January 1962 (OEEC 30th May 1958)

Unspecified 


\section{SCHEME FOR BEET}

Members:

Observers: ${ }^{1}$

Austria

Poland

Belgium

Portugal

Canada

Czech Republic

Slovak Republic

Denmark

Spain

Finland

Sweden

France

Germany

Turkey

United Kingdom

Greece

United States

Hungary

Bulgaria

Ireland

Chile

Italy

Croatia

Japan

Netherlands

Islamic Republic of Iran

Kyrgyzstan

New Zealand

Romania

Serbia and Montenegro

African Seed Trade Association (AFSTA)

Asia and Pacific Seed Association (ASPA)

Association of Official Seed Analysts (AOSA)

Association of Official Seed Certifying Agencies (AOSCA)

Eastern European Seed Network (EESNET)

European and Mediterranean Plant Protection Organization (EPPO)

European Association for Research on Plant Breeding (EUCARPIA)

European Seed Association (ESA)

Federation of Latin American Seed Associations

Inter-American Institute for Cooperation on Agriculture (IICA)

International Center for Agricultural Research in the Dry Areas

(WANA/ICARDA)

International Federation of Agricultural Producers (IFAP)

International Institute for Research in Sugar Beet (IIRB)

International Plant Genetic Resources Institute (IPGRI)

International Seed Testing Association (ISTA)

International Seed Trade Federation (FIS)

International Union for the Protection of New Varieties of Plants (UPOV)

Latin American Integration Association (ALADI)

U.N. Food and Agricultural Organization (FAO)

West Asia and North Africa Seed Network (W.A.N.A)

Date of creation:

30th January 1962 (OEEC 30th May 1958)

Duration:

Unspecified

\footnotetext{
${ }^{1}$ Note: The Director-General of WIPO (World Intellectual Property Organization) is the Secretary General of UPOV.
} 
Members:

\section{Observers: ${ }^{1}$}

Date of creation:

Duration:
Australia

Austria

Belgium

Canada

Czech Republic

Denmark

Finland

France

Germany

Greece

Hungary

Italy

Mexico

Netherlands

New Zealand

Poland

Portugal

Slovak Republic

Spain

Switzerland

Turkey
United States

Albania

Argentina

Bolivia

Brazil

Bulgaria

Chile

Croatia

Egypt

Israel

Kenya

Morocco

Romania

Russian Federation

Serbia and Montenegro

Slovenia

South Africa

Uganda

Uruguay

Zimbabwe

African Seed Trade Association (AFSTA)

Asia and Pacific Seed Association (ASPA)

Association of Official Seed Analysts (AOSA)

Association of Official Seed Certifying Agencies (AOSCA)

Eastern European Seed Network (EESNET)

European and Mediterranean Plant Protection Organization (EPPO)

European Association for Research on Plant Breeding (EUCARPIA)

European Seed Association (ESA)

Federation of Latin American Seed Associations

Inter-American Institute for Cooperation on Agriculture (IICA)

International Center for Agricultural Research in the Dry Areas

(WANA/ICARDA)

International Federation of Agricultural Producers (IFAP)

International Institute for Research in Sugar Beet (IIRB)

International Plant Genetic Resources Institute (IPGRI)

International Seed Testing Association (ISTA)

International Seed Trade Federation (FIS)

International Union for the Protection of New Varieties of Plants

(UPOV)

Latin American Integration Association (ALADI)

U.N. Food and Agricultural Organization (FAO)

West Asia and North Africa Seed Network (W.A.N.A)

30th January 1962 (OEEC 30th May 1958)

Unspecified

\footnotetext{
1 Note: The Director-General of WIPO (World Intellectual Property Organization) is the Secretary General of UPOV.
} 


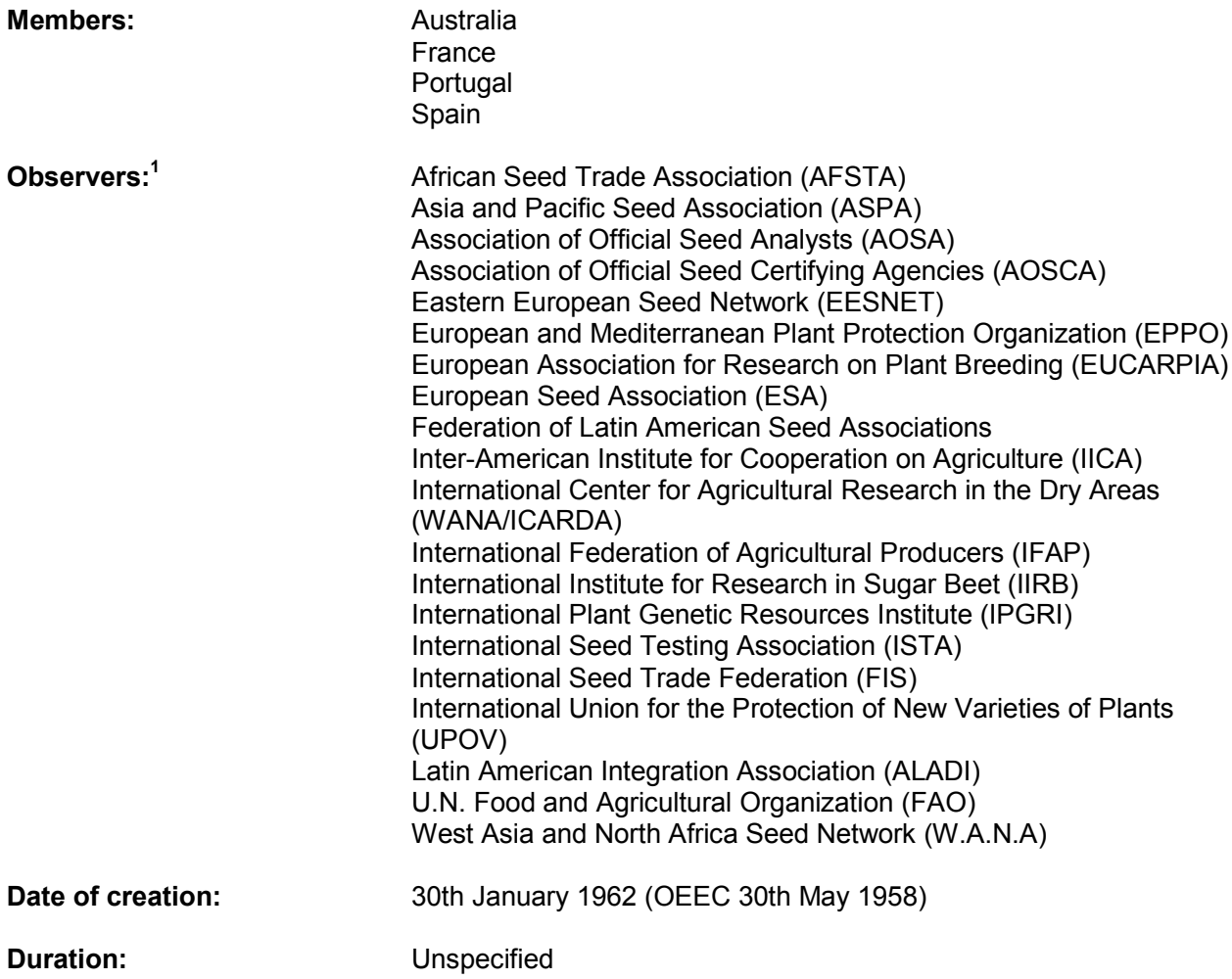

\footnotetext{
1 Note: The Director-General of WIPO (World Intellectual Property Organization) is the Secretary General of UPOV.
} 
Members:

Observers: ${ }^{1}$

Date of creation:

Duration:
Australia

Austria

Belgium

Czech Republic

Denmark

Finland

France

Germany

Iceland

Italy

Mexico

Portugal

Slovak Republic

Sweden
Switzerland

United Kingdom

Bolivia

Brazil

Cyprus

Egypt

Estonia

Israel

Morocco

Romania

Russian Federation

Serbia and Montenegro

South Africa

Uganda

African Seed Trade Association (AFSTA)

Asia and Pacific Seed Association (ASPA)

Association of Official Seed Analysts (AOSA)

Association of Official Seed Certifying Agencies (AOSCA)

Eastern European Seed Network (EESNET)

European and Mediterranean Plant Protection Organization (EPPO)

European Association for Research on Plant Breeding (EUCARPIA)

European Seed Association (ESA)

Federation of Latin American Seed Associations

Inter-American Institute for Cooperation on Agriculture (IICA)

International Center for Agricultural Research in the Dry Areas

(WANA/ICARDA)

International Federation of Agricultural Producers (IFAP)

International Institute for Research in Sugar Beet (IIRB)

International Plant Genetic Resources Institute (IPGRI)

International Seed Testing Association (ISTA)

International Seed Trade Federation (FIS)

International Union for the Protection of New Varieties of Plants (UPOV)

Latin American Integration Association (ALADI)

U.N. Food and Agricultural Organization (FAO)

West Asia and North Africa Seed Network (W.A.N.A)

30th January 1962 (OEEC 30th May 1958)

Unspecified

\footnotetext{
1 Note: The Director-General of WIPO (World Intellectual Property Organization) is the Secretary General of UPOV.
} 


\section{ANNUAL MEETING OF REPRESENTATIVES OF THE NATIONAL DESIGNATED AUTHORITIES FOR THE IMPLEMENTATION OF THE OECD STANDARD CODES FOR THE OFFICIAL TESTING OF AGRICULTURAL AND FORESTRY TRACTORS}

Chair:

Vice-Chairs:

Members:

Observers:

Date of creation:

Duration:
Mr. Hakkyu Kim

Mr. Pekka Olkinuora

Mr. José Luis Ponce de Léon

Austria

Belgium

Czech Republic

Denmark

Finland

France

Germany

Greece

Iceland

Ireland

Italy

Japan

Korea

Luxembourg
(Korea)

(Finland)

(Spain)

Netherlands

Norway

Poland

Portugal

Slovak Republic

Spain

Sweden

Switzerland

Turkey

United Kingdom

United States

China

India

Russian Federation

European Committee for Standardization (CEN)

European Committee of Association of Manufacturers of Agricultural Machinery (CEMA)

European Free Trade Association (EFTA)

International Commission of Agricultural Engineering (CIGR)

International Federation of Agricultural Producers (IFAP)

International Organisation for Standardisation (ISO)

U.N. Economic Commission for Europe (ECE)

U.N. Food and Agricultural Organization (FAO)

3rd May 1962 (OEEC 21st April 1959)

Unspecified

Mandate: Decision revising the Decision of the Council establishing the OECD Standard Codes for the Official Testing of Agricultural and Forestry Tractors [C(2005)1 and $\mathrm{C} / \mathrm{M}(2005) 9$, Item 105].

\section{Appendix 3 to the decision [C(2005)1 and C/M(2005)9, Item 105]}

\section{METHOD OF OPERATION}

1. The names and addresses of the national Authorities designated for operating the Codes and any changes in their designation will be circulated by the OECD to all countries participating in the Codes and to all observers.

2. The operation and development of the Codes shall be reviewed at the Annual Meeting of representatives of the Designated Authorities where Participating Member and non member Countries hold office strictly in alphabetic order. This Annual Meeting shall report on its work and 
make such proposals as deemed necessary to the Council of the OECD, subject to prior endorsement by the Committee for Agriculture.

3. The Officers of the Annual Meeting will be a Chairman, two Vice-Chairmen, who will be nominated at the end of the previous session. They shall take up their duties upon official approval of the Summary Record from the previous Annual Meeting.

4. In order to ensure continuity and efficient co-operation with the Secretariat, except as otherwise provided in the Rules of Procedure of the Organisation, it is desirable that a ChairmanDesignate be appointed to fill one of the offices of Vice-Chairman together with the Past-Chairman. Their terms should not exceed two years. The chairmanship should reflect the participation of various regions of the world and alternate between representatives of European Union Member States and other countries.

5. The chairmanship shall be carried out in one of the two official languages of the Organisation, even if interpretation in a third language is available at the meetings.

6. The co-ordination of Codes implementation on an international level shall be ensured by the OECD. However, the verification of individual test reports submitted by the participating Members as well as the related tasks may be delegated, by contract, to a national institute of a Member Country which will act as Co-ordinating Centre for the OECD Tests. The costs incurred shall be recovered under the annual contract between the OECD Secretariat and this Institute.

7. An Advisory Group is made up of the Officers of the Annual Meeting, and the Coordinating Centre takes part in its work. The Advisory Group shall assist in the preparation of the next Annual Meeting and, where necessary, propose solutions to the Secretariat to deal with urgent problems which may arise out of Codes implementation. The Advisory Group is convoked by the Secretariat at the request of any one of its Members or any country participating in the Codes to provide counsel in writing and invite one or more participating countries to be represented.

8. The Advisory Group will deal with any questions raised by a National Designated Authority regarding denied approval of a test report. The Advisory Group will take the following steps;

8.1 On the basis of the evidence submitted by the National Designated Authority concerned and the Co-ordinating Centre, the Advisory Group will make an initial decision within a week on whether the issue raised merits further examination and respond to the party or parties raising it. Any member of the Advisory Group who is directly involved or connected with the matter will be exempt from taking part in the initial decision. The Advisory Group may seek assistance from one or two experts;

8.2 Where the issue raised merits further examination, the Advisory Group will offer good offices to help to resolve the issue. For this purpose, the Advisory Group will consult with these parties and, where appropriate, seek advice from relevant authorities, and/or manufacturers, other non-governmental organisations, and legal or technical experts as it sees fit;

8.3 If the parties involved do not reach an agreement on the issues raised within two weeks, the Advisory Group will issue a written statement, make recommendations as appropriate on the interpretation of the Codes and their implementation, and refer the matter to the next Annual Meeting;

8.4 While the procedures under paragraph 2 are underway, confidentiality of the proceedings will be maintained;

8.5 If issues arise in non-adhering countries, the Advisory Group will take steps to develop an understanding of the issues involved and follow these procedures where relevant and practicable.

9. When a test report is published, it is understood that all specifications of the tractor or protective structure have been inspected as well as possible and that all tests have been made in strict compliance with the Codes. 
MEETING OF REPRESENTATIVES OF THE NATIONAL DESIGNATED AUTHORITIES FOR THE IMPLEMENTATION OF THE OECD SCHEME FOR THE CONTROL OF FOREST

\section{REPRODUCTIVE MATERIAL MOVING IN INTERNATIONAL TRADE}

Chair:

Vice-Chair:

Members:

Observers: ${ }^{1}$

Date of creation:

Duration:
Mr. Dale Simpson

(Canada)

$(\ldots)$

Austria
Belgium
Canada
Denmark
Finland
France
Germany
Hungary
Ireland
Italy
Netherlands
Norway

Portugal

Slovak Republic

Spain

Sweden

Switzerland

Turkey

United States

Madagascar

Romania

Rwanda

Center for International Forestry Research (CIFOR)

Committee of Forest Nurseries in the European Union (CPFUE)

European and Mediterranean Plant Protection Organization (EPPO)

International Federation of Agricultural Producers (IFAP)

International Plant Genetic Resources Institute (IPGRI)

International Seed Testing Association (ISTA)

International Seed Trade Federation (FIS)

International Union for the Protection of New Varieties of Plants (UPOV)

International Union of Forestry Research Organisations (IUFRO)

U.N. Food and Agricultural Organization (FAO)

30th May 1967

Unspecified

Mandate: Decision of the Council Establishing an OECD Scheme for the Control of Forest Reproductive Material Moving in International Trade [C(74)29(Final)] as amended by the Decisions of the Council [C(91)21/FINAL] and [C(2001)268 and C/M(2001)26, Item 442].

\section{Extract from Annex I to the Decision of the Council C(74)29(Final)}

\section{"METHOD OF OPERATION OF THE SCHEME}

The OECD Scheme for Forest Reproductive Material is open, on a voluntary basis, to all Member countries of the Organisation, as well as to other States being Member countries of the United Nations Organisation or its Specialised Agencies. If a country participates in the OECD Scheme for Forest Reproductive Material, the Rules of this Scheme must be strictly observed for all reproductive material carrying the OECD label.

\footnotetext{
1 Note: The Director-General of WIPO (World Intellectual Property Organisation) is the Secretary-General of UPOV.
} 
a)

Designated Authorities

i) The government of each country participating in the OECD Scheme for Forest Reproductive Material will designate the Authority or Authorities to implement the Scheme in that country.

ii) The names and addresses of the National Designated Authorities and any changes in their designation will be circulated by the OECD to all countries participating in the Scheme and to all observers.

b) Review and Co-ordination

i) The operation and progress of the Scheme shall be reviewed as necessary (in practice every two years) at meetings of representatives of the national Designated Authorities. These meetings will report on the working of the Scheme and make such proposals as are deemed necessary to the Committee for Agriculture of the OECD.

ii) The necessary co-ordination of the operation of the Scheme at the international level shall be ensured by the OECD.

c)

Responsibility

i) When forest reproductive material is labelled and sealed under one of the categories defined in these Rules and Directions it is understood that all controls have been made in strict accordance with the Rules and Directions. ..." 


\section{GOVERNING BODY OF THE CO-OPERATIVE RESEARCH \\ PROGRAMME: BIOLOGICAL RESOURCE MANAGEMENT FOR SUSTAINABLE AGRICULTURAL SYSTEMS}

Chair:

Vice-Chair:

Members:

Date of creation:

Duration:

Mandate:

Article 5 thereof;

THE COUNCIL,

Having regard to the Convention on the Organisation for Economic Co-operation and Development of 14th December 1960 and, in particular, Articles 2 a) and b) and 5 a);

Having regard to the Decision of the Council C(99)169/FINAL;

Having regard to the proposal of the Governing Body of the Co-operative Research Programme: Biological Resource Management for Sustainable Agricultural Systems;

Having regard to the favourable opinion of the Committee for Agriculture;

Having regard to the decision of the Council to fund the "Co-operative Research Programme: Biological Resource Management for Sustainable Agricultural Systems" as a nonconsolidated programme within Part II of the Budget of the Organisation [C(2004)96].

DECIDES:
(United Kingdom)

(Canada)

Japan

Netherlands

New Zealand

Norway

Poland

Slovak Republic

Spain

Sweden

Switzerland

United States
Decision of the Council concerning a Part II Programme: Biological Resource Management for Sustainable Agricultural Systems [C(2004)108] approved by

Extract of the Decision of the Council [C(2004)108]

Having regard to the Financial Regulations of the Organisation and, in particular, 


\section{DEFINITION OF THE RESEARCH PROGRAMME AND WORK PROGRAMME}

a) The Co-operative Research Programme: Biological Resource Management for Sustainable Agricultural Systems (hereinafter "the Research Programme") defined in the Appendix to this Decision is hereby established as part of the co-operative effort between research institutions of Member countries in order to develop agricultural research.

b) A work programme, drawn up within the framework of the Research Programme, shall be adopted by the Council and implemented by the Secretary-General.

Article 2

\section{COMPOSITION OF THE GOVERNING BODY}

a) The Governing Body of the Research Programme (hereinafter called the "Governing Body") shall be composed of one representative appointed by the Government of each participating country. Representatives should be chosen by virtue of their responsibilities in matters relating to agriculture or food.

b) The Government of each participating country may appoint an alternate to its representative on the Governing Body.

c) The Governing Body shall designate each year from among its members a Chair and a Vice-Chair.

d) The Governing Body may invite Member countries not participating in the Research Programme to be represented by observers.

Article 3

\section{FUNCTIONS OF THE GOVERNING BODY}

a) The Governing Body shall be competent to consider all questions related to the carrying out of the Research Programme. It shall exercise its functions in accordance with the Decisions and Resolutions of the Council and shall, in particular, exercise the functions defined in this Decision as well as such other functions as may be assigned to it by the Council.

b) The Governing Body shall define the general orientation of the Research Programme and shall prepare the draft upcoming programme and budget.

c) The Governing Body shall submit a summary report of work each year to the Committee for Agriculture for information and advice.

Article 4

\section{COMPOSITION OF THE MANAGEMENT COMMITTEE}

a) The Management Committee of the Research Programme (hereinafter called the "Management Committee") shall be composed of eight members designated by the Governing Body from a list of distinguished individuals proposed by Governments of participating countries. Four members of the Management Committee shall be chosen by virtue of their scientific responsibilities in the topics of the Research Programme; the four other members of the Management Committee shall have responsibilities at a high level in the administration of agricultural research. In designating these members, the Governing Body shall ensure that, over the 
Programme period, two Scientific Coordinators and two Research Administrators rotate, preferably on an alternative basis.

b) The Management Committee shall designate each year from amongst its members a Chair and a Vice-Chair.

Article 5

\section{FUNCTIONS OF THE MANAGEMENT COMMITTEE}

a) The Management Committee shall be responsible for implementing the programme and ensuring its scientific direction.

b) The Management Committee shall submit to the Governing Body proposals for the upcoming programme and budget.

c) The Management Committee shall submit to the Governing Body regular reports on the implementation of the programme.

Article 6

FINANCING OF EXPENDITURE

a) The expenditure arising from the implementation of the programme shall be defrayed from the appropriations authorised for it under Part II of the Budget of the Organisation.

b) The programme may include activities to be financed in whole or in part from grants by public or private institutions.

Article 7

\section{PARTICIPATING COUNTRIES}

a) The countries participating in the Research Programme shall be: Australia, Austria, Belgium, Canada, Czech Republic, Denmark, Finland, France, Germany, Greece, Hungary, Ireland, Italy, Japan, Korea, Netherlands, New Zealand, Norway, Poland, Portugal, Spain, Slovak Republic, Sweden, Switzerland, United Kingdom and the United States.

b) Any Member country of the Organisation which does not participate in the present Programme or any country having observer status in the Committee for Agriculture may participate in it by addressing a notification to the Secretary-General to this effect.

c) On the basis of a justified opinion of the Governing Body, the Organisation may invite any other country to participate in the present Programme. Such participation will become effective on the date of reception of the acceptance of that invitation by the Secretary-General. The Organisation may suspend or terminate that participation by giving one month's written notice of suspension or twelve months' written notice of termination to that country.

Article 8

\section{DURATION AND REVIEW}

a) The Research Programme is established for a period of five years from 1 January 2005. 
b) By the end of this period, taking into account the results obtained and the recommendations made by the Governing Body, the Committee for Agriculture shall present to the Council proposals concerning the future of the Research Programme. 
Chair: ${ }^{1}$

Vice-Chairs:

Members:

Observers:

Date of creation:

Duration:
Ms. Lori Ridgeway

Mr. Greg Schneider

Mr. Nobuyuki Yagi

Ms. Christa Bauer

Mr. Jan Frederik Danielsen

Open to all Member countries

Argentina

Russian Federation

Chinese Taipei

Thailand

30th September 1961

31st December 2008
(Canada)

(United States)

(Japan)

(Austria)

(Norway)

Mandate: - Paragraphs 21, 24 and 89 of the Report of the Preparatory Committee

- Council Decision regarding a Sunset Clause for all Committees [C/M(2004)5, item

75] entered into force on 22 April 2004 [C/M(2004)10, item 143, IV, c)]

\section{Extract of the Report of the Preparatory Committee}

\section{"Agriculture and Fisheries}

21. The Preparatory Committee agrees that the activities of the Organisation concerning agriculture and fisheries should be strengthened and closely integrated with the Organisation's other activities in pursuit of the objectives of the Convention.

24. With regard to activities in the fisheries sector, appropriate arrangements will have to be made by creating a special, separate, Committee.

89. As a result of the review of the Acts in this sector, the Committee recommends that the following activities should continue to feature in the programme of work to be carried out by the agricultural body or bodies of the Organisation, without, however, excluding the possibility that other activities might be added at a later stage in the light of directives resulting from new requirements:

a) Confrontation and consultations on agricultural, food and fishery policies under their different aspects with a view to promoting the harmonious development of these policies among Member countries in accordance with the objectives of the Organisation and the undertakings entered into under the Convention;

\footnotetext{
${ }^{1}$ Election of the Bureau will take place in April 2006.
} 
b) Examination of the overall situation of agriculture and fisheries in Member countries and of the prospects including examination of the trend of supply and demand;

c) Study of the possibilities for improving the marketing and distribution of agricultural, fishery and food products with a view to determining measures which could be adopted nationally and internationally; similar studies in the field of means of production;

d) Surveys of the market situation for the main agricultural and fisheries products and formulation, in co-operation where necessary with the Trade Committee, of proposals for remedial measures in the event of market difficulties;

e) Examination in liaison and co-operation with the Trade Committee of trade problems directly connected with agricultural and fishery policies and falling within the mandate of the Organisation in trade matters as described in this Report;

f) Assistance in the agricultural field to the economic, trade and technical activities of other bodies of the Organisation in implementing the aims of the Organisation concerning countries, or in special cases, areas in process of economic development;

g) Practical work designed to promote a better use of production factors and to promote technical progress in the sectors of agriculture and fisheries including marketing and distribution.

The nature and extent of such activities and the way in which they will be performed will be decided later. Insofar as they have budgetary implications appropriate rules will be drawn up in accordance with the principles agreed in Part I, paragraph 39." 
STATISTICS 



\section{COMMITTEE ON STATISTICS (CSTAT)}

Chair:

Vice-Chairs:

Bureau Members:

Members:

Observers: ${ }^{1}$

Date of creation:

Duration:

$$
\text { Mr. Ivan Fellegi }
$$

Mr. Brian Pink

Mr. Kjell Jansson

Mr. Jan Fischer

Mr. Jean-Michel Charpin

Mr. Yutaka Kubushiro

Mrs. Adelheid Bürgi-Schmelz

Ms. Karen Dunnell

Ms. Katherine K. Wallman

-..

Open to all Member countries

Brazil
Chile
China
India
Russian Federation
South Africa

22nd April 2004

31st December 2008
(Canada)

(New Zealand)

(Sweden)

(Czech Republic)

(France)

(Japan)

(Switzerland)

(United Kingdom)

(United States)

(European Commission)

Mandate: - Resolution of the Council establishing a committee on statistics [C(2003)217 and C(2003)217/CORR1] approved at its 1077th session on 12 February 2004 [C/M(2004)3, Item 40]

\section{Resolution of the Council [C(2003)217 and C(2003)217/CORR1]}

\section{THE COUNCIL}

Having regard to the Convention on the Organisation for Economic Co-operation and Development of $14^{\text {th }}$ December 1960 , and, in particular, articles $1,3,5 a$ ) and 9 thereof;

18 a) iii);

Having regard to the Rules of Procedure of the Organisation and in particular Rule

Having regard to the Financial Rules of the Organisation;

Having regard to the Council's conclusions of 25 July 2002 on the Structures of Committees and Multidisciplinarity: Recommendations [C/M(2002)17].

\footnotetext{
1 Invitation agreed by Council in document $[\mathrm{C} / \mathrm{M}(2006) 3$, item 33].
} 
Having regard to the recommendation contained in document C(2003)176, Implementation of the Nicholson Report Recommendations to convert the Meeting of Chief Statisticians into a Committee on Statistics;

Committee on Statistics;

Having regard to document $\mathrm{C}(2003) 217$ on the Establishment of an OECD

Recognising that the creation of a Committee on Statistics would reinforce the overall coherence of OECD activities in this field;

Noting that, in this respect, a Committee on Statistics would be a key instrument to improve the overall quality of OECD statistics, reinforcing the co-operation both among countries, and between them and the Secretariat; to reinforce the role of the OECD in influencing the development of reliable and comparable statistics, both at national and international levels and to improve the dialogue between policy makers, analysts and data providers;

Noting that the creation of such a Committee would be budget neutral;

On the proposal of the Secretary- General;

\section{DECIDES:}

\section{Article 1}

A Committee on Statistics (hereafter the Committee) is hereby established.

\section{Article 2}

1. The Committee shall oversee the broad range of statistics and statistical policy issues relevant to the Organisation.

2. In carrying out its responsibilities it shall:

a) be responsible to Council for the statistical policy of the OECD, both within the Organisation and vis-à-vis the rest of the world;

b) ensure that OECD statistics are produced according to high quality standards;

c) oversee the Programme of Work and Budget of the Statistics Directorate;

d) give advice to other OECD committees and to OECD Directorates about their plans, highlighting gaps and challenges, and contributing to the development of an effective and well co-ordinated OECD Statistical Work Programme;

e) officially approve methodological recommendations elaborated on specific subjects, co-operating with other committees in charge of policy issues related to the latter, and promote their implementation;

f) approve common standards for data and metadata exchange between the OECD and national data providers;

g) take appropriate action on any other topics submitted by the OECD Chief Statistician and relevant for conducting his/her tasks. 


\section{Article 3}

1. The Committee shall maintain a close working relationship with other relevant bodies of the Organisation, seeking to ensure that statistics within the OECD are dealt with in a well-coordinated and horizontal manner.

2. The Committee shall maintain, as appropriate, and in conformity with the OECD rules, relations with other international organisations, seeking to achieve co-ordinated and complementary work programmes in areas of shared interest and mutual benefit.

\section{Article 4}

The Resolution shall come into force on 12 February 2004. It shall expire on $31^{\text {st }}$ December 2008 , unless the Council decides otherwise.

\section{Article 5}

The Annex to the Rules of Procedure of the Organisation shall be amended as follows: Committee on Statistics, its terms of reference are defined in the Resolution of the Council C(2003)217. 


\section{OECD SHORT-TERM ECONOMIC STATISTICS WORKING PARTY (STESWP) ${ }^{1}$}

Chair:

Members:

Observers: ${ }^{2}$

Date of creation:

Duration: $\cdots$

Open to all Member countries

Brazil
Chile
China
India
Russian Federation
South Africa

27th October 2005

31st December 2008

Mandate: - Resolution of the Council establishing subsidiary bodies of the Committee on Statistics [C(2005)138 and C(2005)138/CORR1] approved at its $1122^{\text {nd }}$ session on 27 October 2005 [C/M(2005)21, Item 276]

\section{Resolution of the Council C(2005)138 and C(2005)138/CORR1}

THE COMMITTEE ON STATISTICS,

Having regard to Articles 1, 2, 5a) and 12 of the Convention on the Organisation for Economic Co-operation and Development of 14 December 1960;

Having regard to the resolution of the Council creating the Committee on Statistics and granting it the responsibility to "ensure that OECD statistics are produced according to high quality standards" and "officially approve methodological recommendations elaborated on specific subjects" [C(2003)217 and C(2003)217/CORR1];

Having regard to the Rules of Procedure of the Organisation;

Considering that comparable quantitative information on short-term economic variables across OECD Member countries is indispensable for carrying out national and international economic analysis;

Emphasising the importance of the short-term economic statistics and indicators for monetary and fiscal polices economic statistics;

Recognising the role played by the OECD in the development of standards to compile DECIDES:

1. The Working Party on Short-Term Economic Statistics is established;

2. The Working Party will undertake tasks to improve the quality of short-term economic indicators in accordance with priorities established by the OECD Committee on Statistics;

\footnotetext{
${ }^{1}$ Formerly known as the OECD Short-term Economic Statistics Expert Group (STESEG).

2 Invitation agreed by Council in document [C/M(2006)3, item 33].
} 
provide recommendations and guidelines for the development and improvement of internationally comparable methodologies and statistical series and indicators to monitor short-term changes in economies;

act as a forum in which member countries would exchange information and experience on new methods of collection, compilation, analysis and presentation of data, development of new indicators in the field of short-term economic indicators, especially for those areas where statistical measurements appear particularly weak;

encourage the implementation of guidelines and recommendations by Member countries;

provide support for the development of short-term economic statistics in non-member countries;

monitor by regular studies the quality and comparability of data in all domains of shortterm economic statistics;

encourage the methodological transparency, and timely availability of statistical series, and monitor their prompt transmission to the OECD in order to better serve international and national users;

4. The activity of the Working Party will have an appropriate balance between specific statistical domains (such as services, business statistics, etc) and cross-cutting issues (such as seasonal adjustment, quality assessment, timeliness, etc);

5. The Working Party will seek the maximum practicable conformity of its own work with relevant statistical work undertaken by other parts of the OECD, and also with related work on shortterm economic indicators undertaken by other competent international and supranational organisations. To avoid duplication of efforts, a particular attention has to be paid to the coordination of the activity of the Working Party with that carried out by other working groups active at international level;

6. The present mandate shall expire on 31 December 2008. The Committee on Statistics will review the results obtained every year before the end of the mandate. 


\section{WORKING PARTY ON NATIONAL ACCOUNTS ${ }^{1}$}

Vice-Chairs:

Chair:

Members:

Observers: ${ }^{2}$
Mr. Fumikazu Hida

Mr. Csak Ligeti

Mr. Brent Moulton

Open to all Member countries
Date of creation:

Duration:
(Japan)

(Hungary)

(United States)

Mandate: - Resolution of the Council establishing subsidiary bodies of the Committee on Statistics [C(2005)138 and C(2005)138/CORR1] approved at its $1122^{\text {nd }}$ session on 27 October 2005 [C/M(2005)21, Item 276]

\section{Resolution of the Council C(2005)138 and C(2005)138/CORR1}

\section{THE COMMITTEE ON STATISTICS,}

Having regard to Articles 1, 2, 5a) and 12 of the Convention on the Organisation for Economic Co-operation and Development of 14 December 1960;

Having regard to the resolution of the Council creating the Committee on Statistics and granting it the responsibility to "ensure that OECD statistics are produced according to high quality standards" and "officially approve methodological recommendations elaborated on specific subjects" [C(2003)217 and C(2003)217/CORR1];

Having regard to the Rules of Procedure of the Organisation;

Considering that comparable quantitative information on national accounts across OECD Member countries is indispensable for carrying out national and international economic analysis;

Emphasising the importance of the System of National Accounts as a guide for the development of all economic statistics;

Recognising the historical role played by the OECD in the development of standards to compile national accounts data worldwide;

\section{DECIDES:}

\footnotetext{
1 Formerly known as the "OECD National Accounts Experts Meeting".

2 Invitation agreed by Council in document [C/M(2006)3, item 33].
} 
2. The Working Party will undertake work to improve the quality of national accounts data in accordance with priorities established by the OECD Committee on Statistics.

3. In particular the Working Party will:

- facilitate the development and improvement of internationally comparable methodologies in order to allow users to better compare the growth and the levels of national accounts variables between OECD countries, including satellite accounts;

- monitor, in coordination with the Inter-Secretariat Working Group on National Accounts (ISWGNA), the changes and clarification needed in the Manual of the System of National Accounts to increase the relevance and the international comparability of national accounts statistics;

- monitor by regular studies the comparability of the data in all domains of national accounts;

- pay particular attention to the relevance and comparability in the area of general government accounts, considering the increasing use of national accounts data in the domain of government finance statistics;

- encourage the implementation of international guidelines and recommendations by Member countries, including those regarding compilation methods and accurate measurement of key phenomena;

- encourage the timely availability of statistical series and monitor their prompt transmission to the OECD in order to better serve international users of national accounts data.

4. The Working Party will seek the maximum practicable conformity of its own work with relevant statistical work undertaken by other parts of the OECD, and in particular the Working Party on Financial Statistics (WPFS) which covers financial accounts; and also with related work on national accounts undertaken by other competent international and supranational organisations. To avoid duplication of efforts, a particular attention has to be paid to the co-ordination of the activity of the Working Party with that carried out by other working groups active at international level.

5. The Working Party will act as a forum in which Member countries will be able to exchange information and experience on new concepts, best practices of compilation of national accounts and on new experiences on the use of national accounts data.

6. The present mandate shall expire on 31 December 2008. The Committee on Statistics will review the results obtained every year before the end of the mandate. 

TR A N S P O R T 

Chair:

Vice-Chairs:

Bureau Members:

\section{Members: ${ }^{1}$}

Date of creation:

Duration:
Mr. Houko Luikens

Mr. Urban Karlström

Mr. Derek Sweet

Mr. Jacques Roudier

Mr. Konrad Bauer

Mr. Heinrich Nöthe

Mr. Laszlo Ruppert

Mr. Elji Torikai

Mr. Keiji Fukumoto

Mr. Dennis Judycki

Mr. Vadim Donchenko

Australia
Austria
Belgium
Canada
Czech Republic
Denmark
Finland
France
Germany
Greece
Hungary
Iceland
Ireland
Italy
Japan
Korea
Luxembourg
Mexico
Netherlands
New Zealand
Norway
Poland
Portugal
Slovak Republic
Spain
Sweden

1st January 2004

31st December 2006
(Netherlands)

(Sweden)

(Canada)

(France)

(Germany)

(Germany)

(Hungary)

(Japan)

(Japan)

(United States)

(Russian Federation)

Switzerland

Turkey

United Kingdom

United States

European Commission

Albania

Armenia

Azerbaijan

Belarus

Bosnia and Herzegovina

Bulgaria

Croatia

Estonia

Georgia

Latvia

Liechtenstein

Lithuania

Macedonia, Former Yugoslav

Republic of

Malta

Moldova

Romania

Russian Federation

Serbia and Montenegro

Slovenia

Ukraine

Mandate : Resolution of the Council [C(2003)128/FINAL] adopted at its $1059^{\text {th }}$ session on 26 June 2003 [C/M(2003)14]

1 Open to all OECD and ECMT Member countries. 


\section{Resolution of the Council [C(2003)128/FINAL]}

\section{THE COUNCIL}

Having regard to the Convention on the Organisation for Economic co-operation and Development of $14^{\text {th }}$ December 1960 and, in particular, articles 2 b), 5a), 9 and 20 thereof;

Having regard to the Financial Rules of the Organisation;

Having regard to Rule 18 a) iii) of the Rules of Procedure of the Organisation;

Having regard to the Decision of the Council on the programme of co-operation in the field of road transport research and intermodal linkages [C(96)90/FINAL];

Having regard to the Recommendation of the Council of the OEEC on the establishment of a European Conference of Ministers of Transport (ECMT) of $24^{\text {th }}$ July 1953 [C/M (53)22(Final)] and to the Decision of the Council concerning relations between the Organisation and the ECMT of $30^{\text {th }}$ September 1961 [C/M(61)1(Final)];

Having regard to Report of Working Group 3 on improving the co-operation and co-ordination with the affiliated bodies of the OECD [HOD (2003)1];

Mindful of the resolutions of the Council of 28 March and 25 July 2002 concerning the creation of new subsidiary bodies [C/M(2002)6 and C/M(2002)17];

Noting that Working Group 3 recommended that "the OECD should support the creation of a Joint OECD/ECMT Transport Policy Research Unit" and that "this would merge the activities undertaken in the field of transport research by the ECMT's Economic Research Committee and the OECD/RTR's Steering Committee";

Noting that the Council of Ministers of the ECMT agreed on 24-25 April 2003 "to create a joint ECMT-OECD Transport Research Centre, in which members of the two organisation will have full and equal rights" [CEMT/CM(2003)12/FINAL];

On the proposal of the Secretary-General;

\section{DECIDES:}

\section{Article 1}

A "Joint OECD/ECMT Transport Research Centre" (hereafter the Centre) is hereby established. The Centre is set up for an initial period of three years.

\section{Article 2}

The Centre shall promote economic development and contribute to structural improvements of OECD and ECMT economies, through co-operative transport research programmes addressing all modes of inland transport and their intermodal linkages in a wider economic, social, environmental and institutional context.

\section{Article 3}


The Centre shall be open to all OECD and ECMT Member countries. OECD Members which, at the time of the adoption of the present Resolution, already participated in the Programme of cooperation in the field of road transport research and intermodal linkages [C(96)90/FINAL], shall participate in the Centre subject to a notification to the contrary to the Secretary-General of the OECD not later than 120 days before the entry into force of the Resolution.

The Centre shall closely co-operate with the OECD Maritime Transport Committee and all other relevant bodies of the OECD and the ECMT.

\section{Article 4}

The Centre will be governed by a "Joint OECD/ECMT Transport Research Committee" (hereafter the Committee). The Committee will bring together representatives of the existing OECD/RTR Steering Committee and the ECMT Economic Research Committee.

\section{Article 5}

The Committee shall:

a) establish a programme of work that reflects the interests of both ECMT and OECD Members, consistent with a budget dedicated to this transport research programme. This programme of work will use as a base the draft programme of work for the period 2004 to 2006 of the RTR Steering Committee [DSTI/DOT/RTR/SC (2003)3] and the draft programme of the ECMT Economic Research Committee,

b) ensure that the programme of work is carried out through co-operative research working groups, round tables, seminars and other working methods that the Committee considers appropriate,

c) invite international organisations, institutions dealing with matters related to inland transport as well as industry and representative associations as appropriate to participate in selected aspects of the work of the Centre,

d) monitor the execution of its programme of work,

e) report on its activities to the extended ECMT Committee of Deputies and finally to Transport Ministers of OECD and ECMT countries at annual ECMT ministerial meetings,

f) report on its activities annually to the OECD Council, and

g) perform any other function that the governing bodies of both Organisations may jointly decide.

\section{Article 6}

The expenditure arising from the implementation of the work of the Centre shall be financed on an equal basis by countries participating in the OECD/RTR programme and the ECMT and shall be charged against the appropriations authorised under the non-consolidated Part II of the Budget of the Organisation.

The expenditure for special programmes could be financed through voluntary contributions by private and public institutions. 
The budget of the Centre shall be used exclusively to implement the programme of work established by the Committee.

Except as otherwise agreed by the governing bodies of both Organisations, all the Centre staffrelated costs including costs linked to the end of appointments shall be borne by the Centre.

\section{Article 7}

The Centre is to be served by officials working exclusively on transport research issues. Officials, who are administratively integrated into the OECD, shall be appointed in accordance with the OECD's recruitment procedures. Notwithstanding the provisions of Staff Regulation $7 \mathrm{~b}$ ) and the related instruction 107/1, the Secretary-General of the OECD shall be authorised to recruit nationals from any non-OECD country member of the ECMT, as officials for the Centre.

The Head of the Centre, who will be in charge of the day-to-day management of the Centre, will be appointed on a joint decision of the Secretary-General of the OECD and the Secretary-General of the ECMT.

The Secretary-General of the ECMT exercises operational guidance over the officials of the Centre with regard to the day to day implementation of the work programme and budget. In doing so he/she will ensure the necessary consultations with the OECD Secretariat.

Unless otherwise decided by the governing bodies of both Organisations, the Secretary General of the OECD and the Secretary-General of the ECMT shall be jointly responsible for the administration of the programme of work and the budget of the Centre.

\section{Article 8}

The Resolution comes into force on $1^{\text {st }}$ January 2004. It will expire on $31^{\text {st }}$ December 2006 unless the Council decides otherwise. 
INTERNATIONAL ENERGYAGENCY (IEA) 

Chair:

Vice-Chairs:

Members:

Participation in the work:

Date of creation:

Duration:

$$
\text { Mr. John Ryan }
$$

$$
\begin{aligned}
& \text { Mr. Shinichi Kitajima } \\
& \text { Ms. Karen Harbert }
\end{aligned}
$$

All IEA Member countries

European Commission

Pursuant to Supplementary Protocol No. 1 to the Convention on the OECD

15th November 1974

Unspecified
(Australia)

(...)

(Japan)

(United States)

Mandate : - Decision of the Council Establishing an International Energy Agency of the Organisation [C(74)203(Final)]

- Articles 49 to 52 of the Agreement on an International Energy Program signed in Paris on 18th November 1974. [C(74)203(Final) Annex II]

- Decision on an International Energy Program adopted by the Governing Board at its 1st meeting on 18th 19th November 1974 [IEA/GB(74)9(1st Revision);

IEA/GB/DOC.74/5, Annex]

\section{Extract from document IEA/GB(74)9(1st Revision)}

\section{"THE GOVERNING BOARD}

a) Agreed that until further decision its meetings would be deemed to be joint meetings of the Governing Board and the Management Committee of the Agency."

\section{Extract from Decision of the Council [C(74)203(Final)]}

"THE COUNCIL,

Development of 14th December 1960 (hereinafter called the "Convention") and, in particular, Articles 5 a), 6, 9, 12, 13 and 20 of the Convention;

Having regard to the Financial Regulations of the Organisation and, in particular, to Articles 5, 10, $14 \mathrm{~b}$ ) and $16 \mathrm{~b}$ ) thereof;

Having regard to the Regulations, Rules and Instructions for Council Experts and Consultants of the Organisation;

Noting that the Governments of certain Member countries have declared their intention to enter into a separate Agreement on an International Energy Program which is attached to document [C(74)204] of 6th November 1974, and Corrigendum 1 thereto, which is circulated for reference and is hereinafter referred to as the "Agreement";

Having regard to the Recommendation of the Council of 29th June 1971 on Oil Stockpiling [C(71)113(Final)]; 
Having regard to the Decision of the Council of 14th November 1972 on Emergency Plans and Measures and Apportionment of Oil Supplies in an Emergency in the OECD European Area [C(72)201(Final)];

Having regard to the Recommendation of the Council of 10th January 1974 on the Supply of Bunker Fuels for Shipping and Fishing [C(73)257(Final)];

Having regard to the Recommendation of the Council of 10th January 1974 on the Supply of Fuel for Civil Aircraft [C(73)258(Final)];

Having regard to the Note by the Secretary General of 6th November 1974 concerning the International Energy Program [C(74)203 and Corrigendum 1];

\section{DECIDES:}

\section{Article 1}

An International Energy Agency (hereinafter called the "Agency") is hereby established as an autonomous body within the framework of the Organisation. ...

\section{Article 4}

A Governing Board composed of all the Participating Countries of the Agency shall be the body from which all acts of the Agency derive, and shall have the power to make recommendations and to take decisions which shall, except as otherwise provided, be binding upon Participating Countries, and to delegate its powers to other organs of the Agency. The Governing Board shall adopt its own rules of procedure and voting rules.

\section{Article 5}

The Governing Board shall establish such organs and procedures as may be required for the proper functioning of the Agency.

\section{Article 6}

a) The Governing Board shall decide upon and carry out an International Energy Program for co operation in the field of energy, the aims of which are:

i) Development of a common level of emergency self sufficiency in oil supplies;

ii) Establishment of common demand restraint measures in an emergency;

iii) Establishment and implementation of measures for the allocation of available oil in time of emergency;

iv) Development of a system of information on the international oil market and a framework for consultation with international oil companies;

v) Development and implementation of a long term co operation programme to reduce dependence on imported oil, including: conservation of energy, development of alternative sources of energy, energy research and development, and supply of natural and enriched uranium;

vi) Promotion of co operative relations with oil producing countries and with other oil consuming countries, particularly those of the developing world.

The Governing Board may adopt other measures of co operation in the energy field which it may deem necessary and otherwise amend the Program by unanimity, taking into account the constitutional procedures of the Participating Countries.

b) Upon the proposal of the Governing Board of the Agency, the Council may confer additional responsibilities upon the Agency.

Article 7 
a) The organs of the Agency shall be assisted by an Executive Director and such staff as is necessary who shall form part of the Secretariat of the Organisation and who shall, in performing their duties under the International Energy Program, be responsible to and report to the organs of the Agency.

b) The Executive Director shall be appointed by the Governing Board on the proposal or with concurrence of the Secretary General.

c) Consultants to the Agency may be appointed for a period exceeding that provided in Regulation 2 b) of the Regulations and Rules for Council Experts and Consultants of the Organisation.

\section{Article 8}

The Governing Board shall report annually to the Council on the activities of the Agency. The Governing Board shall submit, upon the request of the Council or upon its own initiative, other communications to the Council.

\section{Article 9}

The Agency shall co operate with other competent bodies of the Organisation in areas of common interest. These bodies and the Agency shall consult with one another regarding their respective activities.

\section{Article 10}

a) The budget of the Agency shall form part of the Budget of the Organisation and expenditure of the Agency shall be charged against the appropriations authorised for it under Part II of the Budget which shall include appropriate Budget estimates and provisions for all expenditure necessary for the operation of the Agency. Each Participating Country's share in financing such expenditure shall be fixed by the Governing Board. Special expenses incurred by the Agency in connection with activities referred to in Article 11 shall be shared by the Participating Countries in such proportions as shall be determined by unanimous agreement of those countries. The Governing Board shall designate an organ of the Agency to advise the Governing Board as required on the financial administration of the Agency and to give its opinion on the annual and other budget proposals submitted to the Governing Board.

b) The Governing Board shall submit the annual and other budget proposals of the Agency to the Council for adoption by agreement of those Participating Countries of the Agency which voted in the Governing Board to submit the proposals to the Council.

c) Notwithstanding the provisions of Article $14 \mathrm{~b}$ ) of the Financial Regulations, the Governing Board may accept voluntary contributions and grants as well as payments for services rendered by the Agency.

d) Notwithstanding the provisions of Article $16 \mathrm{~b}$ ) of the Financial Regulations of the Organisation, appropriations in respect of the special activities referred to in Article 11 of this Decision, for which no commitment has been entered into before the end of the Financial Year for which they were appropriated, shall be automatically carried forward to the budget for the ensuing year.

\section{Article 11}

Any two or more Participating Countries may decide to carry out within the scope of the Program special activities, other than activities which are required to be carried out by all Participating Countries under the Agreement. Participating Countries who do not wish to take part in such activities shall abstain from taking part in such decisions and shall not be bound by them. Participating Countries carrying out such activities shall keep the Governing Board informed thereof. 
In order to achieve the objectives of the Program, the Agency may establish relationships with countries which are not Participating Countries, international organisations, whether Governmental or non Governmental, other entities and individuals.

\section{Article 13}

a) A Participating Country for which the Agreement shall have ceased to be in force or to apply provisionally shall be deemed to have withdrawn from the Agency.

b) Notwithstanding the provisions of paragraph a), a Country whose Government shall have signed the Agreement may, upon written notice to the Governing Board and to the Government of Belgium to the effect that the adoption of the Program by the Governing Board is binding on it pursuant to this Decision, remain a Participating Country of the Agency after the Agreement shall have ceased to apply for it, unless the Governing Board decides otherwise. Such a Country shall have the same obligations and the same rights as a Participating Country of the Agency for which the Agreement shall have entered definitively into force.

Article 14

The present Decision shall enter into force on 15th November 1974."

\section{Extract from the Agreement on an International Energy Program [C(74)203(Final), Annex II]}

"Article 49

1.

The Agency shall have the following organs:

- A Governing Board

- A Management Committee

- Standing Groups on:

- Emergency Questions

- Oil Market

- Long term Co operation

- Relations with Producer and Other Consumer Countries.

2. The Governing Board or the Management Committee may, acting by majority, establish any other organ necessary for the implementation of the Program.

3. The Agency shall have a Secretariat to assist the organs mentioned in paragraphs 1 and 2.

\section{GOVERNING BOARD}

Article 50

1. The Governing Board shall be composed of one or more ministers or their delegates from each Participating Country.

2. The Governing Board, acting by majority, shall adopt its own rules of procedure. Unless otherwise decided in the rules of procedure, these rules shall also apply to the Management Committee and the Standing Groups.

3. The Governing Board, acting by majority, shall elect its Chairman and Vice Chairmen.

\section{Article 51}

1. The Governing Board shall adopt decisions and make recommendations which are necessary for the proper functioning of the Program. 
2. The Governing Board shall review periodically and take appropriate action concerning developments in the international energy situation, including problems relating to the oil supplies of any Participating Country or Countries, and the economic and monetary implications of these developments. In its activities concerning the economic and monetary implications of developments in the international energy situation, the Governing Board shall take into account the competence and activities of international institutions responsible for overall economic and monetary questions.

3.

The Governing Board, acting by majority, may delegate any of its functions to any other organ of the Agency.

\section{Article 52}

1. Subject to Article 61, paragraph 2 and Article 65, decisions adopted pursuant to this Agreement by the Governing Board or by any other organ by delegation from the Board shall be binding on the Participating Countries.

2. Recommendations shall not be binding.

Explanatory Note:

The general mandate of the Governing Board is contained in the texts quoted above. In addition, more detailed provisions concerning the Governing Board's mandate are found throughout the I.E.P. Agreement."

\section{Extract from the Annex to document [IEA/GB/DOC.74/5]}

"1. The International Energy Program set out in the Agreement is hereby adopted and shall be carried out by the Agency and Participating Countries in accordance with its terms;

2. The organs provided for in the Program are hereby established as organs of the Agency; they shall carry out their responsibilities in accordance with the procedures set out in the Program and shall take decisions, recommendations and other actions as provided therein." 


\section{STANDING GROUP ON EMERGENCY QUESTIONS}

Chair:

Mr. Pieter Boot

(Netherlands)

Vice-Chairs:

Mr. James Hart

(..)

(United States)

Members:

All IEA Member countries

Participation in the work:

European Commission

Pursuant to Supplementary Protocol $n^{\circ}$. 1 to the Convention on the OECD

Date of creation:

18th November 1974

Duration:

Unspecified

Mandate: - Article 55 of the Agreement on an International Energy Program, signed in Paris on 18th November 1974, deposited with the Government of Belgium

- Decision on an International Energy Program, adopted by the Governing Board at its 1st meeting on 18th-19th November 1974 [IEA/GB(74)9(1st Revision);

IEA/GB/DOC.74/5, Annex]

\section{Article 55 of the Agreement on an International Energy Program}

\section{"Article 55}

1. The Standing Group on Emergency Questions shall carry out the functions assigned to it in Chapters I to V and the Annex and any other function delegated to it by the Governing Board.

2. The Standing Group may review and report to the Management Committee on any matter within the scope of Chapters I to $V$ and the Annex.

3. The Standing Group may consult with oil companies on any matter within its competence."

\section{Extract from the Annex to document [IEA/GB/DOC.74/5]}

"2. The organs provided for in the Program are hereby established as organs of the Agency; they shall carry out their responsibilities in accordance with the procedures set out in the Program and shall take decisions, recommendations and other actions as provided therein;" 


\section{STANDING GROUP ON THE OIL MARKET}

Chair:

Vice-Chairs:

Members:

Participation in the work:

Date of creation:

Duration:
Mr. Graham White

Mr. Manabu Miyagawa

Mr. John Brodman

All IEA Member countries

European Commission

Pursuant to Supplementary Protocol $n^{\circ} 1$ to the Convention on the OECD

18th November 1974

Unspecified
(United Kingdom)

(Japan)

(United States)

Mandate: - Article 56 of the Agreement on an International Energy Program, signed in Paris on 18th November 1974, deposited with the Government of Belgium

- Decision on an International Energy Program adopted by the Governing Board at its 1st meeting on 18th-19th November 1974 [IEA/GB(74)9(1st Revision);

IEA/GB/DOC.74/5, Annex]

\section{Article 56 of the Agreement on an International Energy Program}

"1. The Standing Group on the Oil Market shall carry out the functions assigned to it in Chapters V and VI and any other function delegated to it by the Governing Board.

2. The Standing Group may review and report to the Management Committee on any matter within the scope of Chapters V and VI.

3. The Standing Group may consult with oil companies on any matter within its competence."

\section{Extract from the Annex to document [IEA/GB/DOC.74/5]}

"2. The organs provided for in the Program are hereby established as organs of the Agency; they shall carry out their responsibilities in accordance with the procedures set out in the Program and shall take decisions, recommendations and other actions as provided therein;" 


\section{STANDING GROUP ON LONG-TERM CO-OPERATION}

Chair:

Vice-Chairs:

Members:

Participation in the work:

Date of creation:

Duration:
Mr. Paul Simons

Mr. Kenji Goto

Mr. Hugo Brouwer

All IEA Member countries

European Commission

Pursuant to Supplementary Protocol $n^{\circ}$. 1 to the Convention on the $O E C D$

18th November 1974

Unspecified
(United States)

(Japan)

(Netherlands)

Mandate: - Article 57 of the Agreement on an International Energy Program, signed in Paris on 18th November 1974, deposited with the Government of Belgium

- Decision on an International Energy Program adopted by the Governing Board at its 1st meeting on 18th-19th November 1974 [IEA/GB(74)9(1st Revision);

IEA/GB/DOC.74/5, Annex]

\section{Article 57 of the Agreement on an International Energy Program}

"1. The Standing Group on Long-Term Co-operation shall carry out the functions assigned to it in Chapter VII and any other function delegated to it by the Governing Board.

2. The Standing Group may review and report to the Management Committee on any matter within the scope of Chapter VII."

\section{Extract from the Annex to document [IEA/GB/DOC.74/5]}

"2. The organs provided for in the Program are hereby established as organs of the Agency; they shall carry out their responsibilities in accordance with the procedures set out in the Program and shall take decisions, recommendations and other actions as provided therein;" 


\section{WORKING PARTY ON ENERGY EFFICIENCY ${ }^{1}$}

Chair:

Vice-Chairs:

Members:

Participation in the work:

Date of creation:

Duration:
Mr. Wolfgang Stinglwagner

Mr. Jeffery Dowd

Mr. Peter Bach

All IEA Member countries

European Commission

Pursuant to Supplementary Protocol $n^{\circ}$. 1 to the Convention on the $O E C D$

3rd December 1974

Unspecified
(Germany)

(United States)

(Denmark)

$\begin{array}{ll}\text { Mandate: } & \text { - Summary record of the 1st meeting of the Standing Group on Long-Term } \\ & \text { Co-operation on 3rd-4th December 1974 [IEA/SLT/M(74)1] } \\ \text { - Provisional terms of reference [IEA/SLT(74)3 (2nd Revision)] }\end{array}$

Extract from document [IEA/SLT/M(74)1 - Item 3]

"The Standing Group on Long-Term Co-operation

A. $\quad$ Established a sub-group on conservation to meet 13th-14th January 1975.

B. Agreed that the IEA Secretariat, drawing on comments from all delegations, would draft a set of guiding principles for the work of this sub-group and would circulate them to all delegations prior to the next SLT meeting.

C. $\quad$ Agreed that the SLT at its 18th December meeting plan to adopt these guiding principles and to elect a sub-group chairman."

\section{Document [IEA/SLT(74)3(2nd Revision)]}

"After noting their intention to reduce their dependence on imported oil, as expressed in Article 41 of the Agreement on an International Energy Programme, the members of the Standing Group on Long-Term Co-operation of the International Energy Agency agreed at their meeting on 3rd and 4th December 1974, to establish a sub-group on conservation. This sub-group would operate under the general provisions of Article 42 of the Agreement and should hold its first meeting on 13th and 14th January 1975. This sub-group should undertake the following tasks:

I. It should collate and review planned and existing conservation programmes in Member countries, in order to address the question of the feasibility or desirability of setting dynamic targets or objectives by the SLT for the group's reduction in energy consumption growth rates as related to a reduction in dependence on imported oil. In this regard the sub-group may find it helpful to divide its work into specific time frames of a medium and longer-term nature.

\footnotetext{
1 The Standing Group on Long-Term Co-operation, at its meeting on 21st-22nd October 1997 agreed to the change in name from the Sub Group on Energy Conservation to the Working Partty on Energy Efficiency.
} 
II. With regard to the set of dynamic, long-term targets or objectives, the sub-group should consider whether these objectives should be strictly the sum of individual members' measures or if they should be set so as to take into account any additional conservation effect for the group as a whole which the IEA considers desirable and feasible.

III. The sub-group should define what is meant by conservation and consider the impact which various conservation measures might have on overall economic activities, keeping in mind that while it is important to minimise the adverse economic effects it should recognise that changes in patterns of energy consumption and economies in general are unavoidable. The sub-group might consider the desirability of convening a separate group of economic experts to address the question of economic impact of conservation measures and make recommendations to the SLT on this point.

IV. The sub-group should develop the criteria required to evaluate the relative effort of Member countries needed to realise the objectives established, keeping in mind that the effort should be distributed among members on an equitable basis. The criteria should be developed in the light of each country's pattern of energy supply, patterns of energy use (energy consumption per capita, energy consumption per unit of output, etc.) and economic structure.

V. The sub-group should propose ways and means to the SLT for development of a periodic systematic review programme to evaluate and compare individual countries' conservation measures and progress, noting that such a review on an international level might assist member governments i) in making difficult political decisions requiring changes in patterns of energy utilisation and ii) in avoiding any distorting consequences on other member economies.

VI. The sub-group should consider the desirability and feasibility of constituting binding commitments on member countries to implement a certain set of conservation measures taking into account their differing situations.

VII. The sub-group should also continue the work of the ad hoc Sub-Group on Immediate Energy Saving by:

a) Establishing a system to monitor the results and impact of the 1975 conservation efforts now under discussion;

b) Establishing a system to update continuously the information collected on the conservation measures of member countries;

c) Submitting to the SLT not later than 31st March 1975 an initial report on the results of the tasks in a) and b) above as well as any proposals whose application may result in reinforcement of national conservation efforts for 1975.

In carrying out these tasks the sub-group should bear in mind the principles and considerations as set out in paragraphs I to VI. The sub-group should also keep in mind that the measures to eliminate the waste of energy might have immediate effects while the measures to increase the efficiency of energy require investment use and will have, therefore (in most cases) a longer term effect." 


\section{COMMITTEE ON ENERGY RESEARCH AND TECHNOLOGY (CERT) ${ }^{1}$}

Chair:

Members:

Vice-Chairs:

Date of creation:

Duration:
Mr. Graham R. Campbell

(Canada)

All IEA Member countries

Mrs. Isabel Cabrita

Ms. Alicia Mignone

Mr. David Pumphrey

Mr. Ken Watanabe

(Portugal)

(Italy)

(United States)

(Japan)

Participation in the work: European Commission

Pursuant to Supplementary Protocol $n^{\circ}$. 1 to the Convention on the OECD

21st November 1975

Unspecified

Mandate: Conclusions of the 16th meeting of the Governing Board on 20th-21st November 1975 [IEA/GB(75)94]

\section{Extracts from document [IEA/GB(75)94, Item 7 and Annex II]}

\section{"7. ORGANISATION OF ENERGY R\&D}

\section{THE GOVERNING BOARD}

a) Adopted the Decision on the Establishment of the Committee on Energy Research and Development as set forth in Annex II hereto.

b) Instructed the Committee on Energy Research and Development to discontinue working parties and subsidiary bodies set up to examine co-operative programme possibilities if, within a reasonable time, there appeared to be little possibility of co-operative programmes being achieved."

\section{"Annex II}

Decision of the Governing Board on the Establishment of the Committee on Energy Research and Development

\section{THE GOVERNING BOARD}

and development;

Desiring to establish a body of adequate status to be responsible for energy research

\footnotetext{
1 At the 123rd Meeting of the IEA Governing Board on 20th March 1992, the name of this Committee was changed from the Committee on Energy Research and Development to Committee on Energy Research and Technology (CERT).
} 
Mindful of Article 57 of the I.E.P. Agreement, providing that the Standing Group on Long-Term Co-operation may report on any matter within the scope of Chapter VII of the Agreement;

Decided to establish a Committee on Energy Research and Development with the following terms of reference:

a) To submit to the Governing Board a strategy for energy research and development and to oversee the implementation of this strategy;

b) to ensure, through regular consultation and collaboration with the Standing Group on Long-Term Co-operation, a close co-ordination between the energy research and development strategy and other aspects of the Programme for Long-Term Co-operation of the Agency.

c) In the light of the preparation and surveillance of such a strategy, to review periodically national programmes of energy research and development.

d) Within such a strategy, and utilising the reviews of national programmes, to identify opportunities for collaboration between participating Countries, and to promote such collaboration.

e) To continue the promotion and implementation of co-operation on energy research and development as decided by the Governing Board on 21st November 1975.

f) To report to the Governing Board as appropriate, but not less frequently than once a year, on the above subjects in conjunction with the Standing Group on Long-Term Co-operation.

g) To carry out such other functions as may from time to time be delegated to it by the Governing Board." 


\section{WORKING PARTY ON ENERGY END-USE TECHNOLOGIES}

Chair:

Vice-Chairs:

Members:

Participation in the work:

Date of creation:

Duration:
Mr. Peter Cunz

Mr. Hamid Mohamed

Mr. Hans Otto Haaland

Mr. Egil Ofverholm

Mr. Peter Finckh

All IEA Member countries

European Commission

Pursuant to Supplementary Protocol $n^{\circ}$. 1 to the Convention on the OECD

1st April 1982

Unspecified
(Switzerland)

(Canada)

(Norway)

(Sweden)

(Switzerland)

Mandate: - Summary Record of the 23rd meeting of the Committee on Energy Research and Development, 12-13 October 1981 [IEA/CRD/M(81)11 and IEA/CRD(81)13]; re-endorsed at the 31st, 43rd and 52nd meetings 19-20 June 1984, 21-22 June 1988 and 1-2 July 1991 [IEA/CRD/M(84)10; -- IEA/CRD/M(88)5 --IEA/CRD/M(91)7]

- Summary Records of the 7th, 17th, 29th and 36th meetings of the Committee on Energy Research and Technology 21-22 June 1994, 4-5 November 1997, 26-27 June 2001, and 5-6 November 2003 [IEA/CERT/M(94)2 -- IEA/CERT(97)31 -IEA/CERT/M(97)3 -- IEA/CERT(2001)28/REV1 -- IEA/CERT/M(2001)3 -IEA/CERT(2003)35 -- IEA/CERT/M(2003)3]

- This Working Party continues under the Committee on Energy Research and Technology

\section{Extract from document [IEA/CRD/M(81)11]}

"3. The mandate of the Working Parties would be reviewed by CRD every three years."

\section{Extract from document [IEA/CERT(2003)35]}

“1. Objective

The Working Party on Energy End-Use Technologies (EUWP) shall provide advice to the IEA Committee on Energy Research and Technology (CERT) and other IEA bodies on trends and policies relating to energy end-use technologies; guided by the IEA's Shared Goals of energy security, environmental sustainability and economic growth, it shall also support and facilitate cooperation among Member countries in research, development, demonstration and deployment of energy end-use technologies and, as appropriate, shall seek to expand collaboration with nonMember countries.

2. Functions

The functions of the EUWP are to: 
(1) Identify high-priority areas in which to develop or expand international collaboration in research, development, demonstration and deployment;

(2) Periodically review and assess the effectiveness of such collaboration with a view to identifying gaps and overlaps in existing coverage, renewing existing programmes and stimulating new collaborative activities, discontinuing or expanding activities, and encouraging closer collaboration with industry; and

(3) Identify those technologies, processes and systems in end-use sectors that can effectively help to achieve energy security, environmental and economic goals of Member countries and, where appropriate, contribute to international collaboration in the development and market deployment of such technologies. 
Chair:

Vice-Chairs:

Members:

Participation in the work:

Date of creation:

Duration:
Ms. Barbara McKee

Mr. Jostein Dahl-Karlsen

Mr. Brian Morris

All IEA Member countries

European Commission

Pursuant to Supplementary Protocol $n^{\circ}$. 1 to the Convention on the $O E C D$

13th October 1981

Unspecified
(United States)

(Norway)

(United Kingdom)

Mandate: - Summary Record of the 23rd meeting of the Committee on Energy Research and Development 12-13 October 1981 [IEA/CRD/M(81)11 and IEA/CRD(81)13]; re-endorsed at the 31st, 43rd and 52nd meetings 19-20 June 1984, 21-22 June 1988 and 1-2 July 1991 [IEA/CRD/M(84)10 -- IEA/CRD/M(88)5 -- IEA/CRD/M(91)7]

- Summary Records of the 7th, 17th, 29th and 36th meetings of the Committee on Energy Research and Technology 21-22 June 1994, 4-5 November 1997, 26-27 June 2001, and 5-6 November 2003 [IEA/CERT/M(94)2 -- IEA/CERT(97)31 -IEA/CERT/M(97)3 -- IEA/CERT(2001)28/REV1 -- IEA/CERT/M(2001)3 -IEA/CERT(2003)35 -- IEA/CERT/M(2003)3]

- This Working Party continues under the Committee on Energy Research and Technology

\section{Extract from document [IEA/CRD/M(81)11]}

"3. The mandate of the Working Parties would be reviewed by CRD every three years."

\section{Extract from document [IEA/CERT(2003)35]}

"1. Objective

The Working Party on Fossil Fuels (WPFF) shall, within the framework of the IEA Shared Goals, provide advice to the IEA on:

- $\quad$ fossil fuel technology-related policies, trends, projects, programmes;

- $\quad$ strategies which address priority environmental protection and energy security interests, including adequate, flexible, and reliable supply of power and electrical service of Member countries; and

- $\quad$ carry out activities to meet those needs through international co-operation and collaboration facilitated by the IEA.

2. Functions

The functions of the WPFF are: 
(1) Identification of the fossil fuel technology-related priority interests, including electric power technologies, common to IEA Member countries, including their integration with non-fossil fuel technologies;

(2) Promotion of collaborative RD\&D and technology deployment, as well as electric power production, transmission, distribution and end-use efficiency, by arranging studies and technology information exchange on topics of common interest, conferences, workshops and other activities;

(3) Technology co-operation with non-Member countries;

(4) Initiation, evaluation and review on a periodic basis of Implementing Agreements and other international collaborative activities;

(5) Co-ordination with other sectoral bodies of the IEA which conduct fossil fuel-related studies, information exchanges and meetings relevant to the goals of the WPFF;

(6) Review and evaluation of, and participation in, fossil fuel-related activities conducted by IEA bodies. 


\section{WORKING PARTY ON RENEWABLE ENERGY TECHNOLOGIES}

Chair:

Vice-Chairs:

Members:

Participation in the work:

Date of creation:

Duration:
Mr. Roberto Vigotti

Mr. Norbert Gorissen

Mr. Christophe Jurczak

Mr. Gilles Mercier

All IEA Member countries

European Commission

Pursuant to Supplementary Protocol $n^{\circ}$. 1 to the Convention on the $O E C D$

1st April 1982

Unspecified
(Italy)

(Germany)

(France)

(Canada)

Mandate: - Summary Record of the 23rd meeting of the Committee on Energy Research and Development 12-13 October 1981 [IEA/CRD/M(81)11 and IEA/CRD(81)13]; re-endorsed at the 31st, 43rd and 53rd meetings 19-20 June 1984, 21-22 June 1988 and 26-27 November 1991 [IEA/CRD/M(84)10 -- IEA/CRD/M(88)5 -IEA/CRD/M(91)9]

- Summary Records of the 7th, 17th, 29th and 36th meetings of the Committee on Energy Research and Technology 21-22 June 1994, 4-5 November 1997, 26-27 June 2001, and 5-6 November 2003 [IEA/CERT/M(94)2 -- IEA/CERT(97)31 -IEA/CERT/M(97)3 -- IEA/CERT(2001)28/REV1 -- IEA/CERT/M(2001)3 -IEA/CERT(2003)35 -- IEA/CERT/M(2003)3]

- This Working Party continues under the Committee on Energy Research and Technology

\section{Extract from document [IEA/CRD/M(81)11]}

"3. The mandate of the Working Parties would be reviewed by CRD every three years."

\section{Extract from document [IEA/CERT(2003)35]}

"1. Objective

The Working Party on Renewable Energy (REWP) shall provide advice to the IEA Committee on Energy Research and Technology (CERT) and other IEA bodies on: renewable energy sources and technologies, related policies, trends, projects, programmes and strategies which address priority energy security, diversity and environmental interests of Member countries, and activities to meet those needs through international co-operation and collaboration facilitated by the IEA process.

\section{Functions}

Having regard to the Shared Goals, adopted by IEA Ministers at their 4th June 1993 meeting in Paris, and to the co-operation in long-term research, demonstration and deployment of renewable energy technologies, and to the encouragement to expand clean energy markets, 
including renewables, adopted by IEA Ministers at their $25^{\text {th }}$ May 1999 meeting in Paris, the Working Party shall:

- Provide advice and suggestions on the promotion of collaborative R\&D and demonstration, removal of institutional barriers, policies and other means of accelerating market deployment, and identification and mitigation of environmental impacts;

- $\quad$ Continue strong oversight of and support for the REWP Implementing Agreements to help ensure the effectiveness of their programs for developing and deploying renewable energy technologies;

- Continue and strengthen its role as a primary energy source of information and analysis on renewable energy technologies for IEA committees and offices, and non-IEA stakeholders;

- Liaison with selected non-Member countries, and other institutions and entities whose functions address the area of renewable energy technology, with a view to promote and structure international collaboration. 


\section{FUSION POWER CO-ORDINATING COMMITTEE (FUSION WORKING PARTY)}

Chair:

Vice-Chairs:

Members:

Participation in the work:

Date of creation:

Duration:
Mr. M. Seki

Mr. F. Gnesotto

Mr. Erol Oktay

All IEA Member countries

European Commission

Pursuant to Supplementary Protocol $n^{\circ} .1$ to the Convention on the $O E C D$

28th June 1975

Unspecified
(Japan)

(Italy)

(United States)

Mandate: - Conclusions of the 12th meeting of the Governing Board on 28th July 1975 [IEA/GB(75)54]

- Summary Record of the 23rd meeting of the Committee on Energy Research and Development 12-13 October 1981 [IEA/CRD/M(81)11 and IEA/CRD(81)13]; re-endorsed at 31st, 43rd and 52nd meetings 19-20 June 1984, 21-22 June 1988 and 1-2 July 1991 [IEA/CRD/M(84)10 -- IEA/CRD/M(88)5 -- IEA/CRD/M(91)7]

- Summary Records of the 9th, 19th and 29th meetings of the Committee on Energy Research and Technology 14-15 March 1995, 22-23 June 1998 and 26-27 June 2001 [IEA/CERT(95)7 -- IEA/CERT/M(95)1 -- IEA/CERT(98)37 -- IEA/CERT/M(98)2 -- IEA/CERT(2001)28/REV1 -- IEA/CERT/M(2001)3]

- This Working Party continues under the Committee on Energy Research and Technology

\section{Extract from document [IEA/CRD/M(81)11]}

"3. The mandate of the Working Parties would be reviewed by CRD every three years."

\section{Extract from document [IEA/CERT(2001)28/REV1]}

"1. Objective

The programmatic objective of the Fusion Power Co-ordinating Committee (FPCC) is to benefit the nuclear fusion R\&D and technology applications activities of IEA Member and nonMember countries by promoting, initiating and co-ordinating collaboration among the nuclear fusion programmes using Implementing Agreements and other mechanisms provided by the IEA.

The institutional objective of the FPCC is to provide advice to, and support the activities of, the IEA Committee on Energy Research and Technology (CERT) and other IEA bodies in the area of nuclear fusion power to pursue the IEA's goals, in particular, to promote energy security and respond to environmental concerns.

2.

Functions 
In pursuing these objectives, the FPCC will be guided by the goals of the IEA, in particular with respect to energy security and environmental concerns. The functions of the FPCC are the following:

(1) Identify those areas of nuclear fusion R\&D and technology applications where international co-operation, using IEA collaborative mechanisms, is particularly worthwhile; initiate collaboration in these areas by promoting Implementing Agreements and other mechanisms that provide for joint work and full exchange of information;

(2) Promote, co-ordinate and review the international collaborative activities performed under Implementing Agreements, including non-Member country participation, by considering programmes and priorities of participants in fusion R\&D and technology applications activities, and giving Executive Committees advice and guidance;

(3) Provide the CERT with evaluation and review of the activities under Implementing Agreements and other international collaboration on a periodical basis;

(4) Inform and advise the CERT as requested on progress in international nuclear fusion R\&D and technology applications;

(5) Liaise with other Working Parties and Standing Bodies of the IEA which conduct related studies, information exchanges and meetings as appropriate; liaise with other institutions and entities, including the IAEA. 


\section{COMMITTEE ON BUDGET AND EXPENDITURE}

Chair:

Vice-Chairs:

Members:

Participation in the work:

Date of creation:

Duration:
Mr. Ross Glasgow

Mr. Dominique Paravicini

Mr. Patrick Van Gheel

All IEA Member countries

European Commission

Pursuant to Supplementary Protocol No. 1 to the Convention on the OECD and IEA/GB(74)9 (1st Revision)

18th November 1974

Unspecified
(Canada)

(Switzerland)

(Belgium)

Mandate: $\quad$ Conclusions of the first meeting of the Governing Board on 18th-19th November 1974 [IEA/GB(74)9(1st Revision)]

\section{Extract from document [IEA/GB(74)9(1st Revision), Item 12]}

"THE GOVERNING BOARD

a) Established a Committee on Budget and Expenditure to advise the Governing Board on financial administration of the Agency and to give its opinion on the Annual and other budget proposals submitted to the Governing Board.

b) Instructed the Committee on Budget and Expenditure to convene its first session no later than 9th and 10th December 1974." 


\section{COMMITTEE ON NON-MEMBER COUNTRIES}

Chair:

Vice-Chairs:

Members:

Participation in the work:

Date of creation:

Duration:
Mr. Hartmut Schneider

Mr. Bob Pegler

Mr. Stephen Gallogly

All IEA Member countries

European Commission

Pursuant to Supplementary Protocol No. 1 to the Convention on the $O E C D$

27th June 1977

Unspecified
(Germany)

(Australia)

(United States)

Mandate: - Conclusions of the Thirtieth Meeting of the Governing Board on 27th-28th June 1977 [IEA/GB(77)33]

- Conclusions of the 124th Meeting of the Governing Board on 11th May 1992 [IEA/GB(92)25]

\section{Extract from document [IEA/GB(77)33, Item 8 a)]}

\section{"THE GOVERNING BOARD}

a) Established an informal Ad Hoc Group on International Energy Relations ... to report to the Governing Board on international energy relations and to carry out such other functions as may be assigned to it by the Governing Board."

\section{Extract from document [IEA/GB(92)25, Item 5]}

\section{"THE GOVERNING BOARD}

a) Noted the Note by the Secretariat entitled "Participation by non-Member Countries in the Activities of the IEA" [IEA/GB(92)18] and the statement of the Executive Director, appended [to document IEA/GB(92)25].

b) Adopted the general policy guidance and the specific guidelines for areas of co-operation with non-Member countries as set forth in Parts II and III of IEA/GB(92)18/FINAL.

c) Noted, with respect to Part IV of IEA/GB(92)18/FINAL, that the role of the Committee on non-Member Countries needs to be further developed over time, bearing in mind that specific areas of co-operation with non-Member countries must be integrated into the work of other Standing Groups." 


\title{
INDUSTRY ADVISORY BOARD
}

Chair:

Secretary:

Members:

Date of creation:

Duration:
Mr. Tom Eizember

Ms. T. Fariello

BHP Petroleum Pty. Ltd.

bp Oil International Ltd.

Chevron Texaco Corporation

Conoco Phillips Incorporated

ENI

ExxonMobil Corporation

Fortum Oil and Gas Oy

Japan Petroleum Development Association

Mabanaft Deutschland BmbH

Marathon-Ashland Petroleum

Mineralölwirtschafts-verband

MOLTRADE-Mineralimpex

OMV A.G.

Petro-Canada Products Ltd.

Petroleum Association of Japan

Shell International Petroleum Co. Ltd.

Statoil

Total

5th February 1975

Unspecified
(Industry Advisory Board)

(ExxonMobil)

\begin{abstract}
Mandate: - Article 19, Paragraph 7 of the Agreement on an International Energy Program signed in Paris on 18th November 1974 deposited with the Government of Belgium

- Emergency Management Manual, adopted by the Governing Board at its 21st Meeting on 20th-21st May 1976, updated and adopted by the Governing Board at its 38th Meeting on 25th October 1994 [IEA/GB(94)40, Annex I]
\end{abstract}

\section{Article 19, Paragraph 7 of the Agreement on an International Energy Program}

"7. An international advisory board from the oil industry shall be convened, not later than the activation of emergency measures to assist the Agency in ensuring the effective operation of such measures."

\section{Extract from document [IEA/GB(94)40, Annex I]}

"Section 4

\subsubsection{Industry Advisory Board (IAB)}

The IAB has been established by the IEA to provide advice and consultation on emergency response issues and oil supply/demand questions related to them. In the event of the activation of the IEP emergency measures, the IAB will be responsible, primarily through its ad hoc 
group ISAG, for advising on the practical execution of the emergency measures under the direct supervision of the IEA.

The IAB membership is drawn from the group of Reporting Companies. The IAB meets periodically or when convened by the IEA.

The IAB has been established to:

- be available permanently for consultation on issues of emergency response;

- develop and staff ISAG which would be available to work within the IEA in an emergency or a test;

- be available for consultation with the IEA, if an emergency appears possible, on the evolving supply situation, and assist in determining the extent of any "shortfall" in supplies;

- advise the IEA on general steps necessary to minimise the disruptive effects of an interruption in oil supplies;

- $\quad$ provide expertise in oil supply and logistics as required;

- advise the IEA on technical procedures to be followed in measuring individual countries' stocks;

- advise on information systems and sources of data;

- advise the IEA on timetables and procedures to test emergency response systems;

- be available for consultation with and to advise the IEA on any other issues related to the emergency procedures.

The IAB participates in or establishes working groups to study and make recommendations to the IEA on specific questions on which IAB advice would assist IEA emergency response procedures. the IEA."

The IAB will keep the Reporting Companies generally informed on its discussions with 
INDUSTRY SUPPLY ADVISORY GROUP (ISAG)

$\begin{array}{lll}\text { Manager: } & \text { Mr. Giuseppe Gasparini } & (\text { ENI) } \\ \text { Deputy Manager: } & \ldots & (\ldots) \\ \text { Members: } & \text { Mr. Tony Yates } & \text { (BP) } \\ & \text { Mr. Klaus Dahlmann } & \text { (BP Refining \& Petrochemicals) } \\ & \text { Mr. Michel Cussac } & \text { (Elf Trading SA) } \\ \text { Mr. Pietro Rossi } & \text { (ENI) } \\ & \text { Mr. Thondiyil Premkumar } & \text { (ExxonMobil) } \\ & \text { Mr. Makoto Seto } & \text { (Nippon Oil Corporation) } \\ & \text { Ms. C. Hecht } & \text { (OMV A.G.) } \\ & \text { Ms. Diana Hildebrant } & \text { (Petro-Canada) } \\ & \text { Mr. Ikuo Hamabayashi } & \text { (Petroleum Association of } \\ & \text { Mr. John De Cuba } & \text { Japan) } \\ & \text { Ms. Mato Tonstad } & \text { (Shell Int. Trading \& Shipping) } \\ & \text { Mr. Tibor Vuk } & \text { (Statoil) } \\ & \text { (Hungary) } \\ \text { Mr. Tony Yates } & \text { (BP) } \\ \text { Mr. Klaus Dahlmann } & \text { (BP Refining \& Petrochemicals) } \\ \text { Ad hoc Observer: } & \text { 20th May 1976 } & \\ \text { Date of creation: } & \text { Unspecified } & \end{array}$

Mandate: Emergency Management Manual, adopted by the Governing Board at its 21st meeting on 20th-21st May 1976, updated and adopted by the Governing Board at its 38th Meeting on 25th October 1994 [IEA/GB(94)40, Annex I]

\section{Extract from document [IEA/GB(94)40, Annex I]}

"Section 4

\subsubsection{Industry Supply Advisory Group (ISAG)}

The ISAG is an ad hoc group of the IAB made up of representatives from the Reporting Companies and is the main instrument of industry participation in the operation of the IEP emergency measures. ISAG is activated in the event of an emergency or test to participate in a combined Secretariat/Industry Emergency Operations Team (EOT). When activated for test or emergency purposes, ISAG will:

- $\quad$ provide industry supply expertise to the IEA;

- assist in monitoring the evolving supply situation and evaluate implications of the regional and individual country imbalances calculated by the IEA;

- establish balancing requirements guided by the Allocation Co-ordinator;

- communicate the guidance of the IEA to RCs to ensure the efficient operation of allocation; 
- assist the Allocation Co-ordinator in co-ordinating voluntary offer activities of RCs/RCAs and NESOs (for NRCs) during balancing activities;

- assist the Allocation Co-ordinator in evaluating voluntary offers and the need for further action.

In the performance of the responsibilities listed above, ISAG members will act solely under the supervision and guidance of the Allocation Co-ordinator and the ISAG Manager. ISAG members will adhere to all applicable anti-trust rules, regulations and clearances. They will also adhere to pertinent rules prohibiting dissemination of confidential information gathered for the IEA/ISAG activities and will only make such information available to others on a need-to-know basis and in accordance with IEA rules. ISAG members will not disclose confidential information to their own companies except as required in order to perform their functions as ISAG members.

Outside of tests and the activation of IEP emergency measures, the ISAG Manager and Deputy Manager will co-ordinate assistance to the IEA Secretariat for the improvement of emergency procedures and training directly related to the work of ISAG and the EOT." 


\section{COAL INDUSTRY ADVISORY BOARD}

Chair:

Deputy-Chair:

Vice-Chairs:

Bureau Members:

Ad hoc Observer:

Date of creation:

Duration:
Mr. Preston Chiaro

Mr. Steven F. Leer

Mr. Yoshihiko Nakagaki

Mr. J. Brett Harvey

Mr. Greg Boyce

Mr. Eric Ford

Mr. Matthais HARTUNG

Mr. Steve Lennon

Mr. David MURRAY

Mr. Jürgen Stadelhofer

Mr. Greg Boyce

Mr. Eric Ford

11th July 1979

Unspecified
(Rio Tinto plc, United Kingdom)

(Arch Coal Inc., USA)

(Electric Power Development Company, Japan)

(CONSOL Energy Inc., USA)

(Peabody Energy, USA)

(Anglo Coal Australia Pty Ltd. Australia)

(Germany)

(Eskom, South Africa)

(Australia)

(RAG Coal International AG, Germany)

(Peabody Energy, USA)

(Anglo Coal Australia Pty Ltd., Australia)

Mandate: Conclusions of the $44^{\text {th }}$ meeting of the Governing Board on $11^{\text {th }}$ July [IEA/GB(79)49] as amended on $3^{\text {rd }}$ April 2003.

\section{"THE GOVERNING BOARD}

i) Noting the continuing importance of coal now and in the future as a secure and low-cost source of energy in IEA Member countries and throughout the world;

ii) Noting its support for the IEA Coal Industry Advisory Board ("the CIAB") as a source of advice to IEA Member country governments, particularly in relation to the continued use of coal as a secure source of energy and on measures to mitigate the environmental impacts of its use; and

iii) Noting changed circumstances in energy markets reflected in energy policies of IEA Member countries since the establishment of the CIAB in July 1979;

DECIDES:

1. The CIAB, composed of individuals of high standing and active in coal-related enterprises, shall be a source of advice and suggestions to the Governing Board and to the Secretariat on matters related to coal production, transport, trade and utilisation. With the agreement of the Executive Director, the CIAB shall report to the Governing Board on developments 
and trends in coal production, transport, trade, and utilisation, and on any other matters requested by the Governing Board or the Executive Director.

2. The CIAB may consult with any other bodies and individuals considered appropriate by the $\mathrm{CIAB}$ and the Executive Director.

3. The CIAB shall carry out its functions on a broad, industry-wide basis without the disclosure of confidential or proprietary data of any company or other entity.

4. The CIAB shall consist of members from IEA Member and IEA Non-member countries approved by the Governing Board on the recommendation of the Executive Director. Members may be proposed by national governments for recommendation to the Governing Board if they notify the Executive Director of their intention within one month of being advised by the Secretariat of a new position or a vacancy. If the national government does not indicate its intention within one month, then the Executive Director may recommend a nomination to the Governing Board. Members shall be encouraged to appoint associates to assist them in their work but associates may not represent members at meetings of the CIAB except with the approval of the Executive Director.

5. The term of membership shall be three years and may be renewed by the Executive Director. In consultation with the appropriate national government, the Executive Director also may cancel the term of membership, taking into account the contribution of the member to the work of the CIAB.

6. The CIAB may elect a Chairman and other officers as it sees fit.

7. The CIAB may organise its activities as it considers appropriate, subject to the approval of the Executive Director. The CIAB and the Executive Director may agree to publish and otherwise disseminate the views of the CIAB." 
OECD NUCLEAR ENERGY AGENCY (NEA) 

Chair:

Vice-Chairs:

Members:

Date of creation:

Duration:
Mr. Jussi Manninen

Ms. Sylvana Guindon

Mr. Walter Sandtner

Mr. József Rónaky

Mr. Kenji Seyama

Australia
Austria
Belgium
Canada
Czech Republic
Denmark
Finland
France
Germany
Greece
Hungary
Iceland
Ireland
Italy

Australia

Austria

Belgium

Canada

Czech Republic

Finland

France

Germany

Hungary

Iceland

Ireland
(Finland)

(Canada)

(Germany)

(Hungary)

(Japan)

Japan

Korea

Luxembourg

Mexico

Netherlands

Norway

Portugal

Slovak Republic

Spain

Sweden

Switzerland

Turkey

United Kingdom

United States

Participation in the work: European Commission Under the NEA Statute

International Atomic Energy Agency (IAEA)

By agreement

18th July 1956 (maintained on 30th September 1961)

Unspecified

Mandate: - Decision of the Council Establishing a European Nuclear Energy Agency, as amended [Statute of the Agency] [C(57)255, paragraph 95 of the Report by the Preparatory Committee, C(77)183(Final), C(92)220 and C(95)157/FINAL]

\section{Extract from the Decision of the Council [C(77)183(Final)]}

\section{"THE COUNCIL,}

Having regard to the Convention on the Organisation for Economic Co operation and Development of 14th December 1960 and in particular Articles 5(a), 9 and 20 thereof; Annex thereto;

Having regard to the Rules of Procedure of the Organisation and to paragraph 16 of the

Having regard to the Decision of the OEEC Council of 17th December 1957 establishing a European Nuclear Energy Agency, approved by the Council on 30th September 1961 [C(57)255, $\mathrm{OECD} / \mathrm{C}(61) 5]$ 
Having regard to the Decision of the Council of 23rd February 1965 relating to the Association of the Government of Japan with the Work of the European Nuclear Energy Agency [C(65)17(Final)];

Having regard to the Decision of the Council of 17th May 1972 relating to the Participation of the Government of Japan in the European Nuclear Energy Agency and Amending the Statute of the said Agency [C(72)106(Final)], which Decision altered the name of the said Agency to "OECD Nuclear Energy Agency";

Having regard to the Decisions of the Council of 9th May 1975 and 12th October 1976 relating respectively to the participation of the Governments of Canada and the United States of America in the OECD Nuclear Energy Agency and amending the Statute of the said Agency [C(75)68(Final) and C(76)172(Final)];

Having regard to the draft proposals concerning the modernisation of the Statute of the said Agency which were approved by the Steering Committee for Nuclear Energy on 26th October 1977 [NE(77)17, NE/M(77)2].

\section{DECIDES:}

I. The following amendments shall be made to the Statute of the OECD Nuclear Energy Agency.

$[\ldots]$

III. Paragraph 16 of the Annex to the Rules of Procedure of the Organisation shall be amended to read as follows:

"OECD Nuclear Energy Agency: Its terms of reference are defined in the Decision of the Council C(57)255, with the amendment set out in paragraph 95 of the Report of the Preparatory Committee and in the Decision of the Council C(77)183(Final)."

\section{Annex I}

Statute of the OECD Nuclear Energy Agency

As amended by the Decisions of the Council [C(77)183(Final), C(92)220 and C(95)157/FINAL]

\section{PART I}

Article 1

a) There is hereby established within the framework of the Organisation an OECD Nuclear Energy Agency (hereinafter referred to as the "Agency").

b) Taking due account of the public interest and mindful of the need to prevent the proliferation of nuclear explosive devices, the purpose of the Agency shall be to further the development of the production and uses of nuclear energy, including applications of ionizing radiations, for peaceful purposes by the participating countries, through co operation between those countries and a harmonization of measures taken at the national level.

\section{Article 2}

The tasks assigned to the Agency shall be carried out, under the authority of the Council, by the Steering Committee for Nuclear Energy (hereinafter referred to as the "Steering Committee"), by the bodies which the latter has established in conformity with the provisions set forth below to assist it in its work or perform tasks of common interest to a group of countries, and by the Secretariat of the Agency which shall form part of the Secretariat of the Organisation.

Article 3 
The Steering Committee shall be competent to deal with any question relevant to the purpose of the Agency under conditions resulting from the provisions set forth below and from other applicable decisions of the Council.

\section{Article 4}

a) The Agency shall promote technical and economic studies and undertake consultations on the programme and projects of participating countries relating to the development of research and industry in the field of the production and uses of nuclear energy for peaceful purposes, in collaboration with other bodies of the Organisation in matters falling within their competence.

b) To this end, the programmes and projects shall be examined by the Steering Committee according to a procedure to be laid down by it.

\section{Article 5}

a) The Agency shall, where appropriate, promote the formation of joint undertakings for the production and uses of nuclear energy for peaceful purposes, endeavouring to secure the participation of the greatest possible number of countries.

b) If a group of participating countries declares its intention to set up a joint undertaking, the countries concerned may agree to undertake the necessary work for this purpose among themselves within the Organisation at their own cost, whatever the position adopted by other participating countries. The Working Parties or Study Groups set up in accordance with this paragraph shall keep the Steering Committee informed of their progress and report to it on their conclusions.

c) When joint undertakings have been established on the initiative or with the assistance of the Agency.

i) The Steering Committee - or a Restricted Group of the Steering Committee composed of representatives of the countries which take part in the undertaking -shall exercise the functions assigned to it by the agreements concluded for the establishment of the undertakings concerned;

ii) The joint undertakings shall report each year to the Steering Committee and, where appropriate, to a Restricted Group of the Steering Committee on the state of their affairs and their development;

iii) The Steering Committee shall consider such problems of general interest as may be raised by the operation of joint undertakings, with a view to proposing any necessary measures to the Governments;

iv) The agreements concluded for the creation of joint undertakings should contain provisions under which participating countries or groups of participating countries not taking part in joint undertakings might subsequently accede to them or benefit from the results of their activities.

\section{Article 6}

a) Given the need to prevent the proliferation of nuclear explosive devices, a security control shall be established with a view to ensuring that the operation of joint undertakings and the materials, equipment and services made available by the Agency or under its supervision shall be used solely for peaceful purposes.

b) The security control may be applied, at the request of the parties, to any bilateral or multilateral agreement, or, at the request of a participating country, to any of that country's activities in the field of nuclear energy.

c) The organisation of this control and the functions of the Agency relating to its exercise shall be the subject of a special Convention on security control.

Article 7 
a) The Agency shall encourage the development of research into the production and uses of nuclear energy for peaceful purposes in participating countries.

b) To this end, it shall, where appropriate, promote the conclusion of agreements for the joint use of research installations built by participating countries and, in accordance with the conditions set forth in Article 5 above, the creation of joint research establishments.

c) Agency shall encourage the exchange of scientific and technical information related to its purposes between participating countries.

Article 8

a) The Agency shall:

i) Contribute to the promotion, by the responsible national authorities, of the protection of workers and the public against the hazards of ionizing radiations and of the preservation of the environment;

ii) Contribute to the promotion of the safety of nuclear installations and materials by the responsible national authorities;

iii) Contribute to the promotion of a system for third party liability and insurance with respect to nuclear damage;

iv) Encourage measures to ensure the most efficient use of patented inventions in the field of nuclear energy;

v) So far as may be consistent with Article $1 \mathrm{~b}$ ) above, contribute to the elimination of obstacles to international trade or to development of the nuclear industry;

vi) Contribute to the dissemination of information which may be freely distributed on the peaceful uses of nuclear energy, in particular on the safety and regulation of nuclear activities as well as on the physical protection of nuclear installations and materials.

b) For the purpose of the above mentioned objectives, the Steering Committee shall:

i) Submit to the participating countries recommendations or common rules to serve as a basis for harmonizing national laws and regulations;

ii) Encourage the establishment between participating countries of joint services necessary, in particular, for the protection of public health and the prevention of accidents in the nuclear industry.

c) The Agency shall undertake its activities referred to in paragraphs a) and b) above, as far as possible in collaboration with the International Atomic Energy Agency an the Commission of the European Communities.

\section{PART II}

Article 9

The Steering Committee shall be composed of representatives of all Governments which participate in the present Decision.

\section{Article 10}

a) The Steering Committee shall designate each year a Chairman and Vice Chairmen from among its members. It shall adopt its own Rules of Procedure.

b) The Steering Committee may give its advice, in particular, in the form of recommendations, to participating countries on any question within its competence.

c) Whenever it is necessary to take decisions which are binding on Governments and which exceed the powers specially conferred on the Steering Committee, the latter shall submit proposals to the Council to this end. 
d) The Steering Committee shall report each year to the Council on the execution of its duties and on the situation and prospects of the nuclear industry in participating countries.

\section{Article 11}

a) The reports and proposals prepared by the Steering Committee shall, when appropriate, call attention to the different attitudes adopted by the members.

b) The decisions, opinions or recommendations of the Steering Committee shall be adopted by mutual agreement of those of its members present and voting.

c) However, decisions of the Steering Committee which relate to the adoption of the agenda, the undertaking of studies, the establishment of Working Parties and the submission of questionnaires to participating countries, shall be adopted by a majority of the members of the Steering Committee present.

d) Decisions which are binding on Governments and which are taken by the Steering Committee within the powers conferred upon it shall commit only those countries which have accepted them.

\section{Article 12}

a) The Steering Committee may establish such Commissions and Working Parties as it may consider necessary to assist it in the performance of its duties and entrust them with the execution of any task relevant to the purpose of the Agency.

b) Restricted bodies may be established to study questions or execute functions of interest to a group of participating countries, in accordance with the conditions set forth in Article 5 above or in a decision of the Council. Special expenditure assignable to the work of these bodies, such as the cost of studies or the remuneration of experts, shall be chargeable to the countries concerned.

\section{Article 13}

a) The Steering Committee shall perform its duties in collaboration with the competent bodies of the Organisation.

b) The Steering Committee shall consult these bodies on questions which come within their competence. These bodies shall consult the Steering Committee on all questions relating to the production and uses of nuclear energy for peaceful purposes.

Article 14

a) The Steering Committee and its subsidiary bodies shall be assisted by the Secretariat of the Agency.

b) Expenditures relating to the working of the Agency shall be covered by the Budget of the Organisation. To this end, the Steering Committee shall prepare annual estimates of expenditure, which shall be submitted to the Council for approval.

c) Expenditure of the Agency which is subject to special financial rules shall be covered by separate budgetary provisions and countries which make no financial contributions to such expenses shall abstain when the relevant item in the Budget is approved.

Article 15

a) In the performance of its duties, the Steering Committee shall take account of the work done by other international Organisations concerned and may, subject to paragraphs $b$ ) and $c$ ) below, co operate with them.

b) The Steering Committee shall, in agreement with the Council, establish relations with international governmental Organisations concerned with nuclear energy questions. 
c) The Steering Committee may establish contact with international non governmental Organisations concerned, within the framework of decisions or arrangements approved by the Council.

\section{Article 16}

a) The provisions of the present Decision do not affect rights and obligations resulting from treaties previously entered into by Governments participating in the present Decision.

b) Since the present Decision does not affect the exercise of competences granted to the European Atomic Energy Community (EURATOM) by the Treaty entered into at Rome on 25th March 1957, the Agency shall establish with the said Community a close collaboration, details of which shall be determined by common agreement.

\section{Article 17} the present Decision.

a) Participating countries shall be countries the Governments of which participate in

b) Any Member country of the Organisation, the Government of which does not participate in the present Decision, may notify the Secretary General of its wish to do so and shall become a participant in the Decision upon approval of the Council on the recommendation of the Steering Committee.

c) Any other Government invited by the Organisation to participate in the present Decision may do so by addressing to the Secretary General an acceptance of that invitation. The Organisation may suspend or terminate that participation by giving one month's written notice of suspension or twelve months' written notice of termination to that Government.

d) Any Government participating in the present decision may terminate the application thereof to itself by giving twelve months' notice to that effect to the Secretary General.

\section{Article 18}

The provisions of Supplementary Protocol No. 1 to the Convention on the Organisation for Economic Co operation and Development shall apply to the representation of the European Atomic Energy Community (Euratom) in the Agency and in its Steering Committee as well as to the participation of the Commission of the European Communities in the work of the Agency and of its Steering Committee.

Article 19

The present Decision shall enter into force on 1st February 1958." 


\section{COMMITTEE ON THE SAFETY OF NUCLEAR INSTALLATIONS (CSNI)}

Chair:

Vice-Chairs:

Members:

Participation in the work:

Observers:

Date of creation:

Duration:
Mr. Lothar Hahn

Mr. Keijo Valtonen

Mr. Philippe Jamet

Mr. Kiyoharu Abe

Mr. Gustaf Lowenhielm

All NEA Member countries

European Commission

Under the NEA Statute

International Atomic Energy Agency (IAEA)

By agreement

Russian Federation

Slovenia

Union of the Electricity Industry (EURELECTRIC)
(Germany)

(Finland)

(France)

(Japan)

(Sweden)

1st February 1973

31st December 2009

\section{Extract from document [NEA/NE(2005)2]}

"The Committee on the Safety of Nuclear Installations (CSNI) shall be responsible for the activities of the Agency that support maintaining and advancing the scientific and technological knowledge base of the safety of nuclear installations. The Committee shall constitute a forum for the exchange of technical information and for collaboration between organisations, which can contribute, from their respective backgrounds in research, development and engineering, to its activities. It shall have regard to the exchange of information between Member countries and safety $R \& D$ programmes of various sizes in order to keep all Member countries involved in and abreast of developments in safety technology.

The Committee shall review operating experience and the state of knowledge on selected topics of nuclear safety technology and safety assessment. It shall initiate and conduct programmes identified by these reviews and assessments in order to overcome discrepancies, develop improvements and research consensus on technical issues of common interest. It shall promote the co-ordination of work in different Member countries that serve to maintain competence in nuclear safety matters, including the establishment of joint undertakings, and shall assist in the feedback of the results to participating organisations.

The Committee shall focus primarily on existing power reactors and other nuclear installations; it shall also consider the safety implications of scientific and technical developments of 
new reactor designs. Furthermore, it shall examine any other matters referred to it by the Steering Committee.

The Committee shall organise its own activities. It may sponsor specialist meetings and technical working groups to further its objectives. In implementing its programme, the Committee shall establish co-operative mechanisms with the Committee on Nuclear Regulatory Activities to work with that Committee on matters of common interest, avoiding unnecessary duplications. The Committee shall also co-operate with the Committee on Radiation Protection and Public Health, the Radioactive Waste Management Committee and the Nuclear Science Committee on matters of common interest." 


\section{CSNI PROGRAMME REVIEW GROUP (CSNI PRG)}

Chair:

Mr. Victor Teschendorff

(Germany)

Members:

Mr. Masashi Hirano

(Japan)

Permanent

Mr. Michel Reocreux

(France)

Permanent

Mr. Mark Cunningham

Permanent

Mr. Benoit de Boeck

Rotating

Mr. Andrew White

Rotating

Mr. Zdenek Kriz

Rotating

(United States)

(Belgium)

(Canada)

(Czech Republic)

Observer:

Mr. Jean-Marc Cavedon

(Switzerland)

Date of creation:

December 1999

Duration:

December 2006

Mandate : - The Strategic Plan for the Committee on the Safety of Nuclear Installations [NEA/CSNI/R(2000)3]

\section{Extract from document [NEA/CSNI/R(2000)3]}

"The Programme Review Group is to assist the CSNI Bureau to review proposals from the Working Groups, to ensure that proposals and reports have appropriate focus, and to enable the review of major reports in order to ensure high quality.

The main functions of the Programme Review Group are the following:

- Compile, and prioritise, a "CSNI List of Current Safety Issues" to be discussed and updated at the CSNI meetings.

- Review proposals from the CSNI Working Groups and make recommendations to the Bureau.

- Identify cross-cutting issues and propose projects to address them.

- Review, and if necessary, draft Technical Opinion Papers and Collective Opinion Statements.

- Review major CSNI Reports (i.e., State-of-the-Art Reports and documents of similar significance) and provide guidance and advice to the CSNI.

- Review the CSNI programme of work to identify key lessons and present a report at the CSNI meetings." 
WORKING GROUP ON RISK ASSESSMENT (WGRISK)

Chair:

Vice-Chairs:

Members:

Participation in the work:

Observer:

Date of creation:

Duration:
Mrs. Jeanne-Marie Lanore

Mr. Pieter de Gelder

Mr. Magiel F. Versteeg

Mr. Charles Shepherd

All NEA Member countries

European Commission

Under the NEA Statute

International Atomic Energy Agency (IAEA)

By agreement

International Co-operative Probalistic Risk Assessment (COOPRA)

By agreement

Union of the Electricity Industry (EURELECTRIC)

December 1999

12th October 2006
(France)

(Belgium)

(Netherlands)

(United Kingdom)

Mandate : - Meeting of the enlarged CSNI Bureau [SEN/SIN(81)31]

- Summary record of the 15th meeting of the Committee on Safety of the Nuclear Installations [SEN/SIN(87)68]

- Summary Record of the 26th Meeting of the Committee on the Safety of Nuclear Installations [NEA/SEN/SIN(99)1]

- Summary Record of the 28th Meeting of the Committee on the Safety of Nuclear Installations (CSNI) [NEA/SEN/SIN(2001)1]

- Summary Record of the 33rd Meeting of the Committee on the Safety of Nuclear Installations (CSNI) [NEA/SEN/SIN(2003)4]

\section{Extract from WGRisk Integrated Plan (2003)}

"The main mission of the Working Group on Risk Assessment (WGRisk) is to advance the understanding and utilisation of Probabilistic Safety Assessment (PSA) in ensuring continued safety of nuclear installations and in improving the effectiveness of regulatory practices in Member countries. In pursuing this goal, the Working Group shall recognise the different methodologies for identifying contributors to risk and assessing their importance. While the Working Group shall continue to focus on the more mature PSA methodologies for Level 1, Level 2, internal, external, shutdown, etc. It shall also consider the applicability and maturity of PSA methods for considering evolving issues such as human reliability, software reliability, ageing issues, etc., as appropriate.

The specific mandate should be as follows:

- The Working Group shall report to the Committee on the Safety of Nuclear Installations (CSNI) and assist that Committee with its work. The Working Group shall prepare an integrated plan for their activities consistent with the mandate as well as proposed CSNI safety issues, updated at regular intervals and CSNI directives. The programme of work of WGRisk will be approved by the CSNI. It shall also with the 
approval of the CSNI sponsor specialist meetings and workshops to further its objectives.

- The Working Group shall constitute a forum for exchange of information and experience of activities related to risk assessment in Member countries. WGRisk shall prepare Technical Opinion Papers on questions regarding the applicability of various aspects of risk assessment, results, insights and interactions with other analysis techniques to matters affecting nuclear safety or nuclear safety research. This shall include identifying and prioritising important regulatory issues requiring additional research.

- The Working Group shall prepare technical reviews (such as state-of-the-art reports, compilations of ongoing efforts and standard problems, as appropriate) of work in all phases of risk assessment where such reports are needed for further development and to assist the application of PSA. In doing so, care will be taken to avoid duplication of effort or scope with other Principal Working Groups, or with other international bodies.

- With prior approval of the CSNI, WGRisk shall collaborate with or assist the CSNI Programme Review Group, Working and Special Expert Groups and other NEA committees or other international organisations. This includes assistance to the Committee on Nuclear Regulatory Activities (CNRA)." 


\section{WORKING GROUP ON ANALYSIS AND MANAGEMENT OF ACCIDENTS (GAMA)}

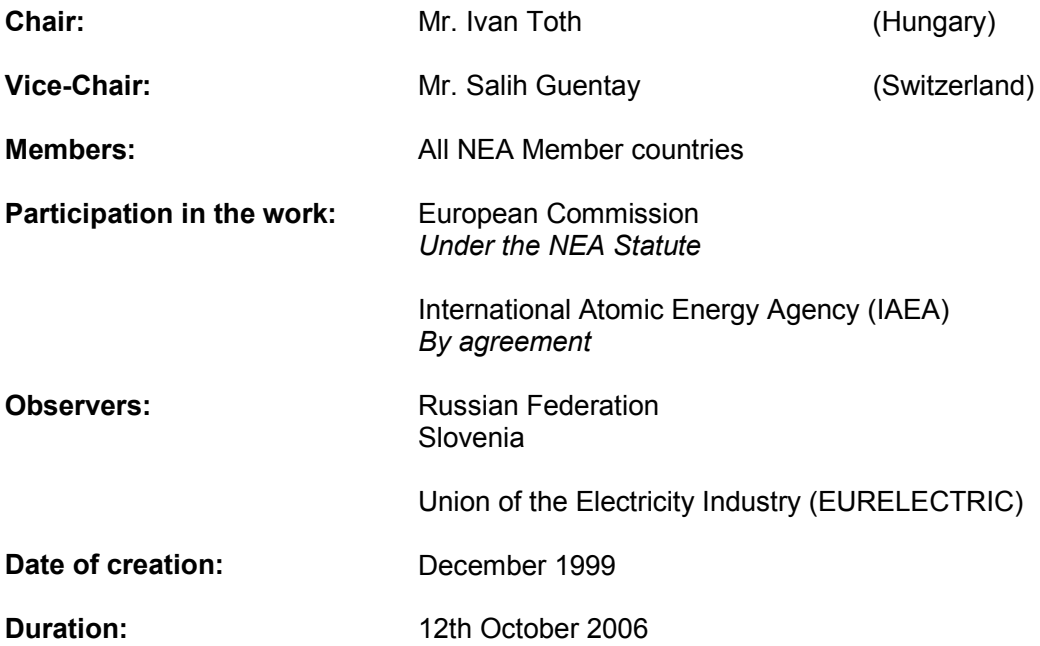

Mandate: $\quad$ - Summary Record of the 28th Meeting of the Committee on the Safety of Nuclear
Installations (CSNI) [NEA/SEN/SIN(2001)1]

\section{Extract from document [NEA/SEN/SIN(2001)1]}

"The main mission of the Working Group is to advance the current understanding of the physical processes and address the safety issues associated with the following areas:

a) The reactor coolant system and related safety and auxiliary systems;

b) In-vessel behaviour of degraded cores;

c) Containment behaviour;

d) Fission product release, transport and deposition.

Both current and advanced reactors are to be considered.

The specific mandate should be as follows:

1. The Working Group shall report to the Committee on the Safety of Nuclear Installations (CSNI), assist the Committee with its work and carry out the programme of work approved by the CSNI.

2. For the technical areas identified above, exchange information on national and international activities, promote co-operation and maintain an efficient network of experts.

3. For the areas identified above, identify research needs and priorities, including validation, enhancement and development of computer codes.

4. For the areas identified above, facilitate international convergence on safety issues and on accident management strategies. 
5. Provide a forum to address emerging relevant safety issues." 
Chair:

Mr. Nilesh Chokshi

(United States)

Vice-Chair:

Mr. Lars Skanberg

(Sweden)

Members:

All NEA Member countries

Participation in the work:

European Commission

Under the NEA Statute

The European Commission shares secretarial duties with the NEA.

International Atomic Energy Agency (IAEA)

By agreement

Date of creation:

December 1999

Duration:

12th October 2006

Mandate: - Summary Record of the 28th Meeting of the Committee on the Safety of Nuclear Installations (CSNI) [NEA/SEN/SIN(2001)1]

\section{Extract from document [NEA/SEN/SIN(2001)1]}

"The Working Group on Integrity of Components and Structures (IAGE) will have the general mandate of reflecting on the logical basis for the maintenance of integrity of components, systems and structures and to propose general principles on the optimal ways of dealing with challenges to integrity in particular from ageing. Specifically the mandate will be:

a) to exchange views on generic technical aspects of integrity and ageing of components and structures and review, as necessary, national and international programmes concentrating on research, operational aspects and regulation;

b) in the relevant technical areas, stimulate the establishment of new required research and recommend possible international co-operative projects;

c) to develop common technical position on specific integrity issues and to identify areas where further work is needed;

d) to discuss the potential impact of ageing and other challenges to integrity on the safety, regulation and operability of nuclear power plants.

The Working Group will have three Sub-Groups dealing with (i) Integrity of Metal Components and Structures, (ii) Concrete Structure Ageing, and (iii) Seismic Behaviour." 
SPECIAL EXPERT GROUP ON HUMAN AND ORGANISATIONAL FACTORS (SEGHOF)

Chair:

Vice-Chairs:

Members:

Participation in the work:

Observers:

Date of creation:

Duration:
Mr. Craig Reiersen

Mr. Yves van den Berghe

Mr. Benito Gil-Montes

All NEA Member countries

European Commission

Under the NEA statute

International Atomic Energy Agency (IAEA)

By agreement

Russian Federation

Halden Reactor Project

World Association of Nuclear Operators (WANO)

June 1999

December 2006
(United Kingdom)

(Belgium)

(Spain)

Mandate : $\quad$ Based on The Principles included in the Strategic Plan for the Committee on the
Safety of Nuclear Installations [NEA/CSNI/R(2000)3]

\section{Extract from document [NEA/CSNI/R(2000)3]}

"The main missions of this Special Expert Group are to improve the current understanding, to advance the utilisation of methodologies for human and organisational factor assessment and to address emerging safety issues, in order to maintain and improve the safety of nuclear installations in Member countries.

The group will report to the CSNI. The group will collaborate and respond to requests from the CNRA and other working groups of the CSNI especially the Working Group on Risk .Assessment and the Working Group on Operating Experience. The group will also establish arrangements with other international organisations operating in the same area for the purpose of identifying and creating synergy's and avoid duplication. The group may also consider relevant input and establish co-operation with non-nuclear organisations when appropriate.

The specific mandate should be as follows:

1. The group will constitute a forum for exchange of information and experience about safety relevant human and organisational issues in Member countries, promoting cooperation and maintaining an efficient network of experts.

2. The group will discuss in detail, compare and benchmark when appropriate programs in place and scientific methodologies currently applied in Member countries for assessing safety relevant human and organisational issues.

3. The group will identify and prioritise safety relevant issues and methodology gaps where further work and research in this area are needed. 
4. The group will compare international practice in Human and Organisational Factor assessment, and establish those methods, which seem most effective and worth to take further in a co-ordinated way.

5. The group will facilitate international convergence on safety issues related to human and organisational factors and develop common technical position on important specific issues (Technical Opinion Papers).

6. The group will sponsor specialist meeting and workshops to further its objectives and propose, if necessary, international co-operative projects.

7. The group should continue to work under the guidance of the five-year strategic plan formulated for the former Extended Task Force.

The guidance of the five-year strategic plan for research on Human Performance should be used in formulating tasks [NEA/CSNI/R(97)24]." 


\section{SPECIAL EXPERT GROUP ON FUEL SAFETY MARGINS (SEGFSM)}

Chair:

Vice-Chair:

Members:

Participation in the work:

Observers:

Date of creation:

Duration:
Mr. Wolfgang Wiesenack

Mr. Ralph Meyer

All NEA Member countries

European Commission

Under the NEA Statute

Russian Federation

Slovenia

December 1999

December 2006
(Norway)

(United States)

Mandate : - The Strategic Plan for the Committee on the Safety of Nuclear Installations [NEA/CSNI/R(2000)3]

\section{Extract from document [NEA/CSNI/R(2000)3]}

"The main mission of this Special Expert Group is to advance the current understanding and address safety issues related to fuel safety margins.

The specific mandate is as follows:

1. The Group will report to the Committee on the Safety of Nuclear Installations (CSNI), assist the Committee with its work and carry out the programme of work approved by the CSNI.

2. Assess the technical basis for current safety criteria and their applicability to high burnup (above $50 \mathrm{MWd} / \mathrm{kg}$ ) and to new fuel designs and materials. The assessment will focus on anticipated transients and postulated accident conditions. Information relevant to fuel performance under normal operating conditions will be considered only to the extent necessary to assess the safety behaviour.

3. Determine needs and priorities for future research programmes in the area of fuel safety behaviour, with the aim of understanding and adequately modelling key phenomena and of quantifying safety margins.

4. Review from the safety point of view, methodologies used for different core assessments as related to complex core configurations. Cores with different fuel assembly, designs and with MOX fuel are considered. Neutronic, thermal-hydraulic and materials aspects are considered as they relate to core safety assessment.

5. Provide a forum where safety relevant fuel issues emerging from operating experience and research work can be addressed and resolved in an effective manner." 


\section{COMMITTEE ON NUCLEAR REGULATORY ACTIVITIES (CNRA)}

Chair:

Vice-Chairs:

Members:

Participation in the work:

Observers:
Professor Jukka Laaksonen

Mr. Jean-Jacques Van Binnebeek

Mr. Alain Schmitt

Mr. Kiyoharu Abe

Mr. Mike Weightman

Mr. James Dyer
(Finland)

(Belgium)

(France)

(Japan)

(United Kingdom)

(United States)

All NEA Member countries

European Commission

Under the NEA Statute

International Atomic Energy Agency (IAEA)

By agreement

Russian Federation

Slovenia

Co-operative Forum for VVER Regulators

Date of creation:

3rd October 1989

Duration:

31st December 2009

\section{Extract from document [NEA/NE(2005)2]}

"The Committee on Nuclear Regulatory Activities (CNRA) shall be responsible for the programme of the Agency concerning the regulation, licensing and inspection of nuclear installations with regard to safety. The Committee shall constitute a forum for the exchange of information and experience among regulatory organisations. To the extent appropriate, the Committee shall review developments which could affect regulatory requirements with the objective of providing members with an understanding of the motivation for new regulatory requirements under consideration and an opportunity to offer suggestions that might improve them or avoid unwarranted disparities among Member countries. In particular it shall review current management strategies and safety management practices and operating experiences at nuclear facilities with a view to disseminating lessons learnt. The Committee shall promote co-operation among Member countries to use the feedback from experience to develop measures to improve safety, to enhance efficiency and effectiveness in the regulatory process and to maintain adequate infrastructure and competence in the nuclear safety field.

The Committee shall promote transparency of nuclear safety work and open public communication. The Committee shall maintain an oversight of all NEA work that may impinge on the development of effective and efficient regulation. 
The Committee shall focus primarily on existing power reactors and other nuclear installations; it may also consider the regulatory implications of new designs of power reactors and other types of nuclear installations. Furthermore it shall examine any other matters referred to it by the Steering Committee. The Committee shall collaborate with, and assist, as appropriate, other international organisations for co-operation among regulators and consider, upon request, issues raised by these organisations. The Committee shall organise its own activities. It may sponsor specialist meetings and working groups to further its objectives.

In implementing its programme the Committee shall establish co-operative mechanisms with the Committee on the Safety of Nuclear Installations to work with that Committee on matters of common interest, avoiding unnecessary duplications. The Committee shall also co-operate with the Committee on Radiation Protection and Public Health and the Radioactive Waste Management Committee on matters of common interest." 
WORKING GROUP ON INSPECTION PRACTICES (WGIP)

Chair:

Mr. Hartmut Klonk

(Germany)

Vice-Chairs:

Mr. Hiroyoshi Koizumi

(Japan)

Mr. Staffan Forsberg

(Sweden)

Members:

All NEA Member countries

Participation in the work:

European Commission

Under the NEA Statute

International Atomic Energy Agency (IAEA)

By agreement

Date of creation:

12th November 1990

Duration:

12th October 2006

Mandate: - Summary Record of the 2nd annual meeting of the Committee on Nuclear Regulatory Activities [NEA/SEN/NRA(90)7]

- Summary Record of the 3rd meeting of the Committee on Nuclear Regulatory Activities [NEA/SEN/NRA(92)1]

- Summary Record of the CNRA Special Issues Meeting on the Regulatory Aspects of Ageing Reactors [NEA/SEN/NRA(98)3]

\section{Extract from document [NEA/SEN/NRA(98)3]}

"1. The Working Group on Inspection Practices shall report to the Committee on Nuclear Regulatory Activities (CNRA) and assist that committee with its work concerning the inspection of nuclear installations with regard to safety.

2. The Working Group shall constitute a forum for the exchange of information and experience among regulatory organisations. In particular it shall review the effectiveness of inspection practices, disseminate lessons learned, and identify commendable inspection practices.

3. The Working Group shall focus on inspection practices by regulatory organisations and associated regulatory frameworks primarily on existing power reactors. It shall also examine other matters referred to it by the CNRA.

4. The Working Group shall agree its programme of work with the CNRA. It shall also with the agreement of the CNRA sponsor specialist meetings and workshops to further its objectives.

5. The Working Group with the prior agreement of the CNRA shall collaborate with, and assist as appropriate, other NEA Committees or other international organisations for co-operation among regulators." 


\title{
WORKING GROUP ON PUBLIC COMMUNICATION OF NUCLEAR REGULATORY ORGANISATIONS (WGPC)
}

\author{
Chair: \\ Mr. Anders Jörle \\ (Sweden) \\ Members: \\ All NEA Member countries \\ Participation in the work: \\ European Commission \\ Under the NEA Statute \\ International Atomic Energy Agency (IAEA) \\ By agreement \\ Observer: \\ Russian Federation \\ Date of creation: \\ 18th June 2001 \\ Duration: \\ 12th October 2006
}

$\begin{array}{ll}\text { Mandate : } & \text { - Summary Record of the 12th meeting of the Committee on Nuclear Regulatory } \\ & \text { Activities (CNRA) [NEA/SEN/NRA(2001)1] } \\ \text { - Summary Record of the 1st meeting of the Working Group on Public } \\ \text { Communication of Nuclear Regulatory Organisations (WGPC) } \\ \text { - } \text { - SumEA/SEN/NRA/WGPC(2001)2] } \\ \text { - Summary Record of the 2005 CNRA Summer meeting [NEA/SEN/NRA(2005)3] }\end{array}$

\section{Extract from document [NEA/SEN/NRA(2005)3]}

1. "The Working Group will share information, news, documents, data, views, ideas, and experiences in the field of public communication and stakeholder interaction. It will keep abreast of activities of a similar or related nature undertaken by other parts of the NEA.

2. The Working Group will review developments, progress, techniques, tools, procedures and achievements in the area of nuclear regulatory communication with the public and stakeholders. It will highlight lessons learned and good practices.

3. The Working Group will provide assistance to CNRA members, through technical notes and workshops, by addressing specific issues and practices.

4. The Working Group will co-operate, internally and externally, with other organisations in regulatory public communication and stakeholder interaction matters, in line with NEA policy." 


\section{WORKING GROUP ON OPERATING EXPERIENCES (WGOE)}

Chair:

Vice-Chairs:

Members:

Participation in the work:

Observers:
Mr. André Vandewalle

Mr. Frederik W. van Iddekinge

Mr. George Lanik

All NEA Member countries

European Commission

Under the NEA Statute

International Atomic Energy Agency (IAEA)

By agreement

\section{Russian Federation \\ Slovenia}

Union of the Electricity Industry (EURELECTRIC)

World Association of Nuclear Operators (WANO)
(Belgium)

(Netherlands)

(United States)
Date of creation:

Duration:
July 2005

12th October 2006

Mandate : - Recommendations to CSNI for Future Activities [SEN/SIN(82)50]

- Recommendation to CSNI from Report of the Task Group Reviewing the Activities of the Principal Working Group 1 (PWG1) [NEA/SEN/SIN/WG1(94)5]

- Summary Record of the 28th Meeting of the Committee on the Safety of Nuclear Installations (CSNI) [NEA/SEN/SIN(2001)1]

- Summary Records from the 2005 Summer Meeting of the Committee on Nuclear Regulatory Activities (CNRA) [NEA/SEN/NRA(2005)3] and the 37th Meeting of the Committee on the Safety of Nuclear Installations (CSNI) [NEA/SEN/SIN(2005)3]

\section{Extract from document [NEA/SEN/SIN(2005)3]}

- The Joint CNRA/CSNI Bureau agreed to propose to the CSNI the move of the WGOE to the CNRA, while continuing to serve also the CSNI. The CSNI chairman proposed to follow the suggestion of the Joint Bureau, with the possibility to revisit the decision, if needed, after one year. The CSNI members were given a two weeks period to provide further consent or submit their position via email to the Secretariat."

\section{Extract from letter dated 19 July 2005}

"Based on an agreement made at the Joint CSNI/CNRA Bureau, the CSNI Chairman proposed to the CSNI to organisationally move the WGOE to the CNRA allowing a provision to revisit the decision, if needed, after one year. The CSNI members were given a two-week period to 
provide further consent or submit their position via email to the Secretariat ${ }^{1}$. The re-constituted WGOE will report directly to the CNRA while continuing to serve the CSNI.

In order to begin this transition, and after consultation with both Bureaus, you are kindly requested to nominate delegate(s) from your country to the newly re-constituted group, by the $\underline{31 \mathrm{st}}$ August 2005. Some of the main objectives of this change, relating to the CNRA are to:

- Allow the group to effectively reach conclusions from the feedback of operating experience, with regard to appropriate regulatory actions in the short to medium term.

- Equally important will be that conclusions from operating and inspection experience could provide improved guidance on needs for reassessments of safety and safety analysis methods. Accordingly, the WGOE will have close co-operation with the WGIP on issues of common interest.

In making this nomination, CNRA members should consider that the re-constituted WGOE members will be required to serve both Committees, as described herein. Additionally it should be noted that the CNRA emphasized the importance to regulators of the efficient and effective review and dissemination of operating experience, derived from both incident analysis and inspection findings. Due to the importance of the group to the NEA safety programme, WGOE members are expected to contribute actively to the work, and therefore be in a position to allocate adequate resources and time for this task.

to:

On the other hand, some of the main objectives of this change, relating to the CSNI are

- allow re-assessments of safety, additional research or other appropriate actions to maintain and improve safety in the long term (e.g., trending, safety significance, specific phenomena like core stability, sump plugging, etc.).

- provide analysis of operating experience in order to improve methods and data used in safety assessments (e.g., risk methodologies, accident analysis) and to judge the need for additional research (e.g. material degradation mechanisms)

It is the objective that after the transfer of the WGOE to the CNRA, the information exchange process with the CSNI and its working groups should be at least as efficient as in recent years. In this sense, the combined conclusions from operating and inspection experience should provide improved guidance for specific CSNI activities.

\section{Procedural matters}

Additional matters to be considered by the WGOE are work prioritisation, development of research recommendations, and measurement of success of the operation of the WGOE. These matters will be handled by the Secretariat, under guidance and review by the WGOE, using procedures developed and maintained by the Secretariat.

With prior approval of the CSNI, the WGOE shall collaborate with, make recommendations to, or otherwise assist the other working groups, the special expert groups, and relevant task groups in areas of mutual interest."

\footnotetext{
${ }^{1}$ No comments opposing this decision were received (Note by the Secretariat).
} 


\section{RADIOACTIVE WASTE MANAGEMENT COMMITTEE (RWMC)}

Chair:

Vice-Chairs:

Members:

Participation in the work:

Observer:

Date of creation:

Duration:
Mr. Alexander Nies

Mr. Peter A. Brown

Mr. Masaaki Mishiro

Mr. Piet Zuidema

Ms. Margaret Federline

All NEA Member countries

European Commission

Under the NEA Statute

International Atomic Energy Agency (IAEA)

By agreement

Slovenia

23rd June 1975

31st December 2009
(Germany)

(Canada)

(Japan)

(Switzerland)

(United States)

Mandate : - Record of the 50th meeting of the Steering Committee for Nuclear Energy on 9th October 1975 [NE/M(75)3]

- Proposed Strategy and Programme of Work in the Field of Radioactive Waste Management [NE(81)14]

- Revision of the Mandate of the Radioactive Waste Management Committee (RWMC) [NEA/NE(92)5], approved by the Steering Committee on Nuclear Energy on 6th-7th October 1992

- Review of the NEA Committee Structure [NEA/NE(2000)11/REV1]

- Review of Mandates of the NEA Standing Technical Committees [NEA/NE(2005)2]

\section{Extract from document [NEA/NE(2005)2]}

"The NEA has an acknowledged role in developing a global strategy for considering aspects of sustainability concerning the use of nuclear power and nuclear materials. The general objective of the NEA in the field of radioactive waste management is to assist Member countries in the area of management of radioactive waste and materials, focusing on the development of strategies for the safe, sustainable and broadly acceptable management of all types of radioactive waste, in particular long-lived waste, and spent fuel. In this context, the mandate of the Radioactive Waste Management Committee (RWMC) shall be:

1. To provide a forum of senior representatives from national agencies, regulatory authorities, policy-making bodies, research and development institutions with responsibilities in the management of waste and materials, as well as other government-nominated specialists, for the exchange of information and experience on waste management policies and practices in NEA Member countries, and for advancing the state of the art on the technical and societal aspects in this area.

2. To contribute to the dissemination of information in this field through the organisation of specialist meetings and the publication of reports and consensus statements summarising the results of joint activities for the benefit of the 
international scientific community, competent authorities at national level and other audiences generally interested in the subject matter.

3. To develop a common understanding of the basic issues involved, and to promote the adoption of common philosophies of approach based on the discussion of the various possible strategies by keeping under review the state of the art in the field of management of radioactive waste and material at the technical, scientific, regulatory and societal levels, and in public acceptance matters.

4. To offer, upon request, a framework for the conduct of international peer reviews of national activities in the field, such as R\&D programmes, safety assessments, specific regulations, etc.

5. To promote co-operative efforts such as the setting-up of joint R\&D projects, or the development of databases, and to promote initiatives to maintain relevant competencies and knowledge.

For developing its work programme, and in its modus operandi, the RWMC will rely on discipline-oriented working parties in the areas of disposal, decommissioning and associated societal issues. RWMC members delegated from regulatory authorities meet also in the RWMC Regulators' Forum (RWMC-RF) to exchange specific information on issues of specific regulatory significance. The RWMC-RF maintains appropriate links with the CNRA.

In the fulfilment of its responsibilities, the RWMC will interact with relevant NEA Committees, OECD directorates, scientific bodies and international organisations." 


\section{RWMC REGULATORS' FORUM (RWMC-RF)}

Chair:

Mr. Carl-Magnus Larsson

(Sweden)

Vice-Chair:

$(\ldots)$

Members:

All NEA Member countries

Participation in the work: European Commission

Under the NEA statute

International Atomic Energy Agency (IAEA)

By agreement

Date of creation:

2001

Duration:

2007

Mandate : - Mandate of the RWMC Regulators' Forum [NEA/RWM/RF(2001)2]

\section{Extract from document [NEA/RWM/RF(2001)2]}

- facilitates multilateral communication and information exchange among RWMC regulators and promotes a frank interchange in open dialogue among peers;

- defines and addresses future regulatory challenges and issues in the area of waste management and disposal; decommissioning and dismantling are also relevant issues;

- promotes discussion and exchange with other groups involved with regulations both within the NEA, i.e., the CNRA and the CRPPH committees, and outside the NEA, such as the IAEA, the EC, and the ICRP. Emphasis is on two-way exchange to benefit from related experience;

- takes initiative within the RWMC in the area of regulation and licensing. This includes promoting discussions within the RWMC, proposing specific products to be developed, recommending relevant initiatives by other RWMC groups, and preparing concerted initiatives by the RWMC and other NEA committees." 


\section{INTEGRATION GROUP FOR THE SAFETY CASE OF RADIOACTIVE WASTE REPOSITORIES (IGSC)}

$\begin{array}{lll}\text { Chair: } & \text { Mr. Hiroyuki Umeki } & \text { (Japan) } \\ \text { Vice-Chairs: } & \begin{array}{l}\text { Mr. Peter De Preter } \\ \text { Mr. Gérard Bruno }\end{array} & \begin{array}{l}\text { (Belgium) } \\ \text { (France) } \\ \text { (Spain) } \\ \text { Mr. Jesus Alonso } \\ \text { (Sweden) } \\ \text { Mr. Piet Zuidema } \\ \text { (Switzerland) } \\ \text { (United States) }\end{array} \\ & \text { All NEA Member countries } & \\ \text { Members: } & \text { European Commission } & \\ \text { Participation in the work: } & \text { Under the NEA Statute } & \\ & \text { International Atomic Energy Agency (IAEA) } \\ & \text { By agreement } & \\ \text { Date of creation: } & \text { June 2000 } & \\ \text { Duration: } & \text { October } 2008 & \end{array}$

Mandate : - Mandate of the RWMC Working Party: "Integration Group for the Safety Case of Radioactive Waste Repositories" (IGSC) [NEA/RWM(2005)6]

\section{Extract from document [NEA/RWM(2005)6]}

$" \ldots$

1. To define, oversee and carry out a work programme of technical activities related to the development, evaluation, and communication of safety cases as a basis for confidence and decision making within the development of repositories for long-lived radioactive waste as well as other specific aspects of repository development as assigned by the RWMC.

2. To inform and advise the RWMC in strategic areas II and VI of its programme of work and, in particular, to promote discussion and recommend relevant initiatives within the RWMC and its subsidiary bodies.

3. To facilitate multilateral communication and information exchange among the IGSC members, and promote a frank interchange in an open dialogue among peers. In particular, the IGSC provides a neutral forum for dialogue amongst representatives of waste management agencies, regulatory authorities and other relevant institutions regarding confidence in the technical results of safety cases with a view to identify emerging issues and trends, review the state of the art, promote further understanding and common views, including the development of tools.

4. To define and address challenges and issues related to developing, evaluating, and communicating confidence in the technical safety case of deep geologic disposal projects in relation to the need for decision making in repository development. Emphasis is on the identification and pursuit of issues and on the development of technical tools for which there is pan-national interest, and on publishing the group's findings where this is found appropriate. 
5. To promote discussion, information exchange and joint initiatives with other groups both within the NEA, e.g., the FSC, and outside the NEA, e.g., the IAEA, the EC, and the ICRP, as well as with the scientific community at large." 


\section{FORUM ON STAKEHOLDER CONFIDENCE (FSC)}

Chair:

Vice-Chairs:

Members:

Participation in the work:

Date of creation:

Duration:
Mr. Peter Brown

Mr. Mitsuo Takeuchi

Mr. Bjorn Hedberg

Ms. Elizabeth Atherton

Mrs. Janet Kotra

All NEA Member countries

European Commission

Under the NEA Statute

International Atomic Energy Agency (IAEA)

By agreement

August 2000

October 2008
(Canada)

(Japan)

(Sweden)

(United Kingdom)

(United States)

\footnotetext{
Mandate : - Mandate of the RWMC Working Party "Forum on Stakeholder Confidence" [NEA/RWM/FSC(2000)1]

- Forum on Stakeholder Confidence - Mandate: Phase 2 [NEA/RWM/2003)4/REV2]

- FSC Mandate [NEA/RWM(2005)13/REV1]
}

\section{Extract from document [NEA/RWM/(2003)4/REV2]}

$" \ldots$

1. To define, oversee and carry out work programme activities in the strategic area of public perception and stakeholders' confidence as assigned by the RWMC.

2. To advise the RWMC on major and emerging issues in the area of public perception and stakeholders' confidence related to waste management.

3. To act as a forum to share experience in achieving stakeholders' confidence and, in particular, in how to obtain the trust of local communities, and their representatives and intermediaries with the technical decision makers. Public input to decision making, while maintaining a workable decision-making process, needs to be more fully explored, especially in relation to the role of the regulator.

4. To analyse today's processes for embedding waste management programmes into a socio-political decision-making context.

To identify opportunities for harmonised views of Member countries, regarding:

- Successful and unsuccessful experiences in interacting with stakeholders (e.g., compiling and reviewing factual information and experiences related both to outreach programmes and to public inquiries, drawing out and examining generic elements that are required to ensure and maintain credibility of waste management organisations);

- Technical concerns of stakeholders; 
- Effective means of communicating with technical and non-technical audiences." 


\section{WORKING PARTY ON DECOMMISSIONING AND DISMANTLING (WPDD)}

Chair:

Vice-Chairs:

Members:

Participation in the work:

Date of creation:
Mr. Ernst Warnecke

Mr. Vincent Massaut

Mr. Doug Metcalfe

Mr. Jean-Guy Nokhamzon

Mr. Luis Valencia

Mr. Ivo Tripputi

Mr. Juan Luis Santiago

Mr. Dominick Orlando
(Germany)

(Belgium)

(Canada)

(France)

(Germany)

(Italy)

(Spain)

(United States)

All NEA Member countries

European Commission

Under the NEA Statute

International Atomic Energy Agency (IAEA)

By agreement

May 2001

Duration:

12th October 2008

Mandate : - Mandate of the RWMC Working Party on Management of Materials from Decommissioning and Dismantling [NEA/RWM/WPDD(2001)2]

- Mandate on the RWMC Working Party on Management of Materials from Decommissioning and Dismantling [NEA/RWM(2003)10]

- Update of the RWMC Working Party on the Management of Materials from Decommissioning and Dismantling (WPDD) Mandate [NEA/RWM(2005)5]

- Summary record of the 38th meeting of the RWMC [NEA/RWM(2005)16, para. 7 e]

\section{Extract from document [NEA/RWM(2005)5]}

"The remit of the WPDD is as follows:

1. To define, oversee and carry out work programme activities as assigned by the RWMC, in order to increase the outreach and efficiency of both the RWMC and NEA in the field of Decommissioning as described in the NEA Strategic Plan 20052009.

2. To identify and analyse main issues regarding policies and strategies for the Decommissioning of phased-out nuclear facilities, including funding related issues, and the attending issues of recycling, reuse and/or disposal of materials and the release of buildings and sites.

3. To observe, on a world-wide level, the development of the state of the art of management and technique of decommissioning projects, and make it better available to other NEA bodies engaged in this crosscutting field, in particular building on the experience from the technical information exchange performed within the CPD.

4. To facilitate multilateral communication and information exchange among the WPDD members, and to promote an open dialogue among peers, in particular the 
regulatory authorities, R\&D institutions and the decommissioning industry both private and public,

5. To keep the WPDD members and the RWMC aware of progress and activities in other international fora and their implications, and help the RWMC participate in international initiatives. Co-ordination with EC and IAEA initiatives is important.

6. In close co-operation with the FSC examine and further develop the link between decommissioning, decision-making and public confidence and acceptance, keeping in mind the long time scales for planning and carrying out decommissioning projects.

7. To set up, manage, and make broadly available a database of information on decommissioning in NEA Member countries.

8. To be of service to the other NEA committees with the goal to strengthen overall visibility of decommissioning as a NEA crosscutting activity." 


\section{COMMITTEE ON RADIATION PROTECTION AND PUBLIC HEALTH (CRPPH)}

Chair:

Vice-Chairs:

Members:

Participation in the work:

Observers:

Date of creation:

Duration:
Mr. Jacques Lochard

(France)

Mr. Wolfgang Weiss

Mr. Sigurdur Magnusson

Ms. Ann McGarry

Mr. Yasuhiro Yamaguchi

All NEA Member countries

European Commission

Under the NEA Statute

International Atomic Energy Agency (IAEA)

By agreement

Slovenia

International Commission on Radiological Protection (ICRP) International Radiation Protection Association (IRPA)

United Nations Scientific Committee on the Effects of Atomic

Radiation (UNSCEAR)

World Health Organization (WHO)

3rd July 1957

31st December 2009
(Germany)

(Iceland)

(Ireland)

(Japan)

\footnotetext{
Mandate : - Minutes of the 322nd Meeting of the Council on 18th April 1973 [C/M(73)10(Final), Item 108]

- Report by the Steering Committee on the Programme and Priorities of the Agency [C(73)55]

- Proposed Strategy and Programme of Work in the Field of Radiation Protection and Public Health [NE(82)5]

- Review of the Mandate of the Committee on Radiation Protection and Public Health (CRPPH) [NEA/NE(93)13/CORR1]

- Review of the NEA Committee Structure [NEA/NE(2000)11/REV1]

- Review of Mandates of the NEA Standing Technical Committees [NEA/NE(2005)2]
}

\section{Extract from document [NEA/NE(2005)2]}

"The general objective of the NEA in the field of radiation protection is to contribute to the adoption and the maintenance of high standards of protection for workers, members of the public, and the environment in all practices involving the use of ionising radiation, and particularly in the field of nuclear energy. (CRPPH) shall be:

In this context, the mandate of the Committee on Radiation Protection and Public Health

- to provide a forum for the exchange of information and the transfer of experience between national radiation protection and public health authorities on radiation 
protection policies, regulatory issues and approaches, and their implementation in the various practices and situations involving radiation exposures;

- to seek international understanding and guidance, in support of national authorities, on questions of common concern regarding the interpretation and implementation of the ICRP recommendations and other international standards in various fields of application of radiation protection, and to contribute to the development of harmonised positions in this field;

- to keep under review and contribute to the advancement of the state of the art in the field of radiation protection at the scientific and technical levels and promote the preparation of authoritative advice and reference documents, for use by national authorities and policy makers, on emerging policy, regulatory and operational issues, and in those areas where international consensus on radiation protection concepts, regulatory issues and practices is required;

- to advance concepts and policies which make the system of radiation protection more simple, transparent and adaptable to the broader social dimensions of decision making in complex radiological situations;

- to promote and initiate international co-operative activities on specific radiation protection and radiation-related public health topics of interest to NEA Member countries in the framework of the NEA Strategic Plan.

In the fulfilment of its mandate, the CRPPH will work in close co-operation with other NEA committees as appropriate, particularly the CNRA and the RWMC, as well as with the competent bodies within relevant OECD directorates and other international organisations active in the field." 


\title{
WORKING PARTY ON NUCLEAR EMERGENCY MATTERS (INEX)
}

\author{
Chair: \\ Mr. Wim Molhoek \\ (Netherlands) \\ Vice-Chair: \\ Mr. Vince McClelland \\ (United States) \\ Members: \\ All NEA Member countries \\ Participation in the work: \\ European Commission \\ Under the NEA Statute \\ International Atomic Energy Agency (IAEA) \\ By agreement
}

Date of creation:

September 1993

Duration:

March 2009
Mandate : - CRPPH - Report on the First International Nuclear Emergency Exercise (INEX 1) [NEA/SEN/SAN(93)2]
- Summary Record of the 51st Meeting of the CRPPH [NEA/SEN/SAN(93)8]
- Summary Record of the 58th meeting of the Committee on Radiation Protection and Public Health [NEA/CRPPH(2000)12]
- Summary record of 62 nd meeting of the Committee on Radiation Protection and Public Health [NEA/CRPPH(2004)8
- Summary Record of the 64th Meeting of the Committee on Radiation Protection and Public Health (CRPPH) [NEA/CRPPH(2006)3]

\section{Extract from document [NEA/CRPPH(2006)3}

"The mission of the CRPPH Working Party on Nuclear Emergency Matters (WPNEM) is to improve nuclear emergency management systems within member states, and to share its knowledge and experience widely. In this context, emergency matters refer to all aspects of planning, preparedness and response for the "early" and "intermediate" phases of a nuclear/radiological event, with a view towards preparation of recovery actions.

Within this framework, the WPNEM develops its programme of work by identifying and analysing areas for improvement in emergency management systems. The programme of work is developed in coordination with member states and other relevant organisations.

Participants are emergency management experts from OECD NEA countries with recognised knowledge, skills and abilities in the nuclear field. The Working Party employs a flexible approach to address issues across the entire spectrum of nuclear and radiological emergency and recovery management. Participants share information, data, knowledge, and experience to test all aspects of emergency management systems and theories, identify gaps and provide recommended strategies to improve nuclear emergency management worldwide.

The Working Party on Nuclear Emergency Matters successfully fulfilled the tasks laid down in its Terms of Reference, NEA/CRPPH/INEX(2003)3, which were approved by the CRPPH at its 62nd meeting in March 2004. The Terms of Reference were valid for a period ending in 2006.

The proposed new Terms of Reference of the Working Party on Nuclear Emergency Matters for 2006-March 2009 are as follows: 
- Continue development of INEX series exercises to address best practices and identify areas for improvement in nuclear/radiological emergency management systems.

- Continue INEX series post-exercise evaluations, conduct international evaluation workshops, and publish reports to enable improvements to nuclear/radiological emergency management systems.

- Provide a framework for validation of relevant products coordinated in advance with the working party. Such products may include those developed under the IAEA International Action Plan, the EURANOS project or other coordinated activities.

- Identify and investigate as appropriate further advancements in all aspects of emergency planning, preparedness and response for nuclear accidents and radiological emergencies, for example:

-- Withdrawal of early countermeasures;

-- International harmonisation;

-- Sustainable approaches;

-- Knowledge of best practices;

-- Approaches to stakeholder involvement;

-- Strategies for implementation of lessons identified;

-- $\quad$ Third party liability issues;

-- Public information.

- As needed, review and update WPNEM documents and reports.

- Upon request, provide input as appropriate for the development of international standards and recommendations on emergency management. Such request may include ICRP and IAEA documents;

- Develop, co-ordinate and evaluate WPNEM objectives for inclusion in international exercises such as those organised under the auspices of the Inter-Agency Committee on the Response to Nuclear Accidents (IACRNA);

- Periodically report programme progress to the CRPPH.

These Terms of Reference, approved for the period 2006-2009, will be used as the basis for the yearly programme of work." 


\section{NUCLEAR SCIENCE COMMITTEE (NSC)}

Chair:

Vice-Chairs:

Members:

Participation in the work:

Observer:

Date of creation:

Duration:
Mr. Tomas Lefvert

(Sweden)

Mr. Pierre Joseph D'Hondt

Mr. Alain Zaetta

Mr. Akira Hasegawa

Mr. John Herczeg

All NEA Member countries

European Commission

Under the NEA Statute

International Atomic Energy Agency (IAEA)

By agreement

Slovenia

1st October 1991

31st December 2009
(Belgium)

(France)

(Japan)

(United States)

Mandate : - Terms of Reference for the Committee and an Executive Group [NEA/SEN/NSC(91)1]

- Review of the NEA Committee Structure [NEA/NE(2000)11/REV1]

- Review of Mandates of the NEA Standing Technical Committees [NEA/NE(2005)2]

\section{Extract from document [NEA/NE(2005)2]}

\section{"SCIENCE}

1. The general objective of the NEA in the field of nuclear science is to help Member countries identify, collate, develop and disseminate basic scientific and technical knowledge required to ensure safe, reliable and economic operation of current nuclear systems and to develop next-generation technologies.

2. In this context, the mandate of the Committee is to:

- help advance the existing scientific knowledge needed to enhance the performance and safety of current nuclear systems;

- contribute to building a solid scientific and technical basis for the development of future-generation nuclear systems and spin-off technologies;

- $\quad$ support the preservation of essential knowledge in the field of nuclear science;

especially, but not exclusively, in the following areas:

- nuclear physics; nuclear data measurements and evaluations;

- computational science and mathematical modelling methods;

- reactor physics, neutronics and coupling with thermal-hydraulics; fuel behaviour;

- criticality safety issues related to the front- and back-end of the fuel cycle; 
- fuel cycle physics and chemistry;

- partitioning and transmutation of nuclear waste;

- radiation shielding and dosimetry;

- accelerator development for future technologies;

- preservation and renewal of expertise in nuclear science.

3. In the fulfilment of its mandate, the Committee will interact with other standing technical committees of the Agency in matters of common interest and with other bodies within the Organisation, as well as with other international organisations, as appropriate." 


$\begin{array}{ll}\text { Chair: } & \text { Mr. Arjan Koning } \\ \text { Members: } & \begin{array}{l}\text { Representatives of the co-operating projects } \\ \text { Participation in the work: }\end{array} \\ & \begin{array}{l}\text { European Commission } \\ \text { Under the NEA Statute } \\ \text { International Atomic Energy Agency (IAEA) } \\ \text { By agreement }\end{array} \\ \text { Date of creation: } & \text { June } 1999 \\ \text { Duration: } & \text { October } 2006\end{array}$
Mandate: - Status of the NEA Nuclear Science Committee Projects and their Evolution in 2004 [NEA/SEN/NSC(2003)2]
- Summary Record of the $14^{\text {th }}$ meeting of the Nuclear Science Committee (NSC) [NEA/SEN/NSC(2003)3]

\section{Extract from document [NEA/SEN/NSC(2003)2]}

MISSION

The goal of the Working Party is to improve the quality and completeness of evaluated nuclear data available for use in science and technology and to promote the efficient use of available resources through international collaboration.

\section{SCOPE}

The nuclear data evaluation co-operation activities described within this document will involve the evaluation projects in the following regions: Japan (JENDL), United States (ENDF), Western Europe (JEFF), and non-OECD countries (BROND, CENDL, and FENDL). Participation of non-OECD Member countries will be channelled through the Nuclear Data Section of the International Atomic Energy Agency (IAEA).

\section{OBJECTIVES}

The Working Party is established to promote the exchange of information on nuclear data evaluations, measurements, nuclear model calculations, validation, and related topics, and to provide a framework for co-operative activities between the participating projects in these technical areas. The Working Party will assess needs for nuclear data improvements and address those needs by initiating joint evaluation and/or measurement efforts.

\section{FRAMEWORK}

This Working Party is established under the auspices of the NEA Nuclear Science Committee (NSC). It represents a merging of the former Working Parties on International Evaluation Co-operation (WPEC) and on International Nuclear Data Measurement Activities (WPMA). The Working Party will meet and report to the NSC on an annual basis.

\section{PARTICIPATION}


The Working Party will consist of four representatives of each participating region, nominated by the respective projects. The representative from the IAEA Nuclear Data Section will nominate participants from non-OECD countries. At least one member of each regional group will be a representative of the nuclear data measurement community. Former Working Party chairmen are permanent members of the Working Party.

Participation in the Working Party and its subgroups is voluntary in the sense that there is no direct funding provided by the OECD/NEA. As a consequence, the interests of the sponsoring agencies/countries, and the specific benefits that accrue to them by their participation, must always be taken into consideration in formulating projects to be undertaken within the frame of this collaboration.

The Working Party may identify specific activities to be co-ordinated directly by the Working Party. The individuals assigned to co-ordinate these activities will be ex-officio members of the Working Party.

In order to promote close co-operation with other relevant activities, the Chairman and Secretariat may invite appropriate experts to participate in Working Party meetings, following approval by the designated heads of the participating projects.

A limited number of observers may be invited to specific Working Party meetings, following official nomination by a designated head of a participating project with the concurrence of the Chairman and the Secretariat.

\section{CHAIRMAN}

A Working Party chairman shall be elected for a two-year period, with possible yearly extensions; the guiding principal should be an alternating chairmanship between the ENDF, JEFF and JENDL projects. Eligible candidates are representatives of the OECD evaluation projects.

\section{METHODS OF WORK}

At its annual meeting the Working Party will review its mandate, discuss the status of the participating projects, review ongoing subgroup activities, and review proposals for new cooperative activities. In addition, the Working Party may organise workshops and specialists' meetings.

Status reports from each of the projects and each of the ongoing co-operative activities will be submitted to the Secretariat for distribution to the participants.

Only proposals for new co-operative activities submitted on the standard proposal form and having support from at least two evaluation projects will be considered.

The Working Party will set up a Subgroup to perform the agreed technical co-operative activities. The number of active Subgroups at one time shall be limited, depending on the available resources within the participating projects, and at the discretion of the Working Party chairman in consultation with the project leaders.

All above-mentioned documents and reports must be submitted to the Secretariat at least six weeks before the Working Party meeting.

\section{SUBGROUPS}

Subgroups will be established with an initial mandate of two years. The mandate can be extended by the Working Party. Subgroups will consist of members who have special expertise in the subject area and are willing and able to participate in the work on a voluntary basis. Subgroups will be responsible for their own working methods. The Subgroup Co-ordinator will be designated by the Working Party.

The Subgroup Co-ordinator will prepare an annual progress report for presentation at the Working Party meeting. The Co-ordinator will also be responsible for producing the final report of the Subgroup and for having it reviewed by Subgroup members before it is submitted to the 
Working Party for publication approval. Final reports should be submitted at least two months before a Working Party meeting.

A member of the Working Party (Monitor) will be assigned to each Subgroup to actively follow the progress. The Monitor will advise the Working Party on the status of the subgroup and will recommend specific measures to promote progress towards the agreed time-schedules and goals.

Each Subgroup will be dissolved when its task is completed. The Working Party can decide to dissolve a Subgroup due to lack of progress.

\section{SECRETARIAT}

The NEA will assure the Secretariat of the Working Party and will be responsible for maintaining the official records of the Working Party and for organising its meetings in consultation with the Chairman. In particular, the Secretariat will consult with the Subgroup Monitors and Coordinators on the Subgroup presentations at Working Party meetings and will send out necessary reminders at least two months before these meetings. The Secretariat will maintain a list of the cooperative activities in progress, the official Working Party Web site and will be responsible for the publication of the final Subgroup reports.

\section{AVAILABILITY OF INFORMATION}

The data files and the results of all co-operative activities will be available without restrictions to all participants. Information developed within the co-operation will be distributed to the Secretariat, the chairmen of the projects, and the IAEA Nuclear Data Section. Distribution of information about the co-operation, to parties outside the co-operation, will be made via the Secretariat. 
WORKING PARTY ON SCIENTIFIC ISSUES OF REACTOR SYSTEMS (WPRS)

Chair:

Mr. Kevin Hesketh

(United Kingdom)

Members:

Participation in the work:

Date of creation:

Duration:
All NEA Member countries

European Commission Under the NEA Statute

International Atomic Energy Agency (IAEA)

By agreement

2004

June 2007

Mandate : - Summary Record of the 15th meeting of the Nuclear Science Committee [NEA/SEN/NSC(2004)3]

\section{Extract from document [NEA/SEN/NSC(2004)3]}

"SCOPE

Under the guidance of the Nuclear Science Committee the Working Party will deal with reactor physics, fuel cycle, fuel behaviour, thermal hydraulics and dynamics/safety of present and future nuclear power systems.

\section{OBJECTIVES}

To provide the member countries with up-to-date information to preserve knowledge on and develop consensus regarding:

- Reactor physics, fuel behaviour, thermal hydraulics and dynamics/safety issues associated with innovative fuels in present and future nuclear power systems.

- Reactor physics aspects considered include:

-- Reactivity characteristics,

-- Core power/flux distributions,

-- Core kinetics and reactivity control,

-- Reactivity coefficients,

-- Safety / system dynamics,

-- Vessel dosimetry.

- Fuel cycle aspects considered will focus on fuel loading and discharge requirements, fission product and minor actinide inventories and radiotoxicity profiles versus time.

- Fuel behaviour, thermal hydraulics and kinetics/safety will be considered insofar as they impinge on the reactor performance.

Reactor types considered include, but are not limited to the following:

- Present generation LWRs with advanced and innovative fuels, evolutionary LWRs and innovative LWRs. 
- $\quad$ Novel reactor systems (Gen IV Systems).

- Accelerator driven (sub-critical) and critical systems for waste transmutation.

To liaise closely with other relevant NEA working groups, especially those operating under the guidance of the NDC and $\mathrm{CSNI}$, to ensure the respective work programmes are complementary and to provide advice and support where required and undertake common work where appropriate. Particularly close working relationships will be maintained with the Working Party on the scientific issues in Fuel Cycle (WPFC) and with the Task Force on Reactor-based Plutonium Disposition (TFRPD).

To provide advice to the nuclear community on the developments needed to meet the requirements (data and methods, validation experiments, scenario studies) for different reactor systems.

\section{DELIVERABLES}

- Publication of Volume VIII - Benchmark exercise on kinetics parameters based on comparison with experimental results from the CROCUS facility - Late 2004.

- Publication of Volume IX - High temperature reactor core physics benchmark Mid-2005.

- Depletion calculation benchmark, Late 2005.

- Publication of Volume X - Physics benchmarks for Gen IV reactor cores - Early 2006.

- $\quad$ MOX-core control rod ejection benchmark - Early 2006.

Meeting frequency: 9 months." 
WORKING PARTY ON NUCLEAR CRITICALITY SAFETY (WPNCS)

Chair:

Dr. Jim Gulliford

(United Kingdom)

Members:

Ad hoc Observers:

Participation in the work:

Date of creation:

Duration:
All NEA Member countries

China

Russian Federation

European Commission

Under the NEA Statute

International Atomic Energy Agency (IAEA)

By agreement

June 1996

May 2007

Mandate : - Agreed at the 7th Meeting of the Nuclear Science Committee [NEA/SEN/NSC(96)3]

- Summary Record of the 15th meeting of the Nuclear Science Committee [NEA/SEN/NSC(2004)3]

\section{Extract from document [NEA/SEN/NSC(2004)3]}

\section{"SCOPE}

Under the guidance of the Nuclear Science Committee, the Working Party will deal with technical and scientific issues relevant to criticality safety. Specific areas in interest include, but are not limited to investigations concerning static and transient configurations encountered in the nuclear fuel cycle such as fuel fabrication, transport and storage. Areas of activities include:

- Evaluation of available experimental data;

- Assessment of experimental needs;

- Code and data inter-comparison;

- Development of codes and models;

- Development of criticality methodologies and data;

- Establishment of technical bases for the application of burnup credit.

\section{OBJECTIVES}

- Exchange of information on national programs in the area of criticality safety.

- Guide, promote and co-ordinate high priority activities of common interest to the international criticality safety community, establish co-operations.

- Monitor the progress of all activities and report to the NSC.

- Publish databases, handbooks, and reports.

- Facilitate communications within the international criticality safety community through relevant Internet sites.

- Co-ordinate the ongoing series of International Conferences on Nuclear Criticality Safety (ICNC), to be held every four years.

- Co-ordinate WPNCS activities with other working groups within the NEA and in other international frameworks to avoid duplication of activities.

- Provide a technical basis for other international activities (e.g. ISO, IAEA). 


\section{DELIVERABLES}

- New editions of the International Handbook of Criticality Safety Benchmark Evaluation Project (2004, 2005 and 2006).

- Report of a study on the effect of axial burnup profile asymmetry on criticality calculation (2004).

- Report of a study on the effect of absorbers on burnup credit (2005).

- Report summarising the findings of the Expert Group on Burnup Credit and lessons learned (2005).

- Report on the study of source convergence issues through the analysis of four intercomparison exercises (2004).

- Report on the assessment of statistical methods for source convergence detection and application in Monte-Carlo criticality safety codes (2006).

- Report compiling and comparing minimum critical data for a selection of fissile media (2004).

- Report on inter-code comparisons for the calculation of criticality transient experiments (2005).

- Web-based information resources on burn-up credit, criticality excursions and source convergence issues.

- Status reports of the progress of ICNC 2007." 
WORKING PARTY ON SCIENTIFIC ISSUES OF THE FUEL CYCLE (WPFC)

Chair:

Ms. Kathryn A. McCarthy

(United States)

Members:

Participation in the work:

Date of creation:

Duration:
All NEA Member countries

European Commission Under the NEA Statute

International Atomic Energy Agency (IAEA)

By agreement

June 2004

June 2007

Mandate : - Summary Record of the 15th meeting of the Nuclear Science Committee (NSC) [NEA/SEN/NSC(2004)3]

\section{Extract from document [NEA/SEN/NSC(2004)3]}

"SCOPE

Under the guidance of the Nuclear Science Committee, the Working Party will deal with scientific issues in various existing and advanced nuclear fuel cycles, including fuel cycle physics, associated chemistry and flowsheets, development and performance of fuels and materials, and accelerators and spallation targets.

\section{OBJECTIVES}

- To provide the member countries with up-to-date information on and develop consensus regarding:

Separations science;

-- Develop a scientific basis for optimisation of the use of future nuclear waste repositories.

-- Establish a methodology for evaluating impacts of various existing and advanced fuel cycle scenarios on potential storage and repositories.

-- Provide a means for the development and evaluation of advanced processing concepts, including design bases for future reprocessing plants.

Fuel cycle scenarios;

-- Assemble and organise scientific information critical to the understanding of the issues involved in transitioning from current fuel cycles to future fuel cycles.

-- Provide scientific bases for fuel cycle deployment strategies.

Chemical partitioning;

-- Keep updated information on separation technologies, including advanced aqueous and pyrochemical processing issues.

-- Perform a detailed scientific study of separations processes for different fuel cycle scenarios.

Fuels and materials;

-- Undertake studies needed for development of fuels and materials for implementing advanced nuclear fuel cycles. 
-- Deal with performance and behaviour of advanced fuels.

-- Publish a handbook on lead-bismuth eutectic (LBE) technology.

Accelerators and targets;

-- Deal with accelerator reliability issues.

-- Target performance, including spallation products.

-- Window performance, including thermal stress and radiation damage.

- To liaise closely with other relevant NSC Working Parties and NEA Standing Technical Committees, especially the Nuclear Development Committee (NDC) and the Radioactive Waste Management Committee (RWMC), to ensure the respective work programmes are complementary and to provide advice and support where required and undertake common work where appropriate. Particularly close working relationships will be maintained with the Working Party on scientific issues of Reactor Systems (WPRS) and with the Task Force on Reactor-based Plutonium Disposition (TFRPD).

- To provide advice to the nuclear community on the developments needed to meet the requirements for implementing advanced long-term sustainable nuclear fuel cycles, including partitioning and transmutation.

\section{DELIVERABLES}

Chemical partitioning:

- State-of-the-art report on national programmes in partitioning in June 2005.

- WG on detailed flowsheet study: Final report in June 2006.

Fuel cycle scenarios:

- WG on Fuel Cycle Transition Scenarios Studies: Final report in June 2006.

Accelerators utilisation:

- Organise the 5th HPPA workshop in Europe in 2006.

Separations science:

- WG on Separations Criteria Studies: Final report in June 2007.

Fuels and materials:

- WG on LBE Technology: Publication of an LBE Handbook in June 2007." 


\section{EXECUTIVE GROUP OF THE NSC (DATA BANK MANAGEMENT COMMITTEE)}

Chair:

Mr. Pierre Joseph D'Hondt

(Belgium)

Members:

Austria
Belgium
Czech Republic
Denmark
Finland
France
Germany
Greece
Hungary
Italy
Japan

Korea

Mexico

Netherlands

Norway

Portugal

Slovak Republic

Spain

Sweden

Switzerland

Turkey

United Kingdom

Participation in the work:

European Commission

Under the NEA Statute

International Atomic Energy Agency (IAEA)

By agreement

Observer:

Slovenia

Date of creation:

1st October 1977

Duration:

31st December 2009

$\begin{array}{ll}\text { Mandate : } & \text { - Terms of Reference for the Committee and an Executive Group } \\ & \text { [NEA/SEN/NSC(91)1] } \\ & \text { - Review of the NEA Committee Structure [NEA/NE(2000)11/REV1] } \\ & \text { - Review of Mandates of the NEA Standing Technical Committees [NEA/NE(2005)2] }\end{array}$

\section{Extract from document [NEA/NE(2005)2]}

"DATA BANK

The Committee shall also supervise the work of the Data Bank, which acts as an international centre of reference for its Member countries with respect to basic nuclear tools, such as computer codes and nuclear data, used for the analysis and prediction of phenomena in the nuclear field, and which provides a direct service to its users by developing, improving and validating these tools and making them available as requested.

To this end, the Committee shall establish an Executive Group with the task of establishing proposals for the work programme and budget for the Data Bank services, to be considered by the Committee with a view to making recommendations to the Steering Committee. The Executive Group shall consist of members of the Committee from each Participating country of the Data Bank ${ }^{1}$ : Representatives from non-participating countries may participate as appropriate.

\footnotetext{
${ }^{1}$ At the date of adoption of these Terms of Reference: Austria, Belgium, Czech Republic, Denmark, Finland, France, Germany, Greece, Hungary, Italy, Japan, Korea, Mexico, Netherlands, Norway, Portugal, Slovak Republic, Spain, Sweden, Switzerland, Turkey, United Kingdom.
} 
In particular, the Data Bank will:

i) assume responsibility for the development, compilation, validation and dissemination within its Participating countries of bibliographic and numerical nuclear and chemical thermodynamic data (including experimental, evaluated and integral data) and computer programs for nuclear technology;

ii) collaborate in the above work with other data and software centres outside the group of Participating countries, notably in the United States and the International Atomic Energy Agency;

iii) maintain the necessary expertise in computing and scientific information;

iv) carry out work in other fields of science as determined by the NSC, either to the benefit of the Participating countries or to that of the Agency's full membership.

\section{COMMITTEE OFFICERS}

The Committee shall designate a bureau with one Chair and four Vice-chairs for a oneyear term. One of the Vice-chairs will act as chair of the Executive Group. The bureau undertakes tasks delegated to it by the Committee, and participates in the preparation of Committee meetings and in the follow-up of Committee decisions, in close co-operation with the Secretariat." 


\section{THE SCIENTIFIC CO-ORDINATION GROUP OF THE JOINT EVALUATED FISSION AND FUSION (JEFF) DATA PROJECT}

\section{Members:}

Date of creation:

Duration:

\author{
Austria \\ Belgium \\ Czech Republic \\ Denmark \\ Finland \\ France \\ Greece \\ Hungary \\ Italy \\ Japan \\ Korea
}

\author{
Mexico \\ Netherlands \\ Norway \\ Portugal \\ Slovak Republic \\ Spain \\ Sweden \\ Switzerland \\ Turkey \\ United Kingdom
}

1st October 1981

June 2006

Mandate : - Established at the meeting of the NEA Steering Committee in October 1981

- Prolonged at the 12th meeting of the Executive Group on the Nuclear Science Committee [NEA/SEN/NSC/EG(2003)4]

- Progress Report for 2002, Work in Hand in 2003 and Programme of Work for 2004 [NEA/SEN/NSC/EG(2003)2]

\section{Extract from document [NEA/SEN/NSC/EG(2003)2]}

\section{"SCOPE AND OBJECTIVES}

The objective of the Joint Evaluated Fusion and Fission (JEFF) file Project is to develop and promote the use of high quality evaluated nuclear data sets in standard formats for a wide range of scientific and technical applications.

The Project assesses the needs for nuclear data improvements and addresses those needs by initiating the necessary measurements, evaluation and benchmarking efforts.

\section{PARTICIPATION}

The JEFF Project is a collaborative effort between NEA Data Bank Member countries, mainly Western European countries and in particular Austria, Belgium, France, Germany, Italy, the Netherlands, Sweden, Switzerland, and the United Kingdom.

The Project provides a framework for co-operative activities between participating countries while seeking to make the most rational and efficient use of the available resources.

As with other NEA activities, the participation is on a voluntary basis, where each participating organisation is responsible for covering the cost of its own contributions.

The Project will maintain close links with other similar international efforts or projects aimed at producing evaluated nuclear data, for example through active participation in the NEA Working Party on International Nuclear Data Evaluation Co-operation (WPEC).

The Project will also maintain close links with the International Nuclear Data Committee (INDC) of the IAEA and with nuclear data activities carried out by the Joint Research Centre (JRC) of the European Commission. 


\section{ORGANISATION}

The Project is established under the auspices of the Executive Group of the Nuclear Science Committee (NSC).

The Project management is assured by a Scientific Co-ordination Group (SCG) composed of up to two representatives for each participating country. The NSC Executive Group nominates the representatives.

The JEFF Project Chairman is elected by the SCG for a three-year renewable term. Eligible candidates are members of the SCG.

The Chairman and the Secretariat may invite a limited number of specialists to participate in SCG meetings.

The SCG elects its representatives to the NEA Working Party on International Nuclear Data Evaluation Co-operation (WPEC).

The Secretariat of the Project is the Nuclear Energy Agency (NEA) Data Bank. The Secretariat is responsible for maintaining the official records of the Project and for organising its meetings in consultation with the Chairman. The Secretariat is also responsible for the publication and distribution of the JEFF documents, as well as for the updating and maintenance of the JEFF files.

\section{METHOD OF WORK}

The SCG forms appropriate Subgroups to perform technical activities. Subgroup leaders are nominated by the SCG and report to the SCG. Subgroup leaders are systematically invited to SCG meetings.

The technical activities cover the following themes: experiments, model codes, data evaluations, assessment of uncertainties, verification \& compilation of the data under strict quality assurance procedures, file processing and benchmarking.

The SCG is responsible for reviewing its mandate and the progress of the different Subgroups, providing directions for further developments or new initiatives, and scheduling the official release of the JEFF files.

The subgroups and Scientific Co-ordination Group meet at least once a year.

Official summary records of each SCG meeting are produced.

\section{DELIVERABLES}

JEFF libraries are distributed by the Secretariat in the form of computer files. All past $\mathrm{JEF}(\mathrm{F})$ libraries are considered frozen. The Project will provide assistance and recommendations to users of the JEF-2.2 library and of subsequent official releases of the JEFF files according to the attached policy.

A specific development plan is produced for each mandate period of the Project (see Annex 2). The data files and the results of the Project activities are available without restrictions to authorised users in participating countries. Information developed within the Project is distributed via the Secretariat." 


\title{
COMMITTEE FOR TECHNICAL AND ECONOMIC STUDIES ON NUCLEAR ENERGY DEVELOPMENT AND THE FUEL CYCLE (NDC)
}

\author{
Chair: \\ Ms. Sylvana Guindon \\ (Canada) \\ Vice-Chairs: \\ Mr. Sándor Élö \\ Mr. Kazuaki Matsui \\ (Hungary) \\ Mr. Pierre Multone \\ (Japan) \\ (Switzerland) \\ Members: \\ Participation in the work: \\ Observer: \\ Date of creation: \\ Duration: \\ All NEA Member countries \\ European Commission \\ Under the NEA Statute \\ International Atomic Energy Agency (IAEA) \\ By agreement \\ Slovenia \\ 26th October 1977 \\ 31st December 2009
}

Mandate : - Minutes of the 55th Session of the Steering Committee for Nuclear Energy [NE/M(77)2]

- Proposed Strategy and Programme Objectives in the Field of Development of Nuclear Energy and the Fuel Cycle [NE(81)19]

- Review of the NEA Committee Structure [NEA/NE(2000)11/REV1]

- Review of Mandates of the NEA Standing Technical Committees [NEA/NE(2005)2]

\section{Extract from document [NEA/NE(2005)2]}

"Under the authority of the Steering Committee for Nuclear Energy, to conduct technical, resource, economic, strategic and policy-support studies and publish documented, authoritative reports on nuclear energy development, its fuel cycle and related issues in support of Member countries' national energy or nuclear energy policies. Specifically, the following topics should be included in the programme of activities:

- Economics of the nuclear option, including fuel cycle, waste management and disposal and decommissioning costs, covering new issues raised by energy market liberalisation.

- Innovation in the nuclear sector and advanced reactor and fuel cycle technologies.

- Infrastructure required for the nuclear option.

- Production, supply and demand of nuclear materials, including radioisotopes, and other aspects of their management.

- Future role of nuclear energy in a sustainable development perspective.

- Support national and international organisations, upon request, in the fields covered by the NDC programme of work according to the Strategic Plan of the NEA.

Furthermore the Committee should address the preceding topics by:

- Contributing to the dissemination of information in the areas listed above.

- Establishing a liaison with other NEA committees and other parts of the OECD, as appropriate, to analyse and comment on aspects within its competence contained in 
any report relating to the mission of the NEA or specifically submitted to the Steering Committee.

- Reviewing related work in national and other international governmental organisations, especially the International Atomic Energy Agency and advising the Steering Committee on the co ordination of the NDC work with that of others.

- Maintaining an understanding of the role and work of all organisations relevant to the area of interest of the Committee, such as industry, trade organisations, regulators, interest groups or professional associations.

- Reporting every year to the Steering Committee, reviewing NEA activities in this field and making proposals for the future programme of work." 


\section{JOINT NEA/IAEA GROUP ON URANIUM}

Chair:

Vice-Chairs:

Members:

Date of creation:

Duration:
Mr. Robert E. Vance

Mr. Ian Lambert

Mr. Georges Capus

Mr. Victor G. Yazikov

Mr. Alexander V. Boitsov

All NEA Member countries

Open also to all IAEA Member countries

Participation in the work:

Mandate : - Proposed reconstitution of the Joint NEA/IAEA Uranium Group [NEA/NE(96)6]

- Minutes of the 92nd Session of the Steering Committee for Nuclear Energy [NEA/NE/M(96)1/REV1]

- Summary Record of the 48th NDC Session [NEA/NDC(2003)25/REV1]
(Australia)

(France)

(Kazakhstan)

(Russian Federation)
European Commission

International Atomic Energy Agency (IAEA)

By agreement

23rd April 1996

12th October 2006

\section{Extract from document [NEA/NE(96)6, Annex 1]}

\section{"General Objectives}

To co-ordinate the preparation of the periodic assessments of the world's supply of natural uranium; to examine the relationship of these supply capabilities to projection of natural uranium demand; to foster the exchange of technical information in the fields of uranium resources, exploration and production technology in co-operation with members, and with other international organisations as appropriate; and to recommend to the NEA and IAEA actions that might be taken to assure an adequate long-term supply of uranium for nuclear power development.

\section{Mandate}

1. To plan, direct and co-ordinate the preparation of periodic assessments of the world's uranium supply capabilities (i.e. levels of uranium exploration activity, estimates of resources and production capability) in co-operation with members, and with other international organisations as appropriate;

2. To examine the world's uranium supply capabilities in relationship to projections of natural uranium demand, and to recommend to the NEA and IAEA actions that might be taken to assure an adequate long-term supply of uranium for nuclear power development;

3. To foster the exchange of technical information in the fields of uranium geology, resources, exploration, mining and ore processing technology, in co-operation with 
members, and with other international organisations as appropriate, with a view to promoting collaborative R\&D efforts in areas that may be identified through these exchanges;

4. To promote the expansion of the geological coverage of information on uranium activities throughout the world, with particular emphasis on developing countries."

\section{Extract from document [NEA/NE/M(96)1/REV1]}

"The Steering Committee:

a) considered the proposal to reconstitute a joint NEA/IAEA Group to prepare studies on uranium resources, with a mandate as specified in the terms of reference presented in Annex 1 of document NEA/NE(96)6; and

b) agreed to reconstitute the joint NEA/IAEA Uranium Group as proposed, with the understanding that its mandate would be interpreted to include exchanges of information on environmental effects and environmental protection technologies associated with mining and ore processing."

\section{Extract from document [NEA/NDC(2003)25/REV1, item 15]}

"NDC Members reaffirmed their support for the joint NEA/IAEA Uranium Group and approved its mandate for a further five years following the expiration of the previous mandate on 12 October 2003." 


\section{NUCLEAR LAW COMMITTEE (NLC)}

Chair:

Vice-Chairs:

Members:

Participation in the work:

Observers:

Ad hoc Observers:

Date of creation:

Duration:
Mr. Roland Dussart-Désart

Mr. Yrjo Sahrakorpi

Ms. Vanda Lamm

Mr. Ben McRae

All NEA Member countries

European Commission

Under the NEA Statute

International Atomic Energy Agency (IAEA)

By agreement

Slovenia

European Insurance Committee (EIC)

Union of the Electricity Industry (EURELECTRIC)

Bulgaria

Hong Kong, China

Lithuania

Romania

Russian Federation

Ukraine

24th January 1957

31st December 2009
(Belgium)

(Finland)

(Hungary)

(United States)

\footnotetext{
Mandate: - Review of the Mandates of the Agency's Committees and Working Groups [NE(74)4]

- Review of the NEA Committee Structure [NEA/NE(2000)11/REV1]

- Review of Mandates of the NEA Standing Technical Committees [NEA/NE(2005)2]
}

\section{Extract from document [NEA/NE(2005)2]}

"The Nuclear Law Committee will work to encourage provisions for equitable compensation of damage in the event of a nuclear incident. In particular, the Committee is mandated to deal with issues relating to civil liability for damage caused by a nuclear incident and to financial security mechanisms designed to ensure that funds will be available to compensate such damage. It addresses these issues in the context of Member countries' nuclear legislation and of international nuclear liability instruments, including 1) the 1960 Paris Convention on Third Party Liability in the Field of Nuclear Energy and the 1963 Brussels Convention Supplementary to the Paris Convention, as amended, 2) the 1963 Vienna Convention on Civil Liability for Nuclear Damage and the 1997 Protocol to Amend the Vienna Convention, 3) the 1988 Joint Protocol Relating to the Application of the Vienna Convention and the Paris Convention, and 4) the 1997 Convention on Supplementary Compensation for Nuclear Damage. The Nuclear Law Committee will also strive to eliminate or minimise any legal impediments to the safe use of nuclear energy.

More specifically, the Committee has a mandate to: 
i) examine issues relating to the interpretation and application of international nuclear liability instruments, especially with respect to their harmonious application under Member countries' national laws, and encourage broader adherence to those instruments with a view to fostering further progress towards a global regime of liability and compensation for nuclear damage;

ii) promote the harmonisation of national policies and legislation in the nuclear liability and compensation field amongst its Member countries;

iii) encourage the development of national legislation governing the peaceful uses of nuclear energy based upon internationally accepted principles, particularly in the area of liability and compensation;

iv) develop recommendations concerning the Paris Convention and the Brussels Supplementary Convention, as amended, for submission, if appropriate, to the Steering Committee for Nuclear Energy;

v) promote the exchange of information and the sharing of experience between Member countries on these issues;

vi) advise the Secretariat on collecting, analysing and disseminating information on major developments in the nuclear law field at both national and international levels.

The Nuclear Law Committee is also mandated to undertake all other work involving legal issues that may be entrusted to it by the NEA Steering Committee.

The Nuclear Law Committee will co-operate with other NEA standing technical committees. It may set up subsidiary bodies to better facilitate the achievement of its goals, invite experts in other fields to attend its meetings, and sponsor meetings of specialists. It may also establish contacts with its counterparts in the European Community, the International Atomic Energy Agency, and other international organisations on matters of common interest." 

JOINTSUBSIDIARY BODIES TO THE CO-ORDINATED ORG ANISATION S 



\section{CO-ORDINATING COMMITTEE ON REMUNERATION (CCR)}

\begin{tabular}{|c|c|c|}
\hline Chair: & Mr. D. Brighty & (United Kingdom) \\
\hline Vice-Chair: & Mr. G. Schmidt & (Germany) \\
\hline Members: & \multicolumn{2}{|c|}{$\begin{array}{l}\text { All the Member countries of the Co-ordinated Organisations: } \\
\text { Council of Europe } \\
\text { European Centre for Medium Range Weather Forecasts (ECMWF) } \\
\text { European Space Agency } \\
\text { North Atlantic Treaty Organisation (NATO) } \\
\text { OECD } \\
\text { Western European Union (WEU) }\end{array}$} \\
\hline Date of creation: & 1st July 1991 & \\
\hline Duration: & Unspecified & \\
\hline
\end{tabular}

Mandate: - Regulation concerning the Co-ordination System

- Appendix to the OECD Council Decision adopted at its 690 session [C(88)117/FINAL]

- Revised by the OECD Council Decision [C(2004)6 and CORR1] adopted at its 1081th session, on 30 March 2004 [C/M(2004)7, Item 107]

\section{Decision of the Council [C(2004)6 and CORR1]}

THE COUNCIL

a) noted documents $\mathrm{C}(2004) 6 \&$ CORR1, and the $154^{\text {th }}$ Report on the Co-ordinating Committee on Remuneration [CCR/R(2004)2];

b) reaffirmed the final authority of Member States of the Co-ordinating Committee on Remuneration to issue recommendations on remuneration issues, including those on the remuneration adjustment method;

c) requested that the CCR examines, as a matter of urgency, alternatives to the current remuneration adjustment method, in order to more closely reflect the real trends in salaries in the national civil services of the reference countries;

d) adopted the revised Regulations concerning the co-ordination system set out in Annex 1 of the $154^{\text {th }}$ Report. These Regulations shall come into force when adopted in identical terms by the Councils of the six Co-ordinated Organisations;

e) subjected its adoption of these Regulations to the reservation that the mandate of the concertation group established pursuant to Article 7 , paragraph a) shall cease to be in effect on 31 December 2007 unless the Council agrees to its continuation in force;

f) invited the Secretary-General to communicate this decision to the other Co-ordinated Organisations, as well as to the Committees of the system of co-ordination, with the understanding that the Revised Regulations would have only provisional effect pending acceptance of the reservation set out in paragraph e) by the other Co-ordinated Organisations, either expressly or tacitly within twelve months from notification, and that, in the event any other co-ordinated Organisation objected to the reservation within that period, the Regulations dated 1 July 1991 would once again be in effect." 


\section{ANNEX I \\ REGULATIONS CONCERNING THE CO-ORDINATION SYSTEM}

The following Regulations update those which came into effect on 1 July 1991.

For several decades, a co-ordinated system of remuneration has been maintained by a group of international organisations [North Atlantic Treaty Organisation (NATO), European Space Agency (ESA), Organisation for Economic Co-operation and Development (OECD), Council of Europe, Western European Union (WEU) and the European Centre for Medium Range Weather Forecasts (ECMWF)]. These Co-ordinated Organisations at present have more than 50 member States, 11000 staff members, and 4000 pensioners. The Co-ordinating Committee on Remuneration (CCR) was established with a role of making recommendations on remuneration, allowances and pensions to the Councils of the Co-ordinated Organisations. The CCR works in conjunction with the Committee of Representatives of the Secretaries/Directors-General (CRSG) and the Committee of Staff Representatives (CRP). The legal and organisational basis for co-ordination is set out in the Regulations below.

\section{Article 1}

\section{Scope of Co-ordination}

(a) The object of the co-ordination system is to provide recommendations to the Governing bodies of the Co-ordinated Organisations, in accordance with the provisions of these Regulations, concerning:

(i) Basic salary scales, and the method of their adjustment, for all categories of staff and for all countries where there are active staff or recipients of a pension;

(ii) Pension Scheme Rules;

(iii) The object, the amount and the method of adjustment of:

- expatriation allowance

- household allowance

- installation allowance

- dependent person's allowance

- daily subsistence allowance

- kilometric allowance

- expatriated child's allowance

- education allowance

- handicapped child's allowance.

(b) According to the procedure referred to in Article 6, recommendations to the Governing bodies are made by the Co-ordinating Committee on Remuneration (CCR), to the extent possible in conjunction with the Committee of Representatives of Secretaries/Directors-General (CRSG) and after consultation with the Committee of Staff Representatives (CRP). Where divergent conditions exist in different Coordinated Organisations, recommendations on allowances may take the form of frameworks applicable to all the Organisations, within which each Organisation shall have the flexibility to adopt implementing provisions to meet its specific needs. The CCR shall be kept informed of these provisions.

(c) According to the procedure referred to in Article 6, the CCR shall give its advisory opinion on any question falling within its mandate asked by the Governing body of any Co-ordinated Organisation.

\section{Article 2}




\section{Co-ordinating Committee on Remuneration (CCR)}

(a) Each member State of one of the Co-ordinated Organisations may nominate one representative to the CCR who may be assisted by alternate delegates and advisers.

(b) The CCR shall elect its Chairperson by consensus for a three year mandate extendible on a yearly basis, after consultation with the CRSG and after being informed of the views of the CRP.

(c) The Chairperson of the CCR shall act as the impartial Chairperson of the whole co-ordination process and shall look after its harmonious, rapid and efficient functioning.

(d) The Chairperson shall be assisted by one Vice-Chairperson elected annually by the CCR.

(e) The CCR may designate one of its members to act as its spokesperson.

\section{Article 3}

\section{Committee of Representatives of the Secretaries/Directors-General (CRSG)}

(a) The Secretary/Director-General of each Co-ordinated Organisation shall appoint one representative to the CRSG who may be assisted by alternate delegates and advisers.

(b) The Chairperson and Vice-Chairperson of the CRSG shall be designated according to the procedures established by the CRSG.

(c) The Chairperson of the CRSG shall act as its spokesperson.

(d) The Secretaries/Directors-General may meet as the Committee of Secretaries/Directors-General (CSG).

(e) The CRP shall be given the prior possibility to outline to the CRSG any subjects related to remuneration policy which they consider should be raised at the sessions of the CSG.

\section{Article 4}

\section{The Committee of Staff Representatives (CRP)}

(a) The representative statutory body of the staff of each Co-ordinated Organisation and the Association of Pensioned Staff of the Co-ordinated Organisations and of their Dependants (AAPOCAD) may appoint one delegate to the CRP as well as the alternate delegates and advisers who may accompany him/her.

(b) The Chairperson of the CRP shall act as its spokesperson. He/she may be assisted by a ViceChairperson.

\section{Article 5}

\section{Proposals and work programme}

(a) The CCR shall adopt a detailed work programme, the draft of which is drawn up by its Chairperson in consultation with the CRSG and the CRP, of all items to be discussed in the next calendar year. This approved work programme shall include the timetable for considering all items mentioned therein. The Secretaries/Directors-General shall submit, each with his/her own comments if appropriate, the CCR work programme to the Governing body of each Co-ordinated Organisation for information and possible suggestions.

(b) The CRSG, after consultation with the CRP, may make proposals relating to matters which fall within the competence of the CCR as defined in Article 1 above, and present them to the CCR accompanied by any comments and views of the CRP. 
(c) Any member of the CCR may make proposals to the CCR. After appropriate consultations, the Chairperson of the CCR shall decide which proposals have broad support amongst member States and therefore shall be brought forward for discussion in the joint meetings.

\section{Article 6}

\section{Recommendations and advisory opinions}

(a) Recommendations, in the form of reports, shall be made by the CCR by consensus and, to the extent possible, in conjunction with the CRSG. The CRP shall be consulted on the draft reports with a view to considering its position.

(b) If no agreement can be reached between the CCR and the CRSG after two meetings following the submission of the proposal, the CCR will issue a report which will reflect the reasons for disagreement and set out dissenting opinions of the CRSG and comments of the CRP. However, discussions concerning the remuneration adjustment method may take longer and could require three meetings.

(c) If no agreement can be reached among the CCR delegates after two meetings following the submission of the proposal, the Chairperson of the CCR shall draft a report in which he/she shall set out the positions that have the largest support of the CCR. Dissenting opinions of CCR delegates as well as the opinion of the CRSG and comments of the CRP shall be set out in the body of the report.

(d) Proposals by the CRSG which are considered non-controversial by the Chairperson of the CCR may be submitted to the CCR through a written procedure. In this case, recommendations shall be considered as accepted by the CCR if no objection has been brought to the attention of the Chairperson of the CCR. Normally any such objection should be brought to his/her attention within three weeks of the notification of the recommendations to the members of the CCR, or before such other deadline as may be set by the Chairperson of the CCR which should be not less than five working days.

(e) Advisory opinions of the CCR shall be made by consensus after consultation of the CRSG and the CRP representatives from the Organisation(s) concerned. In case the subject in question is specifically related to one or more Organisations, the CCR delegations whose country is not a member of the Organisation(s) concerned will exercise due restraint in discussions on the adoption of the opinion. If no agreement can be reached among the CCR delegations after two meetings following submission of the request for an opinion, the Chairperson of the CCR shall draft a report in which he/she shall set out the advisory opinion which has the largest support in the CCR. Dissenting opinions provided in writing shall be annexed to the report.

\section{Article 7}

\section{Concertation group and formal and informal sessions}

(a) The CCR, CRSG and CRP shall establish a concertation group which will be held as needed, in a flexible manner, either as a preparatory step to open discussion, or as a final attempt to achieve a meeting of minds among the Committees. The concertation group shall be limited to two representatives of each Committee. It shall be chaired by the Chairperson of the CCR. The representatives of the Committees will be expected to take into due account the positions of all their members during discussions in the concertation group.

(b) The CCR, the CRSG and the CRP may meet together, separately or any two together in formal or informal sessions. The Chairperson of the CCR shall act as Chairperson whenever the CCR meets with the CRSG or with the CRP.

\section{Article 8}

$\underline{\text { Notification and implementation }}$ 
(a) The Chairperson of the CCR shall notify the Secretaries/Directors-General of all reports, recommendations and advisory opinions. The Secretaries/Directors-General shall transmit these reports, recommendations or advisory opinions, to the Governing body of their Organisations, as soon as possible.

(b) The Governing body of each Co-ordinated Organisation shall decide on the reports, recommendations and advisory opinions made to it by the CCR.

(c) The Secretary/Director-General of each Organisation shall be responsible for the implementation of the decisions.

\section{Article 9}

\section{Members and Observers}

(a) The Governing bodies of the Co-ordinated Organisations may, after having sought the advice of the CCR, accept unanimously that other international organisations participate in the system of coordination as members or observers.

(b) An international organisation may only become a member of the co-ordination system upon approval by its Governing body of the decisions concerning co-ordination then in force.

(c) When an international organisation has been admitted to participate in the system of co-ordination as an observer, the agenda, minutes and documents of the CCR, CRSG and CRP shall be provided respectively to its member countries, Secretary or Director-General and representative statutory body of its staff. Their representatives shall attend as observers the meetings of the CCR, CRSG and CRP.

(d) The Governing body of any Co-ordinated Organisation may decide to terminate the application of these Regulations to that Organisation by giving one calendar year's notice to that effect. It will transmit such a decision to the other Co-ordinated Organisations. In such instance, these Regulations will remain applicable as far as the other Co-ordinated Organisations are concerned.

\section{Article 10}

\section{Entry into force}

These Regulations shall enter into force when approved by the Governing bodies of the six Co-ordinated Organisations. On such date, the Regulations concerning the co-ordination system dated 1 July 1991 shall be replaced by the present Regulations. After three years of operation of the system, these Regulations may be reviewed by the Governing bodies of the Co-ordinated Organisations. 

Council

Council Working Party on the Implications of Future Enlargement on OECD Governance. 12

Sub-group on Questions of Management of the Council, its Subsidiary Bodies and the Committees of the OECD ...................................................................... 14

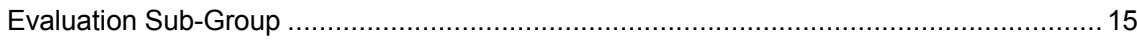

Committee on Co-operation with Non-Members …............................................... 16

Governing Board of the Development Centre ....................................................... 18

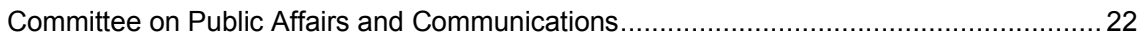

Liaison Committee with International Non-Governmental Organisations ........................... 24

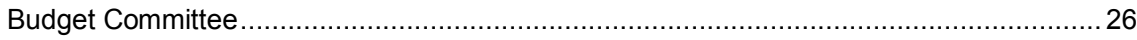

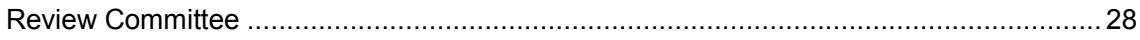

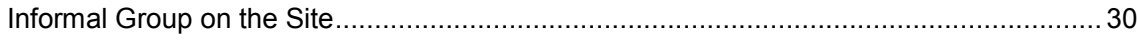

Pension Budget and Reserve Fund Management Board ........................................... 32

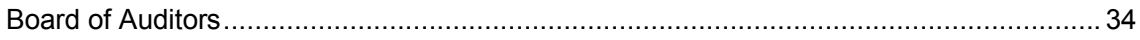

Annual Meeting of Sustainable Development Experts................................................ 37

Liaison Committee between the Russian Federation and the OECD............................. 38

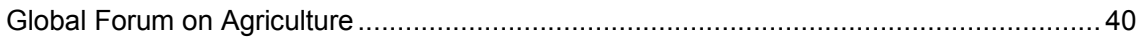

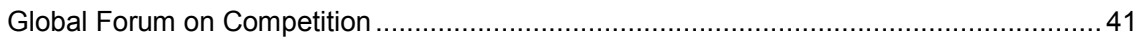

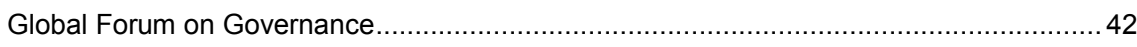

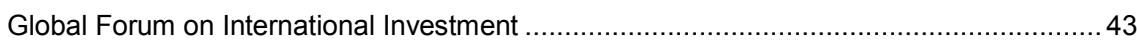

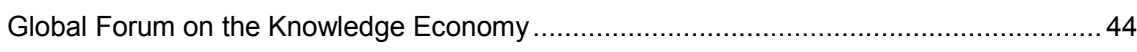

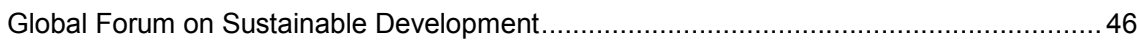

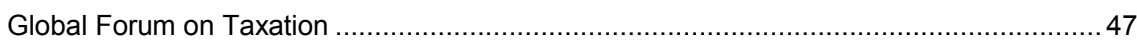

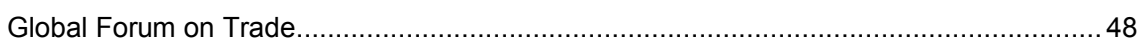

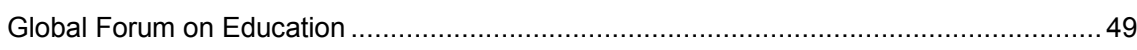

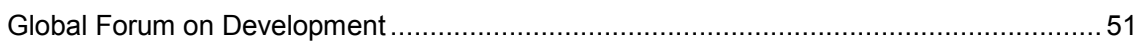

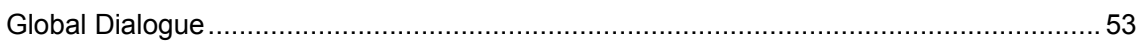

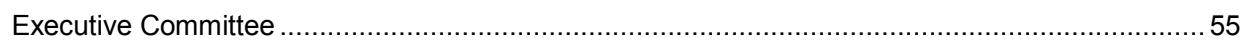

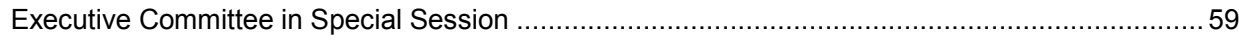

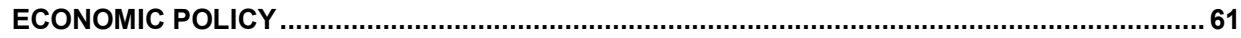




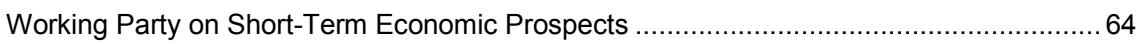

Working Party No. 1 on Macro-Economic and Structural Policy Analysis ............................65

Working Party No. 3 on Policies for the Promotion of Better International Payments

Equilibrium......

\section{ENVIRONMENT}

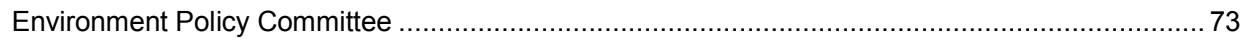

Joint Working Party on Agriculture and the Environment ........................................... 76

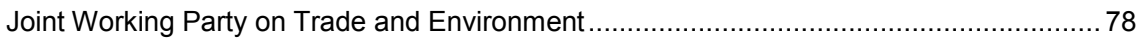

Joint Meetings of Tax and Environment Experts .................................................... 80

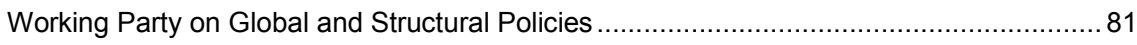

Working Group on Economic Aspects of Biodiversity ...................................... 83

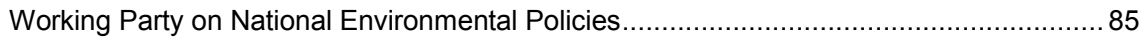

Working Group on Waste Prevention and Recycling ....................................... 87

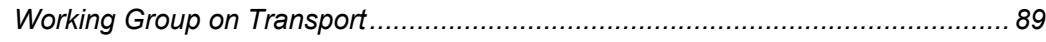

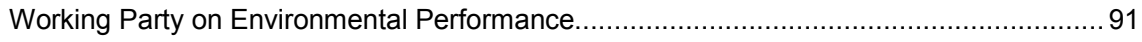

Working Group on Environmental Information and Outlooks ............................. 93

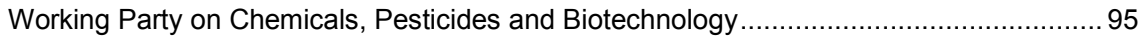

Working Group of National Co-ordinators of the Test Guidelines Programme (WNT)

.

Working Group on Good Laboratory Practice ............................................... 99

Working Group on Pesticides ................................................................ 101

Working Group on the Harmonisation of Regulatory Oversight in Biotechnology. 103

Task Force for the Safety of Novel Foods and Feeds .................................... 105

Working Group on Chemical Accidents ................................................... 107

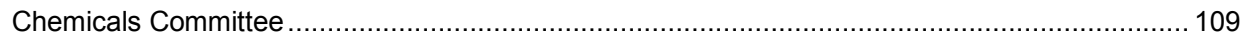

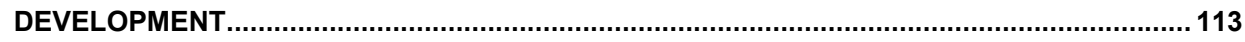

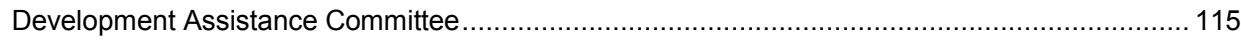

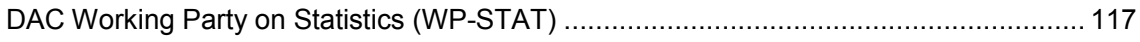

DAC Working Party on Aid Effectiveness and Donor Practices (WP-EFF) ..................... 118 


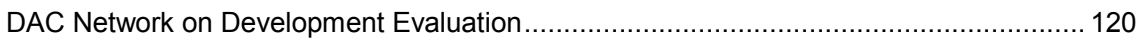

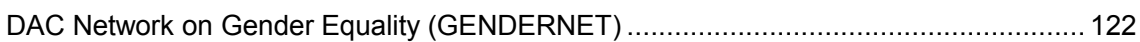

DAC Network on Environment and Development Co-operation (ENVIRONET)................ 124

DAC Network on Poverty Reduction (POVNET) …................................................ 126

DAC Network on Governance (GOVNET) ............................................................ 128

DAC Network on Conflict, Peace and Development Co-operation (CPDC) ..................... 130

PUBLIC GOVERNANCE AND TERRITORIAL DEVELOPMENT ......................................... 133

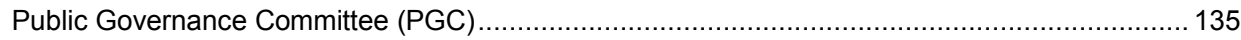

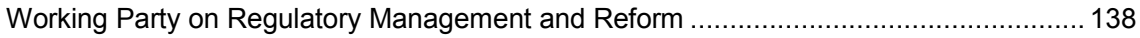

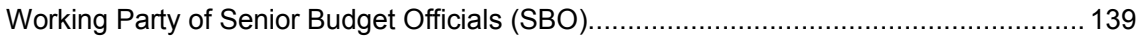

Network on Financial Management ............................................................... 140

Network of Parliamentary Budget Committee Chairpersons ............................ 141

Network on Organisational Structures ....................................................... 142

Network on Performance and Results ......................................................... 143

Network of Senior Officials from Centres of Government ............................................... 144

Human Resources Management Working Party ............................................................ 145

Steering Group on the Complementary Areas of E-Government Work ............................ 146

Expert Group on Conflict of Interest: Ensuring Accountability and Transparency in the Public

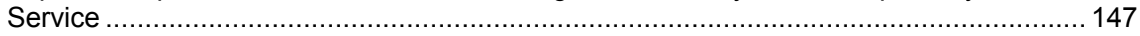

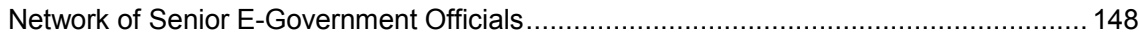

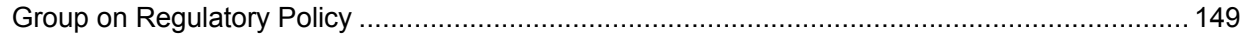

Territorial Development Policy Committee............................................................................. 151

Working Party on Territorial Policy in Urban Areas .................................................... 154

Working Party on Territorial Policy in Rural Areas............................................................ 157

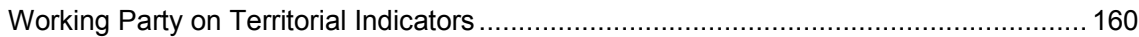

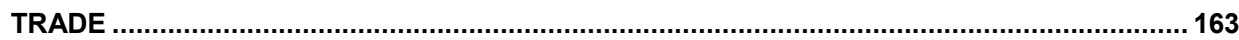

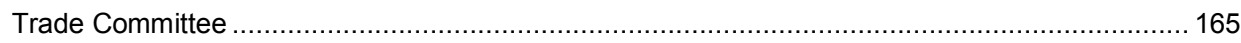

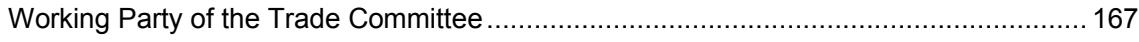

Working Party on Export Credits and Credit Guarantees ............................................. 169

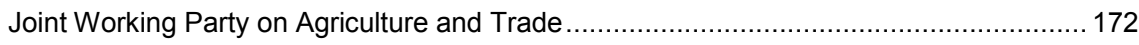

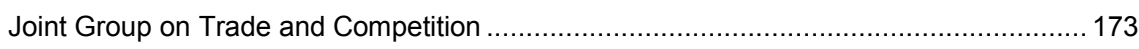

Joint Working Party on Trade and Environment..................................................... 175 


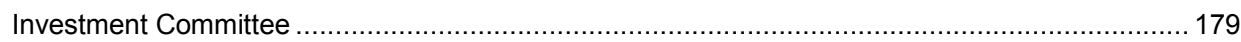

Working Group on Bribery in International Business Transactions ................................ 181

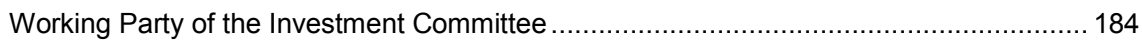

Advisory Group on Co-operation with Non-Members on Investment Matters ................... 185

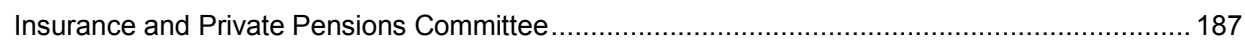

Task Force on Private Health Insurance .............................................................. 189

Working Party of Governmental Experts on Insurance ................................................. 190

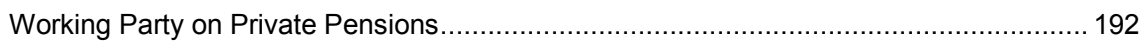

Task Force on Personal Pension Plans....................................................... 193

Task Force on Pension Statistics ................................................................ 194

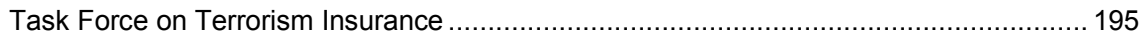

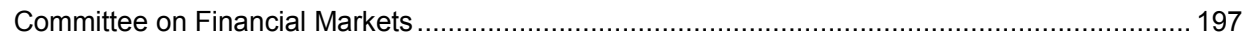

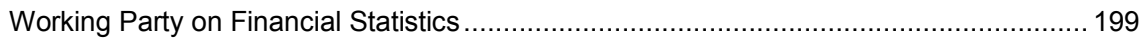

Working Party on Debt Management ................................................................. 200

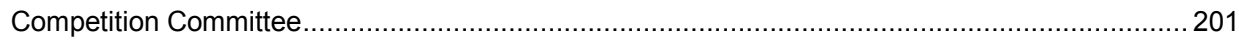

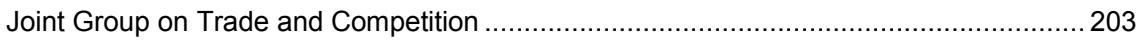

Working Party No. 2 on Competition and Regulation ................................................ 205

Working Party No. 3 on Co-operation and Enforcement............................................ 206

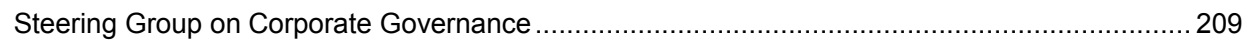

Working Group on Privatisation and Corporate Governance of State Owned Assets ....... 210

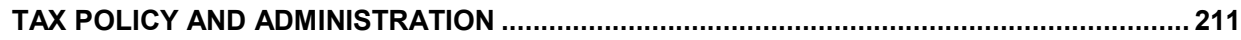

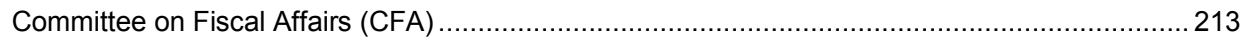

Board For Co-operation With Non-OECD Economies ................................................. 218

Advisory Group for Co-operation with Non-OECD Economies........................... 219

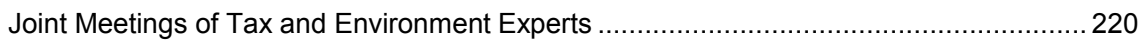

Working Party No. 1 on Tax Conventions and Related Questions.................................. 221

Steering Group on the Revision of the Model Tax Convention............................ 222

Working Group No. 1 on the Application of the Model Tax Convention to

Partnerships, Trusts and Other Non-Corporate Entities................................... 223

Working Party No. 2 on Tax Policy Analysis and Tax Statistics........................................ 224

Working Party No. 6 on the Taxation of Multinational Enterprises ................................. 225 
Steering Group on Transfer Pricing Guidelines ............................................. 227

Working Party No. 8 on Tax Avoidance and Evasion .................................................... 228

Informal Study Group on the Taxation of Cross Border Interest Flows................. 229

Joint Working Parties No. 8 and No. 9 Tax Information Exchange System Sub-

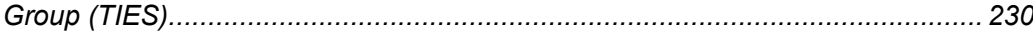

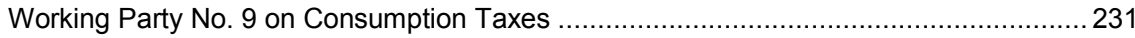

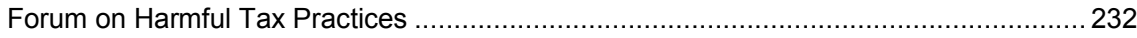

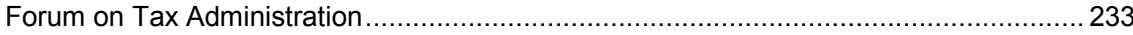

Forum on Tax Administration Compliance Sub-Group (FTACOMP) .................. 234

Forum on Tax Administration Taxpayer Services Sub-Group ............................ 235

OECD Network on Fiscal Relations Across Levels of Government.......................................... 237

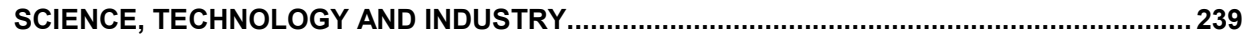

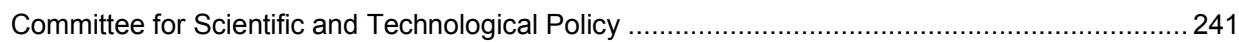

Working Party of National Experts on Science and Technology Indicators (NESTI) ......... 244

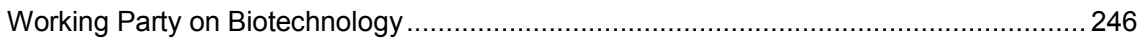

Working Group on Human-Health-Related Biotechnologies ............................ 248

Task Force on Biotechnology for Sustainable Industrial Development................. 249

Task Force on Biological Resource Centres.................................................. 250

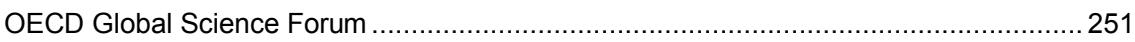

Ad Hoc Working Group on Steering and Funding of Research Institutions...................... 254

Committee for Information, Computer and Communications Policy .......................................... 257

Working Party on Telecommunication and Information Services Policies (WPTISP) ......... 259

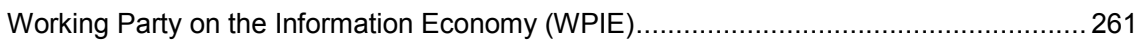

Working Party on Information Security and Privacy (WPISP) ..................................... 263

Working Party on Indicators for the Information Society (WPIIS)................................... 265

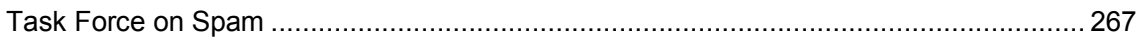

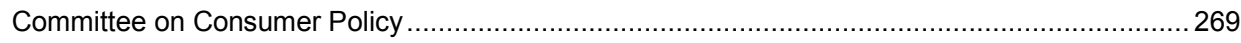

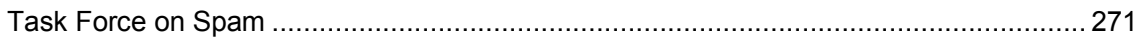

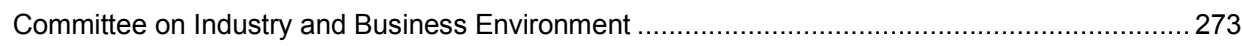

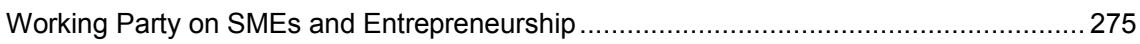

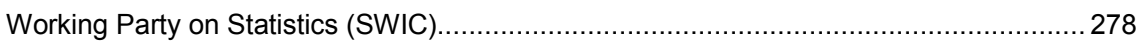

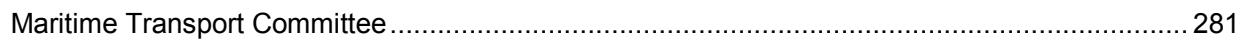




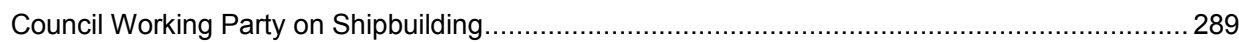

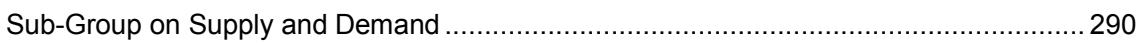

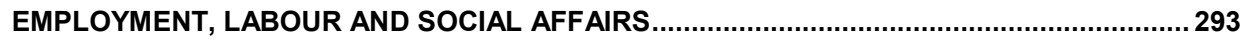

Employment, Labour and Social Affairs Committee (ELSA) …............................................ 295

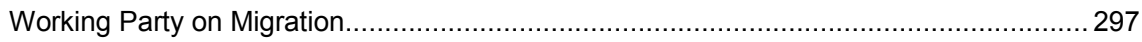

Working Party on the Role of Women in the Economy ................................................. 299

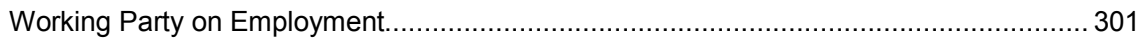

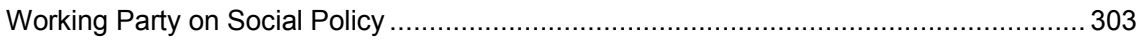

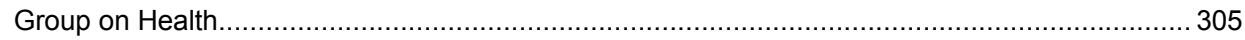

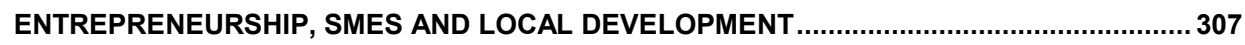

Co-operative Action Programme on Local Economic and Employment Development (LEED) ...... 309

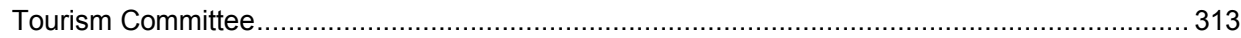

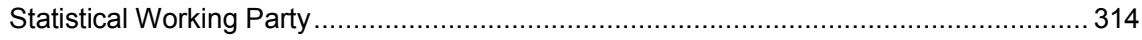

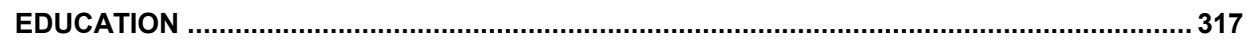

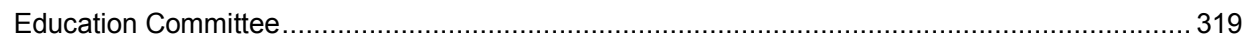

Indicators of Education Systems Strategic Management Group (INESSMG) ................... 321

Centre for Educational Research and Innovation Governing Board (CERI) .............................. 323

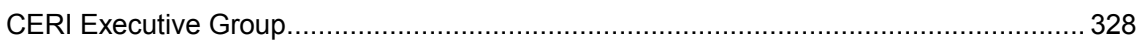

Indicators of Education Systems Strategic Management Group (INESSMG) .................... 329

Institutional Management in Higher Education Governing Board (IMHE) ................................ 331

Programme on Educational Building Governing Board (PEB)............................................. 335

Programme for International Student Assessment Governing Board (PISA) ............................. 337

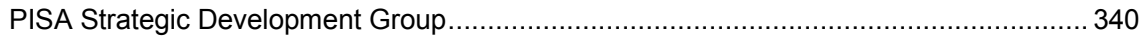

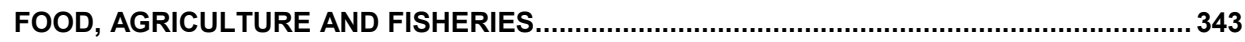

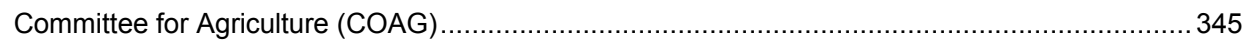

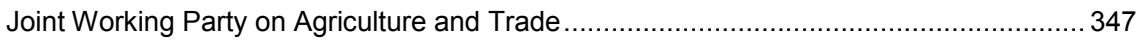


Joint Working Party on Agriculture and the Environment

Working Party on Agricultural Policies and Markets (APM) ........................................... 350

Group on Cereals, Animal Feeds and Sugar............................................................... 351

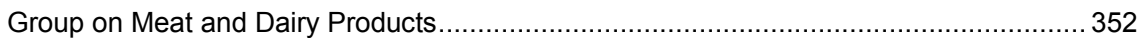

Plenary Meeting of the OECD Scheme for the Application of International Standards for Fruit and Vegetables.

Annual Meeting of Representatives of the National Designated Authorities for the Implementation of the OECD Schemes for the Varietal Certification of Seed Moving in International Trade

Scheme for Grass and Legume Seed....................................................... 358

Scheme for Crucifer Seed and other Oil or Fiber Species.................................360

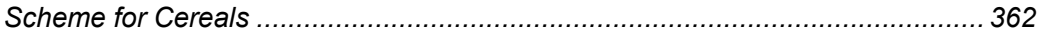

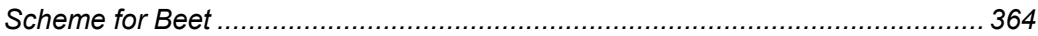

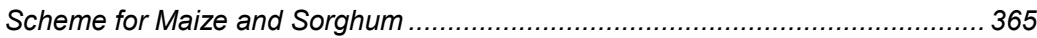

Scheme for Subterranean Clover and Similar Species ................................... 367

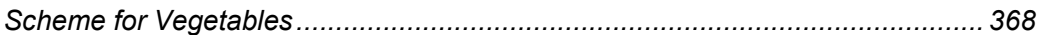

Annual Meeting of Representatives of the National Designated Authorities for the Implementation of the OECD Standard Codes for the Official Testing of Agricultural and Forestry Tractors

Meeting of Representatives of the National Designated Authorities for the Implementation of the OECD Scheme for the Control of Forest Reproductive Material Moving in International Trade.

Governing Body of the Co-operative Research Programme: Biological Resource Management for Sustainable Agricultural Systems

Fisheries Committee (COFI)

STATISTICS

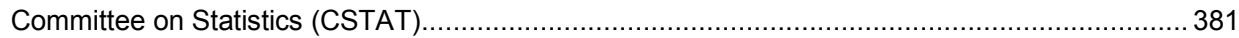

OECD Short-term Economic Statistics Working Party (STESWP)................................... 384

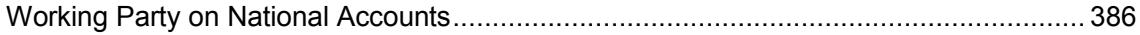

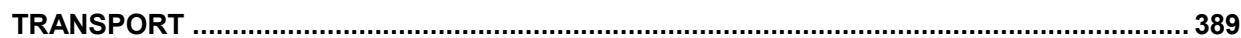

Joint OECD/ECMT Transport Research Committee .............................................................. 391

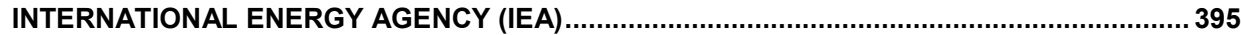


International Energy Agency Governing Board..... 397

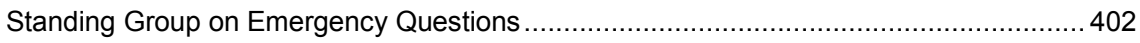

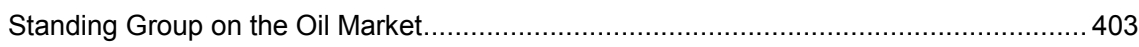

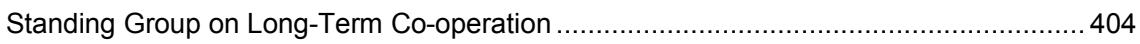

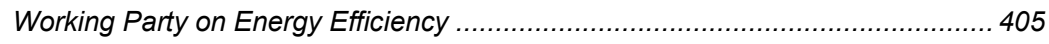

Committee on Energy Research and Technology (CERT) ........................................ 407

Working Party on Energy End-Use Technologies....................................... 409

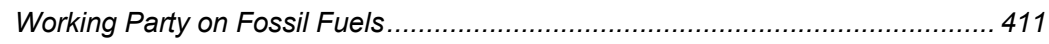

Working Party on Renewable Energy Technologies..................................... 413

Fusion Power Co-ordinating Committee (Fusion Working Party) ........................ 415

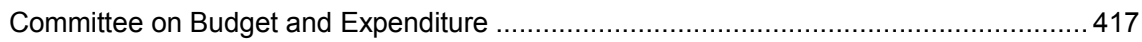

Committee on Non-Member Countries .............................................................. 418

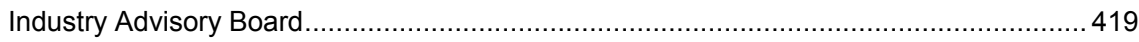

Industry Supply Advisory Group (ISAG) ................................................ 421

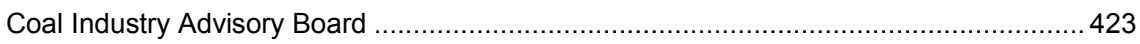

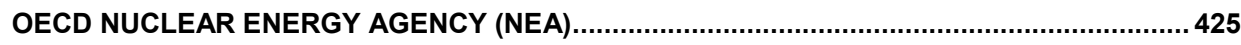

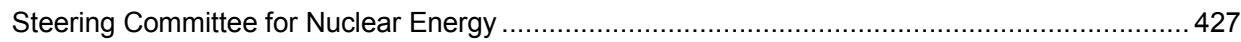

Committee on the Safety of Nuclear Installations (CSNI) ......................................... 433

CSNI Programme Review Group (CSNI PRG) .............................................. 435

Working Group on Risk Assessment (WGRISK)...................................... 436

Working Group on Analysis and Management of Accidents (GAMA)................. 438

Working Group on Integrity of Components and Structures (IAGE) ................... 440

Special Expert Group on Human and Organisational Factors (SEGHOF)............ 441

Special Expert Group on Fuel Safety Margins (SEGFSM) ............................... 443

Committee on Nuclear Regulatory Activities (CNRA) ................................................ 444

Working Group on Inspection Practices (WGIP) ......................................... 446

Working Group on Public Communication of Nuclear Regulatory Organisations

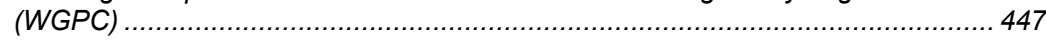

Working Group on Operating Experiences (WGOE) ..................................... 448

Radioactive Waste Management Committee (RWMC)................................................. 450

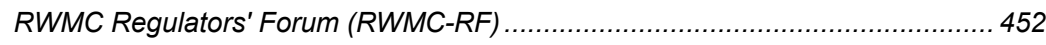

Integration Group for the Safety Case of Radioactive Waste Repositories (IGSC) 
Forum on Stakeholder Confidence (FSC). 455

Working Party on Decommissioning and Dismantling (WPDD)........................ 457

Committee on Radiation Protection and Public Health (CRPPH) ................................... 459

Working Party on Nuclear Emergency Matters (INEX).................................. 461

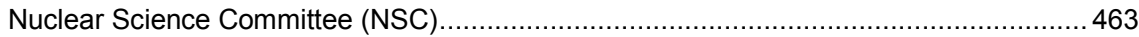

Working Party on International Nuclear Data Evaluation Co-operation (WPEC) .. 465

Working Party on Scientific Issues of Reactor Systems (WPRS) ....................... 468

Working Party on Nuclear Criticality Safety (WPNCS) ................................... 470

Working Party on Scientific Issues of the Fuel Cycle (WPFC) .......................... 472

Executive Group of the NSC (Data Bank Management Committee)............................... 474

The Scientific Co-ordination Group of the Joint Evaluated Fission and Fusion

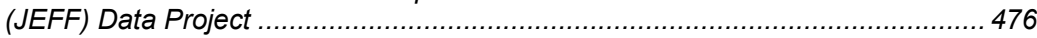

Committee for Technical and Economic Studies on Nuclear Energy Development and the

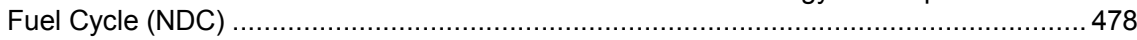

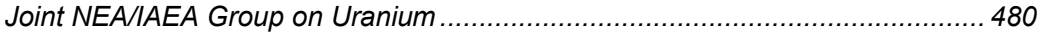

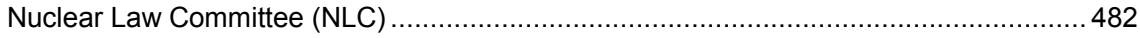

JOINT SUBSIDIARY BODIES TO THE CO-ORDINATED ORGANISATIONS ........................... 485

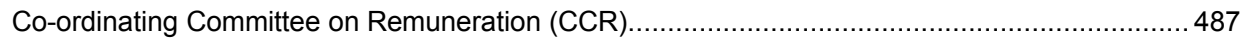

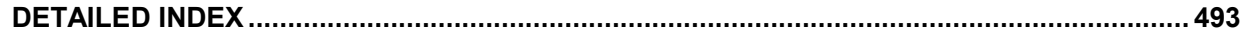




\section{Directory of OECD Intergovernmental Bodies}

\section{MANDATES, CHAIRS, MEMBERSHIP}

This directory provides official information on the mandates, dates of creation and durations of current mandates, composition of member countries and observers, and chairmanship of the OECD Council and its related committees, sub-committees, working groups, expert groups, and ad hoc groups. It includes coverage of the International Energy Agency and the OECD Nuclear Energy Agency and is updated annually. It is, in effect, a guide to country participation in the many activities of the OECD.

The full text of this book is available on line via this link:

http://www.sourceoecd.org/generaleconomics/9264023682

Those with access to all OECD books on line should use this link:

http://www.sourceoecd.org/9264023682

SourceOECD is the OECD's online library of books, periodicals and statistical databases.

For more information about this award-winning service and free trials ask your librarian, or write to us at SourceOECD@oecd.org.

www.oecd.org

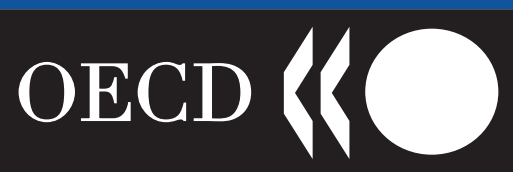

OECDPUBLISHING

ISBN 92-64-02368-2

$012006091 \mathrm{P}$

9 $\left\|_{789264}\right\|_{023680^{2}}$ 